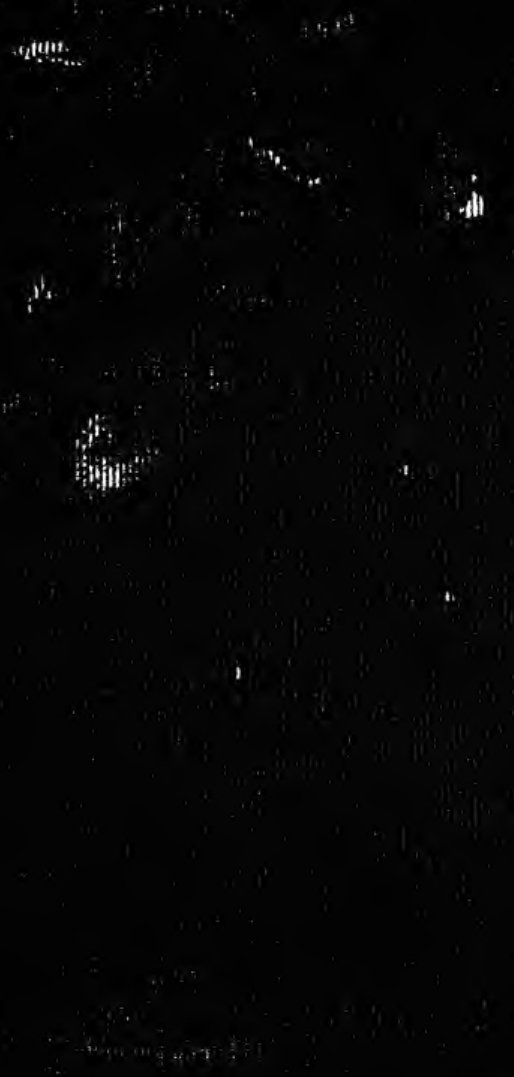


TEP 261909

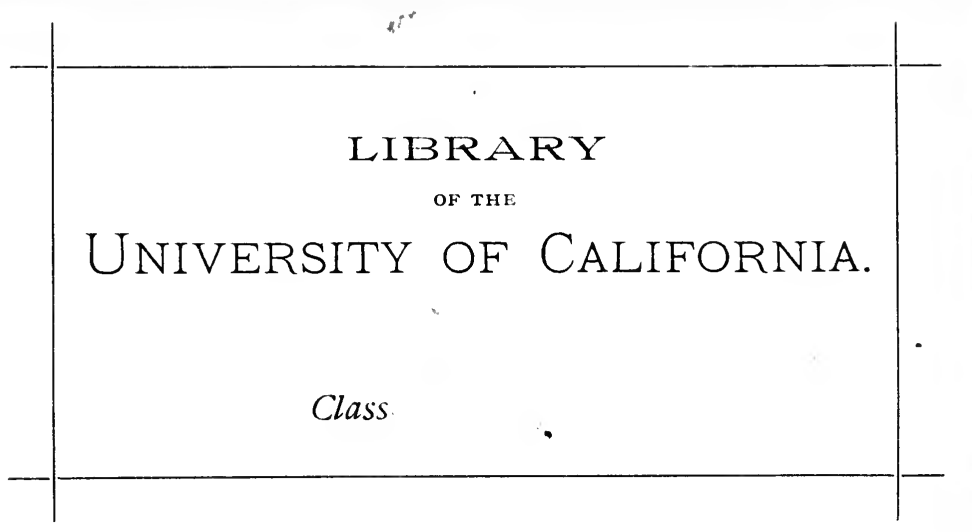





\section{,}


Studies in the

American Race Problem 



\title{
Studies in the
}

\section{American Race Problem}

\author{
By \\ ALFRED HOLT STONE
}

\begin{abstract}
With an Introduction and Three Papers by
WALTER F. WILLCOX
\end{abstract}
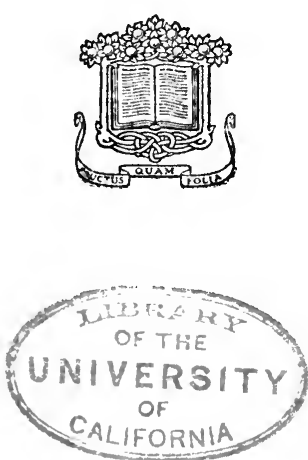

New York

Doubleday, Page \& Company 1908 
ALL RIGHTS RESERVED

INCLUDING THAT OF TRANSLATION INTO FOREIGN LANGUAGES, INCLUDING THB SCANDINAVIAN

COPYRIGHT, 1908, BY DOUBLEDAY, PAGE \& COMPANY

PUBLISHED, SEPTEMBER, 1908 
TO MY FATHER AND MOTHER

CONNECTING LINKS WITH THE OLD RÉGIME 
GEMERAL 
If any one is able to convince me and show that I do not think or act right, I will gladly change, for I seek the truth, by which no man was ever injured. But he is injured who abides in his error and ignorance.

- Marcus Aurelius 



\section{PREFACE}

THE purpose in which these papers are conceived may be read in their first word - the spirit in which they are written in their last. Neither is knowingly departed from.

It is a difficult thing to do - this telling of the truth, the narrating of facts, without at once creating the impression of a partisan temper or a biased mind. Yet so far as this writer knows he has neither.

For a number of years I have studied the various phenomena of racial contact which we conveniently designate the race problem. I have also studied the literature which treats of this problem. If the facts are confusing and difficult of comprehension the literature is scarcely less so. It fails, it seems to me, at a vital point, in that it is based on either side upon an assumed lack of honesty and absence of fairness on the other. The truth is that the conflicting American attitude on the race problem is an entirely natural product of the sectionalism which almost from the beginning has saturated and beclouded the whole subject. It is a humanly difficult matter for people in different environments to look at the basic cause of their differences through the same glasses. One trouble is that we have made too little honest effort to accomplish this difficult but necessary end. By reason of our 


\section{x The American Race Problem}

extent of territory and variety of economic conditions we are confronted with the probability of an indefinite continuance of the physical differences which are the real basis of our differences of mental attitude. It is not possible that sensible people, bound together by innumerable natural ties of race, ancestry, history, religion, and institutions, can regard with unconcern the perpetuation of differences over a matter which is primarily artificial in character. We owe it to ourselves and to those who come after us earnestly to seek the removal of stumbling blocks to the mutual respect and esteem, the better appreciation, the more fraternal regard and good will which make for national unity of thought and purpose - for national peace and happiness.

And it is an intensely practical matter. The child who was born in Boston in 1860 grew to manhood amidst surroundings and influences which through no conscious purpose of his own shaped and determined his attitude toward the American race problem in 1890. The man of the same age in Charleston was merely looking at the same problem in the light of a different environment. Each was the product of conditions entirely outside himself and in the creating of which he had no possible part. In so far as these men typify the great mass of people in their respective sections their conflicting attitudes are entirely normal. They simply accept what they find, and think and feel without seeking for a reason for the contrary operations of their minds. It is a wholly different matter with 


\section{Preface}

either when he undertakes to shape the opinions of others. He then assumes a duty to those whom he seeks to influence, and a duty to the public at large. When he ceases to play an entirely passive part and essays the rôle of instructor to others, he assumes likewise a responsibility which he cannot shirk if he would. $\mathrm{He}$ immediately becomes a factor in determining, however slightly, the current of popular thought. $\mathrm{He}$ will play his part in shaping that current either toward the perpetuation of misunderstanding and error and ill feeling, or in the direction of truth and the just apprehension which is the only sure foundation of lasting good will. He cannot write a line on this much vexed question and continue to occupy a purely negative place. He at once becomes an active agent for either good or harm.

This has been my conception of the responsibility and duty of a student of the American race problem. My only hope is that my influence, however small, may be cast upon the side of better understanding, which shall make for mutual respect and tolerance for our several points of view. My purpose is to interpret and explain, neither speciously to defend on the one hand nor uncharitably to condemn upon the other. It is a fundamental tenet of my philosophy of race relations that the chief sufferer from sectional misunderstandings among white people has been the American Negro. It is a corollary that he would be the chief beneficiary of greater accord between the white parties to the sectionalism created by his presence. 


\section{xii The American Race Problem}

As Professor Willcox says in his introduction, the papers presented here "contain no plan of action, but are confined to the necessary preliminary work of portraying conditions. Agreement must be reached on these before agreement on action can come into sight." The value of most discussions of this general subject is impaired by having imparted to them the tone and purpose of special pleas for some favourite "solution." Neither contributor to this volume is a propagandist, and neither has any panacea to urge for conditions which demand intelligent diagnosis before intelligent treatment is possible. The one aim of these studies is to set forth some of the salient facts of the American race problem, and to point out some of the fundamental principles which underlie it and create it. The hope is indulged that there is also suggested the necessity for a candid recognition of the truth that our problem is not only national in its scope, but that the principles which are indicated as its foundation are in fact of universal application in shaping the phenomena of racial contact. The suggestion or advocacy of remedies is foreign to such a purpose.

For some years I have been working on a study the results of which I had hoped to submit by this time in concrete form under the title "Race Relations in America." The scope of the work, however, has postponed its completion. These papers in the main are byproducts of investigations in the broader field.

Such value as this collection may possess is greatly 


\section{Preface}

xiii

enhanced through the addition of three papers by Professor Walter F. Willcox. These papers cover with the skill of the trained statistician the subjects of Negro criminality, the Negro's economic position, and the frequently agitated question of the probable increase of the race in this country. The paper on Negro criminality is probably the most widely quoted (and most largely misinterpreted) contribution made to the statistical literature of the general subject in recent years. In justice to Professor Willcox I should add that his association with this volume must not be understood as in the least degree committing him to any opinion or statement contained in my own papers. For these I alone am responsible.

For permission to use previously published matter, I wish to acknowledge my thanks to the editors of the Atlantic Monthly, the Outlook, the publications of the American Economic Association, the American Sociological Society, and the Quarterly Journal of Economics. For valued assistance in many ways I am greatly indebted to Mr. Julian H. Fort, of Dunleith, and to Mr. R. H. Johnston, of the Library of Congress, for the verification of references and the preparation of the index.

\section{Alfred Holt Stonb.}

Dunleith Plantation, Dunleith, Miss.

January 28, 1908. 



\section{INTRODUCTION}

A CONFERENCE upon race problems of the South was held at Montgomery, Ala., in May, I900, and I was honoured by an invitation to attend. During that meeting I fell in with the author of these papers, and the acquaintance then pleasantly begun has continued and ripened to my very great profit. From no one have I learned so much as from him about the realities of the race problems in the South, and I gladly avail myself of this opportunity to bespeak for his contributions to the subject the attention and study which their importance deserves. With his permission, and that of the editors who first published them, this collection includes the address to which I owe my invitation to Montgomery, and two other contributions of mine to the study of American race problems.

May I suggest that this combination of writings within one volume has a certain typical significance? Until the present day it would have been hard for Massachusetts and Mississippi to join hands in objective and dispassionate study of the questions which so long have divided those states and the country. The closet student here will be found not widely at variance in his conclusions from the cotton planter and business man who approaches the problem by a different avenue. The statistician, knowing little of the problem beyond 


\section{xvi \\ Introduction}

what he may read in his figures, finds in Mr. Stone's papers a needed complement, and also in the main I believe a confirmation of his results. Thus, North and South, theory and practice, figures and concrete specific experience are approaching a unity of conviction. The essays contain no plan of action but are confined to the necessary preliminary work of portraying conditions. Agreement must be reached on these before agreement on action can come into sight.

Walter F. Willcox. 


\section{CONTENTS}

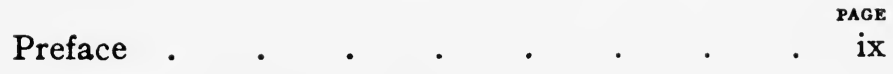

Introduction, by Walter F. Willcox . $\quad . \quad \mathrm{xv}$

$$
\text { PART ONE }
$$

\section{A GENERAL SURVEY}

I. Race Problem Contrasts and Parallels .

Difficulties in discussion of the race problem - Influence of local conditions in determining the problem - Illustrations of local adaptations of standards Northern attitude toward Southern restrictive legislation - The influence of the numerical strength of the Negro in determining race discrimination-Difficulty in getting at Negro's point of view - Negro writers on Negro opportunity, North and South - Contrast between Northern and Southern "equality of the Negro" - Similarity of conditions in South Africa Varying political relations of the Negro-Proportionate population and Negro suffrage - Effect of numbers on the constitutional restrictions on the Negro in Western states - Cape Colony and Mississippi compared in suffrage restrictions Theory and practice in governmental policy.

\section{Foundations of Our Differences}

The Mulatto as affecting the race problem - Mulatto and Negro population - Comparative distribution of Negro population, North and South - Negro urban population in the North American race attitude the xvii 


\section{xviii The American Race Problem}

\section{Foundation of Our Differences (Continued)}

normal Anglo-Saxon attitude - Massachusetts attitude toward Negroes and mulattoes - Northern attitude toward Southern separation of the races Provoking causes of this separation - Knowledge of conditions necessary to understanding of Southern relations to the Negro.

\section{PART TWO}

\section{SOME ECONOMIC ASPECTS}

\section{The Negro in the Yazoo-Mississippi}

\section{Delta}

The race problem a study of local conditions - Location and description of the Delta - Its importance to the future of the Negro - Its Negro population - The white population not a labouring class - The old plantation system and its similarity to the Delta agricultural system - The Census definition of a farm - Relations between the plantation owner and the Negroes - Influence of these relations in preventing rape - Necessity of attitude of superiority toward the Negro race - Housing of Delta Negroes - Share and renting systems - The crop lien - Effect of Negro characteristics on their economic status - Moral delinquencies of the Negro-A renting experiment.

\section{A Plantation Experiment}

Demand for Negro labour in the Delta - Desirability of an assured tenantry - Statistics of a five-year renting experiment on Dunleith plantation - Removals and their effect on the plantation-Condition of the moving families - Comparison of the renting and share systems - Advancement of money - Causes of removals of renters - Lack of home affection in the Negro - His urban drift - Table of Dunleith Plantation statistics 


\section{Contents}

V. The Economic Future of the American Negro - The Factor of White CompeTITION

The wealth of the Negro race, I 860 and I $905-$ Decline of the Negro in former labour monopolies in the North - The influx of foreign white labour and displacement of the Northern Negro - Economic prejudice against the Negro in the North - Contributing causes to be found in Negro character - The Negro's economic situation in the South - The influence of the drawing of the race line - Demand for better service than the Negro's - Influence of Trade Unions - Effect of these limitations on field of Negro's employment The Italian compared with the Negro in Southern agriculture - Necessity of white supervision of work of Negro - The Sunny Side Italian experimentRelative efficiency of Italian and Negro-Negro improvidence and extravagance and Italian thrift Italian and Negro in the garden patch - The Negro and the economic door of hope-Basis of true racial greatness.

\section{PART THREE}

\section{CRUCIAL POINTS OF POST BELLUM RACIAL CONTACT}

VI. Race Friction . . . . . 2 II

Definition of race friction-Colour division among races - The law of contact and race friction - Slavery and its relation to present racial difficulties - The difference in the attitude of the North and South toward the Negro - The Anglo-Saxon attitude of superiority toward the Negro - The adaptability of the Negro masses to conditions of inferiority - The problem of the higher classes - Race consciousness and race friction. 
VII. Mr. Roosevelt, the South, and the NEGRO

The facts in the case - The Booker Washington dinner - The Crum appointment - The Indianola postoffice - The Reconstruction background - Relations between masters and slaves - Negro testimony to its kindliness - The Negro and the carpet bagger and the sundering of kindly relations - The association of ideas and present relations between white and blackNorthern misunderstanding of the South - McKinley, Roosevelt, and the Negro - The South and Negro suffrage - Official recognition of the race - McKinley's "Negro policy" - Roosevelt and the "door of hope" - Different classes of Negroes and their influence on the masses - McKinley and the South and the era of good feeling - A concrete racial attitude Mulattoes in office not a recognition of the "black man" - The rights of the Negro must come as a grant rather than by coercion - Negro view of Roosevelt Social equality - The Booker Washington dinner and Southern sentiment - What social equality means to the Negro - A phenomenon of race consciousness - The Ethiopian movement - Racial conditions in Jamaica - The Southern Referee - Traitors and loyalists - The Referee and the scalawag - Social equality problems in South Africa - Sectionalism and the race problem - The universality of problems of racial contact.

\section{The Negro in Politics}

The Fifteenth Amendment - Negro suffrage and party affiliation - Southern constitutions and Negro disfranchisement - Their requirements directed against Negro characteristics rather than the Negro personally - Decline of the Negro leader and ensuing political lethargy in the race - Interest of white men centred in the primary - Resultant reduction in vote, basis of demand for reduction in Southern representation - The venality of the Negro vote - Danger from the 


\section{Contents}

\section{The Negro in Politics (Continued)}

Negro in politics the explanation of the "Solid South" - Negro solidarity against Southern white people Suffrage qualifications - Capacity for self-government - Negro respect for "strong" government - Political status of the Negro in the West Indies - Suffrage a states' right - The Maoris in New Zealand - The Mississippi constitution of $1890-$ The race war in North Carolina - The Black peril in South Africa The Boers and native suffrage - The indispensable requirements for self-government - The problem in Cuba - In Haiti - The Mulatto's relation to the Negro race - Latin and Anglo-Saxon mulattoes - Inter-racial colour line - The Negro as a "peasant" class Suffrage and expediency - Government without consent of the governed - Characteristics and attainments of the Negro in politics.

\section{PART FOUR}

\section{AN UNCONSIDERED ELEMENT}

IX. The Mulatto Factor in the Race Problem

Ethnic differences between the Negro and white races - Achievements of the mulatto credited to the Negro race - Antiquity of the Negro race and its barren history - Famous mulattoes - Northern solicitude for contented masses of the Negro race - Pernicious influence of mulattoes on the Negro masses - The mulatto an anomaly in American life.

\section{PART FIVE}

PAPERS BY WALTER F. WILLCOX

I. Negro Criminality . . . . .

Proportion of Negro to white prisoners - Conditions North and South - Negroes on increase of crime in their race - Reasons for this growth - Lack of family 


\section{xxii The American Race Problem}

\section{Negro Criminality (Continued)}

life - Increasing competition with white labour in cotton, tobacco, sugar and rice crops-Industrial decline of the Negro - Production of social classes in the Negro race - Race friction as a cause of increase in crime - Development of race opinion - Lynching.

II. Census Statistics of the Negro • 476

The United States and its study of the Negro race The Census classification of races - The mulatto in the Census - The Negro population of the United States and her insular possessions - City and country population - The figures of the Census of $1870-$ Sex in Negro population statistics - Illiteracy - Marital condition - Occupations - Death-rate - Status of the Negro in the professions and skilled occupations.

III. The Probable Increase of the Negro Race in the United States. . . 496

Question of relative growth of the races-Individual estimates of the Negro's probable increase - Tables of increase for the nineteenth century-Decline in the Negro rate of increase - Birth-rate of Southern Negroes - Tables of child population-Immigration as affecting white birth-rate in South - Various influences tending to decrease in birth-rate-Tables of comparative death-rates - Proportional increase in certain occupations - The Negro in agriculture and influence of machinery - Cotton boll weevil and its effect on the Negro in agriculture - The Negro race losing ground.

List of Other Writings of Walter F. Willcox ON THE Negro . . . . . 530

INDEX $\quad . \quad$. $\quad . \quad$. $\quad . \quad 535$ 


\section{PART ONE}

\section{A GENERAL SURVEY}

I. Race Problem Contrasts and Parallels

II. The Foundations of Our Differences 
, 


\title{
STUDIES IN THE AMERICAN RACE PROBLEM
}

\author{
I
}

Race Problem Contrasts and Parallels*

$7 \begin{gathered}\text { HE race problem is a difficult subject to discuss - } \\ \text { peculiarly so for a Southern man to present to }\end{gathered}$ a Northern audience. There are very common-sense reasons for this fact. These are to be found partly in the inherent qualities of the problem itself. In its essence this is a human question. In it are blended all the elements of tragedy and comedy, of pathos and humour, of happiness and sorrow, of hope and fear, of love and hate - all the emotions and contradictions and contrasts that enter into the great problem of human life. Yet with all its human breadth, its very geography colours it with a sectional tone. It is very close to one part of the country and very far removed from the other. And here we have one of the difficulties in the way of the man with whose daily life it is bound up from infancy to the grave, when he would talk of it to those for whom it exists only as a "national question" - a subject merely of academic interest.

*This and the paper following are a consolidation of three lectures - one given at Cornell University, in 1905, and two at the University of Michigan, in 1906. 


\section{4 The American Race Problem}

Then, too, it is so old, and has so long been threshed over, and beaten back and forth as a sort of shuttlecock of debate, that the world seems quite satisfied that it knows all about it, or at least enough to have made up its mind. A result of this prolonged and acrimonious discussion is that the whole question seems to be inextricably confused with partisan and sectional issues. It has become difficult to so present the subject to one's hearers as to convince them that the speaker is treating it solely upon its merits. Extremes of opinion and statement are constantly answered in kind and the waters of a naturally unquiet stream are seldom allowed to run clear and undisturbed.

I am not an extremist, and I long ago made up my mind to keep faith with myself in this, that I would not utter one word upon this perplexing question of which my conscience did not approve as the prompting of a desire to speak the truth for the truth's sake. My memory does not go back to a time when I was not interested in the subject. 'One of the earliest questions that puzzled my childhood's mind was why my plantation playmates were black and I white, why between us here and there the lines were drawn, and here and there they disappeared. From that day to this I have been asking questions of myself and of the world, and seeking for answers with varying degrees of success. One of these questions, the one which overshadowed all the rest, was why our people, the people of one common country, should think and feel and act so differently wherever this black figure loomed upon the horizon. 


\section{Contrasts and Parallels}

It is the answer to this question, as I have found it for myself, that I have come to offer you. I shall be happy if I can make it one half as clear to your minds as fifteen years of study have made it to mine. Please do not misunderstand me. I am not a missionary, seeking converts. I do not wish to impose my views upon yours, nor is it my purpose to endeavour to make you think as I think. It is not necessary to a thorough understanding between us that either shall surrender his opinions to the other. The object I seek is quite different. It is to attempt an explanation of why we do not think alike; to render more intelligible to you, perhaps, the attitude of my people, which will carry within itself the reasons for the differences between our respective points of view.

This may not appear to be a very formidable undertaking, but did you ever try to give a reason for the faith that is within you, on this subject? Do you know why in one section of your country the two races are separated in schools and cars, and are not allowed to intermarry, while in the other such laws do not exist? Honestly and satisfactorily to answer such questions for one's self is by no means a simple mental feat. For a Southern man to do so for others is a hundred times more difficult. Any man who is so situated that in order to present the truth of a given question he is compelled also to present facts that are disagreeable, or unpopular or opposed to commonly entertained conceptions, labours under a twofold disadvantage. $\mathrm{He}$ is very likely to have his motives impugned and his honesty 


\section{The American Race Problem}

questioned. Under such conditions candour is subject to the discount of being mistaken for prejudice, and a premium is thereby placed upon hypocrisy and evasion.

Now this is just what the Southern white man has to confront in discussing the race question. But I shall proceed on the assumption that you at least have faith in my honesty. Also, I am taking it for granted that you do not entirely agree with a certain distinguished magazine editor who last year wrote me on this subject. He told me, in so many words, that the man who was raised among Negroes in the South, and employed them, really knew nothing whatever about them, as compared with the man in the North who "sympathised with their longings and hopes and aspirations."

Here is the key to my philosophy of race relations: it is the influence of local environment and local considerations in determining local attitude. This is my explanation of the differences of opinion among people of different sections of this country, but of equal moral and intellectual integrity, upon our so-called race problem. After a decade and a half of study, I have no hesitation in laying down the fundamental proposition that the attitude of the so-called Anglo-Saxon people toward the Negro the world over is essentially the same under similar conditions. I am willing to go one step farther, and express the conviction that this truth is so well grounded in fact and reason and experience that eventually it will be sufficiently recognised to afford a basis for mutual toleration and respect among all white people, as regards their social and political 


\section{Contrasts and Parallels}

relations with the Negro, and the other inferior or backward races with which they are brought into contact. An important contributing factor to this consummation will be the attitude of such races themselves, as it becomes better understood by white people. They will be first to recognise this common attitude of the white man. Understand me, I am not talking about the exceptional individual, the closet philosopher or the doctrinaire. I speak of the average man.

It is along this line that Mr. Henry Charles Lea takes issue with the dictum of the late Lord Acton as to a fixed standard of moral conduct. I agree with Mr. Lea that our "standards of right and wrong are modified and adapted to what at the moment are regarded as the objects most beneficial to the individual or to the social organisation."* And this local adaptation of standards - this variable conception of wisdom, justice, expediency, enlightened selfishness, right or wrong, call it what you please - finds universal application. It is not confined to given races or periods, or to our attitude toward any certain set of conditions.

We see this illustrated in the practically unanimous adoption of a Japanese exclusion resolution by the California legislature when the rest of the country was wild with enthusiasm over the newly risen Far Eastern world power; we see it in a clause in the warrant for the 1905 "town meeting" of Marion, Mass., providing for a vote on the question of employing only white men on town work; we see it in the erection of

\footnotetext{
*Report of the American Historical Association, 1903, Vol. x, pp.55 et seq.
} 


\section{8 \\ The American Race Problem}

the state of West Virginia during the Civil War, and in the admission of Nevada to the Union; we see it in the action of Mr. Lincoln on the matter of emancipation, within two years after his declaration that he not only had no intention of interfering with the institution of slavery, but had no right or power to interfere with it; we see it in the exclusion of Chinese labourers, and also I may add, in the recent light which suddenly burst upon us as regards the manner of enforcing this exclusion law, after a Chinese boycott had opened our eyes; we see it in the ease and promptness with which we found warrant for recognising the independence of the socalled "republic" of Panama, under the stimulating necessity of a place to dig a canal; we see it in the Platt amendment which we compelled the Government of Cuba to incorporate in her constitution, as a condition precedent to her "independence"; we see it in the enunciation and maintenance of the Monroe Doctrine the quintessence of selfishness, from the world's point of view, a law of self-preservation from our own; we see it in the equanimity with which we acquiesced and assisted in the extinguishing of the sovereignty of the ancient empire of Korea, at the respectful request of our great and good friend, the Mikado of Japan; we see it in the passage by the legislature of the state of Kansas, the home of John Brown, of a law providing separate schools for the two races in Kansas City, and in the governor's approval of the bill, in the face of Negro opposition, under the necessity of what he described as "local conditions that are peculiar." Such 


\section{Contrasts and Parallels}

instances could be multiplied indefinitely, and without any reference whatever to the Negro, if we cared to exclude his case. We need not call this an accommodation of conscience to necessity; it is simply a practical realisation of the difference between theory and practice. It is just what Mr. Lea declares it to be, a modification and adaption of our standards of right and wrong to what at the moment are regarded as the objects most beneficial to the individual or to the social organisation.

No field offers a broader opportunity for the study of the operation of this fixed and inexorable law of human conduct than that afforded by the contrasts and parallels arising out of the contact between the white and Negro races. It is a field which covers the entire group of West Indian Islands, a considerable portion of South America, large areas in East, West, and South Africa, and every state in the American Union wherein slaves were at one time held or where any considerable number of Negroes now reside. Although I have attempted to study race relations throughout this field, as regards conditions both historical and still persisting, I can do no more here than merely suggest for your consideration certain salient facts as I have found them. And in doing this permit me to again emphasise the object I I have in view. Do not understand me as offering you a mere $t u$ quoque argument. I would not travel this far to engage in so puerile a performance. What I shall say is not even offered as a defence of the Southern racial attitude. I do not think the latter needs any defence. All it needs is to be understood. My purpose 


\section{The American Race Problem}

is broader, and grounded upon more substantial foundations. I offer you this testimony to human nature itself - to exemplify the operation of traits as old as man and as broad as the world. I would only show you a very old and very fundamental truth, that it is unsafe for us to say, in the fancied security of untried isolation, just what we would or would not do if in another's place. We do not know when we ourselves may be put to the test, and we may lay it down as a postulate of human nature that we should act just about as the rest of mankind has acted, wherever confronted with conditions instead of theories.

In all the American colonies, in those of England, France, Spain, Portugal, Holland, and Denmark, in the West Indies and Latin America, and in Cape Colony in South Africa, there may be found the same underlying purpose in the statutes and ordinances for the regulation of slaves. This was the ordering and control of their domestic and economic life. Such laws differed only with differences of local conditions, and were modified because of numbers or economic considerations. The same is true with regard to the restrictive legislation which accompanied the abolition of slavery throughout all the foreign colonies I have mentioned, and in all the American states - New England, Eastern, and Southern. I cannot discuss these statutes in detail, but their general form was compulsory apprenticeship and laws against vagrancy, with gradual emancipation in Brazil, Cuba, and Porto Rico. Their uniform purpose was to guard against the effects of sudden and 


\section{Contrasts and Parallels}

revolutionary social and economic changes. As expressed by Mr. Lincoln, in favouring gradual, over sudden emancipation, it was to spare both races "the evils of sudden derangement," and to save the Negroes "from the vagrant destitution which must largely attend immediate emancipation," especially where there was a considerable Negro population.*

Notwithstanding the universality of such legislation, which you will find if you will pursue the study broadly enough, the reception accorded such action by the Southern States in 1865 reveals a not uncommon human failing, particularly apparent in race problem discussions. This is the claiming of higher motives for our own conduct than we are willing to accord to others for similar action, under even more trying circumstances, or the convenient ignoring of our own conduct entirely. This is worthy of your attention in a study of present conditions, for I think there can be no question that the continued and sweeping denunciation of these laws, as defiant efforts on the part of the Southern people to perpetuate slavery, gave to Northern discussion and sentiment at a critical moment a decided and positive trend. It is entirely conservative to say that the effect has been, even to this day, to colour, even though perhaps unconsciously, the opinion entertained by one section of the country of the motives, feeling, and conduct of the people of the other, in all matters wherein the Negro is concerned. It is with peculiar pleasure that I offer you the testimony of the conclusion of a most

* "Messages and Papers of the Presidents," Vol. 6, pp. 68, 92, x 37. 
careful and painstaking New England historian, on the declaration of Southern men in 1866 that the South did not want to reëstablish slavery. I quote you the judgment of Mr. James Ford Rhodes: "After thirtysix years of observation, study, and reflection, I am convinced of the absolute truth of this statment." $\mathrm{Mr}$. Rhodes says further that Mr. Blaine's account of these laws "is inaccurate and unfair to the South."*

It seems to me peculiarly appropriate that here, before the students of a great American university, a body of men and women who in the natural order of things are likely to play an important part in moulding future public opinion in various sections of our country, I should record one of the strongest convictions I hold upon this much-vexed problem. It is this: Without mutual respect, and confidence in one another's honesty of thought and purpose, we may continue to abuse and misunderstand each other to the end of time. Such respect can be developed only upon a foundation of tolerance, appreciation, and understanding of our respective points of view. If ever such foundation shall be laid amongst us, the work must primarily be that of the really unbiased historian, economist, and sociologist. I know of no graver responsibility which a teacher can assume than that which devolves upon him when he essays to lecture on any phase of this general question, for he should know not only his subject, but himself as well. To the first of these is given the privilege of freeing the present from the evil effects of mis-

* "History of the United States," Vol. 5, pp. 6r5, 556, and notes $\mathrm{I}$ and 2 


\section{Contrasts and Parallels}

apprehensions as to the past; while to the latter we have a right to look for discussion farthest removed from passion and prejudice. Upon these groups rests the duty of lifting such discussion out of the quagmire of theorising, intolerance, and hysteria, and putting it upon a plane of reason and common sense. The situation demands the candid treatment and interpretation of facts, not the farther propagation of ancient dogmas because they are ancient, nor the projecting of new speculations because they are new.

Through the whole range of relations between the white man and the black, from the slavery of one by the other to theoretical political equality between the two, we find the attitude of the stronger toward the weaker dictated and controlled by considerations of local public policy, call these by what name we will. The laws and customs of every state in the Union, from the beginning until this good hour, have been influenced by the factor of the relative numerical strength of the Negro. There is not a state in the Union, from Massachusetts to California, which, through some element of its population, does not to-day, somewhere within its borders, in some way discriminate against the Negro race. We are fundamentally alike in our attitude toward the Negro, however much we may deny it on each side of the line. And this truth will more and more be realised as our Negro population becomes more generally distributed, and as political and economic conditions gradually tend toward greater uniformity between the various sections of the country. In the North he is permitted 


\section{I4 The American Race Problem}

to attend schools and ride in cars with white people, and is not segregated in theatres, because as yet he is not numerically strong enough to be personally offensive to the white population, or to justify the expense and annoyance which such general separation entails upon the white man himself. But, generally speaking, he is permitted to work only in menial pursuits. $\mathrm{He}$ is permitted to work in the South, nay, he is besought and begged to work, at any occupation under the sun, because he is still the labourer to which we are most accustomed, and as yet the white man does not want his job. But he is required to attend separate schools and to ride in separate cars.

Suppose we glance at some expert Negro testimony on this general proposition as to race problem parallels and contrasts. No less an authority than Dr. DuBois, in his history of the "Suppression of the Slave Trade," in speaking of New England, says: "The system of slavery had, on this soil, and amid these surroundings, no economic justification, and the small number of Negroes here furnished no political arguments against them." As to the slave trade, however, he says moral opposition "was swept away by the immense economic advantage of the traffic to a thrifty, seafaring community of traders." Again he assures you that "experience proved that an appeal toward rectitude was unheard in Carolina when rice had become a great crop, and in Massachusetts when the rum-slave traffic was paying a profit of roo per cent."* This line of discussion

* "Suppression of the Slave Trade, " pp. 31, 37, x95. 


\section{Contrasts and Parallels}

might be indefinitely amplified. I could exhaust your patience by a mere recital of parallels between the action of the New England, Eastern, and Southern colonies and states in matters touching the institution of slavery. But it would all resolve itself into the suggestion conveyed by the quotation from Dr. DuBois - the ordering and control by each separate community of its individual domestic economy according to its own ideas of self-interest. I have already tried to suggest to you a line of thought in connection with the general restrictive legislation surrounding the various periods of emancipation. Without attempting to bridge the space interevning between $186_{5}$ and the present time, let us look at the American Negro as he enters the fifth decade of his life as a free man.

We have heard Dr. DuBois on an economic parallel, suppose we hear Mr. Washington, and a few others of the race, on an economic contrast. Farther along I want to say a few words of suggestion on the study of this problem, but let me digress for a moment right here. There is one point of marked similarity between the methods of practically all the so-called students of the race question with whose writings I am familiar. Apparently, none of them, North or South, makes more than a mere pretence at getting the Negro's point of view. I admit that it is a difficult thing to do, but in my opinion no man has the right to call himself a student of the question who does not make an earnest effort toward this end. I have been to Negro churches on plantations in my own section, 


\section{I6 The American Race Problem}

and witnessed there the rude and boisterous outbursts of emotionalism which characterises a so-called worship which in countless instances is even now but few degrees removed from the frenzy of a native African religious orgy, and almost akin to the bamboula of Haiti and Santo Domingo. I have also listened to such men as Dr. Francis J. Grimke, of Washington, in the conduct of services in a Presbyterian church which was founded as a protest against emotionalism. I have seen the Negro on his excursions, at the "circus," and in political and religious gatherings in the South, and at various and sundry conventions elsewhere. I have talked with Negroes of high and low degree, and have been in the humblest cabins of the race, as well as in houses furnished with all the taste and refinement of modern civilisation. I have seen the Negro districts of New York, Boston, Philadelphia, Washington, and Chicago, as well as those of Southern cities and towns. I have corresponded with more than four hundred Negroes in various walks of life, and have discussed their most atrocious crimes with hardened convicts. Always I have tried to gain the confidence of these people, and have never knowingly abused it. I have read the books of Negro authors, obscure as well as distinguished, and for a number of years have kept in touch with their magazine and newspaper literature. In all this my sole purpose has been to try to learn what and how the Negro thinks and feels. I do not presume to say that I have succeeded in this, but I do say that the man who has not followed such methods as I have, has more to 


\section{Contrasts and Parallels}

learn about the subject than he dreams of. Some such course of study is essential to the Southern student of the problem, if he would really know something. of the higher classes, as he already knows the lower, and if he wishes to estimate at their approximate value the work and influence and lives of the various men who are to-day moulding conflicting Negro thought in America and in the world. It is essential to the Northern man, if he would really know the truth of his own section, as the Negro sees it, and some of the aspects of the life of the Negro masses as well. Above all, it is the only way in which either the Northern or Southern student can ever hope to learn what the American Negro thinks of the American white man.

I hope you will pardon this digression, and also its very personal tone. A narrative of my own method of study seemed to me the simplest way of suggesting one for you. It occurred to me to make this suggestion to you as I was on the point of quoting from Booker $\mathrm{T}$. Washington on the relative economic opportunities offered his people by the North and South. I have been told frequently by Northern friends that there was a very prevalent belief in their section that the Negro was not given a fair industrial opportunity in the South. I have seen this statement in print many times, and last year an eminent New England historian brought the same grave charge against us. Men who think this way should read what the Negro himself says on the subject. The evidence is voluminous, and also conclusive, it seems to me, and much of it is readily accessi- 


\section{I8 The American Race Problem}

ble. In a plea for industrial education and opportunity, Mr. Washington says: "No one can fully appreciate what I am saying who has not walked the streets of a Northern city day after day seeking employment, only to find every door closed against him on account of his colour, except in menial service."* On the other hand, he says: "Whatever other sins the South may be called upon to bear, when it comes to business, pure and simple, it is in the South that the Negro is given a man's chance in the commercial world." $\dagger$ In the first book he wrote, he sought to show the pathetic results of a cruel industrial discrimination, and he went North, not South, for his concrete illustration. Again, he tells you: "It has been my privilege to study the condition of my people in nearly every part of America; and I say, without hesitation, that with some exceptional cases, the Negro is at his best in the Southern states." $\ddagger \mathrm{He}$ declares that the absence of industrial prejudice in the South, he does not say real or alleged absence of social or political prejudice at the North, furnishes "the entering wedge for the solution of the race problem." "But too often," he adds, "where the white mechanic or factory operative from the North gets a hold, the trades union soon follow, and the Negro is driven to the wall." He also tells you that "where the Negro has lost ground in the South, it has not been because of any prejudice against him as a skilled workman on the part of the native Southern white man." $\$$

\footnotetext{
* "Future of the American Negro," p. 76.

$\dagger$ "Up From Slavery," pp. 219-220.

$¥$ "Future of the American Negro," p. 202.

\$" Future of the American Negro," pp. 78, 79.
} 


\section{Contrasts and Parallels}

In a very instructive study of local conditions, Dr. William N. DeBerry, pastor of a coloured Congregational church in Springfield, Mass., declares that 86 per cent. of the coloured labour of that city is confined to servile employment "by pure race prejudice," which "has closed the door of industrial opportunity against them." He says that all they ask is that "as a class they may be emancipated from the merciless industrial ostracism which shuts out the capable and worthy Negro because God chose to create him black." And Dr. DeBerry says that his study should be "of more than local significance, inasmuch as the situation here in Springfield is fairly typical of the black man's condition throughout the North."* In the very paper in which Dr. DeBerry's report first appeared, I read an account of a Negro convention in my state, at which was adopted a resolution declaring that "nowhere else in the world is there such an opportunity offered to us as is offered on the plantations of the South."

In this connection permit me to quote an opinion of Booker T. Washington, by the spirit of which our national legislators might well have been guided in years gone by, and which might well be kept in mind to-day. He says that the friendship of the Southern white man affords the Negro "a protection and a guarantee of rights that will be more potent and more lasting than any our Federal Congress or any outside power can confer." $\dagger$ Contrast this with Mr. Blaine's declaration

* Springfield Weekly Republican, Feb. ro, r905.

$\uparrow$ "Future of the American Negro," p, 216. 
that the Negro must not be left "to the anger and hate of the class from whose ownership he had been freed."*

I could quote you a great deal of testimony on this matter of comparative economic opportunity between the South and the rest of the country. I would suggest, however, that you read the section on "Colour Prejudice," in the sixteenth chapter of Dr. DuBois's "The Philadelphia Negro." In another chapter he says: "It is a paradox of the times that young men and women from some of the best Negro families of the city . . . have actually had to go to the South to get work, if they wished to be aught but chambermaids and bootblacks." $\dagger$

Abraham Lincoln made one, and only one, declaration of a belief in a specific form of "Negro equality." $\mathrm{He}$ made it in these words: "In the right to eat the bread which his own hand earns, without the leave of anybody else, he is my equal, and the equal of Judge Douglas, and the equal of every living man." $\ddagger$ This right was guaranteed the Negro, as incident to his emancipation. But there follows also another right as an essential corollary to this - a right without which the first is only dead sea fruit - all, indeed, but a mockery and a farce. This is the right to earn his bread, as well as the right to eat it. We have heard much in these latter days about the "door of hope," which the South is charged with attempting to close against the Negro. A number of years of reflection

* "'Twenty Years of Congress," r 886, Vol. 2, p. ro6.

† "The Philadelphia Negro," I 899, pp. 322-355, and pp. 395-396,

‡ "Political Debates, Lincoln and Douglas," r 895, p. I r4, 


\section{Contrasts and Parallels}

have brought me to the conclusion that for the Negro, at this stage of his racial growth, there is but one door worth the opening, and it is not political. It is the door of which Dr. DeBerry speaks, the door of industrial opportunity. It is the door which opens to the touch of honest toil, through which peace and comfort beckon him who wants to found a home. Within its portals contentment may be found, in lieu of bitterness and racial strife which mark the path to false ambition's more pretentious place. Here infancy and age may reap the golden fruit of labour, and character may grow without the hindering hand of want. Here is the one great primal right of man, the right to labour and to live; the right to have the proper wage of skill; the right to toil wherever human needs make work for human hands; the right to sell his labour where he will. Here is the foundation upon which the family may be reared, the only hope of any race. Here is the "door of hope," upon whose cruel closing follow idleness and crime, vice and destitution, vagrancy and death, for the masses of the race, not mere loss of empty political preferment for the chosen few.

To the crude view of the Southern man it seems almost a mockery to say to the Negro: "You may vote, and ride in our cars, and sit in our theatres, and attend our schools," while denying him free access to industrial pursuits. The North gave practical effect to Mr. Lincoln's conception of "equality" when it said to the mason who had been trained in slavery: "Henceforth every dollar you earn at your trade is your own." But 
it should be somewhat chary of laying too much emphasis upon this incidental achievement of a "war for the Union," in the face of the fact that it has since compelled the former slave to abandon his trowel for a hod.

Let us glance at another aspect of race relations the social - the torrid zone of race problem discussion. If we go below the superficial manifestations, we find the same general attitude, North and South, on this social phase of the question. The North draws the social colour line against the race as a whole, but here and there a Northern man permits some favoured individual to cross it. The South draws the line against the race as a whole, and makes no exceptions at all. Save for such individuals, and almost invariably they are not Negroes, as we know the latter in the South, what may be termed social discrimination exists North as well as South. The differences are more apparent than real - and will be found to turn mainly upon different sectional, local, and individual conceptions of what is embraced in the vague yet comprehensive term, "social equality." Such discrimination is emphasised more in the South simply because the far greater number of Negroes, and more numerous possible points of contact, furnish more frequent occasions for its display. But it was not in the South that the most sensitive and most cultured man identified with the Negro race first was made to realise that he "was different from the others." It was "away up in the hills of New England" (he tells those of us who study the life of the race in its own written words) "where the dark Housatonic winds 


\section{Contrasts and Parallels}

between Hoosac and Taghkanic to the sea." It was there he first was made to feel the presence of "the shadow of the veil."*

In a contribution to a leading Negro magazine a Southern Negro has related his experiences in a Northern university. He says he found "not an ounce more of opposition" from Southern than from Northern students, but describes the former as more "frank" and the latter more "secretive" in their racial attitudes. He concludes his article by saying: "To-day the only white members of Yale class of 1904 with whom I correspond, the only ones who expresed a desire to keep in touch with me, are several Southern lads." $\dagger$ A contention that the Negro is treated as an equal in the North is not often made by sensible men, and it cannot be supported by facts. It is idle to point to a mulatto upon whom Harvard has conferred a degree, or to one whom a G. A. R. post has elected its commander, and say to the world: "Here we tolerate no racial discriminations." The world knows better, if it knows anything at all about the subject. And the Negro knows better, aye, and the mulatto, too, whether he considers the discrimination in either its social, political, or economic aspect. There would be precious little room for misunderstanding between us here, if each of us were only more thoroughly acquainted with his own and the other's ground.

And our white brothers in South Africa are in exactly

* "The Souls of Black Folk." DuBois, p. 2.

† William Pickens, The Voice of the Negro, April, r905, pp. 235, 236. 


\section{The American Race Problem}

the same boat with ourselves. Technically the civil rights of whites and Negroes are the same in Cape Colony, but the actual discriminations are just as numerous as in any Southern state. I have a statement from an English resident of the Cape, who spent a winter in Georgia, who said that his observations had been a revelation to him, after the stories he had heard. He says the Georgia Negro is in paradise as compared with his South African brother. Two years ago a lot of American Negroes in Johannesburg memorialised our State Department for a redress of grievances, because they were not permitted to use the sidewalks. Of course Mr. Hay could do nothing. It was a local police regulation, and the authorities made no distinction between an American Negro and one born at home. There and in Natal the races are separated on railway trains, and even Mr. Labouchere, champion of the Negro that he is, has publicly recognised the wisdom of the regulation. There are many Negroes of wealth and education in South Africa, and Mr. James Bryce relates the bitter experience of one of these in trying to get his daughter into a white school. Possibly another parallel may suggest itself to you, in another incident related by Bryce in his description of social conditions. When Khama, the most important chief south of the Zambesi, a man of large influence and high character, and often described as "a Christian gentleman," visited London in 1895 , he was accorded considerable social attention, and the Duke of Westminster and others invited him to dine. Mr. Bryce says that among 


\section{Contrasts and Parallels}

Englishmen throughout South Africa the social reception accorded him excited "annoyance and disgust."* I have heard men from California express themselves in similar terms over the lionising of Mr. Wu Ting Fang, when he was a social favourite in the East a few years ago.

The Southern people have lately been told by an eminent American scholar that they cannot hope to solve the race problem, or any other problem, "until they first learn the real barbarism of their social standards." My reply to this generous suggestion would be similar to Mr. Blaine's answer, as Secretary of State, to the then Italian Minister on a certain important occasion, when the latter found fault with our confusing dual system of state and Federal governments. It was to the effect that he was sorry, but really did not believe we would make any immediate change. It is not safe to generalise about the attitude of fifteen or twenty millions of people on any subject. But I feel that I can say that the white people of the South believe that where two races, as widely different as are the white and black, live together in large masses, public policy requires the observance of certain regulations in the ordering of the social relations between the two. Furthermore, they are entirely satisfied that every single instance of disregard of these established regulations is of harmful tendency, through force of suggestion and example,

\footnotetext{
* "Impressions of South Africa," 1899, p. 354. Mr. Bryce's chapter on "Blacks and Whites, "Chapter $2 \mathrm{I}$, would repay reading by anyone interested in the larger aspects of the question of race relations, which I am here merely touching upon.
} 


\section{The American Race Problem}

and this without the least reference whatever to the social station of the parties immediately concerned, or to the effect upon them as individuals. It matters very little how we may designate this-as "race prejudice," "social barbarism," or what not. There it is, and it is grounded upon no such feeling as may be dismissed with a sneer. It is based upon high considerations of the general welfare of the state, and rises to the dignity of a fixed canon of social and public law. It may be disregarded with possible safety where there is a mere handful of either race in contact with the mass of the other; possibly it may be overridden with impunity where there is only a handful of each; it cannot be safely defied where the millions of the two races embracing all degrees, grades, characters and conditions of each - are destined permanently to occupy the same territory, unless, of course, we are prepared to accept the ultimate blending of the two.

It would be interesting to follow in some detail the course of political relations between the races after emancipation in the more important governments outside the United States. It would also be instructive, at least $I$ have found it so, as throwing valuable light upon this aspect of our own problem. We should find that such relations reduce themselves, ultimately, to one of four conditions. First: The Negro has been absorbed politically into the mass of the population; and where this has taken place practical social absorption has invariably accompanied or followed it. This has come about either through the relative 


\section{Contrasts and Parallels}

insignificance of numbers, or because of the character of the white population, or through a conjunction of the two. Mexico, the Central American, and some of the South American states fall into this class. Or, second: The Negro is nominally entitled to share equally in the government, as part of the electorate, as in Cape Colony and the British West Indies, though his ballot is hedged about with qualifications, and selfgovernment, as we know it, does not really exist. Or, third: $\mathrm{He}$ is frankly recognised as possessed of no political privileges whatever, as in Natal, the Boer states before the war, and now in the resulting Boer colonies. Or, fourth: He has secured sole control of the government, through force of numbers and adventitious circumstances, as in Haiti and Santo Domingo. Liberia is in this class also, but of course it is purely an artificial creation. We should also find that where the Negro participates to any extent in the administration of affairs, as occasionally, here and there, in the British West Indies, the race is almost invariably represented solely by its mulatto type, the latter recognised as a distinct element in the population. The one really dominant fact, however, is that in all these places, regardless of relative numbers or of any other consideration, where racial amalgamation has not taken place, the white man invariably controls the government and administers its affairs. Always excepting Haiti and Santo Domingo, of course. In the former the Negro governs to the exclusion of the mulatto and such whites as chance to live there; in the latter the 


\section{The American Race Problem}

mulatto governs to the exclusion of the Negro and the white man. I am afraid I shall have to revise the latter statement pretty soon. It looks very much as if the white man were about to govern there also. If he ever does, it is only a question of time when the Negroes of Haiti will be in the same boat.

I shall not here attempt to institute a comparison between these foreign states and our own. I merely submit a few suggestions for your consideration. There are factors in the Southern situation not found elsewhere in the political relations between the races. Some of these have only to do with history, others are persistent. For instance, nowhere else was the change of relationship from that of master and slave to one of civil equality accompanied by such conditions as ushered it in at the South. Nowhere else to-day on either the American or African continents - is there being made an attempt to carry on even the semblance of complete republican government with theoretical political equality between large masses of two such diverse races. I once listened to a discussion of the suffrage restrictions of the Southern states by one of the most eminent of living American historians. I was impressed by the seemingly insuperable difficulty in the way of even a man of honesty and courage and brains, when from a position of unthreatened and impregnable Caucasian security he attempts to understand this aspect of our problem.

It is not possible to grasp, through the lifeless medium of what is coldly laid down in the books, the underlying 


\section{Contrasts and Parallels}

motives and principles actuating and determining the political conduct of the Southern white man, and of every other Anglo-Saxon, when confronted by the Negro in even approximately equal numbers. This gentleman correctly recited the historic truth that at the beginning of our government the free Negro was not wholly discriminated against in the matter of suffrage, but was allowed to vote in several states, Southern as well as Northern. Upon this naked fact, apparently, if I correctly apprehend the reasoning, it is sought to build the argument that subsequent suffrage restrictions have been unjust, or at least have been founded merely upon unjustifiable race prejudice-a prejudice which did not originally exist. The trouble here is that this is a superficial view. The significance of original conditions and subsequent changes is entirely lost sight of. There was no discrimination against the Negro at first, it is true, but neither was suffrage specifically conferred upon him. Negroes were enrolled as soldiers in the Continental armies, and they fought in the War of $18 \mathrm{I} 2$. Yet in $186 \mathrm{I}$ public sentiment was such that it was only with the greatest difficulty that the Northern Government was finally prevailed upon to enlist them for a war which very much more concerned them than had either of the other two. The Negro was simply ignored and treated as a negligible quantity in the formation of our general scheme of government. Had his increase of numbers never become sufficient to attract attention, he would have continued to occupy his original position, and it is 


\section{0 \\ The American Race Problem}

doubtful if he would ever have been discriminated against politically.

The constitution of Pennsylvania furnishes a case in point. The suffrage article in the constitution of 1790 gave the elective franchise to male "freemen" with no mention whatever of colour. It was said a number of years later, however, that an attempt had been made to confine the suffrage specifically to whites. Be this as it may, free Negroes did occasionally vote in the state. But when the convention of $1837-38$ framed a new constitution the matter was not again left in doubt, and suffrage was confined to "white freemen." DuBois says: "As the Negro population increased, however, and ignorant and dangerous elements entered, and as the slavery controversy grew warmer, the feeling against Negroes increased and with it opposition to their right to vote."* But I do not think it is correct to describe this as a change of sentiment. It was simply a gradual development of sentiment, where no sentiment at all on the subject can properly be said to have originally existed. It is worthy of mention, however, that there was no change of sentiment in the other direction, and the Negro was not given the suffrage in Pennsylvania until the XV Amendment was adopted in 1870.

It was only through the operation of this amendment that the Negro secured the elective franchise anywhere in this country, with the qualified exceptions of New York and five of the New England States. And in I 860 the Negro constituted but eight-tenths of one per cent.

* "The Philadelphia Negro," p. 370. 


\section{Contrasts and Parallels}

( 0.8 per cent.) of the population of New England, the proportion being 794 Negroes to 100,000 white people. In New York and three of the New England states there was an actual decrease in the number of Negroes between $185^{\circ}$ and 1860 . The question of granting the suffrage to Negroes was submitted to popular vote in the fall elections of 1865 in the states of Connecticut, Minnesota, Wisconsin, and Colorado, the latter just entering the Union. It was defeated in each one, though they were all in the practically undisputed control of the Republican party.* Three years later we can still detect no outward change of sentiment on the part of the Northern states. The Republican National Convention of $\mathrm{r} 868$, which nominated Grant, inserted this well known plank in its platform: "The guarantee by Congress of equal suffrage to all loyal men at the South was demanded by every consideration of public safety, of gratitude and of justice and must be maintained; while the question of suffrage in all the loyal states properly belongs to the people of those states." $\dagger$

I mention these facts in the political history of the Negro, merely to show you that with few exceptions his political status in the Northern states was just what it was in the Southern, just as long as the control of such status remained in the hands of the people of the states themselves. And further, that even after Congress had assumed control of the domestic affairs of the Southern states, the Northern still wished to reserve

* See Blaine's Comments, "Twenty Years of Congress," 1886, Vol. 2, p. 244. †Idem. 


\section{2 \\ The American Race Problem}

to themselves the regulation of Negro suffrage within their own borders. Whatever the fate of the South, these states wanted to control their own political destiny. They did not propose to experiment with Negro suffrage upon their own people.

Through all this may be seen the operation of the influences which $I$ regard as at the foundation of all race relations - the force and effect of numbers, acting directly or indirectly upon public opinion. It may be asked why should the Western states, with practically no Negroes at all, have discriminated against them in specific terms. The question is not a difficult one to answer. Had those states emerged from colonies, as did the Eastern and Southern, their constitutions would have been controlled by the same influences which shaped the creation and development of the organic laws of the older states. As it was, they were settled by Eastern people, and their constitutional provisions on the Negro merely reflected the sentiment which had been developed in the states from which such settlers came. Some of them sought the simplest way out of the difficulty by either frankly prohibiting free Negroes or mulattoes from living within their borders, or requiring bond for such residence. Ohio, Indiana, Illinois, and Oregon are such examples, and they found warrant for their action in analagous provisions in some of the older states. On the other hand, some did not care to go so far at first, or did not think it necessary, and contented themselves with so framing their constitutions as merely to discourage Negro immigration. This fear 


\section{Contrasts and Parallels}

of an irruption of Negroes into the Northern states was a fact with which Mr. Lincoln had to reckon at every step he took in the direction of emancipation. In his second annual Message, December I, I862, he devoted considerable space to urging the adoption by Congress of resolutions providing for gradual emancipation by constitutional amendment. One of his arguments was addressed to this very fear of an influx of Negroes to the North, in the event of their emancipation. He concluded his reasoning against such a possibility with this significant query: "And in any event, cannot the North decide for itself whether to receive them?"*

Already, on June $\mathrm{I} 7 \mathrm{th}$, nearly six months before, in voting on the adoption of a new constitution, his own state had answered his question with a majority of I00,590 votes out of a total of 243,202 votes cast on the proposition, in favour of the continued exclusion of the Negro from Illinois. Six propositions were submitted, including that on the adoption of the constitution itself. Three of these dealt with discriminations against free Negroes, and they were the only ones that were carried. To guard against the evils which might follow the possible failure of the Negro exclusion proposition it was also determined to exclude them from the suffrage by a majority of $176,27 \mathrm{I}$, out of a total vote of 247,569 . The constitution itself failed, by a majority of 16,051 votes out of a total of $266, \mathbf{1} 55 . \dagger$ The statute books of Mr. Lincoln's state contained as severe and drastic anti-

* "Messages and Papers of the Presidents," Vol. 6, pp. r40, 14r.

$\dagger$ "The Illinois Constitutional Convention of $r 862, "$ O. M. Dickerson, pp. 23, 24, University of Illinois Bulletin, Vol. 2, No. 5 . 


\section{4 The American Race Problem}

Negro legislation as could be found in the laws of any "free state" in the Union. This vote merely registered a sentiment unchanged since the adoption of the constitution of 1848 . Yet, in 1865 , a great Illinois paper thus indulged itself on the freedmen statutes then just enacted by Mississippi: "We tell the white men of Mississippi that the men of the North will convert the state of Mississippi into a frog pond before they will allow any such laws to disgrace one foot of soil in which the bones of our soldiers sleep, and over which the flag of freedom waves."*

This throws a flashlight upon the temper of the times, and would be humorous were it not so serious. But it also suggests this reflection for those of us who undertake to study and discuss the problem left us as a heritage from conditions created forty years ago. We would do well to sweep our own doorsteps before calling attention to the condition of our neighbour's. It is a fundamental principle of every proceeding in equity that the complainant come into court with clean hands; yet in the problem before us it is one as easily and frequently violated now as we know it to have been in 1865 .

We need not imagine that we have a monopoly of Negro suffrage history. We see a suggestive parallel in the history of the franchise in Cape Colony. When representative government was granted that colony, and later responsible government, the Negro was not

* Chicago Tribune, December 1,1865 ; quoted in "Reconstruction in Mississippi," Garner, p. I15, note. 


\section{Contrasts and Parallels}

discriminated against. He was simply ignored, because so few were qualified, just as in the American colonies. It was probably as much of a discovery there to find that he was actually a voter as it was in Pennsylvania, or North Carolina, or Connecticut. The status quo was simply permitted to continue from year to year until finally it was realised that the Negro was becoming a menacing factor in Cape politics. Then what happened? Just exactly what has happened in the Southern states, and in Jamaica, and just what will happen whenever and wherever the numerical strength or racial traits of the Negro begin to threaten, or in any way interfere with, the political supremacy of the white man. Negro suffrage was restricted by qualifications which we need not here stop to consider. It is a coincidence that the subject was simultaneously agitated in both Cape Colony and Mississippi. Action was taken by the Cape Government in 1892 , the new constitution of Mississippi having been adopted in 1890 . But in the succeeding fourteen years, owing to a relatively small English population and an increase in the number of qualified Negro voters, affairs at the Cape have again assumed an unhappy aspect. There is one Southern state, with the largest Negro population in the Union, which has never embodied suffrage restrictions in its constitution. To-day [I go6] there is a campaign on in the state of Georgia in which this proposition is the principal issue, while at Cape Colony, several thousand miles away, you will find similar political discord, with similar declarations and counter declarations as to the necessity or 


\section{The American Race Problem}

absence of necessity for a further restriction of the Negro vote.

"The Negroes . . . are becoming year by year a more formidable element, and, if unrestrained, must inevitably undermine the very foundations of white supremacy. Self-preservation is the first law of nature. It is not necessary to be a prophet, or the son of a prophet, to foresee that that law will yet compel the white man to adopt measures against the Negro at which to-day nine people out of ten would raise their hands in pious horror."* This prediction is not mine. It is not even an extract from a speech of one of the present candidates for governor of Georgia. It is the very deliberate statement of a very level-headed Englishman, and one of the best posted men in the Empire on South African affairs, Mr. Roderick Jones, in discussing the present situation in Cape Colony. In quoting his language I have merely changed the word "blacks" to "Negroes," and omitted the words "South Africa."

But some English speaking white people have not even attempted to do what Cape Colony and the Southern states have done. Or, more accurately speaking, they have abandoned the attempt. Jamaica lived for I 37 years - a longer period by two decades than we have lived under the Constitution - under a selflegislating form of government, if I may so describe it, granted under George II. in I 728. But a generation

\footnotetext{
* "The Black Peril in South Africa," The Nineteenth Century and After, May, 1904, p. 723.
} 


\section{Contrasts and Parallels}

after Negro emancipation, even with qualified suffrage, she found herself unequal to its further maintenance. Under the stress of unbearable social and political conditions, following the attempt to assimilate the new Negro element into the body politic, the government went to pieces after the Gordon Riots of $186_{5}$, and rather than longer attempt to perpetuate a farce, voluntarily surrendered its ancient charter to the crown. It is the merest sophistry to try to make it appear, as is sometimes done, that the failure of responsible government in Jamaica was due to other causes. Mr. Bryce frankly acknowledges the truth when, in congratulating his country on the absence of a larger coloured than white population in practically all her self-governing colonies, he remarks that the reverse condition "caused Jamaica to be, some time ago, withdrawn from that category."* To-day, throughout the entire group of West Indian islands, after seventy-two years of Negro freedom, England finds herself unable to establish one responsible government. It has often occured to me that there is something for us to reflect upon in the coincidence that the year which marked the end of an era of such experimentation in the greatest of the British West Indies, witnessed the beginning of the movement toward a similar attempt in the greatest experimental democracy the world has ever known. But when, as in Jamaica, the inevitable happened, and the experiment reached the point of self-demonstrated failure, there was no such

\footnotetext{
* "Impressions of South Africa," pp. 395,396. See also "Jamaica," Frank Cundall, Vol. 3, in British Empire Series, "British America," pp. 419.420.
} 


\section{$3^{8}$ \\ The American Race Problem}

easy avenue of escape for the Southern people as a simple change of governmental form. Only in the District of Columbia, and under the control of the party which had created him, could that convenient expedient for getting rid of the Negro voter be resorted to.

I shall conclude this cursory consideration of the first branch of our subject with this reflection: I believe it is safe to say that we can account for most of the real differences which characterise the relations between the races here and elsewhere, by a recognition of the fundamental differences of governmental theory and policy under which, respectively, such relations are being adjusted and developed toward ultimate stability. We have long prided ourselves upon being an intensely practical and common-sense people. Yet in the most serious crisis which has confronted us as a nation, that of determining the political relations between two races as divergent in history, development, and capacity for self-government as the Negro and the Caucasian, we were not practical, and we exhibited anything but common sense. In commenting upon the differences between the conditions which justify the creation of English self-governing colonies and those which necessitate the continuance of the crown-colony form, Mr.Bryce recognises as a matter of course the force of differences of race in determining differences of governmental policy. He says: "Every one perceives that representative assemblies based on a democratic franchise, which are capable of governing Canada or Australia would not 


\section{Contrasts and Parallels}

succeed in the West Indies or Ceylon or Fiji."* Events have forced us to recognise this in the government of our own dependencies, but in our more domestic affairs we did all that written instruments could do to decree that, regardless of the practical consideration of the differences of racial elements in the state, there should be no difference in the extent to which such elements should share in the State's control. In the differences between the practical operation of these two theories of government for mixed populations, we may read an explanation of such basic differences as exist between conditions in the Southern states and in the British West Indies as may not be accounted for by almost purely physical considerations. If you will study racial conditions in Jamaica during the thirty years preceding I866, and in Jamaica under the crown, I believe you will acknowledge the force of my suggestion.

" "Impressions of South Africa," pp. 346,, 47 


\section{II}

The Foundations of Our Differences

T HAVE attempted to sketch in rough outline the 1 conditions which present certain parallels and contrasts between the social, political, and economic relations of various groups of whites and Negroes. I have stated my belief to be that both the contrasts and the parallels are grounded primarily on certain practical considerations which have little to do with moral or ethical differences among separate groups of white men. The most important of these differentiating factors I have already declared to be that of the unequal numerical distribution of our Negro population. There is one other worth considering. That is the difference between the two types of Negroes from familiarity with which Northern and Southern people form their respective ideas of the race as a whole.

For the most part, the Northern man, at least the one who does the thinking and writing and talking on the subject, comes in contact with a selected mulatto type, while Southern people are in constant association with the millions who compose the masses of the race. A separate enumeration of mulattoes has been made four times, in the censuses of $1850,1860,1870$, and 1890 . The results disclosed the fact that where the proportion 


\section{Foundations of Our Differences}

of Negroes to whites was lowest, the proportion of mulattoes to total Negroes was highest. For example: In 1890 , in the South Central States of Kentucky, Tennessee, Alabama, Mississippi, Louisiana, Arkansas, Oklahoma, and Texas, the mulattoes were but $\mathrm{I}_{4}$ per cent of the total Negro population. On the other hand, they were 32.7 per cent. in the New England group. Expressed differently, of all the so-called "Negroes" whom a white man would see in Mississippi, only Ir.5 per cent. would be of the mulatto type, while of all those observed in Massachusetts 36.3 were mulattoes. In Maine 57.4 per cent. were mulattoes, and in Michigan they were 53.8 per cent.; while in Georgia and South Carolina they were respectively 9.9 per cent. and 9.7 per cent.* This and my own observation are my warrants for expressing the opinion that when the average Northern man writes or talks about the Negro from personal observation, he is unconsciously thinking of another type, the differences between which and the Negro must be recognised if we would intelligently study American race problems.

I am familiar with the names of the handful of pure Negroes who have achieved distinction in America. And they are after all really but a handful. Practically all the so-called Negroes of distinction are not real Negroes at all. The name of Alexandre Dumas is claimed by the French people as one of the glories of French literature. Nobody thinks of using him as a demonstration of Negro capacity, simply because one

\footnotetext{
* "Negroes in the United States," Census Bulletin 8, x904, pp. I5-x 7.
} 
of his ancestors happened to be a mulatto of Martinique. Yet that is just what the dean of American novelists does in the case of an American writer who has less Negro blood in his veins than Dumas had in his. Here is a man who might defy an ethnologist to say that he had a drop of Negro blood; yet because an arbitrary social custom classes him as a Negro (and, by the way, he does not live in the South), thousands read his books, or listen to his spoken words, or engage him in social intercourse - and thereby form mature and well considered judgments as to the character and possibilities - above all, the possibilities - of the masses who confront the Southern white man.

The Negro race never had a truer or more sympathetic friend than Mary Kingsley. In her honour, and as a memorial to her memory, the African Society of London was founded. But she always told the truth as she saw it, and it was she who impressed upon her own and European governments the necessity of a knowledge of the real people for whom they were trying to legislate. These are her words: "The African who turns into a Europeanised man is the exception that proves the rule, and whose isolated conduct misleads the white man, dazzled by the performance of one in a hundred thousand; we seem blind to the inertia of the great mass that we have to deal with to-day in a state practically unaltered by the white work of four hundred years duration." * Is it not reasonable to ask if it may not be too often true that we also are dazzled by the

\footnotetext{
* British Empire Series, Vol. 2, p. 377. London, 1899.
} 


\section{Foundations of Our Differences}

few into blindness of the real needs and capacities of the mass?

But it is to the dull and uninteresting pages of census reports, and to columns of dreary figures, that we must come at last if we would know the real basis of differences of American opinion on the American race problem. These figures, after all, are comprehensive of all other subsidiary causes and explanations. Of course I shall not attempt to review the distribution of the slave population at different periods, or even that of the freedmen immediately after the war. Nor shall I discuss the causes which led to the shifting of the centre of Negro population 476 miles in a southwesterly direction between I 790 and I 900 - or the significance of this movement. The figures of present distribution are sufficient for our purpose, and we have time to glance at only a few of these - barely to skim the surface, in fact.

First, let me say that I regard this race problem as, in a certain very large sense, a national problem. Any question capable of creating two practically distinct schools of national thought is certainly a national question. But like the tariff, or any other question of national dimensions, it has its peculiar and distinctly local phases. The particular situs of any such problem may be found where the elements essential to its composition are known to exist. The elements in this particular problem are the white and Negro races; and the conditions essential to its creation are to be found in the juxtaposition of sufficient numbers of these races. The variants of the problem present themselves 


\section{4 \\ The American Race Problem}

with differences of local conditions, turning mainly upon differences in the proportions of the two races. And here we come to the prime factor of numerical distribution.

By the last census there were in the United States $8,833,994$ Negroes. Nearly 90 per cent. -87.4 per cent., to be exact - were in the thirteen Southern States. Nearly one third, $3 \mathrm{I} .4$ per cent., were in the three contiguous states of Georgia, Mississippi, and Alabama. More than one million, or Ir.7 per cent. of the whole, were in Georgia. Mississippi contained more than 900,000 , or 10.3 per cent. of the whole. New York, New Jersey, and Pennsylvania combined contained but 3.7 per cent. of the whole. The entire group of New England States contained but seven-tenths of I per cent. of the Negro population of the country. Scattered through those six states there were less than 60,000 Negroes, all told, while in Charleston County, S. C., there were 60,312. In my county in Mississippi, Washington, there were 44,r43. This means that in this county alone there were more Negroes than in either one of twenty-eight states and territories of the Union: West Virginia, Indian Territory, Massachusetts, Delaware, Oklahoma, Michigan, Connecticut, Iowa, California, Rhode Island, Colorado, Nebraska, Minnesota, Wisconsin, Washington, Arizona, New Mexico, Montana, Maine, Oregon, Wyoming, Vermont, Utah, New Hampshire, South Dakota, Idaho, North Dakota, or Nevada. Not one of these twenty-eight states and territories contained as much as I per cent. 


\section{Foundations of Our Differences}

of the Negro population of this country. Not one of the last fifteen of this group contained as much as onetenth of I per cent.

There are nineteen of our fifty states and territories which contain, all told, less than one two-hundredth part of our Negro population. Contrast this with the fact, just stated, that three adjoining states, Georgia, Mississippi, and Alabama, contain nearly one-third of all the Negroes in America. Then you may catch, in part perhaps, the significance of what I mean when I speak of the effect of such numerical distribution upon our respective points of view. How can a matter affecting in any wise the relations between the races in the Southern states be expected to appeal to a Senator from Wisconsin, with its 2,542 Negroes, composing one-tenth of I per cent. of its total population, with the same significance that it has for a Senator from Mississippi, with 907,630 Negroes behind him - a number equal to 58.5 per cent. of the entire population of his state? How can the Senators from Rhode Island and from Georgia bring themselves into accord upon such a question - the one with 9,092 Negroes in his state and the other with $\mathrm{I}_{1} \mathrm{O}_{34}, 8 \mathrm{I}_{3}$ in his? Here is the real foundation of our differences. We are all white men, with different admixtures of different strains perhaps, yet with the same race traditions behind us, with the same hopes and aims and aspirations for the future, and subject to the same impulses through life. It is one of the anomalies of this whole race problem business that since the Negro's emancipation every 


\section{The American Race Problem}

single policy of the national Government in which the Negro as a race was in the least degree concerned has been entirely within the initiative and control of the section of the country in which only an insignificant proportion of the Negro population had their homes. The section which contains nearly 90 per cent. of the Negroes of the country has had no controlling voice in any such policy. The Negro has thus been a hapless bone of contention between the white people of the section which has legislated for him and about him and because of him, and those of the section which has absolutely dominated the local situation of the masses of the race.

To make a further comparison: My state contains more Negroes than do the combined twenty-eight states and territories enumerated above, with the great states of Pennsylvania, New York, Ohio, Illinois, and Indiana thrown in for good measure. To the thirty-three states this gives us, you may add New Jersey and Kansas, and make the number thirty-five. After thus offsetting with my state the combined Negro population of every state and territory in the Union outside the South, barring only Missouri, which is itself part Southern, we would still have a surplus of 27,959 Negroes. These would be more than enough to again duplicate the combined Negro population of both Iowa and Connecticut. There are more Negroes in Mississippi than in Cape Colony, or Natal, even with the great territory of Zululand annexed to the latter; more than in the Transvaal, and not far from as many as in both the 


\section{Foundations of Our Differences}

Boer colonies combined; more than in Jamaica and Barbadoes combined; more than in Trinidad and all the remaining English islands combined (excluding those just named); more than in Cuba and Porto Rico combined; more than in either Haiti or Santo Domingo.*

Occasionally we hear a Southern man remark that the North knows little or nothing about the Negro, and has little or no opportunity to learn anything about him. There is a measure of truth in the first part of the assertion, though the latter part must be somewhat qualified. The North is every year learning more about the Negro, and about some of the universal questions growing out of his presence. The leading authorities to-day on several phases of Southern conditions, or on subjects ordinarily classed as peculiarly Southern, are Northern men. Professor William A. Dunning is the best authority we have on political reconstruction; Mr. Carl Kelsey, of the University of Pennsylvania, has made the best study of the Negro farmer that I have seen; Professor James Elbert Cutler has given us the only study of the subject of lynching worth the reading, and it is an admirable piece of work; Professor M. B. Hammond, of Ohio, is the author of the standard work on the cotton industry; Professor Walter F. Willcox is easily the leading authority in the United States on Negro statistics. Not one of these men ever lived in the Southern states. But for all that, if we frame the statement differently, and say that the North knows

\footnotetext{
* The figures for foreign Negro population were the latest obtainable from census reports and estimates at the time this paper was prepared in 1905 .
} 


\section{The American Race Problem}

little about the rather vague, indefinable thing we call "the race problem," we are well within the limits of conservative truth. It is not uncommon to hear even this statement replied to by an enumeration of the number of Negroes in various Northern states. This simply misses the crux of the whole question - the relative proportions of the races. An isolated locality, such, for instance, as the "San Juan Hill" district of New York City, may have a race problem - through a heavy congestion of Negro population. But this is entirely local.

There are twice as many Negroes in New York State as in my county. But in New York they constitute only an insignificant $\mathrm{I} .4$ per cent. of the population. They are swallowed up in an ocean of white people, and are simply numerically incapable of creating a race problem. In my county they are 89.7 per cent. of the population, while for the country districts, and the county is practically all country, they compose 94.2 per cent. of our population. Here a handful of white people is swallowed up in a mass of Negroes - the proportion being about nine to one. There are fifty-five counties in the South in which the Negroes constitute more than 75 per cent. of the population. They constitute r. 4 per cent. of the population of the New England hills, and 62.9 per cent. of the population of the Mississippi alluvial region. The New England and Western states contain I 2.8 per cent. of the total population of this country, and but I per cent. of its Negro population. I have said that there are nineteen of our fifty states and terri- 


\section{Foundations of Our Differences}

tories which have less than one two-hundredth part of our Negro population: these same nineteen states contain more than one-eighth of the total population of the country. The Negro constitutes 58.5 per cent. of the population of Mississippi, and I.I per cent. of that of Massachusetts. $\mathrm{He}$ is 58.4 per cent. in South Carolina and r.4 per cent. in New York. He is 47.r per cent. in Louisiana and r.8 per cent. in Illinois. He is 46.7 per cent. in Georgia and seven-tenths of I per cent. in Michigan. For every 100,000 white people in Massachusetts there are I,I54 Negroes. For each 100,000 whites in Mississippi there are $141,55^{2}$ Negroes. In New York the proportion of Negroes to 100,000 whites is 1,387 ; in South Carolina it is 140,249 . In Michigan it is 659 , in Alabama it is 82,636 ; in Illinois it is 1,797 , while in Georgia it is 87,600 ; in Ohio, 2,387 ; in Louisiana, 89 , r99; it is 2,554 in Pennsylvania, and 77,600 in Florida. For every roo,000 white people in the United States there are 13,223 Negroes. In the South Atlantic group of states the proportion rises to 55,607 : in the North Atlantic group it falls to $r, 866$. It is 42,726 in the South Central division, and only $r, 923$ in the North Central. In the Western division there are but $78 \mathrm{I}$ Negroes for each roo,000 white people.*

I have said that the state of Mississippi contained more Negroes than all the states and territories outside the South combined, including West Virginia. This bare statement may not impress you as being particu-

\footnotetext{
* All the basic figures used here may be found in Census Bulletin 8, 1904, "Negroes in the United States,"
} 


\section{0 \\ The American Race Problem}

larly significant, but let us see what it really means. Their Negro population in I900 was 879,671. This was 27,959 less than that of Mississippi. The latter state contained 907,630 Negroes. But we must not lose sight of the relative proportions of the two races which is the real essence of the matter. Against the less than nine hundred thousand Negroes scattered through this group of thirty-five states and territories we must place 49,081,797 white people. Against the more than nine hundred thousand Negroes compacted in the one state of Mississippi, we have a white population numbering $64 \mathrm{r}, 200$.

The Negro population of Washington county, Mississippi, is greater than that of the combined states and territories of Minnesota, Wisconsin, Washington, Arizona, New Mexico, Montana, Maine, Oregon, Wyoming, Vermont, Utah, Idaho, North Dakota, South Dakota, New Hampshire, Nevada, Nebraska, and California. These states have a Negro population of 39,0 I 2 , less by 5, I 3 I than the 44,143 Negroes in my county. Again, look at the matter of relative numbers. Against this insignificant number of Negroes, less than forty thousand, scattered from the Atlantic to the Pacific, we find a white population of ro,334, rog. Against the 44, I 43 Negroes living within the confines of my county, we have a handful of white people, numbering 5,073 all told.

None of these eighteen great states, except Nebraska and California, has as many Negroes as we have in the little town which is the county seat of my county. The 


\section{Foundations of Our Differences ${ }_{5} \mathbf{I}$}

nearest approach to it is to be found in Minnesota, in the length and breadth of which state the census enumerators were able to discover just 4,959 Negroes. Greenville, my county capital, had 4,987, giving her a majority of 28 . In the matter of relative proportions, however, Minnesota had a little the better of us. Her white population was $1,737,036$, against our 2,644, giving her a clear white majority over Greenville of r,734,392. In the halcyon days about the beginning of the end of carpet-bag rule in Mississippi, we had several counties which could do almost as well as this in the matter of white majorities. The size, in fact, depended only upon the exigencies of the occasion.

Perhaps a few concrete comparisons may interest you, and render more striking the differences between Northern and Southern states and cities. If the proportion between the races were the same in New England as in Mississippi, on a basis of her present white population the former would have $7,737,83^{6}$ Negroes, instead of 59,099 as at present. With the same proportion the state of New York would have ro,or 9,633, instead of 99,232. Pennsylvania would have 8,598,329, instead of 156,845 . If the same proportion existed in Chicago as in Charleston, the former city would have 2,I 52,268 Negroes, instead of 30,150. On the same basis Boston would have 708,598 , instead of II,59I.

Take the county of which Ann Arbor is the capital. Here in Washtenaw you have a somewhat smaller total population than that of my home county. But of your $47,76 \mathrm{r}$ people only 1,240 are Negroes. Of our 


\section{The American Race Problem}

49,2 I 6 inhabitants only 5,073 are white. If the proportion between the races in my county, practically 9 to $\mathrm{I}$, were applied to yours, with your present white population you would have 4 r8,689 Negroes, instead of I,240. I might make these figures more impressive by applying the proportion which obtains in a county adjoining mine. It is there a little more than fifteen to one. But nine to one is heavy enough to make the comparison suggestive. In the state of Michigan you have $2,398,5^{6} 3$ white people and 55,8 I 6 Negroes, the latter but little more than a third of the number in my county. If the proportion between the races were the same as in Mississippi, with your present white population you would have $3,357,988$ Negroes, instead of less than 16,000 . If you did not then have separate schools, separate cars, and a constitution "guaranteed to keep in any climate," the fifteen years which I have spent in the study of race relations have been worse than thrown away, and I do not understand even the elementary principles of the white man's human nature.

This review of some of the salient features of what I term the factor of distribution is necessarily merely a cursory examination. The most I hope for it is that it may possibly suggest to you some new line of thought or investigation. In this connection permit me to emphasise what I regard as one of the most important considerations in this entire problem of race relations, as differentiating Northern and Southern conditions. It is the fact that in the North the Negro lives in cities and towns, subject to all the restraints of compact 


\section{Foundations of Our Differences}

population and police surveillance. In the South they are numerically essentially a rural population, practically, if not entirely, free of any such restraining and controlling influences. It is in the country districts, more than in the city, that those offences are committed which most militate against harmonious race relations and in rural districts that the severest reprisals are exacted. For the United States as a whole, 77.3 per cent. of all the Negroes live in country districts, while for the Northern and Western states, 70.2 per cent. are an urban population. Furthermore, Negroes constitute practically a third of the population in the South, both city and country. In the North and West they constitute but one-fortieth of the city population and only an insignificant, really negligible, one-ninetieth of that of the country.

Finally, let me offer you the testimony of one who probably is as well acquainted with the white people of this country, North and South, as any man in it Booker T. Washington. He says if we were to "move four millions of the eight millions of Negroes from the South into the North and West . . a problem would be created far more serious and complicated than any now existing in the Southern states."* I give you his opinion, in his own words; the application I leave to your own good sense.

Perhaps I should attempt to illustrate more definitely the way in which the juxtaposition of these races operates to produce the more or less uniform results which

* New York Age, August 17, 1905, p. 2, 


\section{The American Race Problem}

I have attempted to outline in general terms. The practical attitude of one race or nation toward another is determined by motives of self-interest, or instincts of self-preservation, upon the part of the one which is able to control and dictate the terms and conditions of contact between the two. It matters not whether the races concerned be white and Negro in Mississippi today, white and Negro or Indian in Massachusetts yesterday, white and Mongolian in California to-morrow. And, furthermore, it matters precious little what the socalled "enlightened sentiment" of the world outside may be on the subject immediately at issue. I am not just now concerned with questions of sentiment. I am endeavouring to offer you a practical consideration of practical affairs. Nor does it make much difference whether the place of such contact be the United States or Egypt, Cuba or the Philippines, Australia or India, Japan or Santo Domingo. The rule which I state here, call it "cold-blooded" if you please, has not often been violated in the past; it is not likely to be in the future. And for a recent specific illustration of the principle I would suggest for your consideration the history of the overthrow of native government in the Hawaiian Islands by the descendants of New England missionaries, and incidentally the resulting annexation of those islands to this country by a Republican administration. The immediately actuating influences may be well grounded, as upon actually demonstrated facts or really existing conditions, or they may be founded solely upon apprehensions of what might occur. In either case the controlling 


\section{Foundations of Our Differences}

motive is the same. The only exception to this rule is in the case of nations or races between whom there exists either sufficient identity of blood and institutions or such a great disparity of numbers or strength that the controlling party has no grounds upon which to base even an apprehension of untoward consequences from unrestricted or unconditional intercourse, or from any specific or general attitude it may assume toward the weaker. Here the stronger may, if it see fit, give full play to policies wholly unselfish and altruistic, or be governed by them in so far as it may be inclined. Our action in the case of the evacuation of Cuba is fairly illustrative of the exception; our action in the case of Columbia may fairly illustrate the selfish and more general aspect of the rule. The conditions which justify, or render possible, a departure from the established principle, are as important in our consideration as are those inducing or compelling continued adherence to it. Both must be kept in view if we would justly and accurately estimate the conduct of races and nations.

In the exploitation, limited or unqualified, of countries and their inhabitants, few people have surpassed that branch of the human family popularly known as the Anglo Saxon. Though they did not begin the African slave trade, they outdid the world in keeping it alive. Though they did not begin the invasion of the Dark Continent, in the partition of Africa no hand has been more potent than theirs. I shall not stop to consider whether in its last analysis it is better or worse for the Negro, but it seems a queer freak of fortune or 


\section{The American Race Problem}

fate that of all the Caucasian peoples, it is the English speaking branch with which by far the greatest numbers of the Negro race have had to deal. Above all others it is the one which has been most uncompromising in its attitude toward the backward or inferior races, in so far as political and social assimilation are concerned. At no time in history, and in regard to none of these races, do we find a departure from this line of conduct. We witness it in India, in Egypt, in South, East, and West Africa, in Australia, in America, and in the East Indian Islands. The American branch of the family has been equally true to its traditions.

A study of our relations with the only three coloured races with which we have come in contact - the Indian, the Negro, and the Mongolian - reveals essentially the same line of policy. We have refused to assimllate them, and in that fact alone is our attitude toward them differentiated from that toward the millions of the various white stocks that have poured in upon us from Europe during the past hundred years. That we have not in any way absorbed them or been absorbed by them, is due to the fact that despite the enactment of general laws, or the influence of extraneous public opinion, the white people of each separate state of the Union, instinctively dominated by considerations of local public policy of which they only could judge, have doggedly, persistently, perhaps even fiercely at times, but always successfully, exercised the right of absolute control over the relations between themselves and each of these races. In their respective attitudes we see illustrated both 


\section{Foundations of Our Differences}

the principle and its exception, as enunciated above, which determine the contact between superior and inferior races.

I lay it down as a fact which cannot successfully be challenged, that the relations between the white and $\mathrm{Ne}$ gro races in every state in the Union have been, and are now, controlled by considerations ultimately governed by the factor of the relative numbers of the two. I have given numerous general illustrations of this rule of conduct, and I shall now endeavour to exhibit its practical operation in certain concrete instances. For this purpose I shall take three states, two of which are entirely outside the sphere of "Southern influence" and the third scarcely much more than nominally Southern, as the world understands the term, although a Southern state. These are Massachusetts, Kansas, and Texas.

The legislature of Massachusetts became alarmed in I 82 I by "the increase of a species of population which threatened to become both injurious and burdensome." Being fully alive to "the necessity of checking it," the legislature appointed a committee to report on the wisdom of excluding free Negroes and mulattoes from the state. The report of this committee, written by its chairman, Theodore Lyman, Jr., stated that " the black convicts in the State Prison formed $146 \frac{1}{2}$ part of the black population of the state, while the white convicts formed but 2r 40 part of the white population." The committee also expressed the opinion that the same proportions would be found to exist in the other state 


\section{$5^{8}$ The American Race Problem}

institutions. The committee stated that it would have been "a matter of congratulation and satisfaction" to themselves if they had been able to frame a law which would "have promised to check and finally to overcome an evil upon which they have never been able to look with unconcern."* But they could not agree on a bill, and reported that a law to accomplish this purpose "would entirely depart from that love of humanity, that respect for hospitality and for the just rights of all classes of men, in the constant and successful exercise of which the inhabitants of Massachusetts have been singularly conspicuous." There was already a law on the books which required free Negroes and mulattoes to give bond to prevent their becoming a charge on the state. This law was passed in 1788 , and reënacted two or three times. In I 825 , three years after this report, it was again reënacted, and was not repealed until I834. Undoubtedly, the character of what this committee described as an "injurious and burdensome species of population" largely influenced the legislature to investigate the propriety of adding to the restrictive laws already in force one of absolute exclusion. The character of the Negro population everywhere has influenced such legislation. In fact, it is the essential difference of racial characteristics which forms the foundation of all distinctions drawn by the white man between himself and the Negro. This is elementary.

\footnotetext{
* Report of Theodore Lyman, Jr., for the Committee, January 15, 1821, "Thorndike Pamphlets," Library of Congress, Vol. 5, No. I5.
} 


\section{Foundations of Our Differences}

But, as a matter of fact, this action of the legislature of Massachusetts illustrates the operation of one of the immediately impelling subsidiary influences to which I referred a while ago - that of apprehension. The Negro population of the state had increased by exactly three persons between 1810 and 1820 , and in the latter year numbered I to 76.6 whites; so there appears to be here no very stable ground for the alarm of the legislature. The real reason is to be found in the apprehension of an influx of free Negroes from other states, caused by the enactment by the latter about this period of various laws discriminating against the Negro with greater or less severity. In other words, it was the same situation which Lincoln confronted forty-one years later, in trying to secure support for the XIII. Amendment. Massachusetts and the North did not want the Negro in either event; no matter whether the apprehended influx were to come from too stringent state legislation on the one hand or an inconveniently liberal constitutional provision on the other. This appears plainly enough elsewhere in the report - when the committee bases its fears of such an inrush upon the belief that the Negro would pursue the same course as white people who might be similarly discriminated against. Here is where the committee displayed its ignorance of the Negro-but that is another story. In the failure of the legislature to be sufficiently influenced by its apprehensions to take drastic measures at this time, we see illustrated an instance in which actual conditions permitted the partial exercise of an altruistic policy. 


\section{6o The American Race Problem}

But when we reflect upon the fact of an already existing law for controlling the state's Negro population, and also upon the rate of increase just mentioned, three in ten years, we may conclude that the legislature felt reasonably safe in simply maintaining the status quo. Nor should it have required any great strain upon the humanities for the exercise of that hospitality of which the committee speaks, upon the part of $5^{16,547}$ white people toward 6,740 Negroes - a considerable number of the latter being in poor houses and jails. We need not feel that we are reflecting upon the hospitality of the good people of Massachusetts of that old day if we ask the question, what in all human probability would have been the action of the legislature if, instead of this handful of Negroes, with their known rate of increase, they had numbered a half, or a quarter, of a million or even one hundred thousand? We may couple this with a question as to what would be the action of Louisiana to-day, if we assume a Negro population of 6,740, or of double that number, on some such suggestion as requiring the railway systems of the state to provide separate cars and accommodations for such of this number as occasionally might happen to travel. We do not need any profound philosophy to answer either question. All we want is a modicum of common sense.

For a period of $\mathrm{I}_{3} 8$ years Massachusetts prohibited intermarriage between whites and Negroes or mulattoes. The statute of Queen Anne of I 705 may be said originally to have been tinctured by the religious objection to a union between Christians and pagans. But it was 


\section{Foundations of Our Differences 6r}

several times reënacted long after such influences had ceased to exist. It was finally repealed in 1843 . By such action Massachusetts did not by any means intend to declare in favour of racial intermarriage. The real significance of the repeal was that, whether consciously or unconsciously, the numerical insignificance of the Negro population had finally brought possibly a majority of the whites to a point from which they were able to view with entire indifference any possible consequences of a formal reversal of the ancient policy of the state. Here, too, we have a situation in which the idealist or the doctrinaire who might wish to remove from the statute books every remaining vestige of discriminating law could receive at least the negative support of the practical man. The latter might simply ask himself, What difference does it make?

In an address in New York some time ago, President Eliot, of Harvard, declared in unequivocal terms that Northern and Southern opinion are as one with regard to the question of admixture between the races. $\mathrm{He}$ said further that a supposed danger of racial impairment should not influence practical measures, as in so far as it might proceed it would be chiefly the result of vice on the part of white men.* It is easy to say what should or should not influence our practical attitude, but if the Negro population of Massachusetts had been $3 \circ$, or 40 , or $5 \circ$ per cent. of the whole, instead of I.2 per cent., can we believe that the legislature would have removed the restriction on intermarriage? As a

* "The Work and Influence of Hampton," r 904, p. 9. 


\section{The American Race Problem}

matter of fact, for the past five years, of all the Negro marriages in Massachusetts, an average of about ro per cent. have been mixed. Moreover, in these cases the white party is the woman, very infrequently the man. Of the 52 mixed marriages in 37 towns and cities of the state in I 900, 43 were between white women and Negro men.* Suppose the Negro population of Massachusetts had increased to 500,000 since the repealing act of 1843 , instead of to only 32,000 in I 900, and the relative percentage of such marriages were the same as now. It is not difficult to see the practical bearing of such legislation under the conditions which would then obtain.

During the five years from I 900 to I 904 there were I 43 marriages between Negroes and whites in the city of Boston, and 907 in which both parties were Negroes. In other words, with a Negro population of I I,59I there were I,050 marriages. Of these, I 43 , or I 3.6 per cent., if my calculation is correct, married white persons. Of these mixed marriages 133 were cases of white women marrying Negro men, while only ro white men married Negro women. With the white woman in this instance representing 93 per cent. of her race's participation in such alliances, it is not safe to dogmatise as to the processes of race intermixture. $\dagger$ And my investigations

\footnotetext{
* Report Massachusetts Bureau of Statistics of Labour, March, 1904, Pub. Doc. I 5, Part 3, p. 263.

† Annual Reports of the Registry Department of the City of Boston; for 1900, pp. 14, 15; 1901, pp. 37,38; 1902, pp. 155, 156; 1903, pp. I53, 154; 1904. pp. 181,182 . Under the classification of "coloured" I have eliminated Indians, Chinese, and Japanese. These records are the best $I$ have found as to clearness and detail. I acknowledge thanks to Mr. E. W. McGlennen, Registrar, for courtesies extended. Anyone interested in this subject will find a valuable and suggestive discussion in Hoffman's "Race Traits and Tendencies of the American Negro," Chapter IV., "Race Amalgamation."
} 


\section{Foundations of Our Differences 63}

thus far lead me to believe that the same conditions exist in Chicago, Philadelphia, and New York.

Of course only a very few people keep in touch with such isolated figures, and legislation against such intermarriage may be ascribed to the instinctive racial selfpreservation of the white man, rather than to mathematical demonstrations of the consequences of a different policy. It is idle to charge it to "race prejudice," as that term is commonly understood.

Individual actions are often the mainsprings of public sentiment, if their correlation be such as to make a sufficiently broad appeal. Without regard to either reason or justice it is a common, almost unconscious, process of thought to ascribe to the mass the characteristics and attributes of the individual. By the same process, and equally without a well reasoned basis, it is also common mentally to hold the mass responsible for the conduct of the individual. Both the Southern white man and the Southern Negro have suffered through the operation of this natural mental process. It is not possible to measure the full and ultimate effect upon this country of the blowing up of the Maine in Havana Harbour. We do know that it had a tremendous immediate effect upon the popular mind. Upon a smaller scale the action of communities or states is influenced by just such concrete incidents. Any student of American politics can appreciate the practical force of this truth, as manifested at every election. We find also a case somcwhat in point in the history of Negro suffrage in Pennsy:hania. One of the features of the 


\section{The American Race Problem}

movement for confining the suffrage to whites, in the convention of $1837-38$, was the number of petitions in its favour sent up from Bucks County, prompted directly by the fact that in that county a Negro once had the temerity to run for the legislature.

These two facts - the effect of seemingly detached actions, and the identification of the individual with the mass - play an important, but little appreciated, part in influencing and determining race relations. I shall try to illustrate their significance by the case of the separate car law of Texas, and that of the separate school legislation of Kansas.

Probably the commonest of all the mistakes of opinion as to the attitude of the Southern white man toward the Negro arises out of the legal separation of the two races in cars and schools. Such legislation is described as "petty persecution of the Negro," and attributed to a desire to "humiliate, stigmatise, and degrade him." These quotations are fairly typical editorial expressions of opinion on the question of Southern motive. As a matter of fact, such legislation is the embodiment of enlightened public policy, and is the surest guarantee of a minimum amount of friction between the races. In almost every instance of separate car legislation, public sentiment was crystallised into law as the immediate result of intolerable local conditions, not infrequently accompanied by concrete acts of racial violence. Local manifestations of irritation and impatience arising out of racial contasct occur here and there throughout the North and Eanc from time to time. 


\section{Foundations of Our Differences 65}

But thus far in none of these states are conditions sufficiently uniform to furnish a general state response to local sentiment. I quite distinctly recall the introduction of a bill in the legislature of a Western state a few years ago to prevent intermarriage between the races. It was prompted by a peculiarly distressing case of the kind-but it failed to meet with sufficient response to become a law.

The Negro population of Texas has never been enough to present for the entire state all the phases of the race problem as we find it in South Carolina, Mississippi, Louisiana, and some other Southern states. In I 900 there were in round numbers, six hundred and twenty thousand Negroes to two million four hundred thousand white people. But it has been sufficient in various places to cause some acute local conditions to present themselves, and large enough in the state as a whole to insure a final response to local demands. The separate coach law, here, as in several other states, merely represented the culmination of a public sentiment which developed through a number of years. The law was not passed until it had clearly become necessary to the maintenance of peace and order, and the prevention of racial outbreaks in many parts of the state. Not until twenty-five years after the Civil War, when the state contained practically five hundred thousand Negroes, was the legislature finally compelled to act. It is idle - it is childishly petulant and ignorant - to charge this action to a desire to "humiliate the Negro," or to "subject him to petty persecutions." 
The final moving cause, the concrete incident which solidified public sentiment into a demand which could no longer be ignored, was a tragedy which occured on a train carrying mixed passengers. It came only after the people of the state realised that they had postponed too long the enactment of a law which would have rendered such an occurrence impossible. And in Kentucky the same result followed the shooting of a young woman by a Negro on a train on which there was no separation of the races. Each case merely furnished the straw which broke the camel's back. People who are accustomed to seeing an occasional Negro on a train, and he ordinarily well behaved and unobjectionable in his person, cannot form the faintest idea of the conditions which render such legislation a necessity. There are sections in every Southern state from which no demand for it ever would have originated. But when from those districts and communities in which conditions were physically unbearable a demand for relief did arise, the more favoured sections of the state simply responded to the appeal. Of course it would be absurd to say that there was some specific incident behind every law of this character in the Southern states. I am merely seeking to illustrate the creation and operation of public sentiment upon a basis of racial contact. It is a question of conditions - not one of geography. If only an insignificant fractional portion of the population of Mississippi were Negroes, there would be no separate cars in that state. If more than 50 per cent. of the population of Michigan were Negroes 


\section{Foundations of Our Differences 67}

I believe I am safe in saying that you would have them here. It is frequently urged that such laws work a hardship on the higher class of Negroes, in compelling them to occupy cars in common with the objectionable masses of the race. This is simply one of the regrettable incidents of an unfortunate situation. The same law holds good for the white man; he is compelled to share his accommodations with the objectionable members of his race also. Legislation is for the masses of the people, not for exceptional classes, and here at least there has been adherence to the rule. Separate car laws, like those against intermarriage, cannot in their very nature be localised. An intolerable condition had to be met, and the only practicable method was by a separation on racial lines, general in its application.

Apropos of separate cars, before we leave the subject, I might suggest that among the earliest cases to be found are those in Philadelphia and New England. Good old Samuel May tells us with evident pleasure of the "admirable letter" in which, in I 842 , Nathaniel Barney "one of the earliest of the immediate abolitionists," refused to participate in dividends on his stock in the New Bedford Traction Railroad because Negroes were excluded from its cars. Apparently they were not allowed to ride at all - even in separate coaches.* And in Massachusetts in I840 the Negro constituted but a pitiable $\mathbf{I . 2}$ per cent. of the population of the state. Colonel Higginson recognises these numerous early

\footnotetext{
* "Some Recollections of our Anti-slavery Conflict," Samuel J. May, I869,
} p. 399. 


\section{The American Race Problem}

New England discriminations, and in their passing he thinks he reads the final death of similar laws and customs in the South.* Maybe so. But when we reflect that they existed openly for so many years, and in modified form and degree exist to-day, in a group of states in which the Negro has not amounted to as much as $\mathrm{I} .7$ per cent. of the total population at any time since the census of $\mathrm{I} 790$, we should be rather guarded in predicting a very speedy disappearance in a section containing a Negro population amounting to practically $33 \frac{1}{3}$ per cent. of the whole.

The necessity for the separation of the children of the two races in schools was always realised as next in importance to laws against intermarriage. Such separation was in fact coincident with the inauguration of Negro schools and has always obtained in the Southern states. President Eliot says: "In Northern towns where Negro children are proportionally numerous there is just the same tendency and desire to separate them from the whites as there is in the South." $\mathrm{He}$ says, further: "This separation may be effected by public regulations, but if not, it will be effected by white parents procuring the transfer of their chidren to schools where Negroes are few." $\dagger$ The esential feature which differentiates such laws from those we have just considered is that they may be made local in their application. The Kansas statute is a case in point.

The Negro population of Kansas City, Kan., is not

\footnotetext{
* Introduction to "The Aftermath of Slavery," Wm. A. Sinclair, 1905, pp. II, $x_{2}$.

†"The Work and Influence of Hampton," 1904, p. 9.
} 


\section{Foundations of Our Differences}

large, but in 1900 it amounted to 12.7 per cent. of the total poulation of the town. The children of the two races had already been separated in the lower grades, but attended the same high school, and during several years there were sporadic outbreaks between the two. And here let me call your attention to one fact of practically universal application. Whenever a personal difficulty occurs between a Negro and a white man, in the presence of any considerable numbers of the two races, without any reference whatever to the merits of the controversy the crowd instinctively separates itself on racial lines. This is true regardless both of the question of geographical location and of the normal relations between the races. These occasional clashes between the races in the high school of Kansas City finally culminated in a tragedy, just as we have seen it in Texas. This time a white boy was the victim, but the immediate result of the killing was the same. Without further delay, the Kansas legislature passed a law providing for separate schools in Kansas City. The Negro population of Kansas is only fifty-two thousand, as against one million four hundred thousand white people-being but 3.5 per cent. of the whole. It is scarcely possible that under such circumstances the legislature could have been induced to burden the state with the heavy expense of maintaining a general system of separate schools. But this bill was of local application, and there were but twenty-eight votes cast against it in the House, and only five in the Senate. It was bitterly opposed by the Negroes of the state, but 


\section{0 \\ The American Race Problem}

was approved by the Governor.* Governor Hoch accompanied his approval with a special message, expressing his good will for the Negro, but saying that in Kansas City "local conditions are peculiar." Its enforcement has also been opposed by the Negroes, but its constitutionality has been determined by the Supreme Court, just as its wisdom had been recognised by the chief executive. $\dagger$

I have collected authentic accounts of a number of such clashes, of various degrees of seriousness, in Eastern and Western schools, but this is the first instance in which the general sentiment of the state has responded to local demands. Of course I do not mean to say that every such outburst has resulted in a demand for separate schools. Very often, as suggested by President Eliot, various, and occasionally devious, expedients are resorted to, to accomplish the end reached by direct legislation in the Southern states.

Just a few suggestions, in conclusion, on the study of this question. It is the duty of every man who undertakes to study the race problem first to study the Negro. Study him just as we would the Chinese, Italian, Russian, or Indian, in both his native and adopted homes, and without the bias, prejudice, or sentiment which for threequarters of a century in this country have rendered such attempted studies almost worthless. There is a lot of common sense in Mr. Kelsey's suggestion that one trouble with too many Northern men who cannot under-

* House Journal, x905, pp. 562,723: Senate Journal, 1905, p. 362.

† Richardson $v$. Board of Education of Kansas City. Pacific Reporter, 84 , pp. 538-541. 


\section{Foundations of Our Differences 71}

stand Southern conditions is that they insist on regarding the Negro as a "dark skinned white man."* We have no such fanciful theory when we approach the Indian or the Chinese. We simply accept him as we find him, and study him as he is. Master the details of the distribution of our Negro population, and of the relative proportions of the races. And above all, disabuse your minds of the notion, if you have it, that your Southern brother is in any essential a different sort of individual from yourselves.

One thing else. Do not get it into your heads that because you have visited this or that Southern locality, or talked to a few of the myriads of "representative Southern men" whom we have down there, you have located and mastered the race problem. Get a descriptive atlas, and study the territory known to American history as "the South." I have often said that the only study of any race problem worth the making is a comparative study, the basis of which must necessarily be a primary study of local conditions. But in this broader field, in attempting to analyse and account for the varying and often conflicting phenomena which racial contact will exhibit in different sections of the United States and in its dependencies, in South Africa, the West Indies, and other countries, I would warn you against the most dangerous pitfall to the dilettante student of race relations. This is the, to my mind, well-nigh unpardonable blunder of failing to distinguish between a contrast and a parallel. It is the commonest mistake

* "The Negro Farmer," 1903. p. 67. 


\section{2 The American Race Problem}

of the closet philosopher who undertakes to institute comparisons between Southern conditions and those which exist elsewhere. The truth is this problem is without a permanent home to-day, and could not be identified by description as the property of any particular locality. It is a vague, indefinable, intangible something, presenting a score of different aspects in as many places; one thing here, another somewhere else, and then again not existing at all. You will find all shades and varieties of Southern opinion on the general subject, just as you will in the North. In fact you are likely to find substantial agreement on only two things, opposition to "social equality" and a recognition of the necessity for white political and general control. And even here you will find confusing differences as to the definition of the one and the necessary means of insuring the other.

It is safe and easy to indulge in sweeping generalisations - but honesty and fair play should cause us to hesitate to condemn our neighbours in such terms. It is characteristic of a great deal of discussion of this question to dwell upon and magnify the darker aspect of Southern race relations. The daily acts of helpfulness and kindliness, the thousand and one little evidences of persisting good will between the races, are unheralded to the world, just as in the days of master and slave. We hear a great deal about peonage practices, but the fact seems to be lost sight of that the judges and juries who try such cases, the prosecuting attorneys and witnesses, all are Southern men. In the public mind the South is represented only as the prisoner at the bar. 


\section{Foundations of Our Differences}

In an open letter to the press, some time,ago, Booker T. Washington said: "I have said that such lawless conditions exist in only a 'few' counties in the South, and I used the word advisedly. In the great majority of the counties in the Suuth life and property are just as safe as anywhere in the United States."* In a county in Mississippi in which the Negroes outnumber the whites by nine to one, I have seen a Negro tried by a white jury for the killing of a white man, and walk out of the court room free and without molestation, and the incident excited no word of comment or surprise. I have seen white men hanged who had been convicted of murder on Negro testimony. Within the same week in my state last year a Negro was acquitted by a white jury of a charge of assaulting a white woman, and a white man was sent to the penitentiary for whitecapping Negroes. There is not a community in the South where such things as these do not constantly occur, but their record is buried in the musty documents of courts, instead of being trumpeted abroad. The white people in these communities accept such incidents as mere matters of course; they are not grouped and paraded in the pages of magazines as rare and striking phenomena. And, besides, it is not justice, but its denial, the portrayal of which appeals to public sympathy with certainty of response. This is human nature.

I know of no other community of white people of equal numbers in the world to-day carrying the burden

\footnotetext{
* Appeared in a number of Southern papers, November 27, 1904. Reprinted
} in pamphlet form. See p. 4 of reprint. 


\section{4 \\ The American Race Problem}

borne by those of the Southern states. I do not mean in an economic sense - taxation and a tremendous mass of labour of a low degree of efficiency. These are things not worth considering in comparison with what I have in mind. I mean the burden of conducting affairs of government under circumstances which do not exist elsewhere; of administering the same law for the two most diverse races on earth; of so carrying themselves in the various relations of daily life with these childish people that their conduct may have the approval of their consciences; of living with a due regard for the opinions of their fellow men, the while oppressed by the consciousness that their fellow men do not, will not, or cannot, understand. I can give you my thoughts in the language of a Northern writer better than in words of my own. Let me ask you to take to your hearts the words in which Professor Cutler expresses one of his conclusions in his study of lynch law - to which I have already referred: "A judicial system adapted to a highly civilised and cultured race is not equally applicable to a race of inferior civilisation, and the failure to realise this fact and act upon it, by making special provision for the control of the Negro population in the Southern states since slavery was abolished is a fundamental reason for the disrepute into which legal procedure has fallen as regards Negroes accused of offences against the whites. The mistakes of Reconstruction times are not yet blotted out in the South. Abstractions still control where racial characteristics, circumstances, and conditions should be the determining 


\section{Foundations of Our Differences}

factors. Ever since the Civil War the Southern people have been blindly groping after some system other than slavery whereby two races of widely different interests and attainments can live together in peace and harmony under a republican form of government, and at the same time a vast number of Northern people have been misinterpreting their motives and watching every move with a critical and suspicious eye, ready at any moment to shout across Mason and Dixon's line that the Negroes must have their rights under the Constitution of the United States and the amendments thereto."*

It is no Macedonian cry that I would send up in behalf of the Southern people. Nor is it merely sympathy we crave. All we ask is that the difficulties of our environment be in some measure appreciated - that we ourselves be rightly understood. Dr. DuBois says the Southern people are "essentially honest hearted and generous," and that "this situation does not fail to interest and perplex the best conscience of the South." "Deeply religious and intensely democratic as are the mass of the whites," he says, "they feel acutely the false position in which the Negro problems place them."* In measuring the success of efforts to give practical effect to abstract conceptions of right and wrong, we have a right to ask the world to be slow in drawing invidious comparisons between those who struggle on and do the best they can from day to day and year to

\footnotetext{
* "Lynch Law," r 905, pp. $224,225$.

*"Annals of the Am. Academy of Political and Social Science," Vol.1 8, p.r 39.
} 


\section{The American Race Problem}

year with conditions which are an inheritance and not a creation, and those for whom such things no more exist than does "the baseless fabric of a dream." We know that we are to answer at the bar of history for our share in the preservation and development of the civilisation of our race, yet history herself offers us the guiding light of no situation to parallel our own. Nor does she show us an example of the dwelling together in "perpetual brotherly love" of large masses of a stronger and a weaker race. The golden rule has not yet become the universal guide of human life. If out of the manifold and trying relations between the millions of these two races in the South the white man should emerge with an unblemished record, it would be without a precedent in the annals of mankind.

Let me once more ask that you do not misunderstand the end I have in view. I do not mean simply to tell you that if similarly situated you would do just as we do and have done. That is the stump speaker's convenient retort, and I am not a politician. $\mathrm{My}$ purpose is a worthier one, I hope, than that of mere parliamentary defence. In pointing out to you a few, and only a few, of the innumerable parallels which mark the history of racial contact, I have merely sought to lay the foundation for a plea for the recognition of the fundamental fact of our common ancestry and blood, our common heritage of motives and feelings, of passions, impulses and instincts, the oneness of our racial hopes and fears. The people of this country cannot forever misunderstand each other over this racial problem, and 


\section{Foundations of Our Differences}

I would ask no greater reward for the labour of life than the thought that when the day of thorough understanding dawns I had in some small measure helped to hasten its approach. And in all this I hold no firmer conviction than that the greatest beneficiary of a better knowledge of each other by American white men will be the American Negro.

Just a few words more. The Southern people have their faults and failings, and I would be the last to attempt to minimise them - but we must correct them from within. Abuse and distortion from without never yet accomplished a permanent reform, and never will. The severest indictments of injustice to the Negro that I have ever read were from the pens of Southern editors. The most effective demands for justice to the Negro that I have ever heard fell from the lips of judges presiding over Southern courts. But all these possessed what outside criticism almost invariably lacks - the saving sense of discrimination. They did not seek to arraign an entire people at the bar of public opinion, but were addressed to particular conditions in this or that particular community.

Reduced to its simplest terms, as it presents itself to this generation, the most important phase of the race problem is that of the quiet, mutually helpful, peaceable, common occupancy of the soil. Right now it seems to me that at this stage of the growth of the Negro masses this dwarfs into insignificance all other considerations. Certainly this is the primary, possibly it may also be the last, phase, for black and white in 


\section{The American Race Problem}

each locality mutually to solve as best they may. This aspect is essentially local, but whether the problem be national or not, it must have a local solution. If each community be permitted to adjust its own relations and solve its own particular phase of the problem, the longest step will have been taken toward the ultimate solution of the problem as a whole. There is no possible workable basis of solution but the individual and community basis.

Thousands of individuals and hundreds of communities have already settled these questions for themselves, and others are working out an adjustment along their own lines. For such as these nothing is surer in human life than that unsought, unsympathetic intervention whether in the form of hostile and uncharitable denunciation of one party to the effort, or in that of foolish and ill-considered advice to the other - will only retard the normal outcome-whatever it is destined to be. After all is said and done, the problem in its larger sense, the ultimate effect upon one another of the juxtaposition of two such different races, must be left to the slow processes of time. We cannot even hasten the end. But for the present each race and each section should summon to its aid the virtues of patience and charity; the patience which should add to itself "knowledge and brotherly kindness," the charity which "vaunteth not itself, is not easily provoked, which hopeth all things, and rejoiceth in the truth." 


\section{PART TWO}

\section{SOME ECONOMIC ASPECTS}

III. The Negro in the Yazoo-Mississippi Delta IV. A Plantation Experiment

V. The Economic Future of the American Negro 
- 


\section{III}

The Negro in the Yazoo-Mississippi Delta.*

MONG the many disturbing questions entering into
our complex national life, the one which above all others seems to have provoked discussion in every quarter is the so-called Negro problem. Under this general designation have come to be embraced all the various and complicated questions arising from the contact at many points of the black race with the white. Not since the formation of this Government has this discussion ceased, and ignorance has never been a bar to free participation in it. In a discussion of these questions in their broader aspects, though I have devoted some years to their consideration, I can claim no peculiar knowledge - no superior wisdom. The problem is so extensive in its ramifications, it presents so many and such varied phases, that to my mind there is but one proper and reasonable method of considering it: that is, through the analysis and study of its component parts - the attempted grasp and comprehension of the minor and elemental conditions and problems which enter into the composition of the whole. The intelligent study of this question must resolve itself at last into a study of local conditions.

* A paper read at the fourteenth annual meeting of the American Economic Association, Washington, D. C., December, 1901 . 


\section{The American Race Problem}

A lifetime spent in the "blackest" of the South's "black belts"; a sharer in the association between the two races in the life of the plantation - the most constant and intimate association that is possible between them; a thorough acquaintance with the conditions surrounding the Negro in a section wherein I firmly believe will be discovered the region of his greatest material possibilities; these constitute my only equipment in venturing upon this discussion. It is to a consideration of local conditions only that this paper is addressed.

In the state of Mississippi, between the $32 \mathrm{~d}$ and $35^{\text {th }}$ parallels of north latitude, its entire western border washed by the Mississippi River, and most of its eastern by the Yazoo, extending north from the confluence of those streams at a point just above the city of Vicksburg, lies the strip of territory known as the YazooMississippi Delta. The exact origin of the word delta, as applied to this region, is not clear; though it was probably a simple extension of the old and accepted use of the word, descriptive both of the character and of the peculiar conformation of the land built up by the diverging mouths of large silt-bearing streams. The character of the soil certainly justifies such a conclusion, for it is entirely of alluvial formation, detritus deposited during thousands of years in which the Mississippi has poured out its muddy flood waters over the adjacent country.

The Yazoo-Mississippi Delta is about one hundred and fifty miles in length, and its greatest width is about one-third of that. Its front along the Mississippi is pro- 


\section{The Yazoo-Mississippi Delta}

tected against overflows of that river by an unbroken line of levees, 3 I 0 miles in length, averaging fifteen feet in height, with a maximum of about thirty. The Delta differs radically from the rest of Mississippi in many important respects, but in none more than in those wherein the Negro is immediately concerned; hence only the nine counties lying wholly within it, Bolivar, Coahoma, Issaquena, Leflore, Quitman, Sharkey, Sunflower, Tunica, and Washington, are considered here. The alluvial valley of which these counties form a most important part has been called by the most distinguished member of the Mississippi River Commission. Judge Robert S. Taylor, of Indiana, "the cream jug of the continent." Of it he has written: "Nature knows not how to compound a richer soil. It can no more lie idle than the sea can keep still. Every square foot of it riots in vegetable life. . . . It's [the Mississippi's] floods came down loaded with skimmings from the great watershed above. Overtopping its banks, the enriched water spreads far and wide over the alluvial area, so obstructed in its flow by the dense growth covering the land that its slackened velocity compelled it to let fall its load of sediment as it went. Thus the floods built up the valley year by year in layers of fatness, to live again in incalculable crops of grain, fruits, and fibres."*

By what warrant does this region claim attention in a consideration of America's gravest question? Simply because of the part it plays, and is destined to play, in

"Tompkins, "Riparian Lands of the Mississippi River," r90r, p. 234. 


\section{The American Race Problem}

the lives and fortunes of a constantly growing percentage of America's Negro population. This has long been recognised by the authority just quoted. $\mathrm{He}$ says: "A feature of special interest in this connection [he was discussing the matter of levee protection] is the opportunity which the reclamation of the alluvial valley offers to the Negro to better his condition. One-half or more of its entire area is suitable for cultivation of cotton. A bale per acre of ginned cotton, weighing 500 pounds, is the standard yield - worth from thirty to fifty dollars according to the ups and downs of the market. . . The Negro is not seizing this golden opportunity as the white pioneer of the Northwest would have seized it, but he is not wholly neglecting it. In considerable and increasing numbers they are buying land and becoming independent cultivators.

Nowhere else in the South are as favourable opportunities offered to the black man as in the reclaimed Mississippi lowlands, and nowhere else is he doing as much for his own uplifting."*

The section of this territory with which we are concerned embraces an area of 5,480 square miles, containing about three and one-quarter million acres of land, with a population of 195,346 . Of these but 24,137 are white, while the blacks number I 7 I,209, a proportion of 7.1 blacks to I white. This proportion has increased steadily from 4.9 to $I$ in $I 880$ and 6.7 to $\mathrm{I}$ in 1890 , while in Mississippi as a whole it is almost stationary, being now $\mathrm{I} .4$ to $\mathrm{I}$, as against $\mathrm{I} .3$ to $\mathrm{I}$ in $\mathrm{I} 890$ and

*Idem, pp. 236, 237. 


\section{The Yazoo-Mississippi Delta}

1880. I think I am not in error in stating that the largest proportion of blacks to whites exhibited by the last census for any part of the United States is found in one of the counties of this group, Issaquena, in which it is $\mathrm{r} 5.5$ to $\mathrm{r}$. In the same county the proportion was I 5.7 to I by the eleventh census, and II.I to I by the tenth. Of the white inhabitants of the state but 3.7 per cent. are found in the Delta, while r 8.8 per cent. of all Mississippi's Negro population make it their home. Comparison with former censuses shows this per cent. for whites to be practically at a standstill, while that for the Negro is steadily increasing. In 1890 these percentages were 3.5 for the white and 17.7 for the Negro, and in $1880,3.4$ and 12.6 respectively. From I 880 to I 890 the per cent. of increase of the white population of the United States was 26.7, and that of the Negro I3.5. For the state of Mississippi these percentages were $\mathrm{r} 3.7$ for the one, and $\mathrm{I} 4.2$ for the other. During that decade the white population of the Delta increased by only 17.3 per cent., while the increase of the black was no less than 60.4 per cent. Between the eleventh census and the twelfth, the white population of the country increased 21.4 per cent., and the Negro 18.1. The figures for Mississippi exhibit a white increase of 17.6 per cent., with 22.2 for the Negro. In the Delta section of the state the increase was 23.5 for the white race and 30.2 for the black. The last census shows that the Negro constitutes r r.6 per cent. of the total population of the country, 58.5 per cent. of that of Mississippi, and 87.6 per cent. of that of the Yazoo-Mississippi Delta. 


\section{The American Race Problem}

Yet here we hear nothing about an ignorant mass of Negroes dragging the white man down; we hear of no black incubus; we have few midnight assassinations, and fewer lynchings. The violation by a Negro of the person of a white woman is with us an unknown crime;* nowhere else is the line marking the social separation of the two races more rigidly drawn, nowhere are the relations between the two more kindly.

For many years this region was largely a terra incognita, and the story of its development and opening explains the figures of Negro population. The character of its white population, and the conditions under which its soil is tilled, explain the relations between the white man and the black. Until recently the only means of communication between the Delta and the outer world were river boats, for not till 1883 was it penetrated by a railroad. We have only to compare the statistics of Negro population of the eleventh census with those of the tenth to see the results of railway construction.

The early settlers were from Virginia, Kentucky, and Tennessee. They were all slaveholders, and the nature of the enterprises upon which they embarked demanded the possession of means. Hence this section early came to be the seat of large planting operations. There was no place for the man who was unable to own slaves; no demand for his services, other than as an overseer. There were no small farms, no towns, no

\footnotetext{
* Since the above was written, x9or, there have been two or three cases of attempted assault.
} 


\section{The Yazoo-Mississippi Delta}

manufacturing enterprises, no foothold for the nonslaveholding white man, who was here a negligible, if not an absolutely unknown, quantity.

Every step taken in the development of this section has been dependent upon, and marked by, an increased Negro population. The railroad rights of way through its forests have been cut out by the Negro, and every mile of track laid by his hands. These forest lands have been converted by him into fertile fields, and their subsequent cultivation has called for his constant service. The levees upon which the Delta depends for protection from floods have been erected mainly by the Negro, and the daily labour in field and town, in planting and building, in operating gins and compresses and oil mills, in moving trains, in handling the great staple of the country - all, in fact, that makes the life behind these earthen ramparts - is but the Negro's daily toil. The capital, the devising brain, the directing will, constitute the white man's part, the work itself is the Negro's. Nowhere else does Negro agricultural labour find a higher or more certain wage; nowhere do better relations exist between employer and employed; nowhere are capital and labour on better terms. There are no strikes, no lockouts, no combinations, no operating on half time, no reductions of force, and the works never shut down.

One of the gravest causes of trouble between the two races is contact on a common industrial plane. A peculiar effect is almost invariably wrought upon the Negro's attitude toward the white man by such asso- 


\section{8 The American Race Problem}

ciation, exemplifying the truth of the old maxim that "familiarity breeds contempt." I am not now discussing its cause, but one who knows the Negro masses knows that their ingrained admiration for wealth and station, strong as it is, is no more a controlling mental habit than is their lack of respect for the opposite conditions. This is as true in the mines of the North as in the fields of the South.

If I were asked what one factor makes most for the amicable relations between the races in the Delta I should say without hesitation the absence of a white Llabouring class, particularly of field labourers.* It cannot be accounted for on the hypothesis that we have a peculiar class of Negroes, for this population is a commingling of blacks from every section of the South, brought here without the slightest process of selection. The white population is composed of the professional class, those engaged in mercantile and manufacturing pursuits, and those interested in cotton planting, either as owners or managers. The white artisans are so few in number as not to affect this division, and the relations between them and the Negro are identical with those between the two masses of population. Of the field of manual labour the Negro holds a practical monopoly. $\dagger$

In saying that each year his feeling grew stronger "that perhaps in the heat of passion, growing out of

* Mr. R. C. Bruce confirms this statement. Publications American Economic Association, February, 1906, pp. 298, 299.

tDuring the years which have elapsed since this was written this monopoly has been visibly impaired. 


\section{The Yazoo-Mississippi Delta}

racial and sectional prejudice we have not given the Southern people due credit for the immense amount of help rendered the Negro during the period he was a slave," that he was then "started on the foundation of agriculture, mechanic, and household arts,"* Booker T. Washington has but given expression to a conviction which unprejudiced study would make universal. I am thoroughly satisfied that the conditions existing here to to-day are largely a heritage from the slavery régime. By the violence of the civil strife which wrought the destruction of Southern social and economic conditions, the Delta was probably less affected than any other equal area in the South. For this its isolation and inaccessibility easily account. Out of the ruin which was the legacy of war to the Southern states no section emerged with less of violent change as regarded race relations.

In the Contemporary Review for July, I900, Mr. Philip Alexander Bruce has drawn a faithful picture of the old plantation system of the South. He says truly that "the most distinctive feature of the old industrial order," next to slavery, "was the large plantation." $\mathrm{He}$ describes the plantation as having been frequently a small principality in extent, the planter the absolute master of his own domain, "his word the supreme law, his wishes the governing influence." Mr. Bruce then sets against this a picture of agricultural conditions in the South of to-day, telling us that the "ruin of the old plantation system is complete." His portrayal of the

\footnotetext{
- Tuskegee Normal Institute, annual report, rgor.
} 


\section{0}

\section{The American Race Problem}

essential features of the old system fairly describes existing conditions in the Delta. Here the era of small farms has not set in, the process of land division has not begun. On the contrary, most of the large plantations are growing larger, and such small farms as do exist have not been erected upon the ruins of larger tracts. Change of ownership has not meant disintegration, but has been effected by sales of property entire.

It may be remarked here, parenthetically, that the census rule treating every tract of land on which agricultural industry is conducted as a farm, while doubtless essential to thorough investigation, is misleading to the student who is ignorant of local conditions that materially modify the application of this method of classification. In the language of Census Bulletin roo, "Agriculture in Delaware": "The number of farmers, that is, persons operating farms as owners or tenants, is the same at any period as the number of farms." Thus every holding becomes a "farm," and a tract of $\mathrm{I}, 000$ acres, known locally as a plantation, though entirely under one ownership and management, would appear in census reports as so many different farm holdings, the number being dependent upon the number of tenants living on it during the census year, the average acreage governed by the size of these various arbitrary and temporary subdivisions. That such figures, unless accompanied by an explanatory note, lead to inaccurate conclusions is well illustrated in an article in the Boston Transcript, May 25, I901, based upon the 


\section{The Yazoo-Mississippi Delta}

showings of the ninth census. Taking Mississippi as a "typical state," the writer concluded - and this was for 1870 - that the figures showed "a revolutionary increase in the small farms," "the great plantations of some states being almost entirely eliminated, as in the black counties of Mississippi."

The plantations of this section vary in size from five hundred to several thousand acres, and the proportion of Negroes to white men living on them, from 25 to I to more than roo to $\mathrm{r}$. Yet there is now no more feeling of fear on the white man's part whether for himself or his wife or his children, than in the days of slavery.* As in the olden time, so now, the word of the planter or his representative is the law of the place, and on the one hand we have implicit obedience, on the other firmness and moderation. Certainly the relation of master and slave no longer exists here, but out of it has been evolved that of patron and retainer. I so designate it because I know of no other to which it more nearly approaches. It is not at all one purely of business, the ordinary relation of landlord and tenant, or of employer and employee.

The plantation owner or manager expects to do more than merely see to the physical needs of the Negroes under him, to provide for their wants and look over their work. He is called upon to settle family quarrels, to maintain peace and order between neighbours, to arbitrate disputes, to protect wives from the punishment of

* Writing to-day, 1908 , it would be necessary to modify this statement somewhat - certainly for some parts of this territory. 


\section{The American Race Problem}

irate husbands, frequently to restore broken conjugal relations upon terms satisfactory to both parties, to procure marriage licences, to advise as to divorces, to aid in the erection of churches, to provide for the burial of the dead, to give counsel in the thousand and one matters peculiar to the plantation Negro's life, whether whimsical or grave. Every plantation Negro expects the discharge of these functions as a mere matter of course. Yet further, when in more serious trouble, he looks to the white man as to a friend, and appeals to him as to a protector, when a possible term in jail or the penitentiary looms up before him, and lawyers and bail are to be provided. All these things are mere incidents to the plantation system, the commonplace affairs of its daily routine. The Negro regards them as his due, in return for the proprietary interest and pride he feels in the plantation at large, his sense of being part and parcel of a large institution, and the certainty, in his own mind, that he himself is necessary to its success. Then, too, there is his never failing assurance of ability to pay his account, no matter how large, his labour, when it is not too wet or too cold, his respect, and his implicit, and generally cheerful, obedience.

The one thing which in the South, directly and indirectly, has been the source of the gravest trouble between the races, and which has most disastrously worked their separation, has been the crime of rape. That it should lead to lynching was inevitable ; it was equally inevitable that in time the same mode of punishment would be extended to less grave offences. 


\section{The Yazoo-Mississippi Delta}

At the April meeting of the American Academy of Political and Social Science, Dr. George T. Winston, of North Carolina, presented a most sombre picture of existing Southern race conditions. He said: "The Southern woman with her helpless little children in the solitary farm house no longer sleeps secure in the absence of her husband, with doors unlocked but safely guarded by black men whose lives would be freely given in her defence. But now, when a knock is heard at the door she shudders with nameless horror. The black brute is lurking in the dark, a monstrous beast, crazed with lust. His ferocity is almost demoniacal. A mad bull or a tiger could scarcely be more brutal. A whole community is now frenzied with horror, with blind and furious rage for vengeance. A stake is driven; the wretched brute, covered with oil, bruised and gashed, beaten and hacked and maimed, amid the jeers and shouts and curses, the tears of anger and of joy, the prayers and maledictions of thousands of civilised people, in the sight of school-houses, court-houses, and churches, is burned to death. . . . I do not hesitate to say that more horrible crimes have been committed by the generation of Negroes that have grown up in the South since slavery than by the six preceding generations in slavery. And also that the worst cruelties of slavery all combined for two centuries, were not equal to the savage barbarities inflicted in retaliation upon the Negroes by the whites during the last twenty years."*

* American Academy of Political and Social Science, Annals 18, r9or, pp. 108, 109. 


\section{The American Race Problem}

This forbidding picture is the best support for my contention that the wisest and most helpful study of this combination of intricate problems is from the local point of view - the exhibition of conditions as presented upon particular horizons. From contrasts and comparisons some good may finally be realised. To be able to say that to one section of the South, at least, this picture presents not one familiar feature, is possibly alone enough to justify my presence here. I do not deny that this is a true statement of conditions in many sections of the South. I know too well that for some it is not overdrawn. I do not even assert that it is not more nearly typical of the South at large than is my own. But I do say that into the minds of the white men and women of my section, where not far from 90 per cent. of all our people are black, where in our rural districts they sometimes outnumber us as much as one hundred to one, the thought of the possibility of rape never comes. Nor do I believe that in all this region there is a single plantation on which may not be found Negroes who if left by the owner or manager in charge of his home would not fail to take the life of any man, white or black, attempting violence. They would know what was expected of them, and that for the uttermost discharge of that duty sot one hair of their heads would be harmed.

What is the cause of this difference between geographic divisions of a common country ? I answer that our freedom from this curse is merely incidental to the general relations obtaining between the races, and prop- 


\section{The Yazoo-Mississippi Delta}

erly ascribable to the general station and character of the white population, to the persistence of the same relative status between the masses of the two races that existed when the one was master and the other slave. Then the Negro was bred to absolute obedience, made to respect the white race because it was white, taught that the person, even the name, of the humblest white woman was something not to be profaned by touch or word or thought. That feeling among the Negroes, the result of this training, had enough vitality to project itself through the Civil War, and through that period rendered safe the white woman who in the absence of her male protector typified in herself the dominance of her race. Through the influence of novel conditions in the process of time it was weakened and rape began to add its horrors and complications to the race problem.* The influences and relations and peculiar lines of contact which wrought in the Negro that mental habit are potent to-day in the Delta, and in consequence rape is a crime we do not fear. I believe that this psychological habit is still latently persistent in the Negro masses, and but requires contact with conditions approaching those which produced it to become again a controlling force. Thus I would account for the fact that in a Negro population drawn from every quarter of the South there is absence not merely of the crime of rape, but of even the slightest disrespect to white women.

\footnotetext{
* This must not be understood to mean that rape was entirely unknown before the war. It became more common after 1865 , and its commission under the later conditions exercised an influence upon race relations which was not possible under the slavery régime.
} 


\section{The American Race Problem}

The peculiar attitude of the Negro toward those upon an equality with himself, makes possible such relations only where between the masses of the two races there is rigidly maintained the status of superior and inferior. This is not possible where a large white labouring class comes into contact with the same Negro class.

To illustrate my general proposition, as seen from the Negro's own standpoint, I may cite the following: In owning and operating a cotton plantation I have come into relations with Negroes from all sections of the country, and have had fair opportunities for observation. Before the abolition of the system I was for a time a lessee of convicts from the state penitentiary. Among the prisoners allotted me was a particularly bright and efficient mulatto of about twenty-five years of age. $\mathrm{He}$ had a common school education, and was apt and skilful. He was serving a sentence for an attempted criminal assault upon a seventeen-year-old white girl in a county of my state where conditions were radically different from those existing with us. I was anxious to know how, if at all, he accounted for his crime, but he was reluctant to discuss it. Finally he said to me: "You don't understand - things over here are so different. I hired to an old man over there by the year. He had only about forty acres of land, and he and his folks did all their own work, cooking, washing, and everything. I was the only outside hand he had. His daughter worked right alongside of me in the field every day, for three or four months. Finally one day, when nobody else was round, hell got into me and I tried to 


\section{The Yazoo-Mississippi Delta}

rape her. But you folks over here can't understand things are so different. Over here a nigger is a nigger, and a white man is a white man, and it 's the same with the women." There was not the slightest intimation of accessory guilt on the girl's part; his only explanation of his act was that "things were different." There was no fault upon the part of the attempted victim of his lust. Her only crime was a poverty which compelled her to do work which, in the estimation of the Negro, was reserved as the natural portion of his own race, and the doing of which destroyed the relation which otherwise would have constituted a barrier to his brutality.*

I do not cite this as a typical instance, for many cases of rape occur wherein there is not even the occasion or opportunity of enforced familiarity. I give it for what it is worth, as the expression of a very intelligent Negro.

If my theory is at fault, I should like to know why it is that a Delta Negro never assaults a white woman, but does commit rape upon the women of his own race. This section while containing I8.8 per cent. of Mississippi's Negroes now furnishes 2 I.7 per cent. of the Negro population of the state prison. Of the total number of convicts from the Delta, 4.9 per cent. are serving sentences for rape. These convictions are upon presentments to grand juries solely by Negroes, and from the circumstances are necessarily had solely upon Negro testimony. It is a difficult crime to prove, but taking no

\footnotetext{
* Possibly I have not emphasised sufficiently the factor of opportunity for assault afforded by economic contact between the races,
} 


\section{The American Race Problem}

account of the alleged cases, of those in which there seemed to the grand jury insufficient evidence to warrant an indictment, of those resulting in acquittals on the ground of consent, and of those which never came to the notice of the law at all, the number of convictions of Delta Negroes for the rape or attempted rape of Negro women during the past four years, is twelve. In 1898 , there were three; one in the following year ; three in I900; and in I90I, to September 30th, there were five. The ages of those committing this crime range from sixteen to fifty-four, all but three being between twenty and thirty-one. Some of these assaults upon their own women have been committed under circumstances as revolting as it is possible for the human mind to conceive.

Returning to the description of the economic condition of the Negroes in my neighbourhood let me say a word as to one of the most discussed features of the Negro's life in the South, the house in which he lives. In the towns, where the Negro rents or owns his home, it is whatever his ability commands, from a bare shelter to a well-furnished house containing four to six rooms. On the plantation the one-room cabin, that bête noire of social scientists, is not in evidence. They disappeared many years ago. Where one still stands it is deserted or temporarily occupied by cotton pickers or day hands. In the competition for labourers a steadily improving class of plantation houses is not the least of the inducements offered. If a family lives in a oneroom cabin, it is a matter purely of choice; there are hundreds of a different kind to be had. 


\section{The Yazoo-Mississippi Delta}

In the cultivation of cotton we have in the Delta nearly every system of labour to be found in the South. They are roughly divisible into two classes, the more general being the true metayer, or some modification of it, and the other the fixed cash rental. Where the Negro does not own the soil he cultivates, his relation to it is either that of a renter or a cropper. The share system presents no peculiar features. The cropper furnishes his labour in planting, cultivating, and gathering the crop; the land owner furnishes the land, the team and the implements; and the crop is divided equally between them. The planter advances to the cropper such supplies as are needed during the year, to be paid for out of the latter's half of the crop. As soon as a quantity of cotton sufficient to pay this account has been delivered to the planter, the cropper usually receives his portion of the cotton, to be disposed of as he sees fit. The extent to which the cropper exercises control over his cotton varies with the locality.

The features of land renting by Negroes vary according to the nature of the tenancy, whether the land is part of a plantation under white supervision, or a small tract, or part of a plantation entirely rented by a nonresident landlord. In the first case the land is rented for a fixed sum per acre, varying with cotton prices and the character of the soil, from five to seven dollars. Where a lint rent is taken it varies from eighty to one hundred pounds. Generally speaking, the supervision" over a renter is not as strict as that over a cropper, and as soon as his account is paid his cotton is at his own 


\section{Ioo The American Race Problem}

disposal. More privileges and a larger measure of independence are considered by the Negro as incident to this tenure, and as he becomes the owner of a mule it is his ambition to become a renter. It frequently happens that a planter will rent a mule to a Negro who has nothing at all, the uniform rent being twenty-five dollars. Under each of these systems certain general features obtain. The planter takes no deed of trust, for the state statutes give him a lien on the crop for rent and supplies. Nor is it usual to have any written contract other than a mere memorandum.* There is generally no definite understanding as to the amount of supplies to be advanced, and it is well within the truth to say that usually the planter is engaged in an effort to keep the Negro's account within such limits as will make it safe, while the Negro is equally anxious to obtain as much as he can on credit.

The Negro discriminates between the two systems, yet when results are considered, when one sees him squander from year to year the proceeds of his labour, however obtained, when he is seen to move restlessly and aimlessly from place to place, gathering less moss than the proverbial rolling stone, it must appear to the close observer that, as a matter of fact, the system under which he works makes but little difference in his material welfare.

Where the Negro rents land not under the supervision

* Within the past few years labour conditions have grown worse, and it is safe to say that probably 90 per cent. of the plantation labour of this region is now under written contract. Specific agreements as to supplies are also now the prevailing rule. 


\section{The Yazoo-Mississippi Delta Ior}

of plantation management, he obtains his supplies from a merchant or cotton factor. Here we have the crop lien system, so often, so earnestly, and, in my judgment, so unjustly inveighed against. What the Negro obtains from the factor, and the manner of his getting it, depend largely upon himself. Usually his advances consist only of supplies, furnished him monthly or weekly. The only money advanced is such as the contingencies of cultivating or gathering the crop make necessary. The Negro is dealt with just as his established reputation and the value of the security he has to offer may justify. The factor's method of self protection is to take a deed of trust on the live stock and prospective crop, and is the same whether the applicant be a twomule Negro renter, or the white owner of a thousand acres of land, wanting ten thousand dollars of advances. The latter attaches his signature to a printed trust deed like that signed by the former, covering his mules and crop to be grown. The amount advanced is governed by the character of the individual and the security. There is, however, this difference: the white man gets his advances in cash, available at stated intervals, while the Negro gets the most of his in the shape of supplies. If, however, the Negro has established for himself a reputation and credit, and is entitled to it under the standard applying to the white man, he can secure advances in the same manner. On the other hand, if the white man is the owner of only two mules, he gets his just as does the Negro. Of Negroes of reputation and credit there are in the Delta a great many; of 
white men without property there are, fortunately for all concerned, extremely few. It is a matter of credit, and not of race.

Nor is the business custom which thus discriminates an arbitrary one. Experience has taught no lesson more severely than that the average Negro will throw away - and I use the expression advisedly - whatever money comes into his hands. If he would refrain from this practice for a few generations, he could own from top to bottom and from side to side the section in which I live. Even where money is furnished the ordinary Negro, it has to be done most carefully; for experience with padded pay-rolls and cotton that failed to make in the bale what the figures promised in the picking is so common as to excite no comment. Aside, however, from any consideration of honesty, the number of Negroes who will not squander and utterly misapply funds coming into their hands - whether received under a solemn obligation to use them in making good the security pledged, a growing crop, or as the result of twelve months of toil - is so small that considerations of common business necessity dictate the course pursued. The Negroes who are independent renters supplying themselves, or land owners, constitute practically the small thrifty class.

As to the crop lien system, per se, I regard it as distinctly the poor man's opportunity. Under it a Negro who is honest - honest with himself in his work, and honest with those with whom he deals - who does not waste his money on excursions, picnics, crap games, 


\section{The Yazoo-Mississippi Delta}

whiskey, women, and pinchbeck jewelry, can out of this soil easily and quickly become an independent man. The proposition appears too simple to argue. Familiar with the capabilities of the soil, the cotton factor knows that it alone can be made to repay what he advances on its cultivation. Upon the security of a lien upon what it shall produce he is willing to make possible its cultivation by one who would otherwise be unable to obtain advances. I believe the figures submitted below will demonstrate that the Delta Negro, by the exercise of common thrift and economy, can become independent as the result of two or three years' labour. But so long as he wastes his money and opportunities, as is now his too common habit, the particular system under which he accomplishes these barren results need occasion economists and himself but little concern. Because better results are not more visible in the way of a greater apparent Negro prosperity, we sometimes hear it asserted that even here the black man is denied opportunities for his betterment. This is a superficial observation, based upon the conditions resulting from a failure of proper achievement, rather than from the absence of opportunity.

One of the greatest factors in our demand for Negroes is the necessity of securing each year a great number of extra cotton pickers. It is an axiomatic proposition with us that no Negro family will pick the cotton which it will raise. Not that it cannot be done; on the contrary in an average year, and by the exercise of due diligence, it can; but it will not. In order to save the crop 


\section{The American Race Problem}

it is necessary to employ additional pickers. The size of the stalk and the great number of bolls make cotton picking on alluvial land very easy work; the utter disregard, by planter and tenant alike, of the true economy of the situation makes it a lucrative employment. Picking is paid for without much regard to the price which cotton commands. Whether it be worth ten cents per pound or six, the price of picking remains very near to fifty cents per hundred pounds of seed cotton. During the fall months a good picker can easily average two hundred pounds, while many can pick as much as three hundred and fifty per day. One of the most difficult matters of plantation management is to get the tenant to act upon the proposition that every hundred pounds of cotton picked by himself means a saving to him of the cost of picking. The opening of each season finds most of them clamorous for extra pickers.

To supply this autumnal demand for labour the towns empty themselves of great numbers of their Negro population. The vagrant leaves for a season his accustomed haunts, the crap shooter and "rounder," in fewer numbers, betake themselves to the country to earn easily a few unfamiliarly honest dollars, and to ply their vocation among their rural friends, the cooks and washwomen desert their regular callings to such an extent as to make the season a time of dread for urban housekeepers. Yet this source of labour is soon exhausted, and the business of securing pickers from towns outside this section and from other states and other parts of Mississippi is regularly pursued by a number of Negro "agents." 


\section{The Yazoo-Mississippi Delta}

Of the great number of Negroes thus brought yearly into the Delta, many remain to make crops themselves, attracted by the superior growth of cotton, and the display of money always incident to the season. I have seen more than a thousand dollars in silver paid out of a plantation office on Saturday night for extra picking alone, and in the presence of a curious, eager throng, coming from sections in which such a thing as a handful of Negroes handling so much cash as the result of one week's plantation work would seem almost incredible. Such things taken with the novel surroundings, the large talk of Negroes making more cotton and handling more money than many white farmers elsewhere, the scale on which affairs are carried on, such as the measuring and selling of cotton seed by Negroes by the ton instead of the bushel, the evidences of plenty and to spare furnished by the spendthrifts around them - for the Delta Negro, especially when in the presence of his brother from some less favoured section, is as free a spender as the world affords - all this tends to fire the stranger with a desire to come into this land of plenty. It is thus that much of our labour is recruited, and some of it the best we have, especially during the first two or three years of residence.

So far as I can judge the Delta Negro presents no peculiar social phenomena. His life is the same which the race leads in sections where its material opportunities are not so great. The only difference I can observe is that there may be a greater tendency among them- 


\section{ro6 The American Race Problem}

selves to the commission of crimes against the person. For purposes of comparison, I have taken the Negroes of a group composed of the nine counties of Mississippi where they are most largely outnumbered by the whites. To this group, for convenience I shall apply the local designation, "Hill" counties. In this group the proportion of whites to blacks is more than 4 to $\mathrm{r}$, as against a reverse proportion of more than 7 to $I$ in the Delta group. We have seen that in the latter the Negroes constitute 18.8 per cent. of the total Negro population of the state; in the Hill group they constitute but 2.6 per cent. We have seen that the Delta furnishes $2 \mathrm{I} .7$ per cent. of the Negro state prison population; the Hills contribute 3.4 per cent. A comparison of the crimes of the two groups discloses the fact that 50. I per cent. of those in the Hills, and only r 9.3 per cent. of those in the Delta, are burglaries, larcenies, forgeries and, arsons. Crimes against the person make up 80.7 per cent. of the offences of Delta Negroes, and 49.9 per cent. of those in the Hills. It may seem somewhat singular that rape constitutes 6.2 per cent. of the graver crimes of the Hill Negroes, while, as has been shown, 4.9 are the figures for the Delta. It is in the crimes of murder, manslaughter, and attempts to kill that the Delta Negro exhibits his criminal propensity most strongly. These compose 75.8 per cent, of all of their felonies, and 43.7 per cent. of those of the Hill Negro. In the two crimes of larceny and burglary the Hill district is far ahead of the other section, the percentage of total felonies being respectively 40.6 and $\mathbf{5} 5.2$. 


\section{The Yazoo-Mississippi Delta}

In the lower class of Negroes a predilection for petty gambling amounts almost to a passion. Their opportunity of indulging it depends upon their command of ready money. A majority of the murders committed in this section arise out of gambling. Therefore, I would attribute the difference in the relative number of homicidal crimes committed by the Negro in the two sections to the Delta Negro's greater command of money. Anyone who has witnessed a genuine crap game, played as only the Negro can play it, has no difficulty whatever in understanding how easy it is for human life to be taken in a dispute arising over the most trivial sum. It is an entirely conservative statement to say that on or near every Delta plantation may be found from one to four regularly patronised crap tables, while in every town and village from one to a half-dozen Negro crap dives are run. Around these tables, especially on Saturday nights and Sundays, gather crowds of men and boys of all ages, scarcely one in five without a knife or pistol. It takes but a word to bring one or both into the game. Making no attempt to estimate the number of such affrays in which both parties are killed, and no trial possible, and not reckoning the number of killings in which the surviving party escapes, is acquitted by a jury, or hanged, there are now* in the penitentiary from this section alone no less than I 54 Negroes serving sentences for taking, or attempting to take, human life. In the courts of this group of counties there were for these crimes in 1898 thirty-three

* September 30, r90r. 


\section{The American Race Problem}

convictions; in I899, twenty-nine ; in I900, thirtythree; in r 901, to September 30 th, thirty-seven.

It would be idle to discuss such a matter as the sexual looseness which marks the conditions obtaining among the masses of these people. No new light could be thrown upon it, and no good accomplished thereby. It may be safely affirmed that the marriage contract possesses for them little, if any, sanctity. This may seem a hard saying, but no man acquainted with the facts will deny its truth.

In discussions of the Negro we have been repeatedly told of late years that the race should be judged by its best element, and not by its worst, and that statistics of criminality were an unfair index to Negro conditions. That it is unfair to base opinions and conclusions upon partial investigations is true. But it is equally true that we cannot form just estimates by considering only the few who have risen superior to general environments and are confessedly exceptional. The only true index to the life of a people is furnished by a study of its masses - its great general class. It is with this mass in $m y$ section that I am dealing, and my statements would lose none of their force or truth by being met with the counterclaim that there are Negroes here who lead decent, respectable lives. No race as a race can rise superior to the condition of its average family unit, and it is the disregard of the marriage relation, the brutality of husbands to their wives and of both to their children, which will probably for a long while most impress the student of the Negro masses, rather than the fact that 


\section{The Yazoo-Mississippi Delta}

here and there may be found families and individuals who have adopted for themselves standards obtaining generally among another people.

One of the traits which militates most against the Negro here is his unreliability. Given certain conditions one may reason to fairly certain conclusions regarding a white man. It is not so with the Negro. $\mathrm{He}$ presents a bundle of hopelessly unintelligible contradictions. Take his migratory habit, for instance, as one manifestation of his characteristic unreliability. The desire to move from place to place, the absence of local attachment, seems to be a governing trait in the Negro character, and a most unfortunate one for the race. It has led to the fixed conviction on the part of many people having constant business relations with him that in this respect the Negro cannot be depended upon at all, and that the treatment he receives has but little real effect in shaping his course. It is undeniable that there is abundant ground for the most extreme opinion. His mental processes are past finding out, and he cannot be counted on to do or not to do a given thing under given circumstances. There is scarcely a planter in all this territory who would not gladly make substantial concessions for an assured tenantry. I do not mean for Negroes who would stay with him always, and never take advantage of an opportunity for genuine betterment, but merely for such as would remain with him only so long as they were willing to work at all under the same conditions, and should receive honest and considerate treatment at his hands. Yet no planter 


\section{10 The American Race Problem}

among us can tell how many or which of his tenants of to-day will be his tenants of another year.

Not all Negroes can become landed proprietors, any more than all mill operatives can become mill owners, or all wage earners capitalists. It is inevitable that there must always be a large class of Negro tillers of other men's soils, corresponding to relative classes among all the races of mankind. It is then manifestly to the interest of these that they should seek for themselves conditions as nearly as possible approaching actual land ownership - a fixed tenure, and the comforts of a home. This status need not mark the limit of advancement of all those entering it; it would but afford a stepping stone to such as proved themselves capable of turning good conditions into better. In all that I have said I would not be understood as claiming that motives of self-interest do not operate with the Negro at all; I simply and emphatically assert that they do not at all intelligently control him.

The Negroes in the Delta not only make in the aggregate a tremendous amount of money, but they squander more than any similar class of people of whom I have any knowledge. There is no way of computing the amount expended by them in railway travel alone, but it is an enormous sum. This travel is for the most part entirely aimless, and it is a common thing for a Negro to take a trip from a plantation to a town fifteen miles distant, with bare train fare in his pocket, and a crop badly in need of his attention at home. On Saturdays field work is practically suspended and the day is usually 


\section{The Yazoo-Mississippi Delta}

given up to such aimless moving about, or to assembling around stations and stores to witness the arrivals and departures of others.

The greatest diversions of these people, however, are excursions and the circus. The former come at irregular intervals, from four to six times a year, and mean trips of from eighty to one hundred and fifty miles. The money spent on this form of amusement is nothing in amount to the annual tribute poured into the coffers of the circus. In the months of October and November, I 90I, two of the largest of these concerns now exhibiting gave a total of ten performances in the Delta. Making a careful and conservative estimate of the amounts spent on the three items of railroad fare, incidentals, and admissions, the sum total could not have been under $\$ 50,000$.*

Among our Negroes we have few drunkards, and but few who do not drink; nor is the drinking by any mears confined to the men. Considering the prevalence of the habit, the only surprising feature is that so few drunkards should be found.

The line of demarcation between rural and urban life is so indistinct, and persons pass so constantly from one to the other, that there is not much difference between the Negroes of the town and those of the country. In each place we find the good, the bad, and the indifferent. As in the country we have the moving, shiftless element, so do we also have the shiftless Negro of the town; as in the one place we have the land owner or

* It was in fact close to $\$ 75,000$. 


\section{12}

\section{The American Race Problem}

prosperous tenant, so in the other we have the man who owns his home, and has steady employment at excellent wages; the "rounder," the pistol carrier, and the professional crap shooter alike infest each. Throughout the Delta there are Negroes filling places of responsibility and trust. In the country the gin crews and engineers are practically all Negroes, and there are Negro foremen, agents, and sub-managers. There are many constables, and there is in my county a Negro justice of the peace. In my own town every mail carrier is a Negro and we have a Negro on the police force. Some are employed by cotton factors and buyers, and earn from $\$ 600$ to $\$ \mathrm{I}, 000$ per annum. Others are employees of electric light companies, some are telephone linemen, and some are engaged in merchandising. Wages paid in the country range from 50 cents to 75 cents per day for common hands, and from $\$ \mathrm{I}$ to $\$ \mathrm{I} .25$ and $\$ 1.50$ for gin crews. In levee work the commonest labourers receive \$I per day, and the more skilled \$I.5O. In towns the wages vary greatly. Hands in oil mills and compresses are paid from $\$$ I to $\$ 2$ per day, while the wages and earnings of porters, hackmen, dray drivers, teamsters, etc., range from $\$$ io to $\$ 60$ per month.

Mississippi makes no separate assessment of the property of the two races, and it is therefore impossible to arrive at the value of the property owned by the Negro in the Delta. The best that can be done is to estimate it. In I 900 the total assessed value of all the property in this group of counties was $\$ 29,095,167$. Of this amount railroad property constituted $\$ 5,396,008$, leav- 


\section{The Yazoo-Mississippi Delta II3}

ing a balance for realty and personalty of $\$ 23,699, \mathrm{I} 59$. Without going into the methods employed in reaching the result, I conclude that a conservative estimate of the value of Negro holdings would be, in round figures, not less than $\$ 1,000,000$. This is probably encumbered to the extent of one-half its value. I give this estimate as a minimum figure, and the correct value may be much greater. It is hardly possible to judge the extent of the increase in Negro property, but it is considerable, though by no means in keeping with the opportunities of the race. But even now one cannot travel through this section without observing Negro land owners everywhere. They are scattered over its entire area, holding tracts varying in size from a town lot to more than a thousand acres.*

In considering the Negro's condition and opportunities here, three factors assume important proportions. The amicable relations between the races, the peculiarly fertile soil - the absence of the necessity for fertilisers alone meaning a great deal - and the superior quality of the cotton produced. Of race relations enough has been said ; of the soil it is sufficient to say that it needs no fertilisation. It has often been the occasion of curiosity to me to know what became of the fertiliser shown by the eleventh census to have been purchased by these counties. The amount expended is stated to have been only $\$ 12,472$ it is true, with a value of farms and products of $\$ I 6,77 \mathrm{I}, 090$, but I have always doubted

\footnotetext{
* The bulk of this property is held by mulattoes, the larger tracts almost without exception being in their hands.
} 


\section{I14 The American Race Problem}

the accuracy of even these figures. Commercial fertiliser is an article unknown to us, and not handled by our dealers in plantation supplies.*

The figures of the last census showing the comparative cotton acreage yield of this section, the state, and the South, are not available, $\dagger$ but it is not likely that much variation will be shown from those of the eleventh. These exhibit an average yield per acre of lint cotton for the South of I 76.67 pounds, and for the state of Mississippi of r 91.03 pounds. The yield of this county group was 257.87 pounds. It is only fair to state that the average of the state was increased by that of counties lying partly in the Delta, but which, as explained above, have not been included here. While for a given year we have this average, the standard yield is with us 500 pounds, and large areas will show a yield ranging between this and 400 pounds.

The cotton grown on this soil is much superior, both in the quality of its fibre and the length of its staple, to upland varieties. Taking its name from the fact of its growth in the bends of the Mississippi River at a time when it found its way to the port of New Orelans by means of boats plying that stream, it is known to the Liverpool, New Orleans, and Eastern markets as "benders," and commands a substantial though fluctuating premium over "uplands."

In conclusion I shall submit some of the features and results of a personal experiment with Negro labour,

\footnotetext{
* Notwithstanding this natural fertility, I am now convinced that excellent results would follow the general use of proper fertilisers here.

$\dagger$ September, rgor.
} 


\section{The Yazoo-Mississippi Delta}

carried on under conditions differing somewhat from those generally obtaining. Several years' experience in cotton planting led to certain conclusions relative to the usual manner of handling plantation labour. I became convinced of one thing, that too much latitude was allowed the Negro in the matter of his account and in the handling of his crop. Observation and experience satisfied me that better results could be obtained for both the Negro and the planter by requiring the former to conform more strictly to business rules, and by making the relations between the two, in crop and money matters, more nearly of a purely business character. I also entertained the belief, not yet entirely dissipated,* that a reliable, industrious, and largely self-sustaining, plantation tenantry could be built up by effort along proper lines, coupled with a degree of liberality at the outset not entirely consistent with the general purpose of putting the Negro on a strictly business footing.

Even casual observation will show that the greatest opportunity enjoyed by the Negro for acquiring property is as a renter. It was determined, therefore, to adopt the rent system. The greatest objection to it is that, as it ordinarily obtains, it allows the Negro privileges which he too often abuses. He does not take kindly to suggestion or direction as to what he shall plant, and wants to put practically all his land in cotton because it is a cash crop; he thinks he should be left free to work his crop when and as he pleases, which means

* See the following paper, "A Plantation Experiment." For convenience of narration, the above is expressed in the first person, while in fact the experiment described was the joint effort of my partner, Mr. Julian H. Fort, and myself. 


\section{I16 The American Race Problem}

frequently neglect, and oftener improper cultivation; having control of mules, he thinks that he should enjoy the privileges of riding them about the country, when both he and they should be at work, and of neglecting and poorly feeding them, if he so elect; in short, that he should enjoy various privileges and immunities which it is impossible to recite, but which are usually accorded by the custom of the country. These things mean that the Negro as a renter is generally undesirable, often troublesome, and that his cultivation of land causes deterioration. To rent and yet avoid the difficulties ordinarily incident to the system was a problem solved by the use of a contract specifying in detail what was undertaken by each party, and reserving to the plantation management absolute control over all plantation affairs.

There is generally a great disproportion between the Negro's ideas and his ability of execution; he wants to plant on as large a scale as possible, and will usually "overcrop" himself, undertake more land than he can cultivate, leading to the neglect of some or all of it. It was accordingly determined to allot to each family only so much as it could cultivate thoroughly under all ordinary contingencies, believing that not only more money, but an actually greater yield could be had by the tenant from twenty acres well handled than from twenty-five half neglected. Mules and implements were sold at reasonable prices and on two years' time, one-half the purchase price payable annually. For handling the crop to the best advantage, as regards economy and grade, a thoroughly equipped gin plant 


\section{The Yazoo-Mississippi Delta}

was substituted for a less modern one, and as a means of lessening the cost of living to the tenant, and of encouraging the raising of corn, it was provided with a mill capable of making an excellent quality of meal, far more nutritious than the purchased, kiln-dried article. The latter is operated once a week, the grinding being done for toll only, a bushel of meal being exchanged for a bushel of shelled corn. It may be remarked that during the three years of its operation there has been a marked increase in the demand for its services among the Negroes of the neighbourhood, many coming to it from distances of five and seven miles. Exercising the contract right of requiring the planting of as much corn as was deemed expedient, it was agreed, in return, that all surplus corn raised by the tenant would be taken off his hands at the market price.

In the accomplishment of the general objects in view, it was of as much interest to the plantation as to the tenant that the best possible price be realised for the latter's cotton. For this and other reasons the privilege of absolutely controlling his crop was denied him. This was clearly stipulated in his contract, but he was not denied all voice in its disposition. He could sell it to the plantation, if a mutually satisfactory price could be agreed upon, or he could let it go forward with the general crop, and have an accounting for its proceeds. One of the essentials to successful cotton growing here is thorough drainage. With this the tenant has nothing to do, it being stipulated that the land is to be kept well drained without cost to him. 


\section{8 The American Race Problem}

Believing that not only is the labourer entitled to proper shelter, but that comfortable homes are a matter of plantation economy, these tenants are furnished excellently constructed houses, well lighted and heated. Each house has its driven well, kept in repair as an item of plantation expense. These houses, with the exception of some of three and four rooms, contain two rooms each, and are constructed with a view to accommodating a family working eighteen acres of land, that being the amount, per average family, from which the best results are found to be obtainable. * It has been determined, however, in order to avoid any possibility of crowding, to add a third room to each of these houses. This is now being done, and within a year there will be no two-room houses remaining. Every effort is made to encourage tenants to raise gardens, and to own cattle and hogs, abundant pasturage being provided free. The proper care of live stock is rendered compulsory by close supervision.

To reduce the matter of advancing supplies as nearly as possible to a business system, a furnishing basis of 50 cents per acre, per month, for supplies only, was fixed upon. Incidentals usually require about 25 cents per acre additional. Each month the tenant is furnished a coupon book for the amount, in money, of his supplies, a twenty-acre family receiving a \$Io book, thirty acres securing one of $\$ \mathrm{I}_{5}$, and so forth. These books are good only for supplies, such as meat, meal,

\footnotetext{
* In the light of the seven years' experience since the above was written our firm, Stone \& Fort, is now reducing this to fifteen acres per family.
} 


\section{The Yazoo-Mississippi Delta}

tobacco, snuff, and molasses, but it is agreed with the tenant that such coupons as he may have left in his book at the expiration of each month will be honoured for whatever he wants. This is done with a view to encouraging economy, and to enable him to secure "extras" without increasing his account. Getting their meal without cost, by grinding corn, and getting flour in its stead out of their books, none of those who were on the plantation last year failed this year to secure with surplus coupons an abundance of sugar, coffee, rice, etc., at the end of each month to carry them through the following. This system possesses several advantages, not the least of which are that it saves the making of numerous small ledger entries, and enables the tenant to tell at any time during the month, from his unused coupons, the exact amount he has left to his credit, so that he may govern himself accordingly. The Negroes regard the system with the utmost satisfaction, and would not exchange it for the usual method of "issuing rations."

To make a success of the system outlined here, three things were absolutely necessary: the utmost patience and good sense at the office, wise management in the field, and discrimination in selecting tenants. Every Negro known to be a professional crap shooter or pistol carrier was run off the place, all families known to be quarrelsome and troublesome were got rid of, and everybody whom it was necessary to compel to work was let go. Under no circumstances is a professional "exhorter," or lodge organising preacher, allowed on the 


\section{20 The American Race Problem}

property. The virtue of patience has been exercised to a degree that has more than once threatened its destruction.

It would be manifestly unfair to judge such an experiment by its first year. This was a most troublesome, and, to the management, rather discouraging experience. Little was accomplished beyond getting affairs in easier running order. The third year is not yet closed,* but promises results about in keeping with the second, the complete figures of which are available. There were in cultivation in $1900, \mathrm{r}, 300$ acres. The total value of the product was $\$ 54,000$, an average of a little more than $\$ 4 \mathrm{I} .50$ per acre. There were on the place $6 \mathrm{r}$ families, containing 80 men and $8 \mathrm{I}$ women, including children old enough to work, and 67 younger children, a total of 228 persons in families. These families occupied 6r houses, containing 147 rooms, an average of 1.5 persons to the room. There was an average of 3.7 persons to the family, while the average number of hands who assisted at some stage of the crop was 2.6. In addition to the families, there were $\mathrm{I} 8$ wages hands employed, who, though separately housed, must be added to the number of working hands, giving a total of I79. We thus have an average acreage to the working hand of 7.2, with an average product value of $\$ 301.67$ per hand. Cotton was raised to the value of $\$ 4 \mathrm{I}, 000$, being 8 I 8 bales of 500 pounds average, or 4.5 bales, 2, $25^{\circ}$ pounds, to the working hand. It should be stated that while these wages hands assisted in various stages of

* September, rgor. 


\section{The Yazoo-Mississippi Delta}

the crop, not all their time was thus employed by any means, for some tenants did not need extra hands at all. They were used, when not in crops, in clearing new land, ditching, and other plantation work.

The Negroes with whom we started, in January, r 899, with possibly three exceptions, had absolutely nothing, barring their clothing, bedding, and furniture - all of the scantiest and poorest kind. It would be a most liberal estimate to put their entire belongings at that date at an average value per family of $\$ 30$. Yet they were an average lot of plantation Negroes; they were of many ages, and came from many sections; of the older ones, most had had something, but had lost it in shifting from pillar to post, and at fifty and sixty years of age were empty-handed; some had lived on a dozen different plantations in as many years. They had thus to start with us actually owing for their first week's supplies. After the lapse of three years, the average value of the property owned by the sixty and more families on the place may be conservatively estimated at $\$ 200$. This, of course, includes no cash on hand or to their credit on our books. After paying their accounts, the tenants on the place in I 900 received $\$ \mathrm{II}, 000$ in cash. Their balances this year (I90I) will amount to about the same figure. They have good clothing, their houses are now comfortably furnished, and for cooking purposes the open fireplace has given way to the kitchen stove.

The following statement is drawn directly from the plantation ledger of $\mathrm{i} 900$. It is the account of two men 


\section{I22 The American Race Problem}

who worked together as a family. These hands were above the average in point of steadiness and efficiency, but the account is fairly illustrative of the possibilities to the Negro of good soil, fair prices, hard work, and economy. It will be noted that the value of their product per acre appears to be greater by about $\$ 8$ than the average of the plantation, but this apparent difference will be explained by stating that in computing the latter the entire acreage of the plantation was included. If we exclude from consideration all raw, first year land, such as was not allotted to renters, the difference will be shown to be very much less.

ACcounT

Debits

Land rent, $2 \mathrm{I}$ acres $\$ 6 . \quad . \quad . \quad . \quad . \quad$. $\$ 126.00$

Mule, paid for entirely in first year . . . 100.00

Gear and implements . . . . . . $18.5^{\circ}$

Planting seed . . . . . . . 10.30

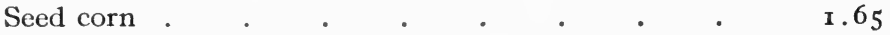

Supply account . . . . . . . . 98.25

Sundries . . . . . . . . 18.20

Picking $6 \frac{1}{2}$ bales cotton . . . . . 59.45

Ginning and wrapping I 9 bales cotton, $500 \mathrm{lbs}$. average $\quad 57.10$

Mule feed . . . . . . . . 43.50

$\$ 532.95$

Credits.

Nineteen bales cotton . . . . . . \$865.I4

Cotton seed, 9.4 tons . . . . . . . II7.75

Corn, 105 bushels - market price at time, 50 cents $\quad 5^{2} .50$

Profits, $\$ 502.44$.

$\$ 1,035 \cdot 39$

Holding their corn, they had, as the result of the year's operations, property worth $\$$ I 7 I.00. It will be 


\section{The Yazoo-Mississippi Delta}

seen that their cash crop overpaid their account by $\$ 449.94$.

As to the effect of the showing exhibited here upon the Negro, if any, it is impossible to judge. Some of those who had least at the outset and have most to-day are preparing to leave - though they may change their minds in a night, after having made their arrangements to depart, while some have already left. To arrive at a just conclusion on this point at least five years would be required, and only such tenants as removed to other places to continue the tenant relation could be considered in enumerating the removals. It would be manifestly unfair, in considering the extent and influence of a migratory, restless habit, to attribute to it such as were actuated by opportunity and desire to purchase land. Of those who have thus far left the place, not one has done so to become a land owner.

All that I have said of general conditions in the Delta applies, in greater or less degree, to all the 29,790 square miles of the alluvial valley of the Mississippi. The future of this territory will inevitably be linked with the future of the American Negro. The movements of black population, as indicated by the last three censuses, show this clearly enough. In discussing the conditions surrounding the Negro in the Yazoo-Mississippi Delta, I have not attempted to present such a picture of rural felicity as John Stuart Mill quotes from Chateauvieux of the métayers of Piedmont. But I am well within the limits of conservatism when I assert that in the material potentialities of his environment the situation of the 


\section{The American Race Problem}

Negro here is infinitely superior to that of any European peasant. It is not claimed that there are no instances of injustic to the Negro. Not at all. But I do claim that nowhere else is his general treatment fairer - nowhere is his remedy more certain. This is but corollary to the proposition that nowhere in the same extent of territory will be found a greater or more constant demand for his labour. Nowhere does he find a better market for his service, nowhere is he freer to change his local habitation.

To say how long conditions, particularly as regards the relations between the races, will remain as they are, would be to enter the field of speculation - a pastime in which I am not engaged. The presentation which I have attempted is believed to be a not unfaithful portrayal of the present; with what the future holds in store this paper has no concern. 


\section{IV}

\section{A Plantation Experiment*}

TN A PAPER on "The Negro in the Yazoo-Mississippi

1 Delta," read at the fourteenth annual meeting of the American Economic Association, $\dagger$ I briefly touched upon the conduct of a plantation in which I was interested. Because of a certain degree of novelty attaching to some of the features which characterised the business relations between the plantation management and its Negro labour, I felt justified in referring to these transactions as an "experiment." It is to a discussion of this experiment, six years after its inception, that the present paper is chiefly addressed.

An adequate supply of labour is the first essential in the business of raising cotton. To secure it constitutes the most serious problem confronting the plantation management. 'Not for forty years has the supply equalled the demand in the alluvial section of Mississippi. Here the Negro still has almost a monopoly of the field of manual labour, though at last his supremacy has been threatened by the white man. So great is the annual competition among planters for Negro labour that the latter is afforded opportunities for driving bargains

* From the Quarterly Journal of Economics, February, 1905. † Chapter III. 


\section{The American Race Problem}

superior to those possessed by any other class of agriculturists with which I have any acquaintance.

There is absolutely no fixed basis among planters for making terms with labour, and in consequence contracts vary through a wide range of conditions. Any Negro family, though it consist of only a man and his wife, and have not a dollar on earth, will be taken into partnership with the planter; for that is the real nature of the share contract. The planter will locate the family for the year in a comfortable house, on its proper allotment of as good land as can be found in America. He will furnish the land (which includes house, fuel, water, and garden free), seed to plant it, and team and implements with which to cultivate it. This is the planter's part, and against it the Negro furnishes his labour, and agrees to make and gather the crop. The two divide whatever is raised, share and share alike. In addition the planter supplies the sharehand with food, clothing, tobacco, medicine, and medical attention. He does this from the day the family reaches the plantation until the day it decides to "move," or, rather, until the planter learns of such decision. He hazards his advances upon the sole security of the crop, and looks to the Negro's share for his reimbursement.

In the paper to which I have referred I made this statement: "There is scarcely a planter in all this territory who would not gladly make substantial concessions for an assured tenantry. I do not mean for Negroes who would stay with him always, and never take advantage of an opportunity for genuine better- 


\section{A Plantation Experiment}

ment, but merely for such as would remain with him only so long as they were willing to work at all under the same conditions, and should receive honest and considerate treatment at his hands."* I would to-day, and with all possible emphasis, reiterate this assertion.

It was to the desire and hope of building up some such "assured tenantry" that our experiment largely owed its inception. Its salient features were: Uniformity of tenant system, all land being rented at a fixed cash rental; the sale of stock, implements, and wagons to tenants upon exceptionally favourable terms; the exercise of proper supervision over the crop; the use of a contract defining in detail the undertakings of each party; the handling and disposition of the gathered crop by the plantation management. Let there be no misunderstanding of the motives behind all this. There was nothing philanthropic about it. It was a business proposition, pure and simple, but certainly one with two sides to it. The plan was to select a number of Negro families, offer them the best terms and most advantageous tenant relation, and so handle them and their affairs as to make them reach a condition approaching as nearly as possible that of independence. The hope was that, having accomplished this purpose, we would thereby also have in large measure solved the labour problem, having attached to the plantation by ties of self-interest a sufficient number of these independent renters to make us in turn measurably independent of the general labour situation. The problem before us

\footnotetext{
*Idem, p, ro9.
} 


\section{I28 The American Race Problem}

was to place in the hands of these people the means of acquiring something for themselves, and then, in every instance of deficient individual initiative, by proper supervision make them acquire it.

The principal statistical features of the experiment during the five-year period which witnessed its beginning and its practical abandonment may be thus summarised. We brought to the plantation, at the close of the season of 1898,30 new families, and began the first year, 1899 , with a total of 58 .* On $\mathrm{I}, 064$ acres of cotton land we made but 459 bales of 500 pounds average, a family average of 7.9 bales. The average price received was $7.5^{\circ}$ cents per pound; and the entire crop, cotton and seed, brought $\$ 2 \mathrm{I}, 663.88$, or a family average of $\$ 373.5$ I. Of the families on the place, 26 , or 44.8 per cent., left at the end of the year. We moved in 27 families, and, with the 59 which the addition gave us, cultivated $\mathrm{I}, 048$ acres of cotton in $\mathrm{I} 900$. The crop was $8 \mathrm{I} 7$ bales, or 13.8 per family. It sold at an average price of 9.94 cents, and with its seed brought $\$ 47,54$ r.66. This was an average cash product value of $\$ 805.79$ per family. $t$ The number of families who left the place at the close of the year was I3, or 22 per cent. of the total. We secured I 5 new ones, and had on the place

\footnotetext{
* The number of persons to the average family remains practically stationary at about 3.7. See Chapter III., p. I 20.

† The "cash product" value must not be confused with the total crop value shown for this year in the previous chapter nor the total acreage given there with the cotton acreage shown above. It may be explained that the number of families given in the previous chapter, sixty-one, included two occupying somewhat anomalous tenant relations, who have been omitted here. The number of bales given here $-817-$ is correct, instead of 818 , as shown in the other paper.-Chapter III., p. I 20.
} 


\section{A Plantation Experiment}

6r families in $190 \mathrm{I}$. We had this year in cotton $\mathrm{I}, 348$ acres, and raised $\mathbf{r}, 270$ bales, 20.8 to the family. At an average price of 7.90 cents for the cotton this crop, including seed, realized $\$ 60,742.04$, being $\$ 995.77$ per family. We lost 16 families this year, 26.2 per cent. of the whole force, and moved in 24 new squads, which gave us 69 for 1902 . The latter year we raised $1,13 \mathrm{I}$ bales of cotton on I,34I acres. Seed and cotton brought $\$ 54,593.26$, the average price of the latter being 8.08 cents per pound. The average product of cotton was I6.4 bales per family, the average value of cotton and seed $\$ 79$ r.20. At the end of the year we lost I 7 families, 24.6 per cent. of the total, and moved in 23 for the following year. This gave us 75 squads for 1903 . We cultivated $\mathrm{r}, 39^{2}$ acres of cotton, and raised $74 \mathrm{I}$ bales, 9.8 to the family. This brought Ir.77 cents per pound, the cotton and seed selling for $\$ 53,527.73$, or an average of $\$ 7$ 1 3.70 per family. At the close of the season 3I families, $4 \mathrm{I} .3$ per cent. of our working force, left the plantation.*

During the period under review the tenant system of the plantation was changed from an exclusively rent basis to just as nearly an exclusively share basis as it was possible to reduce it. In the first two years the entire plantation was in the hands of renters, while of the cotton acreage in 1903 they worked but 54.6 per cent., and produced but 45.3 per cent. of the crop.

\footnotetext{
* The above figures and others of more or less interest in connection with this discussion are given in the table on p. 148. For aid in compiling the data I wish to acknowledge my great indebtedness to my business associate, Mr. Julian H. Fort.
} 


\section{I30 The American Race Problem}

This has been still further reduced, and of a total cultivated acreage of 1,577 in 1904 they worked but 465 acres, or less than 30 per cent. The number of families on the place increased from $5^{8}$ to 75 during this period; the number renting fell from $5^{8}$ to 36 , a decline in per cent. of the total number from 100 to 48 . Here, again, the renters lost still further in 1904 , falling to 30 families out of 79 - a decline to less than 38 per cent. of the total. In 1899 they held 73 head of work stock, 94.8 per cent. of the total number on the place. This fell to 60 head in I 903 , which was but 47.6 per cent. of the total. Here, too, there has been another decline, the 60 in 1903 having fallen to but 23 in 1904.

But the story of the decline of the renter on Dunleith Plantation - of the failure to accomplish what was at least hoped for under the system inaugurated in 1899cannot be told in any statistical display, nor can the reasons which compelled the abandonment of the experiment be set forth in a column of figures. Back of the inception of the scheme was the desire to create a satisfied and satisfactory force of reasonably permanent tenants. Not that we were ever sanguine enough to hope to have them all in this category. We would have been satisfied with a group of 50 per cent. of the total, or even with less. It was hoped to accomplish our object by a direct appeal to self-interest. We demonstrated our ability to make independent propertyowning families out of poverty-stricken material. These families in turn demonstrated the fact of their independence by severing relations with us almost as 


\section{A Plantation Experiment}

promptly as we put them on their feet. After the termination of three years we had begun to feel reasonably certain that even the most practical appeal we could make to radically improved material welfare would be generally overcome by an apparently instinctive desire to "move." After the experience of five years we were quite satisfied of our entire incapacity to make the average plantation Negro realise the remotest causal relation between stability and prosperity.

We were not surprised to have twenty-six families leave us the first year nor were we especially concerned over the departure of thirteen the second. It was not alone the number who left us each year, but likewise the increasing annual drain on the property involved in their departure that forced us to realise the utter impossibility as a business proposition of continuing our general system. In operating a plantation, stock and implements rank with labour as necessary complements. A cardinal feature of our plan involved the placing of the first two essentials in the hands of the latter. If the labour could be depended upon to remain on the property under normal conditions a reasonable average length of time, this result would of course have been merely incidental to a successful conclusion of the experiment. If, however, the labourers proved conclusively that they could not be so depended upon, then to have continued to put the business at their mercy by giving them control over everything necessary to its conduct would have been extending a foolhardy 


\section{The American Race Problem}

invitation to ultimate disaster. It is bad enough to have to face a general exodus of labour, but such a contingency becomes doubly serious when it involves the loss of stock and implements as well. There are on the plantation to-day but two head of work stock that were there in I 899. What has transpired gradually, and without serious consequences, might easily have occurred in a single year with disastrous results, had we allowed the acquisition of stock by the labour to proceed far enough. I wish it understood that not the slightest obstacle is placed in the way of a tenant's acquiring implements and stock, but also that we no longer sell him these things on long time, nor do we otherwise personally encourage their purchase. We simply endeavour to fill the place of each departing renter with a sharehand, and try to confine such renting as we are compelled to do to such as come to us with stock of their own. In short, we are no longer engaged in the altruistic enterprise of converting shiftless and empty-handed Negroes into desirable and well-equipped tenants for the temporary benefit of other planters.

From 1899 to 1903 , leaving out of consideration the 30 new families brought in at the beginning of the former year, we moved in 124 families. In the same period we lost 103. Of the 79 families on the place in 1904 but 8 were with us in 1899 . Of the ro 3 who have left, some with little, some with much, not one has become an owner of land. Most have simply continued as tenants elsewhere. Many have lost what they carried away, 
and have become sharehands on other plantations. Some have dropped into the ranks of day labourers. A few have drifted into towns. Let me illustrate one of these removals. In December, I900, we moved in a crew of seven people. They all represented themselves as working hands, though one of the men was over sixtyfive, with a wife past sixty. Their entire outfit consisted of a horse, worth at a liberal valuation $\$ 5^{\circ}$, and $\$ 58$ worth of miscellaneous and indescribable household effects. In December, 1903, while riding over the place one day, my attention was arrested by a procession slowly approaching me. It consisted partly of two wagons, one buggy, two mules, one horse, three cows, two calves, and five dogs - the property of this same crew of seven. In addition they had with them outside wagons enough to assist them in hauling away 285 bushels of corn, $\$ 190$ worth of household effects (including a sewing-machine for each woman and a gun for each man), and a half-dozen crates of hogs and several of poultry. During the three years they had paid rent and accounts amounting to $\$ 4, \mathrm{r} 68.96$, had received in cash $\$ 747.85$, and had cash paid for help in their crops to the amount of $\$ 393.90$. Their accounts, of course, included a variety of purchases in addition to their living expenses. They carried away $\$$ I, I0o worth of personal property. They left to get rid of the supervision incident to plantation management, and removed a short distance to the property of a non-resident, and secured their advances from a merchant. In November last I learned that the head of the squad had applied to 


\section{I34 The American Race Problem}

a neighbouring planter for a location for I9u5, and wanted the latter to lift a debt of $\$ \mathrm{r}, 000$ for him.*

Of those who have left I have said that it was not so much their number as their condition that concerned us. In this connection let us look into the condition of the thirty-one families who left us at the close of I 903 . It may suggest itself to some that the single illustration just given cannot be typical of the possible consequences of the removal of a large number of renters at one time, but that it is an isolated instance, selected to prove a case. A study of the entire group of families who left that same year will also serve as a reply. Thirteen of these families were renters, and carried with them the following personal property:

25 head of stock .

9 wagons

8 cows and calves

Implements

Household effects

I,400 bushels of corn

$$
\begin{array}{r}
\$ 3,125.00 \\
360.00 \\
200.00 \\
325.00 \\
650.00 \\
700.00 \\
\hline \$ 5,360.00
\end{array}
$$

They also had between $\$ 800$ and $\$ 900$ in cash; but, as this is an estimate it is not included. One of these families had rented twenty-three acres of land, and had been paid a cash balance of $\$ 659.60$. Another rented twenty-five acres, and drew a cash balance of $\$ 734.72$. Of the thirty-one families eighteen were sharehands, and had but $\$ 360$ worth of property, and that in the

\footnotetext{
* Since the above was put in print this squad has returned to us to make a crop the present year. It surrendered all it had, save household effects, to its merchant, and in addition we advanced $\$ 75$ to cover a balance. It begins where it started before, with nothing, and this time will work on shares.
} 


\section{A Plantation Experiment}

shape of household effects. It is not difficult to see why the removal of the thirteen renters was a more serious matter than the loss of the eighteen sharehands.

We hear a great deal about the unequal distribution of wealth in this country, but I have always believed the wealth of the American Negro to be more unequally shared than that of any other class of our population. Of course these figures are too insignificant to be worth anything whatever in this connection, nor is this paper concerned with such a discussion. The remark is suggested, however, by a glance at the average holdings of these two groups of families. If we stop with the statement that thirty-one families owned $\$ 5,720$ worth of property, we have the very fair showing of $\$ 184.5 \mathrm{I}$ per family. The actual distribution of their total holdings, however, gives the renters $\$ 4$ I 2.30 per family, and the sharehands but $\$ 20$. This inequality holds also with the seventy-nine families on the plantation in r 904. They own, all told, $\$ 7,180$ worth of property. This would be $\$ 90.88$ per family. An analysis, however, shows that thirty renters own $\$ 177.33$ per family, or $\$ 5,320$ of the total. (This is within $\$ 40$ of the exact amount taken away by the thirteen renters in I903.) Of the balance; $\$ 1, \mathrm{I} 20$ is held by twelve sharehands, an average per family of $\$ 93.33$. The remaining $\$ 740$ is made up of a distribution of $\$ 20$ each to thirty-seven sharehands, solely for household effects. But a further analysis shows a still more striking inequality. The eight families who have been with us since r 899 constitute but little more than ro per cent. of the total in 


\section{I36 The American Race Problem}

1904, but own more than 60 per cent. of the total property. They own $\$ 4,375$ worth, or $\$ 546.87$ per family.

While there is no question in my mind as to the cash rent tenancy being preferable, from the labourers' standpoint, to any form of métayer, yet I must not be understood as holding that all the advantages by any means accrue to the side of the former system. Earlier in this discussion I gave an entirely unexaggerated statement of what the planter will do in the way of "staking" the sharehand who comes to him with a capital consisting only of ability to work. Thanks to a crop lien law and a fertile soil, such a man can secure advances in my section of the country upon the sole security of the crop to be grown by him. He has the advantage over the renter of having the planter for a partner, and the latter takes all the risk. If disaster overtake him, the renter may lose his stock and implements, but the sharehand operates on another's capital. At worst he can lose but his labour, and for this he has in any possible contingency at least been sheltered, clothed, and fed. After all, the net results to the tenant depend far more upon his individual efforts and upon his habits, whether of extravagance or economy, than upon any fixed features incident to one system of tenure or the other. Upon every plantation are to be found sharehands who make just as much as do any of the renters, and the nature of whose tenant relation is entirely of their own choosing. A number of accounts could be adduced to illustrate the relative results of the two systems, but the personal equation is so large a fac- 


\section{A Plantation Experiment}

tor as to impair the value of bare figures for purposes of comparison. The two following are selected because they are accounts of families equal in all essential respects. They are for 1903 , and are condensed as much as possible. RENTER : I $8 \frac{1}{2}$ ACRES (I $5 \frac{1}{2}$ IN COTTON, 3 IN CORN).

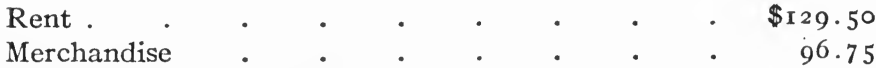
Debits.

Stock feed . . . . . . . . 52.65

Blacksmith, doctor, and planting seed . . . $25.5^{8}$

Work in crop, picking and ginning . . . 42.60

Cash .

Credits.

$$
\frac{\mathrm{r} 62.48}{\$ 509.56}
$$

Net proceeds of 8 bales of cotton, 4,543 pounds and

seed from same . . . . . $\$ 509.56$ SHAREHAND : I 8 ACRES (I6 IN COTTON, 2 IN CORN).

\section{Debits.}

Merchandise

Work in crop, picking and ginning . . . 40.00

Cash .

Credits.

One-half net proceeds of ro bales of cotton, 5,327 pounds, and seed from same . $. \quad . \quad . \quad \$ 328.25$

The renter made 75 bushels of corn, and the sharehand's half of his was 25 bushels. The sharehand made 333 pounds of lint cotton per acre, the renter 293 pounds. The latter was 27 pounds above the plantation average for the year, and 73 pounds above the average yield of renters. The sharehand's yield was 67 pounds above the average of the plantation and I 5 pounds below the average sharehand's. The renter had three items on his account which the planter has to provide under a share contract, namely, blacksmith, stock feed, and 


\section{${ }_{13} 8$ The American Race Problem}

planting seed. The sharehand happened to have no doctor's bill. The renter drew $\$ 4.90$ more in merchandise than the sharehand, but received $\$ 33.92$ less cash. The renter owned two mules, a wagon, and implements, which may be said to have represented his operating capital. He also owned a buggy. The sharehand operated with plantation stock and implements, but owned a riding horse and a cow.

In immediate bearing upon our experiment and as illustrating the gradual transition from a rent to a share system, the most significant figures in the appended table are those which show the stock owned by renters, those showing the rented acreage, and those giving the number of families renting, with per cent. of total number. There are other figures, however, of more or less interest in any general discussion of plantation economy. Take the acreage production of lint cotton, for example. The figures show a-range of from 215 pounds to $47 \mathrm{I}$, and illustrate the fluctuations that may result from various combinations of yield and price. Their study will exhibit the ups and downs of the business - its possibilities and its hazards. The most valuable lesson they offer is the heavy advantage shown to follow a large yield per acre* In the figures showing the

* The fluctuations of yield exhibited here were under conditions well-nigh absolutely uniform during the five years - save in the one respect of weather. Cotton is essentially a "weather crop," and this truism points to the fallacy of most of the deductions and speculations founded upon the indicated yield of 1904. The most assured conclusion as to labour and other conditions, and the most solemnly announced prediction for ensuing years, may both be rendered absurd by too much, or too little, rain during the growing season, by too much while the crop is being saved, or by a killing frost too late in the spring, or one too early in the fall. 


\section{A Plantation Experiment}

amount of cash advanced tenants each year on the two accounts of outside work in making their crops and in extra picking, we are dealing with two of the most important factors in the net results of the Negro's crop. These two items are shown to have been $\$ 4.5^{2}$ for each bale raised in I902. Even if equally distributed, this would have imposed an average charge that year of \$74.I7 per family. But the amount of such assistance needed or demanded by the Negro varies all the way from nothing up to enough to consume what would otherwise be handsome profits. These two items alone during this five-year period would have increased the cash balances to our tenants in the total sum of \$ $5,248.90$.

The transaction between the planter and tenant are frequently utterly devoid of any approach to a proper business basis. This is largely on account of the character of the labour, and rests partly on established custom and partly on the competition for hands. At all events, out of the combination of causes the Negro manages to realise in much too large measure for his own good the gratification of his whims and pleasures. I have yet to know of one so deeply in debt or so far behind with his crop as to cause the least hesitation in the matter of demands for cash for the circus or excursion. But of all plantation customs the most pernicious, in my judgment, is that of advancing "Christmas money." This is just exactly what its designation implies. It is never asked for under any pretext of being devoted to some legitimate or substantial use. 


\section{I40 The American Race Problem}

It is drawn for the sole and express purpose of promoting the pleasures of the holiday season, which begins, according to the recognised plantation calendar, several days before the $25^{\text {th }}$ of December, and terminates several days after the ist of January. I have never heard of a dollar of such money being diverted from its destined aim. It is spent in various and sundry ways, according to the individual estimate of what constitutes "a good time." A good part goes for railroad fare - for " riding the train"; the saloon and the crap table receive more than their share; some goes for cheap finery and pinchbeck jewellery. We tried the experiment of putting this matter on a business basis in 1899 . In consequence there was no "Christmas money," but we have put out our share since. The figures show the aggregate amount on this account to have been $\$ 3,034.70$. This may seem small, but it should be considered in conjunction with the accompanying figures, showing the cash balances and advances during this same month each year. They show that in December during the five years there was advanced a total of $\$ 7,990.63$ in addition to Christmas money. The items are placed in juxtaposition, so that the significance of the latter annual draught and waste may be the more readily appreciated. To illustrate further the amount of cash handled by the Negroes, the table also shows the cash balances and advances to them during the ginning season. This usually begins in September, and runs to January, February, or March, according to conditions. During these months there was paid our Negroes, exclusive 


\section{A Plantation Experiment}

of advances while the crop was being grown, cash to the amount of $\$ 44,727.05$, an average of $\$ 8,945.4$ I each year.

In concluding my earlier paper, to which in some sense this may be considered a second and final chapter, I said that it was impossible for me to judge fairly the effect upon our Negro labour of the showing at that time exhibited. I may quote this statement: "To arrive at a just conclusion on this point, at least five years would be required, and only such tenants as removed to other places to continue the tenant relation could be considered in enumerating the removals. It would be manifestly unfair, in considering the extent and influence of a migratory, restless habit, to attribute to it such as were actuated by opportunity and desire to purchase land."*

We have before us an exhibit of the transactions of a somewhat longer period than the one suggested. As far as possible, it is confined to a bare statement of fact. It is entirely competent for anyone interested in the subject to study the data presented and reason to his own conclusions. In judging how far it might be safe to generalise from a single plantation the following suggestions may with some possible profit be borne in mind. The operations cover a period practically of six years, though all the crop data for the last year are not available. The number of families covered is I5, and of individuals affected more than I,600. The Negroes composing these families came from nearly every section of the South, every Southern state con-

* Chapter III. p. 123 


\section{The American Race Problem}

tributing, with the exception of Texas and Florida. The operations extend through years characterised by extremes both of yield and price, with an excellent general average of each. The plantation management was strongly biased in favour of the rent system at the beginning of I899; it leans as strongly toward the share system at the close of I904. The relations between management and tenants have been uniformly kindly and necessarily most intimate. In the main the families have been of good class, orderly, and well behaved, but one homicide having occurred among them during the six years. No one of the ro3 families that have removed has undertaken the purchase of land. The average age of the heads of families has been about forty years. Of the eight who have remained on the place during six years, four are over sixty-five, one over sixty, two over and one under forty.

To my mind, the most suggestive fact which these operations would seem to establish is, stated conservatively, that the attainment of a prosperous condition by the plantation Negro does not influence him sufficiently to create an attachment for the local environment which accomplishes his material betterment. This seems to me true, unless the removals from such environment are at least in some considerable measure influenced by stronger appeals to intelligent self-interest than are offered by the conditions surrounding the initial improvement. This, of course, presumes the persistence of normal and friendly relations between tenant and management. I take it that in the case 


\section{A Plantation Experiment}

before us we are justified in eliminating at the outset, as one legitimate occasion of removal, if I may use the expression, the desire to become a land-owner, inasmuch as no attempt was made in such direction. In running down the list of recorded causes of removal, I find one, and but one, that can be placed in the class of appeals to self-interest, and then only by not insisting that such self-interest be intelligent. This was the case of several well-to-do renters who left us in 1902 because they were offered a reduction of land rent of one dollar per acre elsewhere. Upon its face such action cannot be criticised. As a matter of fact, it emphasised the operation of an unfortunate racial trait - the thoughtless failure to distinguish between the simplest forms of real and fictitious advantage, the heedless pursuit of the shadow for the substance. The property to which these people removed was run down, its houses were scarcely habitable, its drainage was poor, and there was not another family on it at the time. The reduced rent was a concession to necessity, yet the bait was seized as eagerly as though the hook were not visible to the foresight even of a child. Within a few weeks, whether prompted by characteristic vacillation or by the operation of returning common sense, I do not undertake to say, some of these families wanted to return to us.

It would be well-nigh impossible to enumerate the various causes, real and imaginary, behind the change of abode of the hundred and odd families who left us during these years. In several instances, hands left 


\section{I44 The American Race Problem}

because we were unwilling to advance the amount of "Christmas money" to which they felt themselves entitled. Some departed with the rare frankness of a declaration that they "just wanted a change." Family troubles, the separation of husbands and wives, also account for their share. Still others went because of alleged dissatisfaction with the contract under which they had successfully been brought to a state of independence.*

In saying that I have long since abandoned the hope of fathoming the processes of the plantation Negro's mind, I have "a conscience void of offence" toward these people, to whom I have never knowingly been guilty of an unjust act or word. I mean simply to give expression to the conviction, speaking of the average, of course, and not of the rare exception, that their actions have no logical or reasonable basis, that they are notional and whimsical, and that they are controlled far more by their fancies than by their common sense. Not that the Negro is to be called upon to render to the world a reason for his every act - to account to his critics for the motives behind his comings and his goings upon the earth. But the student of sociology and economics is interested to discover if it be true, as is so generally stated, that a certain large and distinct class of the world's labouring population is characterised

\footnotetext{
* In selling stock, our contract had required the renter to plant enough corn to provide sufficient feed. After a number had paid for their mules, they objected to this because corn is not a cash crop. One of the changes incident to the abandonment of our experiment was the discontinuance of our comprehensive contract, and the substitution of one of a dozen lines in the simplest possible form and terms.
} 


\section{A Plantation Experiment}

by a restless, migratory tendency. This interest attaches to the general subject, whether the concrete illustration be drawn from the fields of the Southern states, from the diamond mines of Kimberley, or from the gold workings of the Rand. The matters and results treated in this paper merely offer cumulative evidence to the correctness of a largely entertained conviction. It is not maintained that they are a demonstration. But the fact does stand out that, in the matter of building up a group of reasonably permanent tenants, these Negroes signally failed to respond to the influence of the most favourable economic conditions with which it was possible for a plantation to surround them. This much is demonstrated, and I account for it in two ways: first, on the hypothesis of a migratory instinct; second, on that of a characteristic easy-going indolence, which seeks freedom to assert itself, and chafes under restraints which measurably restrict its enjoyment.

The Negro race, in the mass, is charged with numerous faults and weaknesses. It is no purpose of mine to discover new ones or to magnify the old. I but give utterance to a sincerely entertained opinion, based upon many years of close personal observation, when I say that these traits to-day present the greatest obstacles to the real, general, permanent advancement of the race, whether in this country, Africa, or the West Indies. I have read a great deal about the Negro's "love of home," and have heard much of the strength of his "local attachment," but in a not unkindly search I 


\section{I46 The American Race Problem}

have been able to discover neither the one nor the other among the masses of the race. To my mind they are a restless people. Ever seeking change, they sometimes wander far afield, and traverse the boundaries of states in its pursuit. Again, like one lost in a forest, they move but in a narrow circle, yet always in the same vain, aimless quest. They have been wanderers since emancipation gave free play to native instinct, and I do not see how a love of home, in the real sense, could characterise a people who in the mass know so little of such an abode. Certainly, the plantation Negro changes his residence far too often for his children to form local attachments or to develop anything akin to such a sentiment. I have often been impressed with the peculiar significance which long usage has attached to the very word "home" among these people. It has come to mean no more than "house," and the two are synonymous terms. When the plantation Negro starts out in quest of an abiding place for another year, he goes in search of another "home."

On November 26th, I904, the principal of Tuskegee Institute gave to the press a statement which has been very widely reproduced and commented upon. It recited "the main complaints of the coloured people," given to him "time and time again," as explaining their preference for the "uncertain existence" of cities and towns to "comparative prosperity upon a farm." I give them in full: "Poor dwelling-houses, loss of earnings each year because of unscrupulous employers, 


\section{A Plantation Experiment}

high-priced provisions, poor school-houses, short school terms, poor school-teachers, bad treatment generally, lynchings and whitecapping, fear of the practice of peonage, a general lack of police protection, and want of encouragement."

Whether or not the really effective causes behind the urban drift observed by Mr. Washington in Georgia are essentially different from those behind migrations from place to place in the Mississippi Delta, we need not stop to inquire. My only suggestion is that not one charge in this comprehensive catalogue was ever laid at our door, yet somehow the fact of local drift and restless movement still remains with us an everpresent reality. And what I say for ourselves I can say likewise for scores of others. I do not say that the complaints recited are not real in some counties of the South. I do assert, however, that they fail to cover the ground. When the friend of the Negro masses would know the whole truth behind the forces which to-day most militate against the material progress of the race, he must go deep below the surface of troubles which the white man can remove or rectify. 


\section{The American Race Problem}

PLANTATION STATISTICS

\begin{tabular}{|c|c|c|c|c|c|}
\hline YEAR. & I 899. & I 900. & I 901 . & 1902. & 1903. \\
\hline Number of families. & 58 & 59 & $6 \mathrm{I}$ & 69 & 75 \\
\hline $\begin{array}{l}\text { Number families leav- } \\
\text { ing................ } \\
\text { Per cent. of total... }\end{array}$ & $\begin{array}{r}26 \\
44.8\end{array}$ & $\begin{array}{l}13 \\
22\end{array}$ & $\begin{array}{r}16 \\
26.2\end{array}$ & $\begin{array}{r}17 \\
24.6\end{array}$ & $\begin{array}{r}31 \\
41.3\end{array}$ \\
\hline Cotton acreage...... & 1,064 & $\mathbf{I}, 048$ & 1.348 & 1,341 & 1,392 \\
\hline $\begin{array}{c}\text { Bales }(500 \text { lbs. aver- } \\
\text { age }) . \ldots \ldots \ldots \ldots \ldots\end{array}$ & 459 & 817 & 1,270 & 1,131 & 741 \\
\hline Lint per acre........ & 215 & 389 & $47 \mathrm{I}$ & 421 & 266 \\
\hline Bales per family..... & 7.9 & I 3.8 & 20.8 & 16.4 & 9.8 \\
\hline Avcrage price, cents. . & 7.50 & 9.94 & 7.90 & 8.08 & $1 \times .77$ \\
\hline $\begin{array}{l}\text { Value of cotton and } \\
\text { seed............ }\end{array}$ & $\$ 21,663.88$ & $\$ 47.541 .66$ & $\$ 60,742.04$ & $\$ 54.593 .26$ & $\$ 53.527 .73$ \\
\hline Value per acre........ & $\$ 20.36$ & $\$ 45.36$ & $\$ 45.06$ & $\$ 40.7 \mathrm{I}$ & $\$ 38.45$ \\
\hline Value per family. ... & $\$ 373.5 \mathrm{I}$ & $\$ 805.79$ & $\$ 995.77$ & $\$ 791.20$ & $\$ 713.70$ \\
\hline $\begin{array}{l}\text { Stock of rentcrs....... } \\
\text { Per cent. of total on }\end{array}$ & 73 & 76 & 89 & 77 & 60 \\
\hline place............. & 94.8 & $85 \cdot 3$ & 78.7 & 64.7 & 47.6 \\
\hline $\begin{array}{l}\text { Cash advanced for } \\
\text { work in tenants' } \\
\text { crops........... }\end{array}$ & $\$ 465.40$ & $\$ 513.90$ & $\$ 856.90$ & $\$ 741.40$ & $\$ 161.80$ \\
\hline Cash for picking...... & $\$ 759.80$ & $\$ 1,536.10$ & $\$ 3,859.55$ & $\$ 4.376 .40$ & $\$ 1,977.65$ \\
\hline $\begin{array}{l}\text { Cash for work and pick- } \\
\text { ing per bale........ }\end{array}$ & $\$ 2.66$ & $\$ 2.50$ & $\$ 3.7 \mathrm{I}$ & $\$ 4.52$ & $\$ 2.88$ \\
\hline $\begin{array}{l}\text { Work and picking per } \\
\text { family.......... }\end{array}$ & $\$ 21.12$ & $\$ 34.40$ & $\$ 77.32$ & $\$ 74.17$ & $\$ 28.52$ \\
\hline Christmas money..... & None & $\$ 375.00$ & $\$ 1,735.35$ & $\$ 473.85$ & $\$ 450.50$ \\
\hline $\begin{array}{c}\text { Additional cash ad- } \\
\text { vanced during De- } \\
\text { cember } . . . \ldots \ldots \ldots\end{array}$ & $\$ 641.59$ & $\$ 2,378.58$ & $\$ 1,871.00$ & $\$ 1,163.95$ & $\$ 1,935.51$ \\
\hline $\begin{array}{r}\text { Total cash balances } \\
\text { and advances during } \\
\text { ginning season.... }\end{array}$ & $\$ 3.077 .22$ & $\$ 12,747.14$ & $\$ 13,899.96$ & $\$ 7.436 .39$ & $\$ 7.566 .34$ \\
\hline $\begin{array}{l}\text { Average per family } \\
\text { during ginning sea- } \\
\text { son } \ldots \ldots \ldots \ldots \ldots \ldots\end{array}$ & $\$ 53.05$ & $\$ 2 \times 6.05$ & $\$ 227.86$ & $\$ 107.77$ & $\$ 100.88$ \\
\hline $\begin{array}{l}\text { Number families rent- } \\
\text { ing......... } \\
\text { Per cent of total. }\end{array}$ & $\begin{array}{r}58 \\
100\end{array}$ & $\begin{array}{r}59 \\
100\end{array}$ & $\begin{array}{r}53 \\
86.8\end{array}$ & $\begin{array}{r}45 \\
65.2\end{array}$ & $\begin{array}{l}36 \\
48\end{array}$ \\
\hline $\begin{array}{l}\text { Rented cotton acre- } \\
\text { age............... } \\
\text { Per cent. of total. }\end{array}$ & $\begin{array}{r}1,064 \\
100\end{array}$ & $\begin{array}{r}1,048 \\
100\end{array}$ & $\begin{array}{l}1,200 \\
89.02\end{array}$ & $\begin{array}{r}884 \\
65.9\end{array}$ & $\begin{array}{r}761 \\
54.6\end{array}$ \\
\hline
\end{tabular}




\section{V}

The Economic Future of the American Negro*

THE FACTOR OF WHITE COMPETITION

MHIS is too broad a subject to be treated compre1 hensively within the limits of this paper. Hence I shall address myself only to what I believe to be the most important question in any practical consideration of the Negro's economic future - the factor of white competition.

I shall not even attempt a discussion of census statistics. Such figures, save in a general way, do not speak for themselves. They must be interpreted. As a result we have a variety of conflicting deductions drawn from the same statistical material. A census volume in some respects resembles the Bible. Each is a repository of truth, and from the one we can fortify almost any economic bias, while from the other we can satisfy any religious opinion we happen to possess. Two courses are open to those interested particularly in this branch of the subject: either to study the mass of data at first hand, and work out one's own conclusions, or accept such findings of others as appeal most strongly to one's judgment or predilections. If I can contribute anything whatever of value

\footnotetext{
* Read at the eighteenth annual meeting of the American Economic Association, Baltimore, Md., December, $x 905$.
} 


\section{I50 The American Race Problem}

to this discussion, I am persuaded it will be by drawing upon those observations and experiences of common life, which, to borrow an idea of Lord Erskine, after all are themselves of the essence of truth.

At the outset of our speculations upon the future of the Negro we are confronted with our ignorance of his present economic status. We are in doubt about even the elementary fact of his present accumulated wealth. Mr. Schurz places it at $\$ 800,000,000$. Mr Edward Atkinson, shortly before his death, accepted a New York World estimate of $\$ 750,000,000$. Mr. Kealing, a coloured authority, claims $\$ 1,000,000,000$. A committee of this association, under the chairmanship of Professor Walter F. Willcox, and including Dr. DuBois in its membership, places the figures at "approximately $\$ 300,000,000$." And after we have agreed upon such figures what do they tell us of the stability and rate, of even the extent, of economic progress? In the answer to this question are involved two widely accepted fallacies: first, that the Negro began life forty years ago with nothing but his freedom; second, that the period of his emancipation has been one of marvellous economic achievement.

It is easy to prove progress if permitted to take zero as our starting point and measure of comparison. Frederick Douglass's plea, that the Negro race be not judged by the heights to which it had attained, but rather by the depths from which it had come, has met with such a response that the acceptance of all it implies has become a cardinal tenet with most of those who 


\section{Economic Future of the Negro ${ }_{\text {I5 I }}$}

discuss the Negro's industrial life. It is both pleasanter and easier to accept this appeal than it is to test its merit. But I take it that we are not willing to flounder about in a maze of speculation, satisfied on the one hand with fulsome eulogies of doubtful achievements, or, upon the other, content to condemn a race to economic servitude without a trial or upon false testimony. If we would know the truth as to where we are, we should at least endeavour to learn how far we have really come. This means a study of the economic status of the Negro in I865, and this I have time only to briefly touch upon.

I merely suggest for your consideration certain facts in this connection, tending to disprove the reiterated assertion of the Negro's pauperism at the time of his emancipation. We seem to overlook the fact that there were half a million free Negroes $(487,970)$ in this country in $x 860$, distributed throughout practically all the states of the union. In their ranks were to be found men engaged in nearly every form of industrial enterprise followed by such persons to-day. Another fact is that the four million $(3,953,760)$ slaves of $x 860$ occupied in $\mathrm{x} 86_{5}$ an apparently impregnable economic position. They furnished a great proportion of the skilled labour of the entire South, and in many parts of it enjoyed an absolute monopoly of this and the field of common labour as well. The evidence as to such conditions is conclusive, but it need not be sought in census reports. It is to be found in the press of the period; in the reported proceedings of Negro industrial 


\section{I52 The American Race Problem}

bodies; in the correspondence of private individuals who went South after 1863 ; in the reports of numerous freedmen's aid commissions and societies; and to some extent in the official reports of agents of the Freedmen's Bureau. It is to be had also in pamphlets and other writings of Negroes themselves. We may not be able to say that in 1865 the race had accumulated a specific number of dollars, though the amount was well into the millions. We cannot do that even in r9o5. We can learn enough, however, to realise that we are only beclouding the truth when we speak of the Negro's economic progress as an achievement of the past forty years. It seems to me, then, that if we seek to measure such progress by present property holdings, it is incumbent upon us to answer the questions, How much has the Negro accumulated during the last forty years? and, How much had he acquired during the preceding hundred and forty?

It is inconceivable that any people who could increase in numbers from four and a half millions in 1860 to nine millions in I 900 could fail also to increase their property during that period. In discussing as something wonderful this very natural increase we lose sight of factors and considerations which must enter into any estimate of the extent to which such increase means genuine and permanent economic racial progress. How far has it been a mere advance along lines of least resistance? In what degree is it indicated by the success of more or less isolated groups, under favourable local conditions? How has this acquisition of property kept 


\section{Economic Future of the Negro 153}

pace with that of others about them, and how far does it represent only the crumbs from the rich man's table? How great a proportion is held by the exceptional few and how much distributed among the masses? How much of the total is traceable to the gifts and bequests of white ancestors? To what extent does this increase mean the holding of their own, or actual, positive progress, in the face of slowly but steadily increasing white competition? In how far is it attributable to the training and steadying influences of the period of slavery? In what proportion do the older and younger elements of the race, respectively, contribute to the total wealth of the whole? These are some of the considerations which must be taken into account, in an estimate of the future based upon something more tangible and stable than the skilful handling of figures or flatteringly expressed sentiments of good will.

The greatest asset in possession of the Negro of 1865 was the great salient fact that at that time, in the section in which he lived, he was practically without the competition of the white man. To-day the most portentous figure that looms upon his economic horizon is that of his white competitor. But even in 1865 he was slowly receding before such competition in the North. To me the most significant utterance at the New York convention of the National Negro Business League in 1905 was the note of warning sounded in Mr. Wanamaker's address. He recalled the fact that Philadelphia once had a number of Negro business men in whom the local business world took pride. But, he 


\section{The American Race Problem}

said, "many of them lost their business before they passed away. As an old business man I am speaking the fact; they lost their business because the Swiss, the Germans, and others who were American white men did that same business better than they did it. Their color had not the least thing to do with it."*

In an address in Brooklyn at about the same time Mr. Samuel R. Scottron voiced the'apprehensions of a thoughtful, courageous man, not dazzled by the outer show of the oft-proclaimed "marvellous progress" of his people. At the same time he gave an insight into the economic position of the Negro in New York half a century ago. He said : "I have hardly to go beyond the years of my own individual experience hereabouts to find cause for grave doubt. Note in this city, which has grown so rapidly that it seems to have been raised by the touch of a wizard's wand, the place in its industrial history that the Negro held forty or fifty or more years ago, the opportunities that were his to build up and to accumulate, and how these opportunities were neglected! This is evidence of a people easily overcome; no, not overcome, but simply retiring without a contest from the places which were not only theirs, but concededly theirs, before the influx of those peoples who represent all that remains of the ancient Greeks and Romans. The Italian, Sicilian, Greek, foreign to America's language and institutions, occupy quite every industry that was confessedly the Negro's forty years ago. They have the bootblack stands, the news-stands, barber-

* New York Age, August 24, r905, p. 2. 


\section{Economic Future of the Negro- 155}

shops, waiters' situations, restaurants, janitorships, catering business, stevedoring, steamboat work, and other situations once occupied by Negroes ; and furthermore, occupy the very houses which were once the homes of Negroes-only the Negro paid rent, while the Italian is now the owner. Look at West Broadway, Lawrence Street, Thompson Street, Sullivan Street, Bleecker Street, West Fourth Street, Thomas, Worth, and Leonard Streets, in New York City to-day, and think of these streets forty, or even thirty, years ago. Look at the ground upon which we now stand, and on the section about one mile square known in early days as Weeksville, after one of our race, named James Weeks. Think of those of our people who occupied all these places when building lots could have been bought for $\$ 25$ and $\$ 50$ and $\$ 100$ each, and look upon the present occupants - Italians. Think of our city's most famous caterers of forty or fifty years ago. They were the Downings, Mars, Watson, Vandyke, Ten Eyck, Day, Green, and others, all coloured. Their names were as familiar and as representative in high-class work as are Delmonico and Sherry to-day. Who have succeeded to the business that these coloured caterers had in those days? With one exception, Italians. Not one has left a child in an enlarged business of the same line. With all of us the business dies with the fathers. Is this showing a capacity to build?"

Again referring to this former Negro quarter he says : "I walked for blocks and blocks recently through that district. I found it strewn with little stores, mainly of 


\section{${ }_{15} 6$ The American Race Problem}

produce, native and foreign ; every store kept by an Italian and scarcely one in which there was not a Negro present as a buyer. One place only was kept by a Negro, apparently, and that was a pool or billiard room filled with young men who were making the echoes sound. The guitar, fiddle, banjo, melodeon, and even piano, were all giving evidence of happiness and contentment amongst our people; but the Italian was doing the business. Certainly these gloomy pictures are not all that the Negro has to show in forty years hereabouts, but it does show that he has by no means taken advantage of the position which he once held. If we were at the top at any time in the past in any line of industry, why are we at the bottom of it to-day? That's the question. In lines concededly belonging to the Negro years ago he has been entirely superseded by the Italian. How far in this direction can we go without getting off the earth entirely? These changes the Negro cannot lay to colour prejudice, surely. Using this as a basis of calculation, what could one say of the 'Future of the American Negro?" "*

Along the same line, an editorial in the leading American Negro newspaper declares that a small Italian colony near New York, under the observation of the writer, had "acquired more real estate and developed more business interests of one sort and another in the past four years than have ten times as many AfroAmericans in the same locality in the past forty years. " $†$

* New York Age, July 27, 1905, p. 7.

†Idem., Jan. 12, 1905. p. 2. 


\section{Economic Future of the Negro 157}

If we go to Chicago, we find the same testimony from another thoughtful and competent observer, Mrs. Fannie Barrier Williams. She writes as follows: "It is quite safe to say that in the last fifteen years the coloured people have lost about every occupation that was regarded as peculiarly their own. Among the occupations that seem to be permanently lost are barbering, bootblacking, cooking, hotel and restaurant waiting, janitors in office buildings, elevator service, and calcimining."

She answers her own question as to the cause of such loss in these significant words: "White men wanted these places and were strong enough to displace the unorganised, thoughtless and easy-going occupants of them. When the hordes of Greeks, Italians, Swedes, and other foreign folks began to pour into Chicago, the demand for the Negro's places began. One occupation after another that the coloured people thought was theirs forever by a sort of divine right fell into the hands of these foreign invaders. This loss was not so much due to prejudice against colour, as to the ability of these foreigners to increase the importance of the places sought and captured. The Swedes have captured the janitor business by organising and training the men for this work in such a way as to increase the efficiency and reliability of the service. White men have made more of the barber business than did the coloured men, and by organisation have driven every Negro barber from the business district. The 'shoepolisher' has supplanted the Negro bootblack, and 


\section{The American Race Problem}

does business in finely appointed parlours, with mahogany finish and electric lights. Thus a menial occupation has become a well organized and genteel business with capital and system behind it."*

As to servant girls in the same city, Mrs. Williams says that white girls prefer to pass by the clerkship, which coloured girls cannot get, and enter schools of domestic science to prepare themselves for trained domestic service, and to fill places scorned by coloured girls though open to them. "It is really alarming," she says, "to look forward to the next decade, when the great changes now going on in the field of domestic science shall have been worked out and developed into a profession. Where will our girls be? Just about in the position of our barbers in the large cities, who have allowed themselves to be forced into the menial service of blacking shoes and brushing the clothes of their former customers." $\dagger$

On the same subject, but in a different part of the country, The Richmond Negro Criterion warns the Negroes that they are losing their hold upon a, to them, vital occupation. It says: "Our young women must take these positions while they can get them. . . . We are told that they (the foreign immigrants) will turn in the direction of the South. When they come, woe, woe to the Negro. His places will be gone, to come no more. The time is fast approaching when domestic employment for females of our race will be as far gone as

* New York Age, June 15, 1905, p. 2.

† Idem, Sept. 28, x905, p. 7. 


\section{Economic Future of the Negro}

that of the barber and those who formerly worked in the factories."*

The New York Age has commented editorially on the fact that Negroes "in the Pullman service are up against the relentless competition which has displaced them to such a disastrous extent in the hotel and restaurant service." It also notes the fact that already they have been supplanted in the dining-car service of some of the Northwestern railroads. $\dagger$ It has been only a few years since an effort was made to supplant the coloured employees of the New York Union League Club. It was an open secret that only traditional and political considerations caused the failure of the movement.

We may go to Kansas and hear the same cry of the disastrous results of white competition. The Topeka bootblacks have been supplanted by Greeks, and the Plaindealer thus accounts for the change: "The Negro is the best bootblack. . . but he studied too much about baseball, policy, craps, etc., and not enough about the comfort of his patrons. He was earning enough to make him feel as though the poeple who patronised him were under obligations to him, and would quit working on a customer to jolly with a bystander." $\ddagger$

From Massachusetts comes the same story, with the addition of other factors inimical to the Negro's future welfare. In a discussion of the economic position of the Negro in Boston, at the South End House, in April,

* Reproduced and endorsed in New York Age, Sept. 28, r905, p. 4.

† New York Age, June 8, 1905, p. 2. Since this paper was read I have seen a news item to the effect that the New York Central Railroad has introduced white waiters on one of its dining-cars.

$\ddagger$ New York Age, May 25, r905, p. 2. 


\section{I60 The American Race Problem}

I 905, Mr. John Daniels said: "There are in Boston today probably ${ }_{15}, 000$ Negroes. The percentage of employment among them is larger than that for the white population as a whole, or for any element of it. This statement, however, is not to be regarded altogether optimistically. In the first place, the figures showing percentage of employment are open to the doubt that most figures of the census are open to. Then even if the figures are correct they go to show how much the Negroes have to work, how severe the economic stress upon them is. This applies especially to Negro women, among whom the percentage of employment is twice as great as that among the whites." "It is not a thing to rejoice over," continues Mr. Daniels, "but a thing to be regretted, that so many Negro women have to work. Turning now to the kinds of work the Negroes are engaged in, we find the majority of them engaged in the meaner sorts of labour, unskilled labour, for the most part, and commanding only the pay of unskilled labour. We find very few of them in the handicrafts of the trades. The problem then, is not so much to get more work as to get better work." At the same meeting the Rev. Henry J. Callis, a coloured minister, made the statement that to-day in the city of Boston "not a single Negro church building is owned by its congregation."*

We have the same testimony on the condition of the Boston Negro as regards domestic service that is so abundant on the question of his practical exclusion from the trades and handicrafts. The Bulletin of the

* New York Age, May 4, 1905, p. I. 


\section{Economic Future of the Negro 16r}

Inter-municipal Committee on Household Research is authority for the statement that the Boston Reform League has been unable to secure an equal chance for coloured girls in obtaining employment, and cannot secure places for more than half who apply. We are told that "Negroes who specialise in house work duplicate the experience of a coloured butler for whom the League tried for three months to find a place, but without success. He was neat in his person and good looking, and was highly recommended. He stated that he had answered, in all, two hundred advertisements, but he was invariably refused the position simply because he was a coloured man. It is not surprising, therefore, that on leaving Boston to return to New York, he said: 'These Boston people beat me. They will have massmeetings and raise money to help Mr. Washington educate the "niggers" down South, but they will let a decent Northerner starve before they will give him a chance to earn an honest living.' "*

Dr. William N. DeBerry, for five years pastor of a coloured Congregational church in Springfield, Mass., has made an interesting study of the general condition of his people in that city. I cannot go into the details of his report, but he speaks in very plain language of the effects of "prejudice and ostracism," "intense antipathy," and kindred race feeling. He does not try to minimise the faults of the Negro, but speaks frankly of "the malady of disunion," "bitter intolerance and strife" in their religious bodies, and of "the worth-

* Bulletin. New York City, May, 1905, p. 15. 


\section{The American Race Problem}

less element, with no visible means of support." It is to the economic feature of his report that I wish to call your attention. He found on January I, I905, a Negro population of 1,253 , with 375 men and 533 women. He enumerates the number of these in each occupation, and asks the question: "Why is it that 86 per cent. of the coloured labour in this city is confined to the lower strata of industry?" His answer is that the large number who "are fitted for other occupations are debarred by pure race prejudice." "Three hundred and twenty black men out of 375 ," he continues, "are confined to certain servile types of employment in Springfield, not because they are all unfit for anything higher, but because race prejudice has closed the door of industrial opportunity against these men as a class. But they continue to knock daily at this closed door and plead only for the chance to fill such places as are open where the service they can render is in demand." $\mathrm{He}$ says they only ask "that as a class they may be emancipated from the merciless industrial ostracism which shuts out the capable and worthy Negro because God chose to create him black. . . . That for which they most earnestly plead at the hands of their more favoured fellow citizens is merited industrial opportunity." And Dr. DeBerry says that his study should be "of more than local significance, inasmuch as the situation here in Springfield is fairly typical of the black man's condition throughout the North."*

\footnotetext{
* Springfield Weekly Republican, Feb. xo, 1905. I am indebted to Dr. De Berry for a copy of his report.
} 


\section{Economic Future of the Negro ${ }_{1} 6_{3}$}

Generally, throughout the North, as Dr. DeBerry tells you, the story is the same. With variations of detail we find practically the same situation presented in New York, Chicago, Boston, Philadelphia, Springfield, and sections of New Jersey, Ohio, Indiana, Kansas and the Northwest. The Negro has lost ground. In a plea for industrial education and opportunity, Booker T. Washington says: "No one can fully appreciate what I am saying who has not walked the streets of a Northern city day after day seeking employment, only to find every door closed against him on account of his colour, except in menial service."* We need hardly seek for further cumulative evidence on a fact now admitted by all save the ignorant; viz., that in the Northern section of our country, with all its wealth, with all its splendid industrial achievement, with all its promise to the child of the white man, the door of economic opportunity is closed before the faces of the masses of the Negro race, even though it reluctantly yield to the knock of the chosen few.

There seem to be two contributing causes to this situation: inefficiency, unreliability, and lack of thrift upon the part of the Negro, and prejudice upon the part of the white man. I shall not attempt to weigh the one against the other, to see where the greater responsibility lies. Upon the statements of eminent Negro authorities their people have themselves to blame certainly in very great measure. I can hardly believe that any considerable body of labouring men, regardless

* "Future of the American Negro," p. 76.

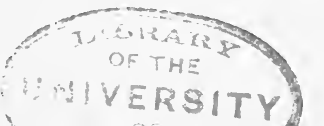




\section{The American Race Problem}

of colour or race, anywhere have ever been successfully and permanently deprived of their opportunities by any other body of men, unless the latter proved themselves the more competent to do the work sought by the two.

It would seem then that it is to the South that the Negro masses must look for their economic salvation. As I have quoted Booker T. Washington on the Northern situation, I may quote him now on the Southern. Of the latter he says: "Whatever other sins the South may be called upon to bear, when it comes to business, pure and simple, it is in the South that the Negro is given a man's chance in the commercial world."* Again, he says: "It has been my privilege to study the condition of my people in nearly every part of America; and I say, without hesitation, that, with some exceptional cases, the Negro is at his best in the Southern states." $\dagger$

For some years I have attempted to study the social and economic relations between white and black races wherever they come in contact, but have not amalgamated, as in this country, some of the West Indies, Africa, and Australia, and I have only to confirm Mr. Washington's opinion. To me it seems that the plainest fact to-day confronting the Negro is that there is but one area of any size in the world wherein his race may obey the command to eat its bread in the sweat of its face, side by side with the white man. That

* Up from Slavery, pp. $219,220$.

$\dagger$ "Future of the American Negro," p. 202. 


\section{Economic Future of the Negro ${ }_{165}$}

area is composed of the Southern United States. I cannot go into details and sift the evidence for you. You may find it in the observations of travellers, distinguished and obscure, in the writings of resident and foreign historians, economists, and sociologists, in the complaints of the black man and his friends, in the enactment of laws and the recorded operations of prejudice. The evidence is voluminous, and it seems to me conclusive, that only in the land wherein for so many years the world has been taught to believe that "the white man despises manual labour," may the black man work by his side.

Washington says that "wherever the Negro has lost ground industrially in the South, it is not because there is prejudice against him as a skilled labourer on the part of the native Southern white man."* This absence of prejudice applies in the case of the skilled white Southern labourer as well as in the case of the employer of such labour. This is not difficult to account for. Here is where the Negro profits by the drawing of the general Southern colour line; through this and the obliterating effect of generations of contact upon what would elsewhere seem to be natural repugnance to physical association. The white mason and carpenter work side by side with the Negro because they know that that line exists for them just exactly as it does for the lawyer or doctor. The Negro recognises that the white man is not lowered one particle in the estimation of the community because of his occupation. Each

" "Future of the American Negro," p. 78. 


\section{The American Race Problem}

knows that the status of the other remains unchanged the Negro is still a Negro, the white man still a white man.

In a country where lines are drawn between races this has its significance; in one where the line is not racial, but is drawn between occupations, or depends upon wealth or other conditions, it would have no such significance. Mr. Bryce speaks of race feeling and the drawing of the colour line in South Africa. He relates the incident of a white man accepting employment under a native of means, but only on condition that the latter call him "boss." This may have been incomprehensible to $\mathrm{Mr}$. Bryce, but a Southern man would have known what was going on in the white colonist's mind. It is my explanation over again. As long as he had verbal evidence that the native Negro still recognised the racial difference between them, that one was still white and the other still black, he had no objection to the altered outward relation.

But while we may be interested in this, as in any other abstract racial phenomenon, for the Negro the cause of the condition is of less importance than is the duration of the condition itself. How long will it be before the Northern attitude impresses itself upon the Southern racial industrial situation, or the Northern situation is reproduced in the South? This is difficult to answer, but we may see two principal causes operating in this direction. One of these is the general spread of trade unions in the South, the other is an increasing demand for better industrial service than the South hitherto has been satisfied with from the Negro. 


\section{Economic Future of the Negro $\quad{ }_{167}$}

As to the second of these influences a discussion which throws some light upon the Northern situation is also suggestive of the probable course of Southern people, if they should ever awaken to a realisation of the difference between competent and incompetent service. Speaking of the disastrous loss of employment by the Boston Negro, Mr. Archibald H. Grimke, of that city, states that it is not due entirely to prejudice, though he says that "all things being equal, the average Northern white man prefers to be served by waiters of his own race and colour." He says: "The battle for employment, for bread, has gone against us as a race at these three points in the domestic and hotel service of Boston. At one point our service body has been almost wiped out, while in the others we are yielding ground, and have been doing so for years, before aggressions of white servant bodies." Summing up the various causes behind this loss, he says: "The coloured coachman got a black eye when people began to travel abroad and to discover in England, for instance, how much more an English coachman knows about horses and their care than a coloured one in Boston. The English coachman not only knows how to sit on his box and hold the ribbons with style, but he is a master of horse lore. He keeps abreast with up-to-date methods and utilities in his world. $\mathrm{He}$ is, in fact, a horse doctor of no mean attainments and skill. $\mathrm{He}$ has fitted himself to do his work not in one line only but in an all-round way. And as the coloured coachman was inferior to him in this respect, he had only to 


\section{The American Race Problem}

come and see and conquer wherever he and his coloured competitor engaged each other in the struggle for employment, for bread." *

Apropos of horses and coachman, it may be remarked that another striking loss suffered by the Negro is in the almost total displacing of the coloured jockey by the white within the last twenty years.

Among Southern men who patronise barber shops there are the fewest number who will go to one conducted by Negroes after having once tried "white shops." This is true despite the deep-rooted general Southern prejudice in favour of the Negro for all forms of personal service. What is true in the case of the barber is likely to be repeated in other lines of work, more or less associated, when Southern people begin to learn, as the Northern did long ago, that the Negro is not the only race on earth engaged in such occupations.

The opposition of the union is as old as the freedom of the Negro, but it is difficult to measure the rapidity of its progress. Mr. Washington declares that the absence of industrial prejudice at the South furnishes "the entering wedge for the solution of the race problem." "But too often," he says, "where the white mechanic or factory operative from the North gets a hold the trade union soon follows, and the Negro is crowded to the wall." $\dagger \mathrm{He}$ candidly acknowledges that in no part of the South is the Negro "so strong in the matter of skilled labour as he was twenty years ago."

* New York $A g e$, October 5, r905, p. 3.

$\dagger$ "Future of the American Negro," p. 79. 


\section{Economic Future of the Negro 169}

We need not be surprised that so far seeing a man watches with what we may well believe is genuine apprehension the slow but steady encroachment of Northern white men and foreigners upon the Negro's ancient Southern stronghold. Nor to hear him reiterate, time and again, such expressions as those in an address before the American Academy, in Philadelphia, last February: "In many respects," he said, "the next twenty years are going to be the most serious in the history of the race. Within this period it will be largely decided whether the Negro is going to be able to retain the hold which he now has upon the industries of the South or whether his place will be filled by white people from a distance."**

A few years ago I happened to be in the office of a leading contractor in my town when he was discussing the erection of a local cold storage plant with a representative of a Chicago packing house. The Chicago man broached the question of the kind of labour to be used on the building. The contractor told him, as a mere matter of course, that it would be Negro labour, as practically his entire force was so constituted. The Chicago party said that if this got back home all the carpenters they had from Chicago to Omaha would strike. The contractor replied that we had no labour unions, that he employed whom he pleased, and that it was Negro labour or nothing. Suppose such a situation should arise in a Northern town, if indeed enough Negro carpenters could be found to make it possible.

\footnotetext{
* Same language in "Future of the American Negro," p. 75.
} 


\section{I70 The American Race Problem}

The result would be the discharge of the coloured carpenters. How long will it be before the same story shall be told in the South?

There is evidence that the tide of industrial ostracism of the skilled Negro is turning southward. After the great fire in Baltimore I was somewhat curious to see the part which the eighty-odd thousand Negroes in its population would take, or be permitted to take, in its rebuilding. During the twelve months following the fire I visited Baltimore a number of times, and on each occasion spent considerable time in research work in the burned district. I was hunting for a Negro mason, or carpenter, or plumber-but if he was there, I failed to discover him. And yet labour had been draughted for this emergency work from every city in the North and East. I found him only as a hod carrier, or employed in wheeling away debris. In Washington last March I watched the erection of a great platform on the east plaza of the Capitol, with a seating capacity of five thousand people. Upon it was to stand, while taking the oath of office, the man who more than any other recent American has been held in the public eye as the exponent of the square deal for the Negro as well as for the rest of us. Yet in all that work no Negro found employment, save in some menial capacity.

How far this movement shall extend before it is arrested, or whether or not it will ever be arrested at all, are questions upon which I shall not stop to speculate. Perhaps your own conclusions may be aided 


\section{Economic Future of the Negro}

somewhat by those of the best living authority on American Negro statistics, carefully and conservatively stated as they are, for the decade ending with rgoo. In stating the loss and gain of the Negro in industrial pursuits during this period, Professor Walter F. Willcox thus closes the account: "He has lost ground in the South as a whole in the following skilled occupations: carpenter, barber, tobacco and cigar factory operative, fisherman, engineer or fireman (not locomotive), and probably blacksmith. He has lost ground also in the following industries in which the degree of skill implied seems somewhat uncertain: laundry work, hackman or teamster, steam railroad employee, housekeeper or steward." "The balance seems not favourable," he says. "It suggests that in the competition with white labour to which the Negro is being subjected he has not quite held his own."*

If we may predict with reasonable certainty anything whatever of the future of the Negro, it seems safe to lay down the elementary proposition that the home of the masses of the race must remain in the Southern states, and that their destiny must be worked out upon the soil. Their wisest leaders apparently are in accord upon this point. Says Mr. Washington: "More and more each year, I feel that . . . the salvation of my race will largely rest upon its ability and willingness to secure and cultivate properly the soil." $\dagger$

The field of the Negro's activities thus becomes

* pp. 493-494

† Annual Report, May 30, I901, p. 8. 


\section{The American Race Problem}

doubly circumscribed, and the fixing of his hold upon that field ceases longer to remain a mere question of expediency and wisdom. It becomes a matter of vital moment and racial concern. It is here that the masses will have to meet the crucial test of the future. Here, in the field that has been the Negro's for so many generations, I believe is to be witnessed some day the ultimate economic struggle in America between the Negro and the white man. Mr. Washington says that he does not believe that "the masses of coloured people are yet fitted to survive and prosper in the great Northern cities to which so many of them are crowding. The temptations are too great," he says, "and the competition with the foreign population, with which they there come in contact, is too fierce."* The tide of immigration is turning slowly southward, and in my judgment the competition of the cities of the North is to be repeated in Southern fields. Mr. Washington sees this coming, if I read his words aright, for he thus warns his people: "If we neglect to occupy the field that is now before us in the South, it will become there as it is in the North - we will be excluded by those who are strangers to our tongue and customs." $\dagger$

More than twenty-five years ago Frederick Douglass took the so-called Kansas exodus of Southern Negroes for the text of an exultantly boastful address on the dependence of the South upon the Negro. His words and predictions are of peculiar interest now, as a sort of

* Charities, October 7, 1905, p. 19.

†Idem, p. 7. 


\section{Economic Future of the Negro}

warning to sociologists to avoid the shoals of prophecy. "Only a few years of non-tillage," he said, "would be needed to give the sunny and fruitful South to the bats and owls of a desolate wilderness. From this condition, shocking for a Southern man to contemplate, it is now seen that nothing less powerful than the naked iron arm of the Negro can save her. For him as a Southern labourer, there is no competitor or substitute. The thought of filling his place by any other variety of the human family will be found delusive and utterly impracticable. Neither Chinaman, German, Norwegian, nor Swede can drive him from the sugar and cotton fields of Louisiana and Mississippi. They would certainly perish in the black bottoms of these states if they could be induced, which they cannot, to try the experiment. . . . Hence it is seen that the dependence of the planters, land-owners, and old master-class of the South upon the Negro, however galling and humiliating to Southern pride and power, is nearly complete and perfect. . . . He stands to-day the admitted author of whatever prosperity, beauty, and civilization are now possessed by the South, and the admitted arbiter of her destiny."*

* "Life and Times," Hartford, r88r, pp. 437 and 438 . In its immediate contrast to this statement of Frederick Douglass, the following, which I am permitted to quote from a personal letter from Professor Willcox, is interesting and significant: "Perhaps you have noticed the rapidity with which the Italians have been getting into the sugar cane districts of Louisiana. My attention was called to it to-day by noticing the statement in the report of the Industrial Commission that 'the Italians of those states (Mississippi and Louisiana) are rapidly dislodging the Negroes from the sugar cane plantations.' I have picked out the five parishes of Louisiana each of which had more than 20,000 acres in cane in 1899 . These five had 54 per cent. of the total sugar cane area of the state. In 1890 they included 960 Italians, or 12 per 


\section{I74 The American Race Problem}

About twelve years after this dogmatic proposition was enunciated I had occasion to investigate the condition of a few Italian families living in my section of Mississippi. This is a region which for years was considered the Negro's impregnable stronghold, the one place, indeed, wherein his freedom from competition and the white man's dependence upon him were as absolute as Douglass imagined. Before this my attention had been attracted by a reference of John Stuart Mill to the achievements of the Italian métayer. I, too, wrote an article and indulged in a little prophecy. As the latter happens to have been verified, I am willing to resurrect it. It was that within fifteen or twenty years we would see the white man's ability to more than successfully compete with the Negro in the latter's strongest field demonstrated through the medium of the peasant farmers of Italy. My prediction was ridiculed by newspapers, North and South, and even many of my friends thought I was indulging in impossible theorisings. For Douglass's idea, not mine, was the popular one. It has been the curse of the South for a hundred years that her people have clung tenaciously and stubbornly to a conviction, never reasonable or well founded, that Negro labor was essential to the cultivation of her soil. Douglass simply gave expression in

cent. of the total number in the state. In r 900 they contained 5,007 Italians, or 29 per cent. of the total number in the state. In each parish also the per cent. of Negroes in the total population decreased, and in four out of the five decreased more rapidly than the average for the whole state." The parishes in question are St. Mary, Lafourche, Assumption, Terrebonne, and St. James. It is somcwhat curious that in enumerating the various people who could not compete with the Negro in the South Douglass should have overlooked the Italian. 


\section{Economic Future of the Negro 175}

offensive and exaggerated terms to a belief which in its essentials had for years been a tenet of Southern political and economic faith.

No wisdom was necessary to such a forecast as I made. Common sense, an acquaintance with what the Italian agriculturist had accomplished at home under a far less favourable natural environment, and a long and intimate familiarity with the Negro farmer - only these were required. No great credit may be claimed for simply pointing out the probable outcome of a contest between thrift and improvidence, between steady, continuous, intelligent labour, and the mere brute strength of the Negro's "naked iron arm," spasmodically and shiftlessly applied. Do not understand me as suggesting that any sudden revolution in Southern agricultural and industrial conditions is about to take place. Thousands, I might say hundreds of thousands, of Southern white men prefer the Negro, under any and all circumstances, to any class of white labour. The problem for the Negro is a larger one than that; it is whether in the years to come he is to acquire his share of the soil; whether he or the white man is to bring and hold under the subjection of the plough the millions of now undeveloped acres of the South; whether in the progress of what seems destined to be one of the greatest economic developments America or the world has seen, he is to play the part of an active, forceful, dominant, contributing factor and beneficiary, or is to be a mere hewer of wood and drawer of water, content with felling the trees for others to reap the reward. We are now 


\section{I76 The American Race Problem}

merely at the insignificant beginning of a movement of the years, the very opening of a struggle between white and black in which there will be no element of sentiment, where sympathy will have no place, where the Negro will be called upon to prove his right to live, or accept the consequences of failure - where "success" will be "equality's" one and only test. The contest will not be in the slums and alleys of the city. It will be fought out in the open field, under the sun and upon the soil where the world may look on.

It is only in the last few years that we have begun to approach such questions as the one before us with a determination to sift the evidence with the sole object of learning the truth. In consequence, as yet we have little comparative data at hand, and few widely separated local studies, upon which to base safe conclusions. We have a great deal to learn along this line, and sweeping generalisations are worth but little when it comes to testing the economic efficiency of a race. But in the light of what we know of the results of competition along industrial lines, we may be justified in hazarding a few speculations as to the outcome of such a contest in the field of agriculture.

Professor Willcox properly says that the most important occupations for Negroes are those of "agricultural labourers, farmers, planters and overseers, and labourers not specified." These occupations "include two-thirds of all the Negro breadwinners." Some light is thrown upon the matter of competition along these lines by Professor Willcox's statement that the Southern Negroes so 


\section{Economic Future of the Negro}

occupied "increased between 1890 and I 900 by 30.4 per cent., the Southern whites in the same occupations increasing in the same period by 43.5 per cent. As a result, the non-Caucasians constituted in I 89044.4 per cent. of the population in these classes, while in 1900 they constituted 42.0 per cent."* While such figures would seem to indicate that already the white agriculturist is gaining on the Negro numerically, they furnish no warrant for assuming that the Negro's position is thereby necessarily seriously threatened. They tell us nothing of the comparative efficiency of the two classes - one of the most important tests by which to measure the probable outcome of competition.

The President of the Mississippi Agricultural and Mechanical College has contributed something toward assisting us in forming an opinion on this matter of efficiency in a study of conditions in several Mississippi counties. "Lowndes county, with three Negroes to one white man, having 21,972 blacks and 7,I2I whites, requires 3.I 5 acres to make a bale of cotton, while Jones county, with three whites to one Negro, having 13,156 whites and 4,670 blacks, requires 1.98 acres to make a bale. The farm lands of Jones county are valued, as found in the census reports, at $\$ 2.85$ an acre, and the farm lands of Lowndes county are valued at $\$ 9.83$ an acre. Yet the poor lands of Jones county, under intelligent cultivation, produced nearly twice as much per acre as the rich lands of Lowndes county when cultivated mostly by Negroes. Noxubee county, with more

\footnotetext{
* p. 489
} 


\section{The American Race Problem}

than five blacks to one white, having 26, 46 blacks and 4,699 whites, requires 3.50 acres to make a bale of cotton, while Union county, with three whites to one black, having I 2,380 whites and $4, \mathrm{I}_{42}$ blacks, requires only 2.56 acres to make a bale. The farm lands of Noxubee county are valued at $\$ 7 . \mathrm{I} 2$ and the lands of Union are valued at $\$ 4.8 \mathrm{r}$. Hinds county, with three Negroes to one white man, having 39,52 I blacks and I3,037 whites, requires 2.50 acres to make a bale, while Perry county, with more than two whites to one Negro, requires only I.96 acres to make a bale. The farms lands of Hinds are valued at three times as much as are those of Perry. In the counties of Leflore, Bolivar, and Washington, where they have about eight Negroes to one white man, but almost without exception the Negroes are under white managers, they make one bale to every acre and a-half, while in Lowndes, Noxubee, and Monroe, where not many white managers are employed, they make on an average about one bale to three acres. While this difference is partly caused by a difference in the fertility of the two groups of three counties, yet the principal reason is the superior intelligence used in the management of the first group. This is proved by the fact that in every comparison made between a white county and a black one the black was the most fertile, yet the white was nearly twice as productive."*

The necessity and effect of some form of white supervision of Negro farm labour, as alluded to by President

\footnotetext{
* Professor J. C. Hardy in "The South's Supremacy in Cotton Growing," p. 9, Manufacturers Record Publishing Company, Baltimore Md,
} 


\section{Economic Future of the Negro 179}

Hardy, are now recognised throughout the South, whereever such labour receives from white merchants or planters advances of cash or supplies. Many thousands of Negroes who appear in a census enumeration as "farmers" really work under the constant and immediate supervision of a plantation owner or manager. Thousands of others, similarly enumerated, are under either the general and occasional supervision of a "riding boss" or some other form of crop inspection. A number of years of observation, and a correspondence covering the entire cotton belt, satisfy me that such supervision is steadily becoming more generally recognised as a necessary incident to the business of advancing to, or operating with, Negro labour.

Mr. Kelsey, in his very valuable monograph thus alludes to this system : "The landlord and the advancers have found it necessary to spend a large part of their time personally, or through agents called 'riders,' going about the plantation to see that the crops are cultivated. The Negro knows how to raise cotton, but he may forget to plough, chop, or some other such trifle, unless reminded of the necessity."* I recently asked a friend who has lately begun to introduce Italians on his plantation, in what particular respect he most preferred them to Negro labour. His reply was: "I don't have to spend my life in trying to make them work. After the first year I don't even have to show them what to do."

As in this paper it is the white immigrant, and more

" "The Negro Farmer," p. 30. 


\section{I80 The American Race Problem}

particularly the Italian, whom I have in mind as the possible competitor of the Southern Negro, I have been to considerable pains in personally investigating the efficiency and general economic condition of the largest group of cotton growing Italians which I have been able to discover. This probably is the most important experiment of its kind in the South - for the reason that it is not only the largest but also the oldest - and, further, because it has been the subject of a great deal of discussion. Repeatedly it has been pronounced a failure by men and writers who could have had no firsthand information concerning it. I have reference to the colony at Sunny Side, Chicot County, Arkansas, on the Mississippi River, between Memphis and Vicksburg, and nearly opposite Greenville, Miss.

I need not go into the details of the early history of this experiment. It is enough to say that it had its inception in the plan of the late Austin Corbin, of New York, to sell to Italians a large body of cotton land in Arkansas. Through no fault of Mr. Corbin's the Italians sent over as purchasers consisted of families representing a number of heterogeneous occupations, instead of being taken solely from the farming class.

If I were to attempt to make a cotton crop in Mississippi with a lot of Negro oyster shuckers gathered along the Maryland and Virginia coasts, failure would be stamped upon the experiment before it was forty-eight hours old. Italian fruit venders, cobblers, and organ grinders are no more farmers than are Negro oyster shuckers. There may have been incidental faults of manage- 


\section{Economic Future of the Negro i81}

ment also, but they do not concern us. Mr. Corbin died, and his experiment was pronounced a failure. One more prop had been placed behind the wall of the American superstition of the eternal and necessary conjunction of a Negro and a mule for the production of a bale of cotton.

Of those families who left some went in one direction, some in another. A number of them settled about seventy miles from Fort Smith, Ark., and founded what is now the flourishing and growing colony of Tontitown. In 1898 a business arrangement was entered into between the Sunny Side Company and Messrs. O. B. Crittenden \& Co., cotton factors, of Greenville, Miss., and the active management of the property passed into the control of experienced resident cotton planters. These gentlemen were business men, pure and simple, and with them the whole matter was, and is, solely a business proposition. They knew nothing of the Italian and cared nothing, from any sentimental or altruistic standpoint. They were not engaged in an attempt either to solve the problem of the distribution of our foreign immigration, or to relieve the congestion of New York tenement districts. I doubt if any member of the firm had ever read "How the Other Half Lives." On the other hand, they did know a great deal about the plantation Negro. But neither were they engaged in any philanthropic experiment in this line. They simply took the two as they found them, without favour or prejuidce on either side - save some misgivings as to the remnant of Mr. Corbin's "Italian experiment."

The number of Italian squads in 1898 was 38 , with 


\section{The American Race Problem}

200 working hands, cultivating $r, 200$ acres of cotton. Of Negro squads there were 203, with 600 working hands, cultivating 2,600 acres of cotton. At the end of I 905 , after eight years, there are on the property 107 Italian squads, with 500 working hands, and 38 Negro families, with 175 working hands - an increase of 69 squads and 300 hands for the Italians, a decrease of r65 squads and 425 hands for the Negro. The total cotton acreage has increased to 3,900 , of which the Italians are cultivating 3,000 acres and the Negroes 900. This bare statement of numerical loss and gain is of itself pregnant with meaning. It becomes doubly significant when we analyse the operations of the period under investigation. Beyond the number of families, hands, and acreage, the details for 1898 are not available. As the year's business for 1905 is not yet closed, I shall eliminate it also. This gives us a six-year period for a comparative exhibit of the two classes of labour, working literally side by side, their land indiscriminately allotted, each on the same tenure, each under the same conditions of soil, climate, and management. I shall confine this exhibit to the salient features of the operations. These are the number of families and hands, cotton acreage and production, and value per hand. I shall consider only the cash commodities of cotton and seed, and shall reduce the figures to annual averages.*

\footnotetext{
* For the privilege of securing this and other data concerning the operations of this property, I am greatly indebted to Messrs. O. B. Crittenden \& Co., of Greenville, Miss. My thanks are also due Mr. J. B. Ray, bookkeeper, and Mr. Shelby Wright, manager, Sunny Side, Ark., and to my partner, Mr. Julian H. Fort, Dunleith, Miss. Without their generous coopperation this study could not have been made.
} 


\section{Economic Future of the Negro $\quad{ }_{183}$}

This gives us the following results: Average number of squads, Italians 52 , Negroes 167 ; average number of working hands, Italians 269, Negroes 433; average number of acres per working hand, Italians, 6.2, Negroes 5.I; average pounds of lint per hand, Italians 2,584, Negroes I, I 74; average pounds of lint per acre, Italians 403, Negroes 233; average cash product value per hand (cotton and seed), Italians $\$ 277.36$, Negroes \$1 28.47; average cash product value per acre, Italians $\$ 44.77$, Negroes $\$ 26.36$. Thus the Italian is seen to have produced more lint per hand, by I,4 IO pounds, or I20.I per cent., and to have exceeded the Negro's yield per acre by I70 pounds, or 72.9 per cent. The difference in money value in favour of the Italian was \$r 48.89 per hand, or II 5.8 per cent., and $\$$ I $8.4 \mathrm{I}$ per acre, or 69.8 per cent.

It is apparent that in the matter of the showing of production per hand the Italian had the advantage of the Negro by reason of the fact that his average exhibit is for a smaller number of hands. But he worked 6.2 acres per hand as against 5.I acres for the Negro, and produced I 70 pounds more lint per acre. It must also be borne in mind that the Negro was cultivating a crop with which his race has been familiar for generations, while the Italian had never seen a stalk of cotton before coming to America only a few years ago. Until shown, they did not even know the difference between the plant they were to save and the weeds they were to cut out in the process of cultivation. But notwithstanding the difference between the two in point of efficiency, 


\section{The American Race Problem}

a difference which is no longer a matter of controversy where the two are practically known, the vital difference is to be found in the story which each has to tell from year to year and season to season.

To state it bluntly and coldly, it is for the Negro a recital of conditions as old as his freedom: too much time spent out of his crop, and away from his work; too much waiting for the weather to improve; too much putting off to a more convenient season; a too constant and too successful besieging of those in authority for money accommodations and supplies; too little reckoning against the future day of settlement; too much "leaning on the Lord," and too little upon himself, in things not spiritual; too much living for to-day and not enough for to-morrow. With the Italian it seems to be simply a grim determination to have more at the end of this year than he had at the end of last, regardless of weather or price; to wrest from every square foot of the soil he rents all that nature can be forced to yield; to get a visible, tangible return for every dime and hour he spends; to live on less than he makes, whether the latter be much or little; to hire nothing done that he can do himself; to keep the future ever in mind, and to lay by a store against age and a rainy day.

Let a few typical accounts speak for themselves. A Negro with three grown working hands in his family cultivates nineteen acres and has an account of $\$ 750.58$. He makes $\$ 506.80$ worth of cotton and seed, and owes a balance of $\$ 243.78$. He made only 230 pounds of lint 


\section{Economic Future of the Negro $\quad 185$}

per acre, or $\mathrm{I}, 460$ pounds per hand, but even this would have left him in fair shape but for his account for supplies and extra work in his crop. These items alone amounted to $\$$ I r.98 per acre, or $\$ 75.96$ per hand. On the other side of a "turn row" we have an Italian with three working hands, two grown and one a child, working 20 acres. They owe a balance of \$139 for transportation from Italy, and their total account for the year is $\$ 394.54$. Of this they owe not one cent for help in their crop, and their supply bill is $\$ 3.17$ per acre, or $\$ 2$ I.I 4 per hand. They make $\$ 804.25$ worth of cotton and seed, and have a cash balance of $\$ 409.7 \mathrm{r}$. The essential difference, I believe, lies in their accounts. They will not hire work done for them where they can possibly avoid it, but when it does become necessary, they will exert every effort to make enough themselves by outside work at convenient times to offset what they hire.

Take the account of a Negro who paid his current debts and had a balance. He had three grown hands, cultivated twenty-five acres, and made $\$ 730.20$ worth of cotton and seed. His account was $\$ 67$ r.26, leaving him a balance of $\$ 58.94$ above his account. His supply bill amounted to \$13.I2 per acre and \$109.37 per hand. His yield of lint was 253 pounds per acre and 2, 106 pounds per hand.

Near by an Italian with four grown hands and two children demonstrated the possibilities of "intensive farming" on alluvial land by working only twenty acres with his extra large force. He produced 685 


\section{I86 The American Race Problem}

pounds of lint per acre, while his yield per hand was only 2,283 pounds - but little more than that of the last mentioned Negro. His account was $\$ 543.35$, and his crop brought $\$ \mathrm{r}, 596$, leaving a balance of $\$ \mathrm{I}, \mathrm{r} 42.65$. In contrast to this we have another group of Italians, with the same force as the one just mentioned, four grown hands and two children, working more than twice as much land. They had forty-three acres, and made 437 pounds of lint per acre, and 3, 355 pounds per hand. This squad has been on the place several years, and is reputed to have accumulated more than $\$$ I $_{5}, 000$ in cash. It goes without saying that they owed no supply account. Their other account, rent, ginning, etc., amounted to $\$ 426.66$. Their crop brought $\$ 2$, I 72 .10, leaving a net balance of $\$ 1,745.44$.

The first of these two squads illustrates what may develop into a tendency of considerable sociological importance. This is the withdrawing of their women and children from regular field labour as soon as the step is warranted by an improved economic condition. Here and there this is being done, though in no case until the stage in which their labour is necessary has been passed. It is frequently true that although women and children are included in the statement of working hands, they merely assist at intervals, according to the necessities of the crop. Any forecast here would be gratuitous, but it is not unlikely that after a single decade any large group of Italian agriculturists would make a much better showing in this regard than either the Negro farmer or the Southern white mill operative. 


\section{Economic Future of the Negro 187}

No large class of our population can make substantial social progress as long as its women and children are compelled to play the rôle of breadwinners in the field of manual labour. I have seen Italian families disembark in my town from New Orleans fruit luggers, and within ten to fifteen years pass through all the gradations of peddlers, oyster dealers, and restaurant keepers, and finally emerge as prosperous merchants and property holders. In every instance the women did their share of the drudgery as long as it was necessary, bui eventually became only the mistresses of their homes. The point of the matter is that there is not one Italian fruit vender in the town who is not to-day striving to emulate the successful examples of his fellows. I do not believe the Italian agriculturist is different in this respect from his urban brother.

To again glance at their accounts. Here is an Italian who worked nineteen and one-half acres with two grown hands and two children. He has practically the same acreage and force as that of the Negro first mentioned above. The Negro had three grown hands, and nineteen acres. The difference between the results of the year's work for the two was due more, probably, to the fact that the Italian contracted no supply account than to their respective crops. The Italian made 488 pounds of lint per acre, which was more than double the Negro's yield. But his 1,586 pounds per hand was only I 26 pounds more than the Negro's I,460. But the Negro's account for supplies and extra work amounted to $\$ 75.96$ per working hand, while the Italian 


\section{I88 The American Race Problem}

has no such account at all. The Italian's account, all told, rent, etc., was only $\$ 2 \mathrm{I} 6.8 \mathrm{I}$, while his crop brought $\$ 1,096.15$. He thus had a net balance of $\$ 879.34$.

I believe the difference is to be found in their accounts as well as in the character of their work. Of course, with a greater production there is room for heavier accounts, if the tenant sees fit to gratify his wishes. But I know it to be a fact that even with his present degree of efficiency, the Negro could very greatly improve his condition if he would constantly try to keep his account down as the Italian does, instead of continually seeking to gratify his wishes and whims with a blindly fatalistic disregard of the future. In a plantation experience of more than twelve years, during which time I have been a close observer of the economic life of the plantation Negro, I have not known one to anticipate the future by investing the earnings of one year in supplies for the next. On the contrary, I have personally known scores of them to fritter away thousands of dollars paid them in cash balances, in ways that would be absolutely beyond discovery. I have seen a man and his wife leave a plantation office in the morning with \$ 50 in cash, spend the day in town, and return in the evening with no money, and practically nothing to show for it. I have also known them, time and again, to leave money to their credit on the plantation books, and absolutely insist on buying their supplies on credit, and at time prices. We have such accounts on our books to-day, notwithstanding that we repeatedly attempt to show them the folly of such methods, and 


\section{Economic Future of the Negro I89}

try to induce them to use their money in a businesslike way. The idea seems to be that the money from a crop already gathered is theirs, to spend as fancy suggests, while the crop to be made must take care of itself, or be taken care of by the "white folks." This sounds ridiculous, and is ridiculous, but it is also none the less true. The money thus thrown away by the Negro the Italians put to cold-blooded business uses. They will take advantage of a discount offered on a \$ 50 purchase of supplies, and I have known instances of their offering to pay land rent a year in advance for a similar consideration.

It is a knowledge of such facts as these, and a familiarity with the "average traits" of the Negro agriculturist, which cause me to believe that from the Negro's standpoint the problem is much graver and more difficult than one of mere efficiency alone. Professor $\mathrm{H}$. T. Kealing, himself of the race, thus speaks of the Negro's "improvidence and extravagance": "He will drop the most important job to go on an excursion or parade with his lodge. He spends large sums on expensive clothing and luxuries, while going without things necessary to a real home. He will cheerfully eat fat bacon and 'pone' cornbread all the week in order to indulge in unlimited soda-water, melon, and fish at the end. In the cities he is oftener seen dealing with the pawnbroker than the banker. His house, when furnished at all, is better furnished than that of a white man of equal earning power, but it is on the instalment plan. He is loath to buy a house, because 


\section{Igo The American Race Problem}

he has no taste for responsibility nor faith in himself to manage large concerns; but organs, pianos, clocks, sewing-machines, and parlour suits, on time, have no terrors for him."*

I can bear witness to the accuracy of this picture. We have to post plantations against various kinds of itinerant "agents," or be harassed at the end of each year by the efforts of foreign concerns, generally in the Middle Western states, to force money out of our Negroes for every imaginable article peculiar to such commerce. These things range from gaudily illustrated "family Bibles" to "sure cures" for rheumatism and nostrums guaranteed to straighten the hair and bleach the skin. Western mail order houses also do a heavy c. o. d. business in this territory, largely in pistols, sewingmachines, and medicines. Meanwhile, throughout the year, the Italian peddler drives through the country in a covered wagon and exchanges with the Negro the "soda pop," sausage, fish, et cetera, mentioned by Mr. Kealing, for the few stray dimes that chance to remain on hand from the last trip to town.

We need not multiply accounts for the mere purpose of comparison. The general results possess a meaning sufficiently significant. Of the rio Italian squads who started to work at the beginning of the current year, 44 were new arrivals. Yet of the total number, 65 squads, or 59 per cent., had no supply accounts during r905. That is to say, practically all who were on the place last year were in a condition

\footnotetext{
* "The Negro Problem," p. 176.
} 


\section{Economic Future of the Negro 191}

of independence this year. Of the 6r Negro families who began to make crops this year only 2 , or 3.2 per cent. of the whole, are independent. This situation may be understood when we know that back of it lies the fact that to the 66 Italian families in 1904 cash balances above accounts were paid in the sum of $\$ 38,764.5^{8}$, an average of $\$ 587.35$ per squad. Of the I IO Negro families in I 904 two drew total balances of $\$ 480.50$, while the firm had on its books at the end of the year the sum of $\$ 6,456.20$ in Negro balances due. (I have a friend, operating on a much smaller scale, who last year charged off to profit and loss $\$ 4,300$ due him by the Negroes on his place.)

Take another illustration of what these operations have meant for the two races: There were 107 Italian squads at the end of r 905. Of these ro4 owned I 23 head of work stock and other live stock, such as cattle, sheep and hogs, to the total value of $\$ 23,400$. Only three squads owned no stock. Of the 38 Negro squads 2 I owned work and live stock to the total value of $\$ 3,360$, and $I_{7}$ owned no stock. This indicates a failure to improve their condition upon the part of the Negroes as a whole, and a grossly unequal distribution of property as well. Of Io7 Italians but 2.8 per cent. have no share in the general wealth; of 38 Negroes 44.7 per cent. have no such share.

Further testimony to the prosperity of the Italian in his new environment is hardly necessary. I may only add that the best evidence of their satisfied estate is the fact that each year some of them furnish trans- 


\section{The American Race Problem}

portation for friends or relatives at home. But wherein lies the advantage to the landowner over the Negro tenant system? This question is pertinent, for in its ultimate answer will be found the key to the attitude of the employer of agricultural labour toward the question of foreign immigration to the Southern states. Without touching the broader aspect of the question - the advantage to the general welfare of efficient over inefficient labour - I would answer specifically by suggesting three points of superiority for the Italian: First, I would put a permanent and assured tenantry; secondly, thorough and careful cultivation of the soil, without the necessity for an almost paternalistic supervision of the labour; thirdly, following as a natural sequence to the other two, greater safety and larger freedom from losses in furnishing, and, ultimately, the employing of a smaller operating capital.

As a cotton planter, the greatest fault I find with Negro labour is not its improvidence or shiftlessness. Certainly these are a source of annoyance to the planter, but they much more vitally concern the Negro himself. They constitute the handicap which, unless removed, will cause him to lose the race to the foreigner. But the planter's greatest trouble arises out of the Negro's unreliability - the fact that he cannot be depended on to be governed by considerations of self-interest; that he changes his habitation in response to the most trifling and whimsical suggestions, and frequently for no reason at all; that out of any group of plantation families we never know toward the close of one year 


\section{Economic Future of the Negro}

upon how many we may depend for the next - regardless of what they tell us, nor how many will carry through a crop after they have contracted to do so.

Here again we may draw on Sunny Side for an instructive comparison. One hundred and ten Italian squads began crops in 1905, and 107 carried them through. One left because of sickness, one ran off, and one was made to leave. Sixty-one Negro squads began the year, and thirty-eight went through; seventeen "turned back" their crops, and six ran off. Of the Italians 97.2 per cent. stayed through the year; of the Negroes, 62.2 per cent. Whereas with the Negro we have the constant difficulty I have mentioned, of not knowing with certainty at the end of one year whose places will have to be filled for another, with the Italians the reverse is true. They come up of their own volition during August and September and arrange their affairs for the following season. And so quickly do they become wedded to a particular allotment of land they are rarely willing to change. When they do, it must be clearly to their interest to make the move. A few have returned to Italy, but a year before their departure they arranged to have their land taken by some relative, and thus retained it in the family. The opportunity which the Negro yearly casts to the winds of improvidence the Italian embraces as something too valuable to fritter away. There is nothing new about any of these traits.

This Italian group has been built up largely through additions brought over by those on the ground, from 


\section{The American Race Problem}

year to year. Possibly they may be above the average of their class, but I have no reason to think so. Certainly these Negroes are not below the average of theirs. The statement of the characteristics exhibited by these Italians might be received with incredulity by a man accustomed all his life to Negro labour. But this would be due to ignorance on his part. They are as old as the métayers of Lombardy, Piedmont, and Tuscany themselves - those frugal and industrious peasants who made the valley of the Arno one of the garden spots of the world. I wish I could give you a description of these people at home - as quoted by John Stuart Mill from Arthur Young, Chateauvieux, and Sismondi. I commend the chapter on métayers in Mill's first volume to anyone interested in the subject we are discussing.

But perhaps a more modern picture may serve our purpose, especially as it is by a practical cotton planter, who recently went from Mississippi to Italy to study at first hand its peasant population. Mr. Charles Scott, of Rosedale, Mississippi, says: "I visited some of these people in their homes. They received me cordially, and I was most favourably impressed with them. They are a stalwart, industrious, and hardy race. I found them frugal and temperate in most things, and while somewhat peppery and excitable, as might be expected from their climate and antecedents, they are not vindictive, but seem to 'carry anger as the flint does fire.' . . . Their diet was simple and inexpensive. A Southern plantation Negro would scorn to accept a similar ration. . . These men are 


\section{Economic Future of the Negro 195}

already good farmers, and on the whole have the right material in them for the making of good American citizens."**

Perhaps the most broadly characteristic feature of Negro argiculture is to be found in the almost universally neglected garden. Nowhere else is the contrast presented more strongly by the Italian. Right here is told in humble eloquence the story of thrift, economy, care, the thought of small things, the whole gamut of homely traits which go to distinguish the ultimately successful tiller of the soil from the man who ultimately fails. Mr. Kelsey says: "In all parts [of the South] it is the custom for the Negroes to save a little garden patch about the house, which, if properly tended, would supply the family with vegetables throughout the year. This is seldom the case." $\mathrm{He}$ quotes as follows from a Tuskegee Catalogue: "If they have any garden at all, it is apt to be choked with weeds and other noxious growths. With every advantage of soil and climate, and with a steady market if they live near any city or large town, few of the coloured farmers get any benefit from this, one of the most profitable of all industries." $\dagger$

To this Tuskegee description I would add this testimony, as I have given it elsewhere: "Given equal soil and equal climatic conditions for growing cotton, and the odds are with the man who cultivates his crop best and most carefully. The Italian works more

* Manufacturers' Record, Nov. 9, 1905, p. 423.

$\dagger$ "The Negro Farmer," p. 3x. 


\section{The American Race Problem}

constantly than the Negro, and, after one or two years' experience, cultivates more intelligently. In comparing the two it is scarcely necessary to go beyond the appearance of their respective premises and fields to gain an insight into the difference between them. The general condition of the plantation premises occupied by Negroes, under whatever system of cultivation, has been an eyesore in the cotton states for more than a generation. The spectacle of broken-down fences, patchwork outhouses, half-cultivated fields, and garden spots rank with weeds, is too familiar to the traveller through the Southern states to need description here. The destructive propensity of the Negro constitutes to-day a serious problem on many a well ordered plantation. On the property in which the writer is interested the effort to maintain the premises of the Negro tenants in keeping with the general appearance of the plantation seems yearly to become a more hopeless undertaking. It seems difficult to escape the conclusion that back of all this lie the characteristics that apparently have always been a curse to the race - whether in Africa, the Southern states, or the West Indies - shiftlessness and improvidence.

"On the other hand, the appearance of the Italian cotton grower's immediate surroundings, working on the same tenant system as the Negro, is alone sufficient to tell the story of the difference between the ultimate end and purpose of the labour of the two. The contrast is not alone in the things that appeal to the eye; it is much more emphasised in the respective uses made of 


\section{Economic Future of the Negro}

the same material and opportunities. From the garden spot which the Negro allows to grow up in weeds, the Italian will supply his family from early spring until late fall, and also market enough largely to carry him through the winter. I have seen the ceilings of their houses literally covered with strings of dried butter beans, pepper, okra, and other garden products, while the walls would be hung with corn, sun-cured in the roasting ear stage. In the rear of a well kept house would be erected a woodshed, and in it could be seen enough fire-wood, sawed and ready for use, to run the family through the winter months. These people did not wait till half-frozen feet compelled attention to the question of fuel, and then tear down the fence to supply their wants. Nor would they be found drifting about near the close of each season, in an aimless effort to satisfy an unreasoned desire to 'move." "*

Elsewhere I have given the results of "A Plantation Experiment," as made on the property in which I am interested. $\dagger$ A study of the figures given there will lead to the conclusion that the Negro can produce as much as the Italian. And so he can; but production is only half the story. And another consideration must be borne in mind: namely, that the Dunleith experiment was conducted on new land, far above the average in fertility, and, above all, that it was a highly paternalistic enterprise. I know of no other plantation in the South where the Negro has been, or is likely to

\footnotetext{
* "The Italian Cotton Grower, The Negro's Problem," Alfred Holt Stone, South Atlantic Quarterly, Jan. 1905, pp. 44, 45.

† Paper IV, supra.
} 


\section{I98 The American Race Problem}

be, surrounded by economic conditions equally as favourable. But the milk in that cocoanut is that the experiment failed, absolutely and lamentably failed, to accomplish its purpose. This was to build up a respectable, industrious, and reliable body of tenants, while this very thing has been accomplished on the Sunny Side property, by the simple expedient of the substitution of a different class of labour. Further than this, from the Negro's standpoint also it failed. For, despite an artificially stimulated efficiency, there was lacking the final essential of thrift. He made, but he did not save.

I hold no brief for the Italian. As far as he is concerned my interest is purely one of abstract economics. For the masses of the Negro race I have only the kindliest feeling. There is not a white tenant on Dunleith Plantation, nor will there be until we are driven to that recourse by the Negro himself. I do not believe it will ever come my way to do these people a greater service than right here, if only my voice could reach them, by pointing out, as I see it, the only key to the safety of their future economic position. There is a great deal of unrest in my section over the labour question. In I905 I travelled more than twenty-five hundred miles through ten Southern states, and also corresponded with men in every part of the South. I do not speak idly when I say that Southern people in constantly increasing numbers are more and more coming to the conclusion that they must at last put forth a determined effort to render themselves inde- 


\section{Economic Future of the Negro}

pendent of the Negro - to begin in some degree the final supplanting of the latter by the white man.

My study of conditions is not so superficial as to betray me into ignoring the fact that Southern economic development during the past two decades has greatly outstripped the growth of Southern population. But this does not tell the whole story. The resulting "labour scarcity" is more apparent than real. The streets and purlieus of our towns are filled with idlers by day and prowlers by night. If the vagrancy statutes of every Southern state were suddenly enforced the jails would be filled to overflowing. We offer the wages demanded, but it is difficult to find those who are willing to accept steady employment. In a town full of Negroes we have had to largely substitute coal as a cooking fuel because we could not get stove wood cut. On a plantation with nearly three hundred Negroes surrounding them my partner's wife has frequently, for long periods, had to patronise a city laundry. I sometimes wonder if the story of Jamaica and the West Indies is to be repeated in the South. It is so easy to exist, by various and devious means, that our Negroes in alarming numbers are ceasing to care to do much more than live from hand to mouth. Thousands of them are doing it today, and too many other thousands are tending that way. Already, here and there, scattered throughout the South, even in many smaller towns white domestic servants may be seen. There are white barbers and bootblacks, and white men in every other trade and calling. States and railroads and private organisations 


\section{The American Race Problem}

are discussing the question of foreign immigration with increasing earnestness. I know that a few leading Negroes have ridiculed this incipient movement, even as Frederick Douglass ridiculed it as a possibility a quarter of a century ago. The most prominent Negro editor in the United States has said that the South is merely putting up a "bluff." But I believe the Southern people are in earnest.

As I have said, the Negro possibly has it in his power to arrest this movement, at least for many years. He can do it, in a measure at least, by making of himself a reliable, dependable factor in the economic life of the South, but not by any other means within my view. I say he can do this. But will he? It would mean a revolution in the present social and industrial life and habits of the masses. To me the outlook for such a course does not seem encouraging. And how long will he require for the process? For meanwhile the world will not stand still.

But in a broader view even this would be but temporary; a mere postponing of the inevitable. This life of ours is, and is likely always to remain, a ceaseless struggle for supremacy among nations, and races, and individuals. Heretofore he has been largely shielded by conditions, partly economic and partly geographic, but it would be unwise for the Negro to cherish the delusion that he alone of all mankind is to remain forever exempt from such a contest. Nothing is more surely written in the book of fate than that he will have to meet it, soon or late. 


\section{Economic Future of the Negro 201}

I have quoted Mr. Washington's opinion that he did not believe the masses of his people fitted to face the competition of Northern cities. There the result of such competition has turned mainly upon the considerations of efficiency, reliability, and thrift, with some account to be taken of Northern economic race prejudice, if I may use the expression. The white people of this country are fundamentally alike as regards their attitude toward the Negro. However much this may be denied on each side the line, as to some particular aspect of the question, its essential truth will gradually be made manifest, as economic and political conditions shape themselves toward greater uniformity between the two sections. Even though we may safely eliminate the factor of industrial prejudice from a present consideration of competition in the South, we need not deceive ourselves. (Eventually we shall have to face it; as soon probably as the South awakens to a realisation of the fact that in her industrial rivalry with the rest of the world she is handicapped by labour of a normally low degree of efficiency - and begins really to stimulate foreign and domestic immigration.

But aside from this, what of the other factors? Have we any grounds for assuming that they would be any less potent South than North, in turning the scales against the Negro? I have never indulged in dogmatic assertions about the present of the Negro, and I shall certainly not begin with a dogmatic prediction as to his future. I have merely tried to indicate some of the factors and results of such a contest, as they have 


\section{The American Race Problem}

already been wrought out before us in a sort of mimic warfare. Is any man, qualified to speak by familiarity with the Negro masses, prepared to promise that in a larger field, upon a broader stage, the end of the struggle would not be the same?

It will be a slow process of attrition, when it really comes, this working out of the results of competition. It will not be attended by any sensational features. There will be nothing sudden about it, nor will it mean the extinction of the Negro as an economic factor. It seems to me that its effect will be merely to submerge the incompetent mass, and elevate, in that very process, such as can weather the storm. In its last analysis, it will be his own, not the white man's hand, that closes in the Negro's face the door of economic hope, for only he can keep it open. If the story of the fate of the old time business Negro of New York and Philadelphia in the years to come shall be related of the Negro agriculturist of the South, it will be for the latter but a final reaping of the fruits of Reuben's ancient curse : "Unstable as water, thou shalt not excel."

My conception of the treatment of the question before us does not involve an outlook upon the thirteenth census. On the other hand, I am not projecting it into a future too remote for practical consideration. I have not founded conclusions upon isolated phenomena, nor am I particularly concerned with this or that group of conditions, save as they disclose the results of the working out of what reasonably seem to be persistent factors. The particular demonstration of relative efficiency be- 


\section{Economic Future of the Negro 203}

tween Italians and Negroes which has been used here would lose nothing of its significance if through some adventitious circumstance the Sunny Side colony were wiped out of existence to-morrow; or if for reasons sufficient unto themselves the operators of that property were immediately to displace every Italian on it, and return to Negro labour. I have merely endeavoured to deal with forces already widely and actively at work, and with human traits the operation of which has already been unfolded to our view. If these constitute two groups of fixed elements in the problem then the future is no more uncertain than are the operations of the natural laws by which we forecast the outcome of any other struggle between weakness and strength. True, "the race is not always to the swift, nor the battle to the strong ;" but in this case the initial distance between the contestants would seem too great to be overcome by time or chance.

Very likely it will be urged that I have given the point of view of the employer of Negro labour, and have too greatly emphasised the force of the weaker side of the Negro masses. The other side has been presented many times, in the attempt to make out a case against the white man which would lift the onus for existing conditions from the shoulders of the Negro.

Mr. T. Thomas Fortune quotes from Dr. DuBois the statement that "in well-nigh the whole rural South the black farmers are peons, bound by law and custom to an economic slavery, from which the only escape is death or the penitentiary." He adds his own to this effect: 


\section{The American Race Problem}

"It is a dark and gloomy picture, the substitution of industrial for chattel slavery, with none of the legal and selfish restraints upon the employer which surrounded and actuated the master. And this is true of the entire mass of the Afro-American labourers of the Southern states."* I submit the picture just as it is drawn. This is not the place to discuss the question of its fidelity to truth. My only comment is that I am not able to fathom the buoyancy of spirit which can believe in the accuracy of this presentation of the Negro's present economic condition and at the same time profess a hope for his future.

It is idle here to confuse the practical question of actual conditions with the ethical question of cause. For our purpose we need not stop to multiply words in an effort to determine where rests the burden of responsibility. Between the white man and the black it is likely always to remain a disputed question. This is human nature. But a man who has ceased to breathe is equally dead, whether he came to his death by assassination or suicide. If the end is to be the same, the Negro masses will not be particularly interested in the academic question of causes and means. If the white man is responsible for the Negro's condition; if the latter cannot remove the obstacles from his own path, then his economic future no longer remains within the field of speculation, and the efforts toward his industrial training become a mockery to him and a fraud upon those who support them.

* "The Negro Problem," pp. 228, 229. 


\section{Economic Future of the Negro 205}

But I take the view which at least holds something of hope for the Negro, in that it does not entirely remove his present or future from the range of his own individual efforts. As I have expressed it elsewhere: "When the friend of the Negro masses would know the whole truth behind the forces which to-day most militate against the material progress of the race, he must go deep below the surface of troubles which the white man can remove or rectify." *

In the larger sense there is another aspect of the Negro's life that must be considered in attempting to estimate his future. The two gravest obstacles to be overcome by the race are improvidence and immorality, each in its broadest significance. Of the first I have already said quite enough. Of the second I shall let Mr. Washington and Dr. DuBois speak for me. The former says: "No one who wants to be honest and at the same time benefit the race will deny that here is where the strengthening is to be done." $\dagger$ Dr. DuBois says: "The evil is still deep seated, and only a general raising of the standard of living will finally cure it." In this connection he says of the Negroes of a Georgia county: "Perhaps ro per cent. compose the well-to-do and the best of the labourers, while at least 9 per cent are thoroughly lewd and vicious. The rest, over 80 per cent., are poor and ignorant, fairly honest and well meaning, plodding, and to a degree shiftless, with some but not great sexual looseness." $\ddagger$ I might

\footnotetext{
* p. 147

+ "The Future of the American Negro," p. I69.

\$"Souls of Black Folk, p. 143 .
} 


\section{The American Race Problem}

alter some of these proportions, but, applied to the country as a whole, they tell the story well enough as they stand.

Here, then, it seems to me, is the first great problem of this people, the problem of the moral elevation of the masses, whose status will at last determine that of the race as a whole. No man is further than I from attempting to discount the value to a race or nation of its exceptional few - the wealth it has in the possession of a "talented tenth." But, after all is said and done, the race, it seems to me, must stand or fall by the character of the masses of its people. It cannot be saved by the poetry of Dunbar, by the novels of Chestnutt, by the music of Coleridge-Taylor, by the surgical skill of Williams, or by the culture and intellect of DuBois.

In his work on "Social Evolution" Mr. Benjamin Kidd says that the future demands that we realise more clearly just what constitutes superiority and inferiority of race. He says that science gives us no warrant for claiming superiority for a certain race on the ground alone of colour, descent, or even high intellectual capacity. In his opinion the only test lies in the measure of the possession of "qualities contributing to social efficiency," and high among these he places "strength and energy of character, humanity, probity and integrity, and simple-minded devotion to conceptions of duty in such circumstances as may arise." Mr. Kidd quotes Mr. Lecky's opinion as to the causes of the prosperity of nations. The latter's words are more impressive than 


\section{Economic Future of the Negro 207}

his own, for they apply to races as well as nations, to black as well as white. And here is his judgment on real "prosperity," which the friends and leaders of the American Negro may not unprofitably take to heart: "Its foundation is laid in pure domestic life, in commercial integrity, in a high standard of moral worth and of public spirit, in simple habits, in courage, uprightness, and a certain soundness and moderation of judgment which springs quite as much from character as from intellect." And his conclusion seems to me to be especially applicable to our discussion: "If you would form a wise judgment of the future of a nation, observe carefully whether these qualities are increasing or decaying."*

The Negro has often demanded another standard than that of race as a measure of his capacity and value as a people. Here is one, severe possibly, but fair : The extent to which the race as a whole shall prove its ability to lay the foundation of "a pure domestic life," and erect thereon a superstructure of character and moral worth. If it shall establish the capacity of its masses to meet this test, then it will have proved its title to a place among the superior races of the earth, and this regardless of your opinion or of mine, or of that of our fathers before us. But, though it become ten thousand times richer than it is to-day, and overflow the land in numbers, and fill all offices of profit, if it fail in this supreme criterion it will still be an inferior people.

\footnotetext{
* "Social Evolution," Kidd, N. Y., r898, pp. 348-350, quoting from Mr.
} Lecky's "The Political Value of History." 


\section{The American Race Problem}

The foundation of the greatness of England and Germany and America does not consist of material things alone, nor of the brilliant achievements of their "talented tenths." It is to be discovered in the character of the home life of their great average classes - the masses of their people. It is the latter which makes possible and assures the former, and there is no shorter, easier road for the Negro than for the white man. Then the current measure of the real progress of the race is to be found in the extent to which the characteristics of one of the other of its two extremes - its highest or its lowest class - are most impressed upon the mass. It is not alone in the possession of houses that the foundations of prosperity, as Mr. Lecky defines it, are laid; nor in their possession alone that racial advance is indicated. It is, rather, in the extent to which these houses possess for their owners the true significance of homes. This test is sound, but difficult of certain application. It is easier to enumerate the houses of a people than it is to count their homes. 


\title{
PART THREE
}

\section{CRUCIAL POINTS OF POST BELLUM RACIAL CONTACT}

\author{
VI. Race Friction \\ ViI. Mr. Roosevelt, the South, and the Negro \\ VIII. The Negro in Politics
}




\section{VI}

\section{RACE FrICtION*}

\section{$\mathrm{O}$} $\mathrm{N}$ THE evening of December 17,1855 , there assembled a gathering of the coloured citizens of the city of Boston to do honour to a member of their race. The man was William C. Nell, a name familiar to students of Negro history. The occasion was the presentation to him of a testimonial of appreciation of his labours in behalf of the removal of the colour line from the public schools of Boston. The event commemorated the crowning achievement of a purpose formed and a work begun some twenty-six years before. It marked the close of a quarter century of patient and unremitting struggle with established law and custom. The meeting was made memorable by the presence of such men as Wendell Phillips and William Lloyd Garrison, who rejoiced with their coloured brethren that "the prejudice against colour was dying out." This was the keynote of all the addresses made - the faith that the final surrender of this long-stormed citadel marked the passing of the prejudice of race.

Fifty-two years later, in November, 1907, a great concourse of Boston's coloured citizens assembled in

\footnotetext{
* A paper read before the Second Annual Meeting of the American Sociological Society, Madison, Wis., Dec. 30, 1907 , on the question, "Is Race Friction Between Blacks and Whites in the United States Growing and Inevitable?"
} 


\section{The American Race Problem}

Faneuil Hall to protest against the steady and wide increase of race prejudice in America. The meeting was addressed by the gray-haired son of the great abolitionist, in tones which were far from sounding an echo of the hopeful, long forgotten words of his father.

And after this more than half century of American advance in moral and intellectual and material things, we too have come together, in the free atmosphere of this academic seat, to consider coolly and dispassionately the causes which really lay behind these two meetings in Boston - further apart in spirit and in purpose than in time. We have come to inquire whether friction between the white and Negro races in America is growing and inevitable.

In the first place, what is race friction? To answer this elementary question it is necessary to define the abstract mental quality upon which race friction finally rests. This is racial "antipathy" - popularly spoken of as "race prejudice." Whereas prejudice means a mere predilection, either for or against, antipathy means "natural contrariety," "incompatibility," or "repugnancy of qualities." To quote the Century Dictionary, antipathy "expresses most of constitutional feeling and least of volition"; "it is a dislike that seems constitutional toward persons, things, conduct, etc.; hence it involves a dislike for which sometimes no good reason can be given." I would define racial antipathy, then, as a natural contrariety, repugnancy of qualities, or incompatibility, between individuals or groups which are sufficiently differenti- 


\section{Race Friction}

ated to constitute what, for want of a more exact term, we call races. What is most important is that it involves an instinctive feeling of dislike, distaste, or repugnance, for which sometimes no good reason can be given. Friction is defined primarily as a "lack of harmony," or a "mutual irritation." In the case of races it is accentuated by antipathy. We do not have to depend on race riots or other acts of violence as a measure of the growth of race friction. Its existence may be manifested by a look or a gesture as well as by a word or an act.

A verbal cause of much useless and unnecessary controversy is found in the use of the word "race." When we speak of "race problems" or "racial antipathies," what do we mean by "race"? Clearly nothing scientifically definite, since ethnologists themselves are not agreed upon any classification of the human family along racial lines. Nor would this socalled race prejudice have the slightest regard for such classification if one were agreed upon. It is something which is not bounded by the confines of a philological or ethnological definition. The British scientist may tell the British soldier in India that the native is in reality his brother, and that it is wholly absurd and illogical and unscientific for such a thing as "race prejudice" to exist between them. Tommy Atkins simply replies with a shrug that to him and his messmates the native is a "nigger, " and in so far as their attitude is concerned that is the end of the matter. The same suggestion, regardless of the scientific ac- 


\section{The American Race Problem}

curacy of the parallel, if made to the American soldier in the Philippines, meets with the same reply. We have wasted an infinite amount of time in interminable controversies over the relative superiority and inferiority of different races. Such discussions have a certain value when conducted by scientific men in a purely scientific spirit. But for the purpose of explaining or establishing any fixed principle of race relations they are little better than worthless. The Japanese is doubtless quite well satisfied of the superiority of his people over the mushroom growths of Western civilisation, and finds no difficulty in borrowing from the latter whatever is worth reproducing, and improving on it in adapting it to his own racial needs. The Chinese do not waste their time in idle chatter over the relative status of their race, as compared with the white barbarians who have intruded themselves upon them with their grotesque customs, their heathenish ideas and their childishly new religion. The Hindu regards with veiled contempt the racial pretensions of his conqueror, and while biding the time when the darker races of the earth shall once more come into their own, does not bother himself with such an idle question as whether his temporary overlord is his racial equal. Only the white man writes volumes to establish on paper the fact of a superiority which is either selfevident and not in need of demonstration, on the one hand, or is not a fact and is not demonstrable, on the other. The really important matter is one about which there need be little dispute - the fact of racial 


\section{Race Friction}

differences. It is the practical question of differences - the fundamental differences of physical appearance, of mental habit and thought, of social customs and religious beliefs, of the thousand and one things keenly and clearly appreciable, yet sometimes elusive and undefinable - these are the things which at once create and find expression in what we call race problems and race prejudices, for want of better terms. In just so far as these differences are the fixed and permanently associated characteristics of two groups of people will the antipathies and problems between the two be permanent. We speak loosely of the race problems which are the result of European immigration. These are really not race problems at all. They are purely temporary problems, based upon temporary antipathies between different groups of the same race, which invariably disappear in one or two generations, and which form only a temporary barrier to physical assimilation by intermarriage with native stocks.

Probably the closest approach we shall ever make to a satisfactory classification of races, as a basis of antipathy will be that of grouping men according to colour, along certain broad lines, the colour being accompanied by various and often widely different, but always fairly persistent, differentiating physical and mental characteristics. This would give us substantially the white - not Caucasian, the yellow - not Chinese or Japanese, and the dark - not Negro, races. The antipathies between these general groups, and between certain of their sub-divisions, will be found 


\section{The American Race Problem}

to be essentially fundamental, but they will also be found to present almost endless differences of degrees of actual and potential acuteness. Here elementary psychology also plays its part. One of the sub-divisions of the Negro race is composed of persons of mixed blood. In many instances these are more white than black, yet the association of ideas has through several generations identified them with the Negro - and in this country friction between this class and white people is on some lines even greater than between whites and blacks.

Race conflicts are merely the more pronounced concrete expressions of such friction. They are the visible phenomena of the abstract quality of racial antipathy - the tangible evidence of the existence of racial problems. The form of such expressions of antipathy varies with the nature of the racial contact in each instance. Their different and widely varying aspects are the confusing, and often contradictory phenomena of race relations. They are dependent upon diverse conditions, and are no more susceptible of rigid and permanent classification than are the whims and moods of human nature. It is more than a truism to say that a condition precedent to race friction or race conflict is contact between sufficient numbers of two diverse racial groups. There is a definite and positive difference between contact between individuals and contact between masses. The association between two isolated individual members of two races may be wholly different from contact between masses of the same race groups. 


\section{Race Friction}

The factor of numbers embraces indeed the very crux of the problems arising from contact between different races.

A primary cause of race friction is the vague, rather intangible, but wholly real feeling of "pressure" which comes to the white man almost instinctively in the presence of a mass of people of a different race. In a certain important sense all racial problems are distinctly problems of racial distribution. Certainly the definite action of the controlling race, particularly as expressed in laws, is determined by the factor of the numerical difference between its population and that of the inferior group. This fact stands out prominently in the history of our colonial legislation for the control of Negro slaves. These laws increased in severity, up to a certain point, as the slave population increased in numbers. The same condition is disclosed in the history of the ante bellum legislation of the Southern, Eastern, New England, and Middle Western states for the control of the free Negro population. So to-day, no state in the Union would have separate car laws where the Negro constituted only Io or I5 per cent. of its total population. No state would burden itself with the maintenance of two separate school systems with a Negro element of less than ro per cent. Means of local separation might be found, but there would be no expression of law on the subject.

Just as a heavy increase of Negro population makes for an increase of friction, direct legislation, the protection of drastic social customs, and a general feeling 


\subsection{The American Race Problem}

of unrest or uneasiness on the part of the white population, so a decrease of such population, or a relatively small increase as compared with the whites, makes for less friction, greater racial tolerance, and a lessening of the feeling of necessity for severely discriminating laws or customs. And this, quite aside from the fact of a difference of increase or decrease of actual points of contact, varying with differences of numbers. The statement will scarcely be questioned that the general attitude of the white race, as a whole, toward the Negro would become much less uncompromising if we were to discover that through two census periods the race had shown a positive decrease in numbers. Racial antipathy would not decrease, but the conditions which provoke its outward expression would undergo a change for the better. There is a direct relation between the mollified attitude of the people of the Pacific coast toward the Chinese population and the fact that the Chinese population decreased between 1890 and 1900 . There would in time be a difference of feeling toward the Japanese now there if the immigration of more were prohibited by treaty stipulation. There is the same immediate relation between the tolerant attitude of the whites toward the natives in the Hawaiian Islands and the feeling that the native is a decadent and dying race. Aside from the influence of the Indian's warlike qualities and of his refusal to submit to slavery, the attitude and disposition of the white race toward him have been influenced by considerations similar to those which to-day operate in Hawaii. And the same 


\section{Race Friction}

influence has been a factor in determining the attitude of the English toward the slowly dying Maoris of New Zealand.

The character and violence of race friction or conflict will depend upon the immediately provoking cause, but will be influenced by a variety of accompanying considerations. Open manifestations of antipathy will be aggravated if each group feels its superiority over the other. They will be fewer and milder when one race accepts the position of inferiority outwardly or really feels the superiority of the other. In all cases the element of individual or racial self-assertiveness plays an important part. The white man on the Pacific coast may insist that he does not feel anything like the race prejudice toward the Chinaman that he does toward the Japanese. In truth the antipathy is equal in either case, but the Chinaman accepts the position and imputation of inferiority - no matter what or how he may really feel beneath his passive exterior. On the other hand, the Japanese neither accepts the position nor plays the role of an inferiorand when attacked he does not run. Aside from all question of the relative commendable traits of the two races, it is easy to see that the characteristics of one group are much more likely than those of the other to provoke outbreaks of antipathy when brought into contact with the white race. We need not ask what would be the situation in India, and what the size of the British garrison there, if the Hindu had the assertive and pugnacious characteristics of the Japanese- 


\section{The American Race Problem}

veiled though the latter are behind a bland and smiling demeanour.

It is a common remark that the relations between the white and Negro races in this country are not "as good," as the expression runs, as they were before the war. The fundamental cause of most race friction is in the operation of racial antipathy which leads to the denial by one race of the racial equality of another, coupled with the assertion of equality by the other party to the contact. Post bellum racial difficulties are largely the manifestation of friction growing out of the novel claim to equality made by the Negro after emancipation, either by specific declaration and assertion, or by conduct which was equivalent to an open claim, with the refusal of the white man to recognise the claim. The commonest mistake of race problem discussions is that of treating such problems as a heritage from slavery. Slavery was responsible only in so far as it was responsible for bringing the races into contact. The institution, per se, was not only not the cause of the problem, but, on the other hand, it actually furnished a basis of contact which as long as it existed minimised the problems which result from racial contact upon a plane of theoretical equality. We may obtain a conception of an American race problem without the background of antecedent slavery relations, if we can imagine the situation which would be created by the precipitation upon the population of the Pacific coast of a million Japanese. The late Professor Shaler, of Harvard, summed up with absolute accuracy the 


\section{Race Friction}

function of slavery in making possible relations of mutual amity between the white and Negro races in this country, when he declared that, "The one condition in which very diverse races may be brought into close social relations without much danger of hatred, destructive to the social order, is when an inferior race is enslaved by a superior." His opinion was that "this form of union is stronger than it has appeared to those who have allowed their justifiable dislike of the relation to prejudice them as to its consequences." Professor Shaler struck one of the keynotes of the ante bellum situation when he said that slavery made impossible any sort of rivalry between the races. He declared his utter detestation of the institution, but said it should be recognised that "it was effective in the prevention of race hatreds." To quote his words: "Moreover, it brought the two races into a position where there was no longer any instinctive repugnance to each other, derived from the striking differences of colour or of form. If the Negroes had been cast upon this shore under any other conditions than those of slavery, they would have been unable to obtain this relation with the whites which their condition of bondage gave."*

But Professor Shaler recognised the innate potential force of antipathy of race and he observed that, "It remains to be seen whether the race hatred, which was essentially lost during the period of slavery, will return in the conditions of freedom." Twenty-one years have

*"Race Prejudice," N. S. Shaler, A tlantic Monthly, October I 886, pp.5 I6, 5 I 7. 


\section{The American Race Problem}

elapsed since Professor Shaler wrote, and it is in the light of these two decades of additional experience that we are to-day attempting to answer his query.

It is impossible to discuss here, as I should like to do, the broader question of race relations, as preliminary to an inquiry into relations in this country between whites and Negroes. We may, however, suggest some of the more elementary principles of such relations as a basis for a reply to the concrete question before us. In the first place, I lay down as a fundamental law of racial contact the proposition that the terms and conditions of racial association will be dictated by the stronger of the two parties to such association actuated by motives of self-interest, or by instincts of self-preservation.* In the second place, the resulting relations will be least conducive to friction when the terms insisted upon by the stronger race are accepted without protest by the weaker. The converse of this follows as a corollary - that the relations which are most conducive to friction are those under which the conditions laid down by the stronger party are not accepted by the weaker. The friction which racial contact engenders under such conditions will be in proportion to the degree of the insistence of one party upon its terms of association, and of the resistance to such conditions offered by the other.

The absence of ante bellum racial friction was due to the general acceptance by the Negro of the status assigned him by the white race. The further removed

* For a fuller statement see pp. 54 et seq. and 57 et seq. 
the two races are from this basis of association, which Professor Shaler declared to be the only one upon which they could safely have been brought together in the first place - the greater the probability that friction will follow contact between them. The whole matter resolves itself into very simple terms. The simpler the relations between diverse races, the less friction there will be; the more complex the relations, the greater the friction. The simplest relations possible are those in which the relative status of superior and inferior is mutually accepted as the historical, essential, and matter-of-fact basis of relationship between the two. The most complex relation possible between any two racial groups is that of a theoretical equality which one race denies and the other insists upon. The accepted relation of superior and inferior may exist not only without bitterness on one side or harsh feelings upon the other, but it may be characterised by a sentiment and affection wholly impossible between the same groups under conditions demanding a recognition of so-called equality. We should try to gain a clear grasp of the importance of this mutual recognition of a different racial status in minimising racial friction, and of the significance of the converse condition in increasing it.

The Northern white man often remarks upon the inconsistent position of the Southern white man. The former objects more than the latter to personal contact and association with the Negro-but theoretically he is willing to grant to the Negro the full exercise of 


\section{4 \\ The American Race Problem}

all the legal rights and privileges which he himself enjoys. The Southern white man, on the other hand, does not object to personal association with the Negro provided it be upon terms which contain no suggestion of equality of personal status - but he is not willing to grant the privileges which his Northern brother concedes to the race in the mass. The truth is that the difference between their respective attitudes is largely a matter of fiction. It is more apparent than real. The attitude of the Northern man toward the matter of personal association is really the natural attitude of the white man. It is the unconscious expression or feeling of instinctive racial antipathy in its elementary form. The attitude of the Southern man toward the same association is in reality the wholly artificial product of the relations made possible by slavery. The Northern man prides himself on not "looking down on the Negro," as the expression goes. He regards him unconsciously as theoretically, potentially, his racial equal. His unconscious mental attitude does not immediately upon personal contact establish between himself and the Negro the relation of superior and inferior. $\mathrm{He}$ is conscious only of strangeness, difference. But in the presence of this difference his mind reacts normally, and a sufficient degree of latent antipathy is aroused to create a natural barrier, which he merely "feels" and does not attempt to explain. On the other hand, through the influence of generations of association under the purely artificial relations of slavery, the mind of the Southern white man instinc- 


\section{Race Friction}

tively responds to accustomed contact upon inherited lines with the unconscious concept of an inequality of racial status which neutralises or prevents the operation of racial antipathy. In other words, to borrow Professor Shaler's illustration of the operation of slavery in destroying race hatred - the long continued association has destroyed the normal operation of elementary racial antipathy. In its primary form, it is simply not provoked by an association to which it has long become accustomed. It may be asked at once, if such association has been sufficient to thus impair what is claimed to be an instinctive mental impulse, and not only to do this, but to establish in lieu of such a feeling relations and sentiments of genuine and unquestioned affection - why then is it not able to destroy all racial antipathy and thereby in time enable the races to live together in absolute concord? Where is the ground for even the possibility of increased racial friction? The answer is not difficult. The potential results of such long continued racial contact and association may be fully granted, for the sake of discussion. But the question is the primary one of accomplishing the association. Our original proposition is that racial harmony is greatest under an association determined by one party and accepted by the other. This was precisely what made for such relations under slavery. But slavery is dead - and with the passing of the generation of whose life it was an accepted part, both black and white, the relations which it slowly evolved are passing also. A new basis of contact is 


\section{The American Race Problem}

presented - that of unconditional equality. It is a basis which the white race is not willing to concede in practice, whatever the white man may do in theory and hence we have the essential elements of racial friction - a demand for and a denial of racial equality.

Whether or not race friction in the United States is increasing and inevitable depends upon the attitude of the two parties to the racial contact. Does the American Negro demand racial equality, and does the American white man deny it? The latter branch of the question we shall attempt to answer first. Racial antipathy, which we have said to be the basis for the "lack of harmony," the "mutual irritation," which we translate as race friction, is practically universal on the part of the white race toward the Negro, and is beyond question stronger in the so-called Anglo-Saxon stocks than in any other. If it is less apparent in one place than in another, the difference is a mere incident to differences of local condition. It is protean in its manifestations - and subject to such a variety of provoking causes as to defy classification. It is exhibited here in the individual and there in the mass, and elsewhere in both. One man may draw the line against association in a public conveyance, another at the relations of domestic service. One may draw it in the public dining-room of a hotel - another at his private table. One man or one section may draw it in the public schools - another only in fashionable establishments for fashionable young women, or in private academies for boys. Here and there we find 


\section{Race Friction}

a man who realises no feeling at such contact, and he imagines himself to be "free from race prejudice." But even for him there exists the point of racial recoil though it may be reached only at the altar or the grave. It is, after all, merely a difference of degree. Racial antipathy is a present, latent force in us all. As to this we need not deceive ourselves.

At no time in the history of the English speaking people, and at no place, of which we have any record, where large numbers of them have been brought into contact with an approximately equal number of Negroes, have the former granted to the latter absolute equality, either political, social, or economic. With the exception of five New England states, with a total Negro population of only 16,084 in 1860 , every state in the Union discriminated against the Negro politically before the Civil War. The white people continued to do so North as well as South - as long as they retained control of the suffrage regulations of their states. The determination to do so renders one whole section of the country practically a political unit to this day. In South Africa we see the same determination of the white man to rule, regardless of the numerical superiority of the black. The same determination made Jamaica surrender the right of self-government, and renders her satisfied with a hybrid political arrangement to-day. The presence of practically 100,000 Negroes in the District of Columbia makes 200,000 white people content to live under an anomaly in a self-governing country. The proposition is too elementary for dis- 


\section{The American Race Problem}

cussion, that the white man when confronted with a sufficient number of Negroes to create in his mind a sense of political unrest or danger, either alters his form of government in order to be rid of the incubus, or destroys the political strength of the Negro by force, by evasion, or by direct action.

If we survey the field of economic contact we find but one considerable area in which the white man permits the Negro to share his occupancy practically upon equal terms. That field is the Southern part of the United States. The unusual conditions there are the direct and immediate product of relations established or made possible by slavery - coupled with the maintenance of a rigid colour line, which minimises, if it does not prevent, racial friction. This condition, like the other purely artificial products of slavery favourable to amicable race relations, is changing, and will disappear with the increased tendency toward general uniformity of labour conditions and demands throughout the country. Such measure of freedom of economic opportunity as the Negro has is not due to any superior virtue on the part of Southern people, any more than is the larger political tolerance of the North due to any peculiar virtue of that section. Each situation is a mere incident of general racial conditions. Outside the South, whether in New York, Philadelphia, Chicago, the Middle West, or New England, the absence of economic racial friction is due to the economic segregation of the Negro. The race outside the South is in the main confined to humbler occupa- 


\section{Race Friction}

tions, where the absence of white competition makes for racial peace. I am speaking of the many, not of the exceptional few who here and there are not discriminated against. What is true of the North is true of South Africa. Economically, every country apparently is either a "white man's country" or a "black man's country." It does not exist half one and half the other - always excepting the South. In South Africa the great problem is to get white men to work at trades with black men, or to permit black men to work at them at all. The white colonist either monopolises a field himself - despite the fact that his numbers render the effort ruinous - or he permits the Negro to monopolise it. He will not share it equally.

But it is in the sphere of relations which the world calls social that the white man's attitude toward the Negro becomes most uncompromising - at least the attitude of the English speaking white man. This, too, is universal. This social prejudice is no respecter of geographical lines. Its intensity varies of course with local influences - primarily with differences of numerical distribution. But that is a mere superficial consideration. This form of "race prejudice," if we elect so to designate it, is probably more fundamental and far reaching than any other.

This fact is clearly recognised by Professor Kelly Miller, of Howard University, who says: "Where two races of widely different corporal peculiarities and cultivated qualities are brought into contact, serious frictional problems inevitably arise. - . The 


\section{The American Race Problem}

American Negro may speak the same language, conform to the same institutions, and adopt the same mode of religious worship as the rest of his fellow men, but it avails him nothing in the scale of social eligibility, which is the one determinative test of all true equality. . . Without social equality, which the Teuton is sworn to withhold from the darker races, no other form of equality is possible."*

I shall add this further reflection: If slavery is the cause of race prejudice, why has slavery not produced it among the Arabs toward their Negro slaves? Slavery is not the cause, nor is the Christian religion its cure, nor does Mohammedanism or Catholicism prevent it. The reason of its non-existence among the Mohammedans is not because of Mohammedanism, but because the Mohammedan is an Arab or a Moor. It does exist among the Berbers of Morocco, notwithstanding their Moslem faith. These Berbers are not only prejudiced against the Negroes, but their prejudice has created continual unrest in Morocco, through their refusal to fully acknowledge the present Sultan because of his Negro blood. The reason this prejudice is less pronounced in Catholic than in Protestant countries is because of the fact that the Catholic countries which have had most to do with Negroes are mainly Latin countries, and the Latin's prejudice of colour is no where as strong as the Teuton's. Under similar racial conditions the Catholic Teuton is just as much influenced

\footnotetext{
* Southern Workman, November, 1900, pp. 601, 602. See also page 325 for fuller quotation.
} 
by racial antipathy as his Protestant brother. It is not a question of religion or slavery - of Protestantism or Catholicism. It is finally and fundamentally a question of race.

In spite of all our protestations of democracy, the people of this country are not superior in their racial charity to the people of other parts of the world. I question if we are even as liberal in that regard as the average of Caucasian mankind. I sometimes feel that the very democracy among American white men of which we boast so much develops a concomitant intolerance toward men of another race or colour. Without other fixed or established distinctions in our social order, we seem instinctively to take refuge in that of colour as an enduring line of separation between ourselves and another class. Now and then, as the Southern part of our country comes to be more dispassionately studied, an occasional observer finds himself puzzled by the conclusion that among its white population the South, taken as a whole, is the most democratic part of America. In the presence of the Negro, and by contrast and comparison, all white men are equal. A horizontal racial line is drawn between the two sections of the population. All on one side of the line are conceded certain privileges and a certain status, based not upon merit but solely upon the accident of colour. To the whole group on the other side of the line a certain status is assigned solely because of identity with another racial class. In each case what should be controlling differences within each 


\section{The American Race Problem}

group, along certain fairly tangible lines, are wholly ignored. In steadily increasing degree, it seems to me, certain privileges and a certain place in the larger life of the country are coming to be regarded as the peculiar and particular asset of Caucasian racial affiliation.

We have seen the fulfilling of DeTocqueville's prophecy that emancipation would be but the beginning of America's racial problems. The history of the world is a more open book to-day than it was a half or threequarters of a century ago, and we have a larger perspective of racial contact. One of the editors of "The Wealth of Nations" has justly said that Adam Smith was instrumental in bringing different nations and cities closer together through a realisation of their interdependence. But there is apparently a line which distantly related races cannot yet cross in safety. Such races have been brought into more intimate contact since the great economist lived, and the association has given rise to problems unknown to his generation, yet probably as old as the time when the first two groups of strangers on earth came together in suspicion and distrust. The diverse peoples of the world do not yet understand each other. Perhaps they never shall. We have no excuse if we wilfully blind ourselves to the stubbornest facts in human experience, and persist in regarding racial antipathy, or "race prejudice," as a mere passing relic of slavery, peculiar to one part of the country. We can make no progress even in the comprehension of our problem 


\section{Race Friction}

if we circumscribe our vision by any such narrow view. It was Jefferson's opinion that the emancipation of the American Negro was one of the inevitable events of the future. It was also his conviction that the two races could never live together as equals on American soil. His solution was colonisation, but the time for that had probably passed when he wrote. As late as I $862 \mathrm{Mr}$. Lincoln expressed practically the same opinion as Jefferson's. To a delegation of Negroes he said: "You and we are different races . . . Your race is suffering, in my judgment, the greatest wrong inflicted on any people. But even when you cease to be slaves, you are yet far removed from being placed on an equality with the white race . . . The aspiration of men is to enjoy equality with the best when free, but on this continent not a single man of your race is made the equal of a single man of ours. Go where you are treated the best, and the ban is still upon you."*

To me the problems of racial contact, of which friction is but one, seem as inevitable as apparently they did to DeTocqueville and Jefferson and Lincoln. But I have no solution - because of my conviction that in a larger, final sense there is no solution of such problems - except the separation of the races or the absorption of one by the other. And in no proper conception is either of these a "solution." We do not solve a problem in geometry by wiping from the blackboard the symbols which are the visible expression of its terms. The question which the American people

* "Works of Abraham Lincoln," Nicolay and Hay, N. Y., x 894, II., pp. 222-225. 


\section{The American Race Problem}

must first be prepared to answer, if they demand a solution of their problem, is whether, within a period which may be practically considered, they will grant to another race, darker, physically different, and permanently distinguished from themselves, all and singular the rights, titles, and privileges which they themselves enjoy, with full and complete measure of equality in all things, absolutely as well as theoretically. If they can do this, they will reverse the whole history of their own people, and until they do it, not only will there be race friction here, but it will increase as the weaker race increases its demands for the equality which it is denied.

Thus we return to the first branch of our inquiry the attitude of the Negro as one of the determining factors in the increase or decrease of race friction. It is more difficult to answer for him than for the white man. The latter has a history in the matter of his relations with other races-perfectly well defined to anyone who will study it candidly. He has either ruled or ruined - to express it in a few words, and pretty often he has done both. It has been frequently said that the Negro is the only one of the inferior, or weaker, or backward, or undeveloped races (the terms are largely interchangeable and not at all important), which has ever looked the white man in the face and lived. But for all the significance the statement holds we have only to go to Esop's fable of the tree which would, and the tree which would not, bend before the storm. I know of no race in all history which possesses 


\section{Race Friction}

in equal degree the marvellous power of adaptability to conditions which the Negro has exhibited through many centuries and in many places. His undeveloped mental state has made it possible for him to accept conditions, and to increase and be content under them, which a more highly organised and sensitive race would have thrown off, or destroyed itself in the effort to do so. This ability to accept the status of slavery and to win the affection and regard of the master race, and gradually but steadily to bring about an amelioration of the conditions of the slave status - made possible the anomalous and really not yet understood race relations of the ante bellum South. The plain English of the situation was that the Negro did not chafe or fret and harass himself to death, where the Indian would have done so, or massacred the white man as an alternative. In many respects the Negro is a model prisoner - the best in this country. He accepts the situation generally speaking - bears na malice, cherishes no ill will or resentment, and is cheerful under conditions to which the white man refuses to reconcile himself.

This adaptability of the Negro has an immediate bearing on the question before us. It explains why the Negro masses in the Southern states are content with their situation, or at least not disturbing themselves sufficiently over it to attempt to upset the existing order. In the main, the millions in the South live at peace with their white neighbours. The masses, just one generation out of slavery and thousands of them still largely controlled by its influences, accept the 


\section{${ }_{23}$ The American Race Problem}

superiority of the white race as a race, whatever may be their private opinion of some of its members. And, furthermore, they accept this relation of superior and inferior, as a mere matter of course - as part of their lives - as something neither to be questioned, wondered at, or worried over. Despite apparent impressions to the contrary, the average Southern white man gives no more thought to the matter than does the Negro. As I tried to make clear at the outset, the status of superior and inferior is simply an inherited part of his instinctive mental equipment - a concept which he does not have to reason out. The respective attitudes are complementary, and under the mutual acceptance and understanding there still exist unnumbered thousands of instances of kindly and affectionate relations relations of which the outside world knows nothing and understands nothing. In a Boston coloured magazine some months since,* Miss Augusta P. Eaton gives an account of her settlement work among Negroes in that city. In describing relations where coloured and white families live in contact, she says: "The great bond of fellowship is never fully established. There is tolerance, but I have found few cases of friendly intimacy." Here is just the difference between the two situations. "Friendly intimacies," probably not in the sense meant by Miss Eaton, but friendly and kindly intimacies none the less, do exist in the South, despite all we hear to the contrary. They are the leaven of hope and comfort for white and black alike

\footnotetext{
*Alexander's Magazine, June, r907, p. 93.
} 


\section{Race Friction}

in what does appear to be a pretty big lump of discord. In the mass, the Southern Negro has not bothered himself about the ballot for more than twenty years not since his so-called political leaders let him alone; he is not disturbed over the matter of separate schools and cars, and he neither knows nor cares anything about "social equality."

"I believe there may develop in process of time and evolution a group of contented people, occupying a position somewhat analagous to that of the Jamaican peasant class, satisfied in the enjoyment of life, liberty, and the pursuit of happiness, and afforded the full protection of the law." I believe it is possible for each of the various groups of the two races which find themselves in natural juxtaposition to arrive at some basis of common occupancy of their respective territories which shall be mutually satisfactory, even if not wholly free from friction. I express a belief that this is possible - but to its accomplishment there is one absolute condition precedent: they must be let alone and they must be given time. It must be realised and accepted, whether we like it or not, that there is no cut and dried solution of such problems, and that they cannot be solved by resolutions or laws. The process must be gradual and it must be normal, which means that the final basis of adjustment must be worked out by the immediate parties in interest. It may be one thing in one place and another thing in another place - just as the problem itself differs with differences of local conditions and environment. We must realise that 


\section{The American Race Problem}

San Francisco is not Boston - that New Orleans is not New York. Thus much for the possibilities as to the rank and file.

But what of the other class? The "masses" is at best an unsatisfactory and indefinite term. It is very far from embracing even the Southern Negro, and we need not forget that seven years ago there were 900,000 members of the race living outside the South. What of the class, mainly urban and large in number, who have lost the typical habit and attitude of the Negro of the mass, and who, more and more, are becoming restless, and chafing under existing conditions? There is an intimate and very natural relation between the social and intellectual advance of the so-called Negro and the matter of friction along social lines./ It is in fact only as we touch the higher groups that we can appreciate the potential results of contact upon a different plane from that common to the masses in the South. There is a large and steadily increasing group of men, more or less related to the Negro by blood and wholly identified with him by American social usage, who refuse to accept quietly the white man's attitude toward the race. I appreciate the mistake of laying too great stress upon the utterances of any one man or group of men, but the mistake in this case lies the other way. The American white man knows little or nothing about the thought and opinion of the coloured men and women who to-day largely mould and direct Negro public opinion in this country. Even the white man who considers himself "a student of the race 


\section{Race Friction}

question" rarely exhibits anything more than profound ignorance of the Negro's side of the problem. He does not know what the other man is thinking and saying on the subject. This composite type which we poetically call "black," but which in reality is every shade from black to white, is slowly developing a consciousness of its own racial solidarity. It is finding its own distinctive voice, and through its own books and papers and magazines, through its own social organisations - is at once giving utterance to its discontent and making known its demands.

And with this dawning consciousness of race there is likewise coming an appreciation of the limitations and restrictions which hem in its unfolding and development. One of the best indexes to the possibilities of increased racial friction is the Negro's own recognition of the universality of the white man's racial antipathy toward him. This is the one clear note above the storm of protest against the things that are - that in his highest aspirations everywhere the white man's "prejudice" blocks the coloured man's path. And the white man may with possible profit pause long enough to ask the deeper significance of the Negro's finding of himself. May it not be only part of a general awakening of the darker races of the earth? Captain H. A. Wilson, of the English army, says that through all Africa there has penetrated in some way a vague, confused report that far off somewhere, in the unknown, outside world, a great war has been fought between a white and a yellow race, and won by the yellow man. 


\section{The American Race Problem}

And even before the Japanese-Russian conflict, "Ethiopianism" and the cry of "Africa for the Africans" had begun to disturb the English in South Africa. It is said time and again that the dissatisfaction and unrest in India are accentuated by the results of this same war. There can be no doubt in the mind of any man who carefully reads American Negro journals that their rejoicing over the Japanese victory sounded a very different note from that of the white American. It was far from being a mere expression of sympathy with a poople fighting for national existence against a power which had made itself odious to the civilised world by its treatment of its subjects. It was, instead, a quite clear cry of exultation over the defeat of a white race by a dark one. The white man is no wiser than the ostrich if he refuses to see the truth that in the possibilities of race friction the Negro's increasing consciousness of race is to play a part scarcely less important than the white man's racial antipathies, prejudices, or whatever we may elect to call them.

In its final analysis the sum and substance of the ultimate demand of those Americans of African descent whose mental attainments and social equipment identify them much more closely with the Anglo-Saxon than with the Negro masses, is definitely and clearly stated in the words of Dr. DuBois: "There is left the last alternative - the raising of the Negro in America to full rights and citizenship. And I mean by this, no half-way measures; I mean full and fair equality. That is, the chance to obtain work regardless of colour, 


\section{Race Friction}

to aspire to position and preferment on the basis of desert alone, to have the right to use public conveniences, to enter public places of amusement on the same terms as other people, and to be received socially by such persons as might wish to receive them. These are not extravagant demands, and yet their granting means the abolition of the colour line. The question is: Can American Negroes hope to attain to this result?"*

With equal clearness and precision, and with full comprehension of its larger meaning and significance and ultimate possibilities, the American white man answers the question in the language of another eminent American sociologist, Professor Edward A. Ross, in contrasting the attitudes of Anglo-Saxons and Latins toward other races on this continent: "The superiority of a race cannot be preserved without pride of blood and an uncompromising attitude toward the lower races . . . Whatever may be thought of the latter policy, the net result is that North America from the Behring Sea to the Rio Grande is dedicated to the highest type of civilisation; while for centuries the rest of our hemisphere will drag the ball and chain of hybridism." $\dagger$

And thus the issue is joined. And thus also perhaps. we find an answer to our own question, whether racial friction in this country is increasing and inevitable.

* "The East and the West," January, r 904, p. 16

t"The Foundations of Sociology," 1905, p. 379. 


\section{VII}

\section{Mr. Roosevelt, the South, and the Negro*}

\section{T N GREATER degree than that of any other President 1 since the Negro was set free has Mr. Roosevelt's administration been the storm centre of the modern} American race problem. It is probably safe to say that he went into the White House without having given a thought to the question of formulating a "Negro policy." It is equally safe to say that he has not at any time in his official career been guilty of the childish whim of deliberately offending any section of the country. Yet before he had been in office many months he succeeded in offending the South as no other

\footnotetext{
*The following paper is an attempt to interpret the true significance of the incidents which led to the estrangement between Mr. Roosevelt and the Southern people. These incidents are treated in their relation to the American race problem. There is no such barren purpose as that of stirring dead embers. It is not intended to discuss the mere facts themselves. The object is to endeavour to discover the meaning of the attitudes which the Negro and the South respectively assumed toward the President, as determined by certain executive actions with which those parties were concerned. The spirit is not controversial, howsoever far the words may have inadvertently departed from their proper purpose. The incidents are first stated and the meaning which the South and the Negro attached to them is suggested. The historical reasons underlying the attitude of the South are traced, and the logical relation between such attitude and the period of reconstruction is sought to be established. The psychological force of suggestion is pointed out. The real significance to the Negro of one of the incidents is shown. Its interpretation is given as a manifestation of a developing consciousness of race, the true import of which has been lost sight of in preoccupation with the incident itself. In conclusion, there is indicated the historical association which Mr. Roosevelt's "referee system" possessed for the Southern people, as a contributing element of discord.
} 


\section{Mr. Roosevelt and the Negro}

public man has done in recent years. Before a year had passed he had adopted a well-defined policy toward the political aspect of the race problem. This policy was simple enough. Its one tenet was that colour should not bar him from making political appointments. He doubtless thought that the Constitution was a safe enough platform for a President to stand upon, even as regards the race problem. And so it would be, if the latter were something which had respect for the artificial metes and bounds laid down in our organic law. Fortunately or unfortunately, according to one's point of view, it is beyond the control of any legislative act which the ingenuity of man has thus far been able to devise. Mr. Roosevelt's attempted application of his policy to the field of practical conduct, his general attitude, the hue and cry which his actions at once aroused, the inability of the South and the President to understand each other, the inability of the North to understand the South and its attitude toward him, all furnish an inviting field for study to anyone interested in the problems of American democracy.

\section{The Facts in the Case}

Three incidents marked the progress of the controversy which broke upon the country shortly after Roosevelt's succession to the presidency. These were the Booker Washington dinner, the appointment of Crum, and the closing of the Indianola post-office. There were four parties in interest - Mr. Roosevelt, the 


\section{The American Race Problem}

Southern press and people, the Northern press and people, and the American Negro. The attitude of the first three will be stated in general terms. The President acted clearly within his "rights" in each case. This point must be conceded without argument. The dinner episode was in itself no more than a matter of White House routine. It was more a business conference than a social function.*

There is no reason to believe that either party to the much magnified affair regarded it in any other light. Such instances are of daily occurrence and are familiar to all readers of Washington papers. They are announced as locals, in two or three line statements to the effect that "yesterday at luncheon," or "last night at dinner," Mr. Blank "discussed with the President the question of Western forest reserves," or something

\footnotetext{
* Francis E. Leupp gives the following authentic account of the incident: "I happen to know that this affair was not of Mr. Washington's seeking. $\mathrm{He}$ had been sent for because the President wished to consult him on a special subject. Realising that any needless publicity given to his relations with the President might lay him open to the suspicion of having political ends to serve and thus interfere with his educational work, he wished to avoid newspaper mention of his visit to the capital as far as possible. To that end one of his friends came to me in his behalf for advice as to how he could get into and out of the city and make his brief call at the White House without meeting any reporters. I suggested a plan which worked admirably as far as it went, but failed at its final stage because we could not very well make the President a party to it. Mr. Washington escaped the dreaded interviewers, but fell a victim to the routine of the executive mansion. It was a custom, devised for the convenience of the local press, to furnish to the doorkeepers the names of all guests received by the President out of office hours, and the doorkeepers communicated this list to any reporter who called in the evening. The uniform practice was followed in this instance, and the next morning's Washington Post contained a two-line paragraph, in an obscure place at the bottom of an inside page: 'Booker T. Washington, of Tuskegee, Ala., dined with the President last evening.' These facts appear here for the first time in print, because I feel that their correct statement is only just to both parties to the dinner episode. It was highly creditable to Mr. Washington that he did nothing to promote, but everything in his power to prevent, the exploitation of the honour shown him."-"The Man Roosevelt," Francis E. Leupp, pp. 218-219.
} 
else equally lifeless. On the day in question the usual perfunctory announcement was charged with dynamite, through the casual insertion of the name of Booker T. Washington.*

Within forty-eight hours the President was being denounced for having crossed the "social equality" dead-line, through breaking bread with a Negro. Surprise was probably the first emotion excited in the mind of Mr. Roosevelt by the storm which burst upon him from the South. But for once he was silent. There was no official "announcement" from the White House.

Not until three years later did he state his position, and then it was as an abstract, unrelated proposition. This was the declaration, in his New York Lincoln Day race problem address, that social association between the races was a matter of purely private and personal interest between the parties concerned.

The attitude of the South was one of general disapproval. In some instances the disapprobation was couched in violent and abusive terms. In many the tone was one of dignified resentment. By some papers the affair was dismissed as not worth noticing. The one

* "Booker T. Washington, of Tuskegee, Alabama, dined with the President last evening." -Washington Post, Oct. I7, r 90 r, p. 3, col. 8, bottom of page. "Prof. Booker T. Washington was in the city yesterday, and dined with the President last night. While here he was the guest of Mr. Whitefield McKinlay." -Washington Star, Oct, r 7, r gor, p. r, col. 6 . The item furnished by wire to the Southern press was in the main similar to the following: "Washington, Oct. r6. Booker T. Washington, principal of the Negro school at Tuskegee, Ala., dined with the president this evening. It was largely at Washington's suggestion that ex-Governor Jones of Alabama was appointed a judge on the Federal bench in that State. It is understood that Washington will make a number of recommendations for appointments in the South, but just what they are cannot be learned yet. He seems to be very influential with the administration." - Memphis Commercial Appeal, Oct. I 7, r gor. 


\section{${ }_{246}$ The American Race Problem}

universal note was that the incident would have a harmful effect on the relations between the races.*

The attitude of the Northern press was generally an unqualified defence of the President, with an occasional questioning of the wisdom of his act. Of course the inevitable newspaper controversy at once ensued with the usual result of adding nothing either to sectional good feeling or to sectional enlightenment.

Before these echoes had died away the other two incidents occurred. When Dr. Crum was appointed to the collectorship of the Port of Charleston the Presiident did not hesitate to define his position. He took and maintained the ground that unless some valid reason, other than colour, could be urged against the appointment it would stand. It was in this connection that he issued his "door of hope" declaration, in an open letter to a Charleston man. The nomination was finally confirmed, and Crum is still in office. The attitude of Southern papers was no less positive, though

\footnotetext{
* The following extracts are fairly illustrative of the social emphasis placed upon the incident by a number of Southern papers: "That was a deliberate act, taken under no alleged pressure o necessity, as in the Albany case, and may be taken as outlining his policy toward the Negro as a factor in Washington society. . . With our long-matured views on the subject of social intercourse between blacks and whites, the least we can say now is that we deplore the President's taste, and we distrust his wisdom."-Richmond Dispatch, Oct. 18, 190x. "There is not the least reason, however, to fear that his (Washington's) position in the South will be improved on this account. Call it what you please, call it prejudice, or race hatred, or significance, or what not, the people of the South have to deal with the coloured question as it is, and as it affects their civilization, and they may be depended upon to deal with it as it touches them and their interests. We do not know, of course, what we should have done if we had been in his place, but, knowing the conditions as they are, Washington might have protected the President from much unpleasant criticism, and himself and his people from possible injury, by respectfully declining the President's invitation."-News and Courier, Charleston, Oct. 2x, г90х. See Literary Digest, Oct. 26, 1901, pp. 486-487 for résumé of newspaper comment.
} 


\section{Mr. Roosevelt and the Negro}

in the main much more conservative in tone, in regard to this appointment than in reference to the dinner episode. The extreme Northern view found expression in threats of a reduction of Southern representation in retaliation for continued Southern opposition to a political "square deal" for the Negro. Some papers even suggested the possibility of another force bill. The position of the more conservative, or liberal, section of opinion was that of attempting to show the folly and injustice of attacking Roosevelt, by an argument based upon a comparison of the number of Negro appointments during his and McKinley's administrations.

Almost simultaneously with the Crum appointment came the closing of the Indianola post-office. The Negro postmistress was a Harrison and McKinley appointee, and had for some years held office under both administrations. Her resignation was requested by a so-called mass-meeting. It was tendered, but its acceptance was refused by the department. 'The postmistress declined to serve and the office was closed. Mail for Indianola was ordered sent to Greenville, twentyfive miles distant, though there were other offices nearer. Thus apparent spite was added to useless punishment.*

\footnotetext{
* Indianola is a town of 2,000 or 2,500 people. It is a place of large local business importance. It has banks, oil mills, compress, a $\$ 20,000$ public school building and a $\$ 40,000$ court house. It is the capital town of Sunflower County and the seat of circuit and chancery courts. In its character as the seat of a county government it is guaranteed postal facilities by Federal statute. The evasion of the law was accomplished by resorting to a rather petty subterfuge. The position was taken that the post-office had not been "abolished," but merely temporarily "closed." The act was clearly punitive in intent. If there was anything unlawful in the conduct of those who asked the resignation, the United States Court could easily have been resorted to. It was in charge of Republican officials, some of them Mr. Roosevelt's own appointees.
} 


\section{The American Race Problem}

Mr. Roosevelt again became silent. He gave out no statement in regard to the case. Southern papers denounced him as guilty of a "high-handed outrage." Northern papers denounced the white people of Indianola for having "intimidated and bullied" the postmistress into resigning. With practical unanimity they upheld the President's course, and saw in the deprivation of the entire town of postal facilities, on account of the alleged "lawless conduct" of a few of its people, only an act of righteous justice. The most significant feature of this affair, it may be remarked in passing, is the fact that the Indianola post-office is open to-day, with a white postmaster, while the former postmistress and her husband are still residents of the town, and enjoy the confidence and regard of its white people.

Query: Why could not the powers that be have recognised the inevitable a few months earlier, and effected the final harmonious adjustment without the intervening process of Sturm und Drang. However, if things were always handled that way we would be approaching dangerously near a dissolution, if not a solution, of the race problem.

The attitude of the fourth party, the Negro factor, will be considered later.

If these incidents were mere tempests in a teapot, as was repeatedly declared by Northern papers, they would not merit thoughtful consideration. If the storm which they raised was a mere newspaper squall they might be dismissed as not worth an effort at analy- 


\section{Mr. Roosevelt and the Negro}

sis of their significance. But they had a deeper meaning. In a letter to the writer in March, 1903, the editor of one of the most ably conducted magazines in the North expressed the opinion that "the present irritation over Negro appointees is incidental and ephemeral." The irritation may have been ephemeral. But it is true of many inherently trivial incidents that they leave behind them a train of consequences whose import is out of all proportion to the irritating cause. The burdens of an administrative official are rendered doubly difficult in any country where to the ordinary affairs of government are added the necessity of dealing with two or more diverse racial elements. The capacity of such an official may be measured by his ability to weigh and determine in advance the reasonably probable consequences of acts in themselves unimportant, and then to chart a proper course across the reefs and shoals of racial complications. It is with the consequences and significance of the incidents before us, rather than with the incidents themselves, that we are here concerned.

\section{The Reconstruction Background}

In many of its most perplexing phenomena the American race problem is largely a matter of sentiment and psychology. It exhibits few manifestations which a just apprehension of the very essentials of the problem, the factors of race, might not have discounted in advance. The chief difficulty has been that the treatment of the modern American problem has been char- 


\section{$25^{\circ}$ The American Race Problem}

acterised throughout by an incomprehensible disregard of these essentials. Its history since $186_{5}$ is an almost unbroken succession of policies and conduct based upon the assumed non-existence of any such fundamental complicating factor. The entire question has from the very beginning been made the plaything of partisan politics, rather than the grave concern of nonpartisan statesmanship. If England had adopted toward her numerous and widely scattered racial problems the peculiarly American attitude, her colonial empire would have been a miserable failure, instead of a bulwark to the Mother Country. If we had attempted to apply to the racial problems which have confronted us in the Philippines the same policy which we apply to our race problem at home, we would have made of ourselves a laughing-stock in the eyes of the world.

It is not uncommon to charge that the South attempts to lay too much responsibility for existing conditions upon the blunders of reconstruction. Theories of incidence are often difficult to apply, whether in economics or politics. The ultimate placing of responsibility is not always an easy problem to solve. Cause and effect are not always readily associated. The correlation is sometimes difficult to establish or apprehend. It has occasionally been declared in reply to this position that the Southern people themselves were responsible for reconstruction, and are responsible for present conditions, because "they hardened their hearts and would not let their people go." Causal association 


\section{Mr. Roosevelt and the Negro 25I}

between the South's failure to voluntarily adopt some plan of emancipation, and the problems which to-day confront her people, cannot be established. The two propositions are too remotely removed. This is too great a straining of the post hoc, ergo propter hoc to be practically tenable ground. We would as well seek to locate the trouble with those responsible for the first importation of African slaves in r6rg. On the other hand, the connection between reconstruction policies and incidents and existing race problem phenomena is that of direct and historical sequence.

Booker T. Washington discloses the connecting link in a single sentence. With the judgment which has always marked his consideration of policies affecting his people, he declares that relations of kindliness and friendship between the Southern white man and the Negro afford the latter "a protection and guarantee of his rights that will be more potent and more lasting than any our Federal Congress or any outside power can confer."* The complement of this proposition is that whatever tends to break down such amicable relations also necessarily tends to erect, and leave in their place, relations of a less kindly, if not positively hostile, nature. The essence of the race problem is that of the peaceful common occupancy of the same territory by two widely differing people. Whatever builds up amicable relations between these tenants in common tends to minimise the problem of their tenancy. Whatever tends to create friction between

\footnotetext{
* "The Future of the American Negro," p. 216.
} 


\section{The American Race Problem}

them renders their problem more acute. It is only necessary to show what effect our particular method of inaugurating the novel relations of freedom upon the old relations of slavery had upon the new relations themselves, to determine the measure of responsibility of the system for its results. If it is shown that the system and policies of reconstruction tended to destroy those relations which $\mathrm{Mr}$. Washington now regards as the chief guarantee of the right of his people, and that the replacing of these natural relations by the purely artificial guarantees of legislation tended to create racial friction, then the responsibility of the system for certain of its consequences would seem to be established.

To take the ground that all the complicated phases of the modern problem of race relations are attributable to Reconstruction, or to any other one line of policy, anywhere or at any time, would be to assume a wholly untenable position. The simpler the form of relation between two different races the simpler will be the problems between the two; the more complex the relation the more complex its problems. The simplest relation that could exist between the white and Negro races, in the mass, was that of the physical control of one by the other. The most complex relations that can exist between the two, or between any racial groups, are those predicated upon a condition of actual or technical equality. And the complications to which this relation gives rise will be difficult and severe in proportion to the degree of artificiality which characterises 


\section{Mr. Roosevelt and the Negro 253}

the equality sought to be established. The greater the natural differences in the way, the more complicated and serious will be the problems incident to the artificially created relations. The mere grant of immediate freedom to a large mass of Negro slaves would inevitably have produced its own racial problems. Every step taken toward the removal of the further barriers between white and black multiplied such problems and created new ones. The only escape from a cataclysm lay in allowing sufficient time to elapse between the removal of one barrier after another for the races to adjust their relations to the change along normal lines. But this would not have been "Reconstruction." That was a process the logical dogma of which was the proposition that nature has erected no barrier to racial equality which legislation cannot remove.

The only defence which can be attempted of the policy of giving the Negro the ballot in 1867 , and of confirming the grant in 1870 , is that it was necessary to enable him to "protect" himself. The very thought suggests the idea of a conflict between former master and slave. Apparently it has been impossible for politicians and publicists to comprehend the existence of the relation of master and slave without a resulting state of inconceivable hostility between the individuals thus associated. We are prone to interpret the things which affect other people in terms of our own consciousness. This is the basic error of many people who discuss the problems before us. They would be miserable and unutterably wretched in a state of "bondage," 


\section{The American Race Problem}

ergo, the Negro was miserable and wretched. The mistaken policy of Reconstruction was but the practical application of a mistaken theory of race relations under slavery.* Many thoughtful men were amazed that the Negroes did not massacre their masters at the first opportunity. There is no escape from the candid conclusion that $\mathrm{Mr}$. Lincoln had prepared himself to accept a "servile insurrection" as an entirely possible result of his calling Negro slaves to freedom and to arms. That none of these things occurred has been ascribed to the "forgiving and benignant gentleness" of the Negro. It is only occasionally that someone sees deeply enough to realise the whole truth.

We need not take too literally the pleasing romances which deal with Southern ante bellum life, in order to realise the fact that there was much in the relations between the races under the old régime which was, and is, incomprehensible to the mind of anyone to whom slavery was merely the sum of all villainies. On the one hand we have balls and chains, auction blocks and weeping children, bloodhounds and swamps, the slave driver and the lash - all the accessories and paraphernalia necessary to equip a Southern plantation in a New England novel. On the other, we have the big house and its gentle mistress, the kind and indulgent master, the black mammy, the enduring friendship between the races, the Christmas frolics, and the various other things which live in the picture painted upon

* I am here eliminating from consideration all the baser motives of that policy, and am reviewing only that which honestly, even though mistakenly, sought the welfare of the Negro. 


\section{Mr. Roosevelt and the Negro 255}

another canvas. We need not be deceived on either side. The truth will usually be found between any two given extremes.

Slavery was neither all the one nor all the other. It was essentially a human institution, and as such was no better and no worse than the individuals with whose lives it was inseparably associated. It was mild or harsh as the individual was mild or harsh. The history of its relations has not been written, and probably will not be by this generation. By whomsoever the task may be assumed, two people will have to collaborate in the work - a Southern Negro and a Southern white man. And the record will miss an essential truth if it fail to recognise the great potential force for usefulness in adjusting succeeding relations which was bound up in the ties which existed between the higher type of master and the higher type of slave. We are apt to miss this truth, through dwelling on the limited number of the higher domestic class as compared with the whole. We fail to realise that it was this higher class, in the main mulatto types, who in such large measure constituted the "Negro" leaders of the Reconstruction era. It was through them that a great beneficent force might have been exerted upon the mass, just as it was through them that this force was in fact too largely exerted for evil. Such men as Hampton, Lamar, Hill, and Gordon on the one side, and Revels, Bruce, and many more on the other, both bond and free, might not have been able entirely to control their respective constituencies. It is morally certain, however, that 


\section{The American Race Problem}

acting together, as under normally developed conditions they would have acted, they could and would have brought to bear a powerful pressure for good. That the normal relations between these men were all too nearly destroyed is one thing for which Reconstruction was immediately responsible. We have abundant testimony as to what in very large degree such relations were under slavery, and much from people of colour themselves. As barely suggestive only, we give two or three expressions from men who certainly cannot be charged with partiality toward the institution itself:

Dr. DuBois says: "Nothing has come to replace that finer sympathy and love between some masters and house servants, which the radical and more uncompromising drawing of the colour line in recent years has caused almost completely to disappear."*

With a touch of genuine pathos Professor Councill says: "The Negro must just take his chances. That is all. When the old, gray-haired veterans who followed General Lee's tattered banners to Appomattox shall have passed away, the Negro's best friends will have gone; for the Negro got more out of slavery than they did. 'Now there arose up a new King over Egypt, which knew not Joseph." '†

Mr. John Henry Smyth, of Virginia, ex-minister to Liberia says: "To my mind but one merit can be claimed for the old system of enslavement - a discipline as to labour which produced the best results to the

* "Annals of the American Academy," July, r gor, Vol. x8, No. x, p. 138.

$\dagger$ "The Future of the Negro," Forum, July, 1899, p. 575. 


\section{Mr. Roosevelt and the Negro}

master class and made the slave orderly and systematic in the performance of his tasks. Though smarting, even now, under the resultant influences of a destroyed system, we can afford to do justice to the good men and women of the white race who constituted a part of the system. Slavery as it has been known in the outside world, is not slavery as it was in the genteel and pious homes and households of the South. Here the 'people' were treated almost as members of the family, 'uncles' and 'aunts' and 'mammies' and playmates. They were necessary supplements, sharers of all great occasions of joy or sorrow, of feasts and sufferings. And the tenderest and most watchful care was bestowed upon them. Consideration for the servants was the test of the 'quality.' Mutual influences went to make as pure, high and beautiful a civilisation as the system was capable of. And no philanthropist on earth has ever had a deeper horror for the evils that have been represented as slavery in the South than many of the 'quality.' Nor anywhere was the wise abolition of slavery more earnestly studied and desired than by the good people of the Southern states." *

In an appreciation of "The Services of Dunbar," Mr. George Davis Jenifer says: "In those days when master and man were united in the bonds of slavery, there was abundant intercourse between the races and much of trustfulness and of affection. The black man's hand received the new born master; the black man's

\footnotetext{
* "Negro Criminality," John Henry Smyth, Southern Workman, Nov .. r900, pp. 628,629 .
} 


\section{${ }_{25} 8$ The American Race Problem}

feet were patient to stay beside the faltering baby steps of his charge and swift to the rescue when danger threatened; the black man chastened the unruly spirit of the child that it might grow strong and comely in character as a gentleman's spirit should; trembling with eagerness and affection, black hands clad the master for his marriage and when the white man's hour was come, black hands, faithful to the last, gently closed his eyes in death. In spite of slavery, the people of the South recognised a common humanity.

If habit tended to assuage the poignancy of this aftermath of war, and to restore the old affability between the races, time interfered; for the men of the old régime, both black and white, who had known and loved each other well, fast went the way of all flesh and new generations arose. . . Unto these, who should be brethren, comes Dunbar singing of the Negro, not as a beast, not as a fiend, but as a gentle, simplehearted man. And the Southern white man remembers again the traditional kindliness between his fathers and the fathers of his black neighbour; while the Northerner, perplexed to find a refutation of his theories, is disposed to be more generous. Possibly, then, when the future has witnessed a complete revival of that friendship between the races, for lack of which our common country suffers to-day, men may see fit to raise in our national capital a monument to the black poet, whose songs made two angry peoples mindful of their common brotherhood."*

*Voice of the Negro, June, 1906, pp. 408, 409. 


\section{Mr. Roosevelt and the Negro}

And comes also a discovery in the columns of the paper which probably more than any other in America still talks of the "Southern slave driving spirit," when it would typify the attitude of the Southern white man toward modern racial conditions. A special correspondent tells this paper of a favourable opinion of the Negro which he has found in the South: "This opinion," he says, "is confined, of course, to the better element of whites - mostly, one is bound to add, to the descendants of slave-owners."*

Of all the miserable heritage of Reconstruction, probably the most harmful, all things considered, was the bequest to this generation of the foundation and beginning of a peculiarly uncompromising, indiscriminating colour line, one such as was unknown in older days. $\dagger$ There is no other element in the present situation so pregnant with hurtful possibilities, no factor the inexorable operations of which are so difficult to escape. It is hard for a Southern man fully to understand the attitude of mind which persistently holds the belief that such relations as we have just suggested did not exist under slavery, or at best were rare and curious phenomena. That this was a fundamental tenet with thousands of honest and intelligent people is not a matter of debate. It is testified to by innumer-

* "Traveller," in New York Evening Post, Jan. 29, 1907, p. 7. col. 4.

† The purpose of this paper is to explain certain phases of conditions in which all of us, white and Negro, are more or less concerned. If in the pursuit of this object the writer seems occasionally to go somewhat far afield, it is only that he may weave into the narrative some more or less related thread. So here, he trusts he may be pardoned for following this digression one step further along the line of the historic background of modern relations. 


\section{The American Race Problem}

able specific declarations, by countless acts, by a policy too definitely based upon the theory to admit of doubt as to its controlling force. There was also always in evidence the corollary to this idea, a proposition equally as logical in its ignorance of fact. This was that, conversely, there must be, from the very nature and constitution of the Southern institution, a bond of unity and sympathy between the "oppressed Negro slave" and the "oppressed non slave-holding white man." To the Northern view they were the sharers of a common fate, and, upon the logic of well reasoned human conduct, they could be counted upon to make a common cause against their common oppressor. The great war governor of Massachusetts tells his people in 1865 to "remember that the poor oppressed democracy of Georgia and the Carolinas are their brethren." $\mathrm{He}$ warns against letting "sentimental politics surrender either them, or the black man, with whom they have shared the voiceless woe of his servitude. . . to the possibilities of any reactionary theory."*

Governor Andrew almost completely reversed his own attitude toward Reconstruction, but the logic of his counsel lived. Though he would have had it otherwise, the policy of that period was not addressed to the former slave owner, and it met with no response from those who were said to have "shared the voiceless woe" of the former slave. By no people in the South was the equalising programme of Congress more

\footnotetext{
* Governor John A. Andrew's address to Massachusetts Legislature, Jan. 6. x865. Massachusetts Senate Documents, x, pp. 96, 97,
} 


\section{Mr. Roosevelt and the Negro 26I}

bitterly resented and opposed. One inevitable result of that programme was to estrange from the Negro those men the habit of whose lives was that of personal kindliness to the race. There was created for the first time a partial identity of abstract attitude toward the Negro between the slave-holder and those whom the North vainly imagined were the only logical friends of the slave. But one division was permitted by the policy which allied the Negro with his new found Northern friends and taught him to regard his master as his enemy. Upon one side of this dividing line were the Negro and the carpetbagger; upon the other were the white people of the South, save the scalawag, without regard to previous party affiliation or other association, without question as to natural identity of interests or normal community of thought. The odium thus attached to political association between whites and blacks not only perpetuated itself in the popular mind, but communicated its taint to all other forms of public association as well. The community of interest between master and slave was destroyed, and hostility was the bitter fruit of the attempt to create a hopeless and senseless "equality" between the two.

But the old relations were too strong to be wholly broken down by even the iron policy of Reconstruction. To this day there yet survives more of ante bellum racial kindliness than the outside world, with its ignorant wisdom, is able to comprehend. But what remained was peculiarly personal. In all public affairs, wherever there was an open alignment of men, white 


\section{The American Race Problem}

men stood by white men, and the Negro stood by the stranger and the renegade. All public support of the Negro became measurably identified with the odium of this political association, and the Negro suffers the consequences. In any matter which becomes a question of race, in any matter wherein the white man is bound by public opinion to openly espouse one side or the other, as between that which is historically and sentimentally identified with the cause of his own people, and that which is identified with those who were their enemies in peace, there is little doubt as to where the decision will lie. From the warning of Councill we may read that the Negro in large part has himself to blame - himself and those who were the real creators of the Southern colour line.

The man who does not know, may catch some faint hint of the significance of this line as the coloured man sees it, if he will listen to Dr. DuBois. $\mathrm{He}$ says: "It is usually true that the very representatives of the two races who for mutual benefit and the welfare of the land ought to be in complete understanding and sympathy are so far strangers that one side thinks that all whites are narrow and prejudiced and the other thinks educated Negroes dangerous and insolent. Moreover, in a land where the tyranny of public opinion and the intolerence of criticism is for obvious historical reasons so strong as in the South, such a situation is extremely difficult to correct. The white man as well as the Negro is bound and tied by the colour line, and many a scheme 


\section{Mr. Roosevelt and the Negro $\quad 263$}

of friendliness and philanthropy, of broad-minded sympathy, and generous fellowship between the two has dropped still-born because some busybody has forced the colour question to the front and brought the tremendous force of unwritten law against the innovators."*

As I look back over the events which followed the Civil War, and think of the sundered race relations of the period which preceded it, I feel as a supreme conviction that if any one of the Southern states had been a far off island in the sea, it would have known no such problems as were forced upon it from without; but that the best in its life, both white and black, would have given the world such an example of the possibilities of racial coöperation along normal lines as it has not the benefit of to-day in all its wide experience.

For a student of race relations, seeking light upon the results of the artificial adjustment which followed the Civil War, rather than upon the barren facts of such adjustment, most of the literature which deals with the period possesses little value. It is of course worth while to know with accuracy just what the "Black and Tan" legislatures of Southern states spent on their printing bills and stationery accounts. The truth should of course be established as to the public debts which they did or did not create. Also by all means let them be given credit for the good they did, as well

* "The Relation of the Negroes to the Whites in the South," W. E. B. DuBois, "Annals of the American Academy of Political and Social Science," July, I 901, pp. 137, 138. 


\section{The American Race Problem}

as the evil, and for all of the former which research can bring to light.

But this was but a comparatively small part of Reconstruction, as that term was seared into the minds and hearts of Southern people. Tradition may not be history, but if we would interpret the meaning and significance of the great epoch-marking events in the life of a people, we must take account of the one as well as of the other. History was handed down by word of mouth before it was recorded with the pen. For the light we need it is idle to point out with scientific exactness that in actual fact technical "Reconstruction" lasted just so many months and weeks and days. For this purpose it is equally idle to point out the exact part which the Negro played in those troubled times - to give the number of Negro voters in each state and county, and the number who were members of state legislatures. This writer has more than once declared that unscrupulous mulattoes and white men - carpetbaggers and scalawags - have more and greater sins to answer for in Southern political history than the Negroes who became their ignorant dupes and tools. The latter have simply shared the catspaw's fate. And of this one crime against the Negro, that of deliberately pitting him against his former master in a contest about the inevitable end of which there could have been no shadow of doubt, the South can wash its hands. It did not invite the unequal contest.

What, then, is this thing which we call "Reconstruc- 


\section{Mr. Roosevelt and the Negro 265}

tion"? In the South it is that period of misery which covered the decade or more between 1865 and 1875 or 1880 , and measured the time during which the control of their domestic affairs was lost and regained by Southern white men. It is in popular comprehension the more or less clearly defined, but always darker, part of the bitter twenty years after 1860 , during which the South was the scene of war, rehabilitation and the undoing of the latter process. It was the period during which, amid the wreck of its old order and in the midst of its poverty, it was delivered up, as President Hyde, of Bowdoin, puts it, in the name of racial equality to political and social chaos. And these people trod the wine press alone. They were pilloried in public print, "investigated" time after time, almost as a holiday task, and "reported on" by committees of hostile congresses. They were cartooned by the pen of Thomas Nast, their every fault was hunted out and magnified and set upon a hill, for all the world to gaze at as typical of "a barbarous people." Their misfortunes were paraded as the well earned fruit of treason. They were branded and set apart in outer darkness, to work out their salvation as best they might, under a handicap such as has not been imposed upon any other group of English-speaking people in modern times.

We are faced with the simple but pregnant fact that since 1865 the Southern people have constituted what is probably the most doggedly determined and compact body of men this country has known. Racial solidar- 


\section{The American Race Problem}

ity has become the fixed and natural habit of their thought and lives. People running well into the millions in numbers and occupying a vast expanse of territory, do not, cannot, maintain such an attitude through an unbroken reach of more than forty years without the existence of some great fundamental reason. It is folly to suppose that this could be kept up as a result of "senseless race prejudice." We must account for conditions of such significance, when we write wise monographs on the "Negro question" or learnedly descant upon the best methods of spreading education for the developing of "backward Southern civilisation." Much as we might like to forget this period of our history, it cannot be ignored. The race problem is a broad one, and these conditions form one of its essential parts - the forbidding background of the recent past, upon which the picture of the present must be thrown if all its lights and shadows would be brought to view.

\section{The Association of Ideas}

It is a far cry from Southern Reconstruction to the present peace-loving chaplain of the United States Senate. Yet Dr. Hale gives us a clue which should help us to understand how the stress of the Negro's first days of freedom is naturally associated with that of his later life. In one of his "Tarry at Home Travels" the venerable New Englander indulges the following reflective passage: "The French always brought 


\section{Mr. Roosevelt and the Negro 267}

Indians with them. And you may charge it to the French religion or not, as you choose, but the savage warfare which they carried on under French direction was of the most horrible kind. If anybody cares, it is to be observed that the hatred of the Roman Catholic Church which existed formerly in New England was due to the memory that the savage raids of the eighteenth century were in all instances mixed up with French invasion, and were ascribed by the sufferers, more or less, to the machinations of Latin priests." *

One of the simplest psychological processes of the human mind is that of the association of ideas. And, "if anybody cares," it operates as effectively in the South in associating the Negro in politics with the odium of a hundred acts of Reconstruction days, which apparently lie beyond the reach of history, as it did in New England in associating Catholicism with Indian massacres. And we might call on psychology to help us interpret more than one other phenomenon which seems to puzzle the race problem specialist. The writer has a friend, born and reared and living in a Northern state, whose family was "expelled" from Haiti at the time of its slave insurrection. His people suffered unspeakable barbarities in the process. Whether or not family tradition has magnified those sufferings might interest the historian bent upon an exclusive search for time-worn actualities. It is not of so much concern to our present purpose as is the knowledge of the very real and existing fact that this man can with

*Outlook, May 6, 1905, p. 76. 


\section{The American Race Problem}

difficulty to-day tolerate a Negro in his presence. Yet he is a kindly man and a just.

A picture comes to my mind of a gentle, almost womanly tender old man, telling in the monotone of age, around a winter's fireside, some of his Reconstruction experiences - the kind which only Southern children have heard from reminiscent lips, the kind which find no place in Reconstruction histories. He had surrendered in good faith at Appomattox, and had found his way back to the place he had once called home, thinking in his heart that war and invasion were really over, now that the fighting was done. He told of the humiliations and heartburnings and bitter things which followed the second invasion. And of how mild and commonplace by comparison became the incidents of real war, in which he had been given a fighting man's chance. He told of how he had been arrested by a Negro bureau officer upon some trivial charge. He was a peaceable and law-loving man, and accompanied his custodian without hesitation or suspicion. The bureau headquarters were some distance away and the night was bitter cold. Darkness coming on, the officer suggested stopping at a Negro cabin for the night. $\mathrm{He}$ demurred, but finally consented. While standing in front of the fire he was suddenly seized by the officer and his Negro host. He was tied hand and foot and taken to the stable lot. Here a rail fence was raised and his head thrust under it, his neck resting on the bottom rail. In this position he was left during the long winter night, his face beat upon by driving sleet, 


\section{Mr. Roosevelt and the Negro 269}

his war-worn body racked with pain. That was a long while ago, and he all but smiled as he told the story - a queer, non-humorous sort of smile. I dare say it would be almost a useless waste of time to tell him and his family and his country neighbours that the so-called "horrors of Reconstruction" were in fact, upon the latest scientific analysis, found and actually demonstrated to have been mere creations of the overwrought Southern mind.

And how many such "trivial incidents," as the great world's history is measured, incidents long since forgotten elsewhere, were necessary to create a more or less fixed and definite mental attitude toward the period with which they are inseparably associated? Scattered throughout all this region there were enough and to spare. Each county, each little community or isolated group, has in its own simple way its own tales to tell to its children - even though they may not be recounted in the books from which we learn the history of that time.

If you live in a part of the world where present environment makes it possible to do so, attempt to frame for yourself a picture of the horrors through which the white people of Haiti lived during the inception of a government founded upon a massacre and perpetuated by assassination. Then read Wendell Phillips's apostrophe to Toussaint L'Ouverture, or Harriet Martineau's "The Hour and the Man." Picture to yourself the mental suffering inflicted by such experiences as I have described above. Estimate 


\section{The American Race Problem}

the abiding effect upon the communities in which they occurred, and you may then begin to appreciate how far such an observation as the following falls short of fathoming the depth of the real relation between Reconstruction and present conditions: "Now ensued the trial of Negro suffrage, and most Southern writers on the subject of the present relations of the Negroes and whites trace all the trouble back to those unholy acts of Congress and Constitutional Amendments. Every southern child as he grows up becomes possessed of a fixed belief that from 1865 to about 1875 the South was governed by an unrighteous combination of Negroes with a few 'scalawags' or on-the-soil Republicans, and 'Carpetbaggers,' or Northern political adventurers. These things are within the memory of thousands of living men and women, and yet how warped already is the popular impression!"*

Any postgraduate man at Harvard, Columbia, or Johns Hopkins might easily submit as a thesis a more "accurate" account of Reconstruction than would probably be written by anyone who had himself undergone the process, saving a few rare exceptions. It would answer every purpose of any investigator who wished for knowledge of the exact dates between which this state or that lived its Reconstruction life, who wanted to know the amount of each and every issue of bonds made during the period in question, the tax levy of each county, and the amount of taxes squan-

* "The Realities of Negro Suffrage," Albert Bushnell Hart, Proceedings of the American Political Science Assn., second annual meeting, Baltimore, 1905. p. 154 . 


\section{Mr. Roosevelt and the Negro}

dered, as well as properly used. From it possibly we could learn much about the proper division of responsibility between Negroes, scalawags, and carpetbaggers. We might be told just how honestly or dishonestly the affairs of the Freedman's Bureau were administered. But after all, for the purpose of measuring the effect of Reconstruction upon present relations between Negroes and whites in the Southern states our information would be of little value.

The heart of it all is simply the common-sense fact that, like New England hatred of Catholicism, to revert to Dr. Hale, the still surviving Southern hatred of Reconstruction and opposition to Negro suffrage are due in large part to the "mixing up" of many things, "ascribed by the sufferers, more or less," to the injection of the Negro into politics. The one inevitable result of this programme was to hopelessly, almost cruelly, and as it now seems perhaps even permanently, identify him with a period for which in our history we find no parallel. Professor Dunning, with a discernment of the acute mental aspects of the situation, which are usually lost sight of in a mass of physical details, has likened the condition of the Southern people, in the presence of the "remorseless approach of Negro rule," to that of "the prisoner of tradition who watched the walls of his cell close slowly in from day to day to crush him."* But neither "The Pit and the Pendulum," nor any other creation of Poe's imagination, nor even the miseries of the crimes in the South

\footnotetext{
* "Essays on the Civil War and Reconstruction," p. 248.
} 


\section{2 \\ The American Race Problem}

of France, as touched by the magic pen of Dumas, can convey to the mind which does not know and the heart which has not felt, a sense of the exquisite mental torture through which these people passed. Mr. Lamar, great apostle of peace as he was, said that "the iron thrust into the hearts of the Southern people by this wicked and relentless policy burned deeper than the wounds which followed hostile armies."

Before we go further we may learn something else from this association of ideas. Probably one of the most difficult things for a Northern man to understand about Southern conditions is the attitude so generally assumed in the South toward Northern teachers of Negro schools. It is largely a matter of sentiment and suggestion. There is no opposition to such schools, per se, and no personal feeling toward those who conduct them.* The chief ground of complaint is against the social attitude of Southern people toward teachers in these schools. This is not difficult to explain. If we will study the one phase of Reconstruction of which the North is proud, the crusade for education, we will have little difficulty in catching the spirit which seemed to characterise the times. A candid reading of contemporary literature compels the realisation that where the white people were considered at all it was too often

\footnotetext{
* When the Mary Holmes Seminary, at West Point, Mississippi, burned some years ago, its president wrote: "The kindness of the citizens here white and black - has been very marked. The best people in the town came out during the fire and urged us and the teachers to come to their houses. Twice our number could have been comfortably provided for in the places that were offered. Certainly we can not doubt the unselfish sympathy and interest of the people in this place in our work." Letter from Rev. H. N. Payne, in Assembly Herald, N. Y., May, 1899, p. 285.
} 


\section{Mr. Roosevelt and the Negro}

in the spirit of a "charity" more galling than bayonetted tyranny itself. These early teachers came from a section which had long boasted its intellectual and educational superiority over the South. Feeling their superiority they too often showed that they felt it. It is not uncommon even now, to see this idea coupled with the very complaints of which we speak.

During the decade after 1865 the South was made to realise this attitude in a way which must have been irritating beyond measure. The keynote to the too common spirit behind this propaganda may be read in the following extracts from an "official" sermon before the Massachusetts legislature: Speaking of "the obduracy of rebellion" the preacher said it was "Of God""like the hardening of Pharaoh's heart, that the whole Southern system of life, labour, and society may be drowned together in this red sea - and not a vestige of the old malign civilisation of that portion of our country survive these bloody years." Then he told of "our new duties" - "to send thither the seeds of New England life and institutions, to be scattered broadcast and first of all to occupy the ground. There will be also a work," he continued, "worthy our best endeavours, to bring up, ennoble and save a degraded remnant of Southern population.* Here all that is generous and charitable, all that is magnanimous and forgiving in the heart of New England, will have free scope. We shall have to show our former enemies how sincerely and truly we can be, and are their friends.

\footnotetext{
* Italics in the original.
} 


\section{The American Race Problem}

We shall have to bless them in spite of their prejudices and all the depressing weight of their old habits. We shall have to show them how much better we can do for them than they have ever done for themselves. . . to inspire them with hope, diligence, economy, and the ambition for self-improvement - to set before them on their own soil the models of our own sweet and comfortable domestic life - to build school houses and churches and send them teachers and preachers, and sift into all their brightening consciousness the light of letters, the issues of the daily press, and a fresh, healthful, evangelical literature. This grand charity will tax our faith and our self-denial to the utmost for years to come."* Less than thirteen years ago this writer listened to an address by a Northern woman, before a convention in a Southern town, which breathed in its every word the same sentiment, spirit, and ideas which permeated the sermon from which we have quoted.

And these teachers did but little to seek the goodwill of white people. How could they hope to, coming as they did? They were peculiarly evangels of light to the brother in black. And it is too true that many of them taught politics as well as books. The two were closely associated. The controlling purpose in many minds was the fitting of the freedmen for the share in public life which they were told was theirs of "right."

\footnotetext{
* "The Work of New England in the Future of Our Country." A sermon before the Executive and Legislative Departments of the Government of Massachuetts at the Annual Election, January 4, 1865, by A. L. Stone, D. D., Boston, I 865, pp. 43,44 .
} 


\section{Mr. Roosevelt and the Negro}

In a rhapsody on "labour and education linked hand in hand" one enthusiastic heart predicted that the freedmen, "ambitious only for an extended freedom of soul and mind," "are destined shortly to become the ruling race in the South."*

It is hardly strange that the Southern people, situated as they were during this period, should have adopted the rigid policy which became almost a law of their social life. Their attitude was simply this: "You come here as the 'friends, deliverers, and saviours' of the Negro. You have taught him that we are his hereditary enemies, and have been for generations his heartless taskmasters. In season and out you delight to tell him of his 'rights,' while to us you speak only of 'duties.' You instill it into his mind, as a cardinal tenet of his new found faith, that he is the equal of the white man - as good as, if not better than, his former master. Holding your ideas, and pursuing the policy you do, there is nothing in common between you and us. Go your way and we shall go ours. We shall not molest you, but we will let you alone." We must appreciate and bear in mind the conditions which surrounded Southern people, if we would understand their course. They were helpless in the presence of what they felt to be another invasion, and used such weapons as they could command. One of the most powerful of these was social ostracism, and it was invoked against all who in their minds sought to keep the iron heel upon their necks. Northern teachers

* "Freedmen of the South," Slaughter, x 869, p. x79. 


\section{${ }_{276}$ The American Race Problem}

shared the fate of association with the Northern carpetbagger, the Negro, and the scalawag. They all came in together, and it was inevitable that to some extent for many years they should share in Southern minds the odium attached to the period and institution whose inauguration was first heralded by their approach. We are not concerned here with the question of the correctness or incorrectness of the Southern attitude. This is neither an indictment nor a defence. It is an attempt to in part explain a condition which so many people seem not able to understand.

\section{McKinley, Roosevelt, and the Negro}

It must not be understood that the Negro was not a very real, and often controlling, political factor during Reconstruction. The most far reaching, as it was criminally inexcusable, feature of the politics of the time, was the deliberate engendering of animosity between the Negro and his former master. In a hundred ways hatred of the master was taught as a tenet of political faith. The inculcating of lessons of racial estrangement rose to the dignity of a party dogma and became the stock in trade of party success. This was the work of a class of white men and mulattoes whose sole object was that of turning the Negro's ignorance to their own unscrupulous ends.* There is

* I have often had recalled to my mind a personal incident which made a lasting impression upon me, and which throws a suggestive side light upon this feature of the period in question. Shortly before the election of Mr. Cleveland, in $x 884$, I was one day fishing with a very close and confidential frienda very black little darkey of about my own age. He edged closer to me on the 


\section{Mr. Roosevelt and the Negro}

abundant testimony to their success. As late as I $90 \mathrm{r}$ Booker T. Washington tells us of Negroes who, "through the encouragement, help, and advice of Southern white people, have accumulated thousands of dollars' worth of property, but who, at the same time, would never think of going to those same persons for advice concerning the casting of their ballots."*

Mr. Baldwin remarks of Negro suffrage that "From this source alone the difficulties of the problem have been infinitely increased. . . The legal right of the Negro to vote has been the only serious cause of hostility on the part of the Southern white man." He thus confirms Mr. Washington: "The Negro is the friend of the white man in all matters except politics; but in politics he has seldom joined forces with his white neighbours for the common interests of the community in which he lives." $\dagger$

This is merely one of the seemingly permanently harmful results of the policy in question. Its immediate effect was to give to the dominant white and mulatto factions absolute control of a compact body of votes which they could always use as at least a

projecting $\log$ on which we sat, and almost in a whisper asked me if I knew that if Mr. Cleveland were elected the white folks would have slavery again. Close as was the daily companionship between us, he would not accept my youthfully indignant denial of such a programme, nor disclose the source of his private information. Between laborious whiffs at our "crossvine cigars," he finally told me that "de word had been spread" by a local political preacher, of the dire consequences of a Democratic victory - and that "it had been sont down to him fum de Noth." And this was more than nineteen years after the Civil War.

* "Up from Slavery," p. 236.

†Wm. H. Baldwin, Second Capon Springs Conference, r 899, Proceedings, pp. 98-99. 


\section{${ }_{278}$ The American Race Problem}

balance of power. Hiram R. Revels, once a Senator from Mississippi, himself an excellent man of mixed blood, in a letter to Grant, urging the use of the President's influence on the Senate in seating Mr. Lamar, declared that his people had been "enslaved in mind by unprincipled adventurers." The South has been charged for more than a generation with drawing the colour line for political advantage, and the term "Solid South" is sought to be converted into one of reproach. The South established no colour line when she attempted the rehabilitation of her fortunes under the Lincoln-

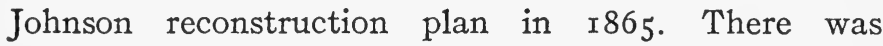
simply no such thought as that of taking the Negro into political partnership. To people who lived in the South and appreciated the conditions which surrounded them, such a thing was unthinkable. The failure or refusal to offer suffrage to the Negro was merely the natural, as it should have been the expected, course, and was entirely devoid of any colour-line significance. The foundations for this line were laid when the white man was discriminated against politically, penalised and deprived of controlling voice in his own domestic affairs. It came with the military Reconstruction Act of 1867 , and the first "Solid South" known to American political history was not white but black. When the white man slowly, and in the face of almost overwhelming obstacles, regained control of his own, the colour line had been drawn by other hands than his distinctly and pitilessly drawn. He simply accepted what he found. 


\section{Mr. Roosevelt and the Negro}

Twenty-six years ago Professor W. H. Councill, now head of the coloured Agricultural and Mechanical College of Alabama, warned his people against continuing to perpetuate this line. In a speech at Tuscumbia, Ala., in I88I, he frankly recognised the conditions referred to here - the solid racial alignment of Negroes under pernicious leadership. A prophetic extract from his speech is worth recalling, in view of a subsequent fulfilment to its very letter: "If you do not now make friends of, and unite with, the white people among whom you live, on all questions touching our civil and political welfare, you will regret it in time to come. It will not be twenty-five years before the white people of this country, if they have found that you go en masse against them, right or wrong, on all political questions, will come into power and take from you the ballot which you continue to cast against them. The Republican party will grow tired of you, and seek to unload the Negro element, and like the bat which was disowned by the beasts, and not recognised by the birds, you will find favour with neither Democrats nor Republicans."*

But aside from its general bearing on the modern problem, what has Reconstruction to do with $\mathrm{Mr}$. Roosevelt's appointment of Negroes to office? How do we account for the storm which his actions raised, when we are told that the South accepted without protest similar appointments at the hands of his prede-

\footnotetext{
* Reproduced in "Bright Side of the Southern Question" - an address at Corona, Ala., Aug. 25, 1903, p. Io.
} 
cessor? Probably the best statement of the case for Mr. Roosevelt was that made in an editorial on the President and the South, in the Outlook, of February 7, r903. That thoroughly fair and honest journal in part thus diagnosed the then rather turbulent situation: "Nor is it out of the common that this race prejudice should disregard the plain facts of current history, for none are so blind as those who do not wish to see. Certain it is that the notion that President Roosevelt has been forcing the race issue upon the South is in curious contradiction to the actual facts. Probably no man ever went into the Presidential chair with a more sincere desire to promote harmony between the North and the South as well as between the races, and at the same time to do something really to help the blacks through rewarding those who by their lives had won the confidence of the whites, and who possessed high individual character." Then follows a recital of various appointments, and the statement is made that "The net result is that at the present time there are fewer Negroes, by two, holding Presidental offices in the South than there were under President McKinley." The review concludes as follows: "We think ourselves warranted in saying that the President believes that the Negro should give himself to the work of securing education, property, and the cultivation of high character, and that it has been and is far from the President's intention to do anything that would unduly excite the political ambition of the black man; but he also believes that the recognition 


\section{Mr. Roosevelt and the Negro 28I}

of some of the worthy coloured men of the country is wise and proper, and tends to encourage others to make themselves worthy and deserving of recognition. We believe that the best men in the South agree with the President in this conviction now, and more of them will agree with him as time goes on."

It is here assumed that opposition to the appointments in question was based on a blind "race prejudice" which ignored "the plain facts of current history"; that the Southern idea of the forcing of "the race issue" was based upon the assumption that Roosevelt had made more Negro appointments than McKinley, whereas the contrary was true; that "the blacks" were helped through thus "rewarding" the worthy; and that "the best men in the South" agreed with the President's opinion in this regard. Who, then, and what, were responsible for the indisputable attitude of the South toward the President? Surely there must have been at least a few "best men" in that section who did not share the President's "conviction," and yet were actuated by something higher than blind and unreasonable "race prejudice." The matter cannot be thus dismissed, if we really care to sound its depths - whether from motives of interest or curiosity.

The truth is, there was much more in the situation than could be comprehended within the limits of a mathematical demonstration that the number of Negro office-holders was greater under McKinley than under Roosevelt. The mere making of such appointments did not differentiate one of these men from the other. 


\section{The American Race Problem}

In a speech in the House, on June 4, I 900, Mr. Grosvenor, of Ohio, placed upon enduring record this eulogium of William McKinley's official recognition of the American Negro: "And here it is proper to say that while Mr. McKinley has been deeply engrossed with the most intricate problems of statecraft, he has not been unmindful of the just claims of the race. He has distributed the official rewards with rare tact and judgment, and no element which assisted in the masterful triumph of 1896 is without representation. The Negro vote has fared handsomely at his hands. Coloured men of intelligence and character have been selected from every section of the country to fill positions of trust and profit under the administration, and the instance has yet to be recorded where the honour has been bestowed unworthily. Indeed, while it is a fact of great significance that the President has within nineteen months appointed twice as many Negroes as any previous administration, developments are now being so shaped by him, through a revision of the civilservice regulations, that the number of Negro officeholders will be increased fourfold."*

Not only did Mr. McKinley appoint more Negroes to office than did Mr. Roosevelt, but he was equally as much abused for doing so. Here is where some of the "plain facts of current history" have really been ignored, both North and South. Nor was the violent opposition to his Negro appointments confined to the Southern press. A resolution passed by the legisla-

\footnotetext{
* Congressional Record, Vol. 33, Part 8, appendix, p. 44x.
} 


\section{Mr. Roosevelt and the Negro $\quad 283$}

ture of Georgia censured him in unequivocal ierms for appointing a Negro postmaster at the town of Hogansville in that state. He not only appointed more Negroes to office than Roosevelt, but he appointed, in the main, a "meaner" class of Negroes - or more of the meaner class. With the indisputable facts of the records of both men before us, with Grosvenor's unstinted praise of McKinley in mind, we must go deeper than the bare matter of official conduct if we would find the explanation we seek.*

In an interesting essay on "Representative American Negroes" the late Paul Lawrence Dunbar declares that "Some men are born great, some achieve greatness and others lived during the Reconstruction period." $\dagger$ From the very circumstances of the Negro's introduction to the world of freedom, the man who had greatness thrust upon him, the Negro of the Reconstruction period, became the type of representative Negro to Southern people. The "Negro" in office in the South,

* It is not possible here to discuss the history of Negro office holding in this country, but historically the idea of Negro officialism has always been much more repugnant to American white people than that of mere Negro suffrage. The history of the XV. Amendment resolution discloses the contemporaneois white attitude on the former proposition with unmistakable clearness. That resolution was barely forced through, as it was, and then only by a conference committee compromise which eliminated the words which inhibited restrictive state and Federal action as to holding office. Senator Edmunds refused to sign the conference report, because the compromise amendment, as we have it now, did not go far enough, in that it left with the state the right to prohibit Negroes from holding office. Suffrage merely, not office holding, was the only thing thought to have been effected at the time. In the Georgia readmission case Congress dodged the question, and I do not now recall any decision on the precise point by the Supreme Court of the United States. Historically, there is nothing in the XV. Amendment to prevent a state from fixing different qualifications for white and Negro office-holders - or even declaring Negroes entirely ineligible to office. Voting and holding office are two distinct privileges, for which different qualifications are quite commonly required.

t "The Negro Problem," 1903, p. 189. 


\section{The American Race Problem}

when placed there over local protest, means, much more to the protesting community than a more or less pompous, and more or less efficient mulatto official.' $\mathrm{He}$ stands for something else to them, for something they would like to forget. Put in over protest, he becomes typical of a period and condition much too recent to have been forgotten. Once more, in ways not noticeable to those for whom he has no such significance, he represents the idea of a government of force. He becomes, almost unconsciously to themselves perhaps, the living symbol of a government alien to local sentiment, one to which the wishes, instincts and traditions of those most concerned by every claim of local interest, are all mere relics of a bygone time.

Dunbar would draw the line against the political Negro as a representative of his race. This is easier said than done. If we could blot from the history of the past generation the strife occasioned by the Negro in politics, there would not be left enough of sectional differences to furnish material for a question for a schoolboy's debating society. Remove that from the record, and you would not have a baker's dozen of contested election cases. There would have been nothing for investigating committees to "investigate," and Reconstruction would possess no such significance as it holds to-day for millions of Americans. The Negro has played too prominent a part in Southern politics to be relegated in a moment to the limbo of things not only dead but unreturnable. Now and then he is forced to the front again, and comes just 


\section{Mr. Roosevelt and the Negro 285}

sufficiently in evidence to stir old embers and galvanise dead issues into seeming life. And the extent to which this effect follows Negro appointments depends in large degree upon all the attendant circumstances upon the manner in which the appointment is made and the manner of man who makes it. And here is in part an explanation of the difference of the significance of this aspect of the McKinley and Roosevelt administrations to the Southern people.

In an address in Worcester, Mass., in I905, Mr. Roosevelt stated the proposition that "even justice can be administered in a manner which leaves you with the heartiest dislike for the person who administers it."* Here he gives a clue to the secret of part of his trouble with Southern people. $\mathrm{He}$ has in large measure been the victim of his own personality. In the relations of men with men there is a difference between the suaviter in modo and the fortiter in re. It often marks the difference between success and failure in matters wharein tact must play its part. It is sometimes the difference between the simple and the strenuous life, betwisn William McKinley and Theodore Roosevelt. In his every public and private relation Mr. McKinley was one of the most diplomatic presidents this country has known. Tender and gentle in marked degree, his was easily the most lovable personality that has filled the executive chair. The possession of either of these attributes - gentleness or diplomacy so valuable to McKinley in inaugurating the era of

\footnotetext{
* Press report, Washington Post, June 22, 1905, p. x. col. 2.
} 


\section{The American Race Problem}

good feeling which was the chief glory of his final days, unfortunately can in no sense be truthfully ascribed to his successor.

In none of McKinley's Negro appointments was there an accompanying flourish of trumpets. They were not heralded as ushering in the dawn of the day in whose sun was to ripen the final fruit of emancipation. They were plain, every-day political rewards for political service, placed where they were supposed to do the most good for the party. This was all there was of McKinley's "Negro policy." His appointments were devoid of other significance. On the other hand, Mr. Roosevelt's course could not have been better adapted to making an impression upon the minds of these childish people if he had been a lifelong student of Negro character. Without knowledge that he was doing so, he appealed irresistibly to the Negro's love of talk, his fondness for palaver, his delight in the cajoling jugglery of words, however specious the promises they frame. The frequent declarations of a policy of "square deal for black and white alike" the enunciation of the platform of "all men up, not some men down," the solemnly proclaimed opening of "the door of hope," with himself as its beckoning warder, all this expressed in printed or spoken words was music to the Negro's ears. All of it was reproduced and magnified and dwelt upon in every Negro publication in America, and quickly earned for its author the affectionate title of "Our President," "the first since Lincoln set us free." His photograph be- 


\section{Mr. Roosevelt and the Negro}

came a stock cut with Negro magazines, and its numberless reproductions were generally accompanied by some endearing phrase. And McKinley's record was forgotten by the Negro before the grass was green upon his grave. It was only resurrected by white men, to prove that he had made more Negro appointments than the man whose face and words had suddenly become familiar in every Negro home in the land.

It is a plantation saying that a man can do more with a Negro by talk and cajolery than by fair dealing without indulging in palaver. It is one trait which makes it so difficult to do business with the race in a business way. The average plantation Negro would rather transact business with a man who will rob him with much fair speech than with one who will give him a square deal with few words. It is said that the late Thomas B. Reed once referred to Mr. Roosevelt as "the young man who discovered the Ten Commandments." Certainly no other man of this generation has made so frequent use of the common injunctions and precepts of the Decalogue in public speech. His announcements in regard to the Negro - "the door of hope" for example - were little more than platitudes. No one was trying to close "the door of hope" in the Negro's face. There was no such question at issue. But the phrase sounded well, and it immediately took with the Negro. To his untutored mind the President was engaged in a fierce struggle with the South over the question of the Negro's "rights." The South had been trying to strangle the Negro to death, with Mc- 


\section{The American Race Problem}

Kinley in collusion, when like a rescuing knight Mr. Roosevelt appeared upon the scene. This is no picture of fancy. If anyone questions its accuracy, let him search the files of Negro periodicals and papers, and read the almost amazing evidences of the Negro's peculiar mental attitude toward these two men. If McKinley had talked more about Negro rights and opportunities and hopes, even with fewer appointments his memory would have fared better at their hands. A writer in the leading coloured magazine of the country declared that "After President Hayes, the Republican party of William McKinley has done the coloured man the greatest harm." The article states that "President Roosevelt found us standing on the ragged edge of despair." From this position the race was rescued by Mr. Roosevelt. The "door of hope" declaration is quoted, and the writer adds this comment: "These words are full of hope for the Negro and deadly miasma for the Southern whites."*

But the Negro was not the only one to thus peculiarly identify Mr. Roosevelt with the idea of openly avowed and active hostility to "the Southern racial attitude." The record of his predecessor was forgotten, and "the plain facts of current history " ignored, in other quarters than the South. Throughout the country, with little regard to party lines, he was either hailed or accepted, as the spirit might be, as the special champion of the Negro. The leading humorous journal of the country,

* "Latest Phases of the Race Problem," Coloured American Magazine, Boston, Feb. 1903, pp. 245, 246. 


\section{Mr. Roosevelt and the Negro}

never politically identified with Mr. Roosevelt's party, produced a cartoon which told the story of the popular mind. It was entitled "Justice versus Prejudice." It shows the Emancipation Statue of Lincoln, in Washington. At its base stands Mr. Roosevelt, facing a Negro, his left hand on a scroll of the XV. Amendment, his right hand on the Negro's shoulder. The President is saying to the latter: "Lincoln emancipated you, the people gave you citizenship and I 'll protect your rights."* These cartoons were reproduced as separates, and, along with other pictures more or less related, but some less innocent for harm, found their way into the Negro's hands in all sections of the country. $\dagger$

Clearly, the naked facts of the records of McKinley and Roosevelt give us but little light. For this we must attempt an analysis of the general attitude of the Negro toward these two men. This is a difficult subject to make clear to anyone who is not himself familiar with the large mass of the Negro's own literature, the organs and books of the race, upon which we must depend for most of our interpretative material. We should understand at the outset that there is a great difference between the classes into which the Negro in

\footnotetext{
* Puck, January 28, т903.

† See advertisement, Coloured American, Washington, D. C., May r6, r9o3, and later dates. Three or four years ago, within five miles of the plantation on which this is written, two white men from a Middle Western state were arrested for selling nude pictures to Negroes. As part of their stock, and as their "leader," was an assortment of pictures illustrating the White House incident narrated here. Since the action of the President in the Brownsville affair a leading Southern Negro paper has said that in consequence of such action the Negroes "have turned the Roosevelt social equality picture to the wall." It is impossible to trace the ramifications of the results of an incident unimportant in itself.
} 


\section{The American Race Problem}

this country may be roughly grouped. These classes are made up on the one hand of the great mass of the race, with a constantly decreasing percentage of illiteracy, and of a large and increasing number of more or less educated, thinking and writing Negroes on the other. In the main, the first class is found in the South and the second in the North, though this is of course by no means an exact division. There are thousands of ignorant and uneducated Negroes in the North, while very many of the best educated and most forceful writers and speakers of the race are in the South.

Through the medium of newspapers, magazines, and books the militant members are making an impression upon the steadily increasing literate mass. When we speak of the Negro's attitude toward Mr. Roosevelt, we have in mind those who have found their voice, and who are giving expression, in more or less coherent form, to the feelings and emotions by which they are swayed. And among the educated also we must realise the established lines. In this second class are to be found men and women who in respect of education, travel, and general mental culture, are entitled to rank with the corresponding group in any race. There are two distinct schools of American Negro thought - which in their turn may be classed as radical and conservative. It is worth remarking that it is not from the highest types of the radical school that Roosevelt has received his vociferous, emotional support. They attach no undue significance to a Presidential appointment, and many of them are entirely capable 


\section{Mr. Roosevelt and the Negro 29I}

of discriminatingly weighing the acts and words of public men. These could not be led into nonsensical eulogies of a Republican President for giving a Southern Negro an office, nor would they go into hysterics over a White House dinner. But it is not likely that they represent a very large element of Negroes - nothing like as large as that for which the more "conservative" stand. The latter, with exceptions, are nearer the real Negro in certain peculiar racial characteristics - though in its leadership neither group is "Negro" in more than name. Save one here and there, the leaders are all mulattoes, some more white than "black" - hardly any related to their Negro brethren further than sentimentally, and by a more or less attenuated consanguineous bond. The doings of the great white world about them are translated to the Negro masses by these two groups. It is possible that the group which is nearer the masses through a larger identity of emotional racial traits exercises the greater influence of the two. It is this group with whose attitude toward Mr. Roosevelt we are at present concerned. It must not be understood, however, that any hard and fast line is attempted to be established here. Individual alignment, as well as the differentiating characteristics of the two groups, are not yet sufficiently defined and fixed to make this possible.

It seems at times as if the gulf between Southern white people and most of the leaders of educated Negro thought and opinion is hopelessly impassable. Nothing seems clearer to the analyst of race relations than that 


\section{The American Race Problem}

those relations are best between the higher groups of white people and the Negro masses, and most strained between the higher groups of Negroes and the white race as a whole. Our earlier observation as to the increasing complexity of race relations as they approach the plane of racial equality, applies here as well as in the connection in which it was used. The differences of points of view between white people and the higher Negro groups are too pronounced to be misunderstood. And they are the source, or at least the evidence, of many of the most regrettable manifestations of the problem.

The official careers of Mr. McKinley and Mr. Roosevelt, when they touch the racial sectional line, illustrate the practical results of the operation of this apparently well established, but exceedingly unfortunate, law of race relations. So invariable is the rule, that we are practically safe in stating the proposition that if we are given the attitude of the South as a whole, toward any specific act or policy of national administration, in matters of racial or sectional concern, we may predicate upon it the converse attitude of the higher Negro groups, and vice versa.* We have seen how easy it is to confuse current history, in the matter of the respective McKinley and Roosevelt attitudes toward Southern Negro appointments. We shall see how easy it is to understand why the confusion arose,

* Thus in the third year of Mr. Roosevelt's second administration we see Southern papers speaking of his "changed attitude toward the Negro and the race problem," while Negro papers are denouncing him as "the worst enemy the race ever had." It is doubtful if Mr. Roosevelt himself would admit the slightest change of attitude on his own part. 


\section{Mr. Roosevelt and the Negro}

why in both the white and Negro mind McKinley ceased to be associated with such a policy, and why Roosevelt became so closely identified with it, if we but follow the operation of our law, if it can be dignified by that convenient and elastic term.

Mr. McKinley went into office as a result of a hardfought political fight in 1896 , but one in which sectional lines were disregarded to a greater extent, probably, than in any other election since the war. If any Republican President might have been expected to attempt to seize an opportunity to build up a respectable Republican party in the South, McKinley was that one, if conditions were to count for anything at all. But William McKinley was not a "reformer." $\mathrm{He}$ was a politician, pure and simple, and nothing else-save an honest and amiable man. He had been nominated by a well organised machine, of which the Southern Negro was an important part. When elected he very naturally followed the political policy which had been that of his party since 1868 , as to the Negro and Federal offices in the South. Turn back to the speech* of his Ohio friend and champion, and read the open bid for continued Negro allegiance, and you can see the practical politics in it all. Many of his appointments were unopposed, just as many of Roosevelt's have been. But others met with as bitter denunciation as ever greeted any political act of his successor. We have mentioned the resolutions adopted by the Georgia Legislature. They should be recalled if we would grasp the signifi-

-p. 282. 


\section{The American Race Problem}

cance of the subsequent change of attitude. The legislature declared that the President had seen fit to appoint a Negro postmaster at Hogansville over the protest of " 90 per cent. of the property owners and responsible citizens" of the town; that in no other section of the country would the best interests and people of a community have been thus disregarded; that on the Pacific slope he would not dare appoint a Chinaman over such a protest; nor would such a protest be ignored in any town in the North. It condemned the alleged attempt to kill the postmaster in question.

The resolutions concluded as follows: "Resolved, That we deplore this and similar appointments as exhibitions of petty spite and narrow sectional hate, unworthy of the high office of chief magistrate of this great nation. Resolved, That we appeal to impartial public opinion to enter its powerful protest against presidential appointments to office for the manifest purpose of affronting and humiliating a community of American citizens for no other reason than difference in party affiliation."*

\footnotetext{
* Constitution, Atlanta, Ga., Oct. 28, 1897, p. 5. The full text is given under the caption: "The Georgia Legislature Denounces President McKinley." Under date of Sept. 18, r897, the Constitution declared that McKinley's Negro policy should warn the white people of the South to stand "closer together than ever," that more than any other administration, McKinley's had demonstrated "that Republican victory means Negro office-holders and Negro domination." On Sept. 23, 1897, the Charleston News and Courier spoke of the "cheap sentimentality" which talked of "brotherly love" and "the unity of the country," while "contemptuously disregarding the strongest and most radical sentiment of the Southern States." Both these comments, in fact all Southern papers, contain the suggestive note of the identity of interest throughout the South. The News and Courier says: "The one thing to be borne in mind is that these instances of discrimination against the white people of the South do not concern alone the particular community against which they are aimed. Every town
} 


\section{Mr. Roosevelt and the Negro}

One trouble in this country is that in racial matters the Southern people take Republican Presidents and politicians entirely too seriously, while the latter do not take the former seriously enough. It is absurd to say that McKinley ever appointed a Negro to office "for the manifest purpose of affronting and humiliating a community of American citizens." It is equally so to charge that Roosevelt dined with Booker T. Washington "for the deliberate purpose of defying Southern sentiment, breaking down Southern social barriers, and establishing social equality." One proposition is about as silly as the other. In the Hogansville appointment there was nothing more significant than a purpose to reward a "Negro" politician. In the Washington episode, whatever the potential effect, there was about as much "deliberation" as there is in most of the actions of an uncertain and erratic President. The most that can be justly said of either man is that he showed an entire disregard of the wishes and sentiments of Southern white people, coupled with a curiously obtuse unconcern for the real interests of the real Negro.

Mark Twain says that after one of his early satirical efforts he enjoyed the unique distinction of being the only man on earth whom good old Captain Isaiah Sellers would actually "sit up nights" to hate. One

and city in this section is liable to the humiliation which has been imposed on Hogansville, Atlanta and New Orleans. Their experience this year may be that of any other place, or places, at any time when there is a Republican administration at Washington." The Literary Digest, Oct. 9, 1897, and March 5, $\times 898$, contains résumés of Northern and Southern press comments on McKinley's policy. 


\section{The American Race Problem}

would imagine from some expressions of Southern opinion that it was the daily routine of Republican Presidents to spend part of their time in devising means of "humiliating and offending Southern people." The trouble is that such Presidents do not give enough time to any sort of consideration of Southern conditions. They do not know, or will not understand, the significance of their unstudied acts to the Southern people and to the American Negro. Many Northern people, politicians and laymen, err too greatly on the other side. Their environment robs these acts of the least significance to them, and they are too prone to measure the South by their own yardstick. There is more in such things than is expressed in the violent language of occasional intemperate newspaper criticism. There are many thousands of thoughtful Southern people who ponder these things in their hearts, but, feeling deeply, say not a word. It is not altogether wise, as is so often done, to dismiss these "Southern outbursts" as "tempests in a teapot."

As long as McKinley's Negro appointments were the most prominent feature of his "Southern policy," he enjoyed the usual affection and esteem of Negroes all over the country, and received the average amount of criticism and denunciation in the South. But with the approach of the Spanish-American war there came a change. The immediate result was to bring the sections closer together. Mr. McKinley's military appointments of Southern white men effaced for the time the rankling memory of his civil appointments 


\section{Mr. Roosevelt and the Negro}

of Southern Negroes.* The country became engrossed in other than racial and sectional affairs. In the hall of the Georgia House of Representatives, where fourteen months before he had been denounced in almost unmeasured terms, Mr. McKinley gave utterance to those sentiments of sectional good will and fraternal kindliness which seemed to place the capstone upon the last work of an amiable and lovable life. The legislature which had spoken so harshly but a short while before, at once eulogised him in terms strikingly in contrast to those in which his political actions had been characterised.

The Southern people have their full measures of sentiment - possibly more than their share. There has not been a day since 1865 when the country could not have touched their inmost heart, touched it so that great and enduring good would have come to us all, black as well as white, above as well as below the line. No people in history ever accepted more honestly and manfully the hostile verdict of war than those who had raised the ill-fated standard of a second English-speaking republic in America. They accepted as absolute, conclusive, and irrevocable the verdict which sounded the doom of the ultimate rights of the States and destroyed the institution of slavery. These things were the legitimate fortunes of war, and as such they were acquiesced in without complaint and without equivocation. They were not prepared for all

\footnotetext{
* But even then he appointed an old time Reconstruction mulatto politician, formerly of Mississippi, paymaster in the Army. Of course there was trouble the first time his duties brought him into contact with a Southern regiment.
} 


\section{The American Race Problem}

that followed, for the illegitimate fruit of victory, and they did not accept it all. They have not accepted it yet.

We talk about the effect of the association of ideas upon the present relations between the white and Negro races in the South. What about its effect upon the present relations between the Southern States and the Federal Government? Answer the question fairly. Could a Southern man, though he were not born until I860, and though he were the embodiment of all that makes a man - could such a man be elected President of the United States, all things else being equal? The South was surfeited with the interminable eulogies of her "loyalty" in I 898 . It seemed to dawn upon the country as something novel, something which had just arrived. The Southern people have been "loyal" since they laid down their arms forty years ago. But in the minds of the rest of the country it is

only within recent years that they have ceased to be associated with the idea of "treason," and a foreign war was required to accomplish the result. Even in I 898 an act of Congress was necessary to make possible the acceptance by men who had fought for their States of the commissions which the President was tendering amid the sentimental applause of the country

The world does not know how easily the confidence and affection of the South may be won There was nothing inconsistent in the two Georgia resolutions to which we have referred. And the country makes a mistake if it assumes because of the second that the 


\section{Mr. Roosevelt and the Negro}

first was mere brutum fulmen. The two together should rather prove to the skeptical man that the most profound feeling on the first question is not incompatible with the highest sentiments of sectional fraternity and good will. Mr. Roosevelt, though he could never evoke Southern affection as McKinley did, has himself been most kindly received in the South. On the occasion of one of his extended visits this writer carefully studied the utterances of more than a dozen leading Northern Republican and Independent papers. On the whole the impression made was clearly enough that the attitude of the South and the meaning of its reception of the President were almost hopelessly misunderstood. It was said time and again that $\mathrm{Mr}$. Roosevelt had won the South's approval of his actsof the things for which she had once reviled him. Nothing is further from the truth, and nothing is more probable than that a repetition of those acts would meet with criticism even more severe than that which they first aroused.

In the ratio in which Mr. McKinley gained the esteem and regard of Southern white people he lost that of the groups of American Negro leaders to whom we have referred. The average man might take issue with this statement. But the average man would have Booker T. Washington in mind, while the latter is not included in either of the two groups as we define them here. He and his policies are, rather, the subject of controversy between the two. Though practically identified with the conservative group, he does not 


\section{The American Race Problem}

discuss men and measures from the political standpoint. He preaches the gospel of industrialism to the masses of his people. He does not interpret to them through magazines and newspapers and personal utterance the significance of incidents and policies. $\mathrm{He}$ was himself the storm centre of one such incident, the significance of which others are left to interpret for themselves.

The opinion which we have quoted above, that McKinley did the race more harm than any President since Hayes, and that Roosevelt found the "Negro" "standing on the ragged edge of despair," is one of the mildest expressions which could be used to illustrate our position. The chief indictment against McKinley was that he had encouraged "the Negro-hating South" by his conciliating attitude during the Spanish-American war. Even death did not shield him. His memory has been reviled by the foremost living American "Negro" editor in terms unworthy of respectable reproduction. But to the masses of the race, the Southern millions whose lives are lived in a world of their own, McKinley and Roosevelt are not much more than names. To these people "policies" mean little, whether national or state. For them the only meaning of the Civil War was its association with their emancipation. They cherish no abstract ideas of resentment on account of the institution of slavery. They did not care how close McKinley and the South drew to one another. They do not care how far the South and Roosevelt may draw apart. They do not look to 


\section{Mr. Roosevelt and the Negro 301}

Washington or the President, but to the white people nearer home. And in the main they would go first to the man, or his children, to whom they may once have "belonged." This is not the case with the other class. How far these may be able to impress their ideas and teachings upon such of the mass as may come under the influence of their writings, cannot be told and need not be speculated upon.

\section{A Concrete Racial Attitude}

The following fairly illustrates the attitude and temper of the writings which at once express and mould Negro thought in the United States. The extract is from an editorial discussion of the candidates and platforms of 1904 in a prominent magazine: "President Roosevelt has made his record on the question of human rights, and in doing it provoked all the venom which lurks habitually in the fangs of those who believe that the War of the Rebellion was fought in vain and that Afro-Americans should be slaves or pariahs in the body politic, without the pale of citizenship, to be governed by a body of special laws as infamous and degrading as the slave code."*

Here we have the idea of a perpetual conflict between North and South, in which the South is trying to enslave the Negro. Mr. Roosevelt's "human rights" stand in behalf of the Negro provokes the habitual venom of the South whom he has defied - just as we

\footnotetext{
* Coloured American Magazine, Aug., r904, p. 534.
} 


\section{2 \\ The American Race Problem}

have seen how his "words of hope to the Negro" were "full of deadly miasma" for Southern white people. According to the carefully expressed and probably authoritative opinion of the Outlook, in connection with the Crum case, the object of the President's appointment was to encourage worthy "blacks," through rewarding the specially fit among them. Here is the point of view of the type to which Dr. Crum really belongs, the "rewarding" of which has about as much to do with "encouraging" the real Negro as it has to do with promoting kindly relations between the races. It is given as follows, in an editorial under the caption "The Confirmation of Dr. Crum": "It was only after the American people had emphatically and almost unanimously endorsed the nomination and rebuked the Senate for its stupid fear of the champion of the opposition to Negro culture and education, that the committee mustered enough courage to report the nomination to the Senate. . . . The coloured American has witnessed his greatest political triumph in twenty years. This struggle was indeed one, not of a man, but of a principle. And this time might and right were arrayed on one side against arrogant weakness and prejudice on the other. . . . In this crusade against the confirmation of Crum, the South has greatly weakened the growing regard which the North has here of late entertained for it. Body and soul, it went in to oppose Crum; with sleeves rolled up and a red bandana around its red neck to wipe the perspiration which it anticipated in such a warm contest. 


\section{Mr. Roosevelt and the Negro}

Under a general of less courage and honour than Roosevelt, history would read differently. It has been thoroughly established that the law recognises no man by the colour of his skin; but rather that no drunken Democrat who revels in the aristocracy of his slaveholding parents, is as good as a coloured Republican of ability and character. More coloured men should be appointed to office in the South. The brains and character of that section are in its black men."*

This is the frankly avowed opinion not of some insignificant country newspaper, but of one of the two leading "Negro" magazines in America - formerly published in Boston but now in New York. We have here another inner glimpse of the so-called "Negro's" point of view of the situation which elicited Mr. Roosevelt's letter on the door of hope. From the educated mulatto standpoint, at least from the group standpoint which we are trying to interpret, these affairs are all mere contests between the South and the Negro, with the North and the Republican party on the Negro's side. The result is neither more nor less to them than an augury of larger victories upon a broader field. Whether or not this apparently fixed idea which the Northern mulatto holds - of an unending struggle between the South and "the race," also has its roots deep in the soil so thickly sown with racial troubles, that of Reconstruction, I shall not attempt to say. We may note, however, that there is a difference between the significance attached by these people to

* Coloured American Magazine, Feb., 1905, pp. 64, 65. 


\section{The American Race Problem}

appointments in the two sections of the country. One of the shallowest of sectional retorts to Southern objection to Negroes in Southern offices is that made so frequently by Northern papers during Mr. Roosevelt's administration - that of reciting the occasional instances of such appointments in the North.* There is no connection between the two things. The South is not concerned with such appointments. It is no business of hers if the President appoints a Negro postmaster at Boston, New York, or Chicago. The fact would be no argument for, or justification of, such an appointment in New Orleans or Atlanta, though this is frequently superficially urged. The historical backgrounds are so different that such appointments have no such significance in the North as in the South. Historically, there are abundant reasons in favour of such appointments in the North, and just as many against them in the South. There is not one logical and fair ground for opposing them in the former section, and they should there neither create comment, arouse protest, nor excite racial ill feeling. Decidedly the contrary.

We are a practical people, we Americans - at least we think we are. Why not be practical about the

\footnotetext{
* The vital difference of actual attitude toward the Northern and Southern situations, respectively, is illustrated in the Crum and Tylor cases. When opposition to a coloured appointee came from South Carolina Mr. Roosevelt was absolutely uncompromising in his refusal to concede anything whatever to "Southern race prejudice." When positive opposition developed in Ohio against a coloured appointee, Mr. Roosevelt at once took a very sane, not to say "practical," view" of the situation, and provided a place for the objectionable though influential coloured politician in the Navy department at Washington. This was a method often adopted by Mr. McKinley in placating Southern communities, while at the same time caring for coloured appointees.
} 


\section{Mr. Roosevelt and the Negro 305}

gravest problem which vexes our national life to-day? If we are to appoint coloured men to office in Southern States, regardless of local sentiment or protest, why not learn something from the real and only beneficiary, as we have quoted him above, and do it at the face value of each transaction? Why not do it as McKinley did, as a plain proposition in practical politics, and let the fact be advertised openly and above board, as Grosvenor did for McKinley, as a keeping of party faith or a bid for party advantage? Why attempt to deceive ourselves with the fanciful notion that by appointing educated mulattoes to office we are "doing something for the black man"? There is something difficult to comprehend in the serious declaration of purpose behind Mr. Roosevelt's Negro appointments. As given by the Outlook this was "to do something really to help the blacks, through rewarding those who by their lives had won the confidence of the whites and who possessed high individual character." What have "the blacks" to do with Southern offices, and how many are filled by "blacks" to-day? And how are the "blacks" to be "helped" by such appointments?

In all the controversy over "Negro appointments" there have not been a baker's dozen of Negroes concerned. These appointees are almost invariably mulatto politicians, frequently with less of real interest in the "blacks" than have the white people among whom the latter live. There are scores of such Southern appointments to which there never was the slightest 


\section{The American Race Problem}

outspoken opposition. The world hears only of the insignificantly few cases in which some audible but ineffectual protest is made by the white community. These unopposed appointments probably do no harm within themselves. But it passes belief that it can be seriously thought that such an appointment, when bitterly opposed and bitterly acquiesced in, or even if uncomplainingly accepted, can really help the labouring millions of the Negro people. Does it open to them new opportunities, or enlarge existing ones, for improving the status of themselves and their families? Does it bring about better feeling between themselves and their white neighbours? Does it make the latter more kindly disposed toward them, or more willing to lend them a helping hand? Does it make the Negro's path less thorny or more easily trod? Above all, does it hasten the day when, as Booker T. Washington says, the South will no longer feel that at times she is still the object of a government of force? Does it add to the number of those friendships which he considers more valuable to his race than Federal laws?

It seems to me that he who for some absurd and fanciful abstraction touching the "elevation of the race" forces a political appointee upon an unwilling community, barters away the now almost priceless birthright of a whole people - the birthright of peace, for much less than a mess of pottage for a chosen few. $\mathrm{He}$ is the truest friend of the real Negro who contributes most to sectional and racial harmony and good will. It would be well if those who sit in high places could 


\section{Mr. Roosevelt and the Negro 307}

finally realise that they govern most wisely for the weaker race when they frankly recognise the universal and indisputable truth that in the last analysis it is the actual living sentiment of the masses that most largely determines the attitude of the white race toward the black. This sentiment cannot be altered by coercive action, nor can it be disregarded with impunity. In dealing with the manifold problems of our complex national life, common sense is the essence of wisdom. The greatest civic courage, as well as the wisest statesmanship, will be found to lie sometimes along the line of temporary concession to conditions we cannot control.

The doubtful boon of a relation with, or share in, local administration of political affairs will not be gained or hastened for the Negro through the medium of Federal appointments. In the chapter on his Atlanta Exposition address Booker $\mathrm{T}$. Washington says: "My own belief is, although I have never before said so in so many words, that the time will come when the Negro in the South will be accorded all the political rights which his ability, character, and material possessions entitle him to. I think, though, that the opportunity to freely exercise such political rights will not come in any large degree through outside or artificial forcing, but will be accorded to the Negro by the Southern white people themselves, and that they will protect him in the exercise of those rights." Even if the relation between Reconstruction and present conditions is a matter of doubt in some minds, it apparently is clear to Booker T. Washington. He con- 


\section{The American Race Problem}

tinues: "Just as soon as the South gets over the old feeling that it is being forced by foreigners, or aliens, to do something which it does not want to do, I believe that the change in the direction that I have indicated is going to begin."

How long will it be before the South gets over "the old feeling" of outside coercion? The answer depends on forces and movements beyond the South's control, largely upon the common sense of those in Federal power. But one thing is as certain as the dawning of another day: the approach of that time will not be hastened by threatening planks in national platforms; by forcing upon an unwilling community a distasteful official; by the punitive denial of the common postal facilities of the Government to a Southern town. It is useless to reply that these are isolated cases. Their effect is like that of an isolated case of assault. Here white people instinctively draw closer together, prepared to make the case of one the concern of all. In such matters there are in the South neither state, nor county nor community lines.*

To return to $\mathrm{Mr}$. Washington. $\mathrm{He}$ adds: "Let me illustrate my meaning. Suppose that some months before the opening of the Atlanta Exposition there had been a general demand from the press and public outside the South that a Negro be given a place on the opening programme, and that a Negro be placed upon the board of jurors of award. Would any such recognition of the race have taken place? I do not think

* See observation on Southern community of feeling in note on p. 294. 


\section{Mr. Roosevelt and the Negro 309}

so."* Here is another illustration. After the Indianola affair, which would not have occurred but for Mr. Roosevelt's Southern "referee system," and which could have been straightened out with an ounce of tact, the people of that town were compelled to devise their own postal facilities. In doing so they employed a Negro driver for their private mail wagon. I collected a number of Northern editorial efforts to convict the white people of the town of almost criminal inconsistency in thus engaging a Negro to assist in doing the very thing which they had objected to having a Negro do for them. The essence of the difference lay in the respective relationships of the two Negroes to the community. One represented a voluntary connection of their own creation, the other the enforced continuance of a relation to which they objected.

Professor Dunning says: "Seven unwholesome years were required to demonstrate that not even the government which had quelled the greatest rebellion in history could maintain the freedmen in both security and comfort on the necks of their former masters. The demonstration was slow, but it was effective and permanent." $\dagger$ We are no longer confronted with the extreme aspect of that question - thanks to the thoroughness of the demonstration to which Professor Dunning alludes. But there are other things also which the Government, with all its power, cannot do. It cannot "solve the race problem," nor determine

\footnotetext{
* "Up from Slavery," p. 235.

† "Civil War and Reconstruction," p. 252.
} 
the status of the Negro, nor insure his "rights," by coercive or penalising measures. If we will hold in mind the prediction of Professor Councill and the words of Professor Dunning, we shall not have to learn anew the lesson of an experiment that failed. We may realise, with $\mathrm{Mr}$. Washington, that whatever share the Negro is destined to have in the political life of the Southern states must come as a grant from the Southern people. We need not argue abstractions and theories, we would be wiser to face and accept the fact. If the time which has been wasted in America since I $86_{5}$ in discussing the Negro's abstract "rights" had been applied to a non-sectional effort at realising and providing for his real "needs," both the Negro and the country would be better off to-day. But it seems difficult for us to realise that questions of race are not questions of law, that problems of race cannot be solved by decrees of courts. The Negroes in the District of Columbia can tell you just how much a "civil rights" law is worth in the face of local public sentiment.

To return from this digression to Mr. Roosevelt and the South, and the racial and sectional troubles upon which we were trying to find some light from the only source worth considering, the Negro himself, the principal party in interest. If we grant that $\mathrm{Mr}$. Roosevelt had no intention of "forcing the race issue upon the South," that is about as far as the facts will warrant us in going. That the issue was brought to the front cannot be questioned. No matter what the President's intentions were. We are not at all concerned with 


\section{Mr. Roosevelt and the Negro}

that phase of the question. We are interested in the results of his general attitude rather than with any consideration of motive. If we go below the surface at all we realise how much more there was involved in the question at issue than could be embraced within a mathematical statement of the respective number of Negro appointments by McKinley and Roosevelt. The essence of the whole matter lies in what Mr. Roosevelt stood for in the eye and mind of the Negro. And this is not difficult to discover.

In a discriminating essay on Mr. Roosevelt, Judge Robert H. Terrell, the husband of the most distinguished woman now identified with the Negro race, writes as follows: "In the annals of events the muse of history will tell how this remarkable man, this advocate of universal liberty, strove to make effective and to bring to a triumphant issue all that his great predecessor and prototype, Abraham Lincoln, planned for the people whose chains he broke. We are too close to his efforts to do them justice now. The influence, however, of his activity in behalf of a race young in opportunity, and without prestige in any particular walk of life, has already made a profound impression upon the thoughtful men of our day and generation." Mr. Roosevelt's attitude toward Negro appointments is then touched upon, and it is stated that he began to take interest in the matter when he first became connected with the Civil Service Commission. We are told that on his motion examinations were held in the larger Southern cities. "Notices were so given of 


\section{I2 \\ The American Race Problem}

these tests that coloured young men of scholastic training eagerly sought an opportunity to take them. Hundreds of them passed the examinations, many at the head of the lists. Through the influence of Mr. Roosevelt large numbers of them were designated for appointments." Mr. Terrell says that Mr. Roosevelt "watched with unusual solicitude the career of this new element of coloured men, the products of post-bellum days," and that "their efficiency was commended in terms of the warmest praise" in the report of the Commission for I890.* Mr. Terrell says that he wishes to show that what Mr. Roosevelt has said and done about "coloured men in office" is "no new propaganda so far as he is concerned." "When this great and good and just man writes of the door of hope for the coloured American, he is simply reiterating a doctrine which he has always cherished, and one altogether consistent with his deep sense of right and equity." $\dagger$

And yet how many times are we told that the position of the South, in claiming that Mr. Roosevelt had revived the "race question" to a greater extent than any other President in recent years, was wholly absurd and untenable. And for proof we were furnished with

\footnotetext{
* Under the caption "Benefit to the Coloured Race," the report states that an excellent feature of the Southern examinations "has been the elimination not only of the questions of politics and religion but of the question of race." The chance to enter Government service on their merits is said to have been a boon to "these coloured men and women." It is also said that a much larger proportion of coloured people receive appointments than under the patronage system. - Report of Civil Service Commission, July r, r89o, June 30, r89r, p. 6. Report signed by all three Commissioners. Note Grosvenor's speech in this connection.

†"Theodore Roosevelt," Robert H. Terrell, Coloured American Magazine, August, 1904, pp. 542-544.
} 


\section{Mr. Roosevelt and the Negro}

the "facts" of his and McKinley's Negro appointments. Evidently then, there must have been something more than Mr Roosevelt's appointments operating upon the processes of the American "Negro" mind. One enthusiast declares that "few men in any age have ever been adored by a people as President Roosevelt is adored by the Afro-American people, and few men ever so fully deserved such honour as they would pay him."* It is hardly worth while to multiply evidence of the extravagant adoration in which $\mathrm{Mr}$. Roosevelt was at one time held by a large group of so-called Negroes. It would be better to attempt a further search for the cause of such adulation.

\section{Social Equality}

We have alluded above to the operation of a racial trait to which Mr. Roosevelt unconsciously but strongly appealed by his characteristic habit of speech. There is another which has played an equally important part in influencing Negro attitude. This is the tendency to magnify and exalt out of all true proportion matters of personal concern, and to distort, as well as magnify, their personal significance. I am aware that one skates on thin ice who touches the "social equality" aspect of the race problem, much less attempts an interpretation of the significance of the Washington-Roosevelt dinner episode. This writer has never concerned himself over either racial or sectional hysteria, whether

\footnotetext{
* R. C. Murray in Coloured American Magazine, Dec., I905, p. 7x2.
} 


\section{The American Race Problem}

North or South. He is interested in all the varying phenomena of race relations, whether elementary or complex, whether manifested in this country or elsewhere. And to the serious student of such phenomena, one of the most peculiarly interesting to be found anywhere in recent years was this inherently insignificant, unofficial White House incident. Trivial as it was in itself, in the relations between Mr. Roosevelt and the South, as established by the latter, and in those between the Negro and Mr. Roosevelt, as established by the former, it explains more than any other group of factors which must be considered in this connection. Appointments, per se, did not control on either side. Mr. McKinley made more than Mr. Roosevelt. Personality, as far as the South was concerned, must certainly be taken into account, but it was not half the story. Roosevelt's "Southern referee system," which will be noticed later, is also responsible for its share of complications. With both the South and the Negro, the "manner" of Roosevelt's appointments, impossible of definition though it is, played a most important part. To this we have called attention above.

I have kept in touch with white public opinion, North and South, on the race problem attitude of both McKinley and Roosevelt, and have studied carefully, and I believe honestly, Negro opinion on both, as expressed publicly through group leadership, and as I could learn it by personal discussion. And there is left little room in my mind for doubt that without the background of that Wednesday dinner at the White 
House the canvas which subsequently absorbed and reflected such lurid colours would have given us an almost lifeless picture, as tame and dull as the usual afterglow of Southern appointments by Mr. Roosevelt's predecessors. That episode tinged for the South every subsequent act of his in which the Negro was concerned.

It is foreign to our purpose to discuss the Southern attitude toward "social equality." It is enough to say that amid the confusion of ideas as to just what is required to constitute the relation, the one clear fact is that the breaking of bread between the races upon equal terms is its ultimate and positive expression. That is the one unpardonable violation of the Southern racial code. We shall not stop to consider here the wisdom, necessity, expediency, or justice of this state of public opinion. We need concern ourselves only with the facts as we find them before us. This much we may say: Within the sphere of her own peculiar environment any position assumed by the South as a development of her racial difficulties cannot be successfully attacked or criticised from without. On the other hand, the world without is not to be dictated to and should not be undiscriminatingly criticised by the South in matters which are no proper concern of the Southern people. If any man outside the South see fit to do those things which in the South are by public opinion not permitted to be done, he is not to be criticised by Southern people for his acts. The South cannot arrogate to herself a censorship of the opinions or tastes which govern the social intercourse of people 


\section{The American Race Problem}

beyond her jurisdiction. On this ground her criticism of Mr. Roosevelt, for violating a social canon which she has erected for the conduct of the relations of her own people, will not be justified by the public opinion of the world or the country at large. In so far as such criticism was based upon an honest belief in the ill effects of the action upon conditions with which she was intensely concerned, she stands upon more tenable ground. It is in this aspect of the case, the Negro's own attitude toward the incident in question, that we are interested here.

The American Negro has had no truer friend that the late William H. Baldwin. The country has found in no other man a better balanced combination of philanthropy and good works with the saving grace of common sense. He gives his point of view in the following statement: "It may be proper for me to say that my observations are those of a New Englander, with all the inherited tendencies and sympathies of that people, supplemented by three years of active and intimate relations with the whites and blacks of the South, and, all told, about six years' service as a trustee of the Tuskegee Institute."* With these qualifications, he thus expressed his opinion on "the social question": "Whoever lives in the South for a year or more is inclined to reach the same conclusion as the intelligent Southerner on the social question. . . . Social recognition of the Negro by the white is a simple

\footnotetext{
* Proceedings of Second Capon Springs Conference for Education in the South, 1899, p. 93.
} 


\section{Mr. Roosevelt and the Negro}

impossibility, and is entirely dismissed from the minds of the white, and by the intelligent Negroes. There is no need of social recognition. It is largely demanded by sentimental theorists, who would be the last to grant such recognition if they were to live with the problem. The ordinary Negro would have as much difficulty in obtaining a room and board in a hotel in Boston as he would have in the city of Atlanta. Social recognition, for this generation at least, is denied; properly so, naturally so. Any attempt to force it merely complicates the situation and injures the cause of the black man."*

The last observation is a clear statement of the ill effects, from the standpoint of the Negro's interests, of attempting to "force" "social equality." The injury to "the cause of the black man" follows as a natural and inevitable consequence of the irritation to the white. The situation is just as much complicated by acts which both the Negro and the white man interpret as such attempts as Mr. Baldwin warns against, as by acts which are really meant to be such attempts. Under the influence of feeling the mind does not always draw nice distinctions between the apparent and the real. The necessity for careful conduct and prudent policy on the part of those whose very position clothes their simplest acts with peculiar and individual significance, cannot be too constantly kept in view and acted upon. Whether the South was right or wrong, wholly or in part, in its apprehen-

\footnotetext{
* Second Capon Springs Conference, r 899, p. 98.
} 


\section{${ }_{318}$ The American Race Problem}

sions of the effect of this incident in complicating its situation, is a matter for individual opinion to determine for itself. As to one factor in shaping such effect, however, we need not be in doubt. This is the significance of the incident, as interpreted by many of the men who through their utterances are to-day moulding and directing American Negro thought. The most striking feature of the situation which the incident created was the identity of opinion between these men and Southern white men on this matter of understood and accepted significance and meaning - aside from the question of intent.

The volume of evidence as to the significance immediately attached to this episode is measured only by the number of Negro newspapers and magazines published in this country at the time. It may be found also in the expressions of Negroes in South Africa and the West Indies. One of these leading papers, published in Washington, had the following notice of the incident under the caption, "President Roosevelt. The Lie Nailed that He Is Opposed to the Negro. The First President to Entertain a Negro. Booker T. Washington Dined": "The many false reports that have been circulated that President Roosevelt was opposed to the Negro have been eliminated by the many kind acts that he has done prior to his election, and while he was Vice-President, and since he has been President. While Governor of New York a distinguished coloured singer was denied lodging in Albany, New York, in one of the hotels. The circumstances having reached Mr. 


\section{Mr. Roosevelt and the Negro}

Roosevelt he went in person and invited the citizen to his residence, where he gave him lodging. When he assumed the office of Vice-President his first act was to appoint a coloured man an executive messenger against the protest of certain officials. Since he assumed the office of President he entertained Professor Booker T. Washington in the Executive Mansion on last Wednesday evening. The first President of the United States to entertain a coloured man. These many acts of recognition of the Negroes show that President Roosevelt is a man."*

In the next issue of the same paper the subject is discussed at some length, and a number of extracts from Southern papers are given: "The Southern Democrats," we are told, "hoped and expected to blarney the President so as to continue unrestrained in their wicked reign of terror and proscription against the coloured race. They are shocked, boiled, smitten, and exasperated. In one fell swoop Mr. Roosevelt has smashed to smithereens their fondest idol. They are fuming with dire imprecations against him, and all because he took a meal of victuals with a coloured gentleman who had been entertained by the nobility of England, and the best people of America." $\dagger$

Among the Southern editorials quoted in this issue, two or three will serve to illustrate the point contained in Mr. Baldwin's warning on the subject: "Roosevelt has done an injury to the Negroes of the whole country,

* Washington Bee, Oct. r9, r ror.

† Idem., Oct. 26, r $90 \mathrm{r}$. 
especially those in the South, and has damaged the wisest and most useful Negro in America." "The people of the South, who had warmed up to the President, have had their feelings rasped. In irritating the South he has lost power for good." "The President could not have committed an act not actually unlawful that would have excited as much popular feeling or aroused as much public attention. Nobody knows what he will do next. He has seriously fallen from popular favour in the Southern states." The same issue of the Bee contained a cut of Mr. Washington with this legend: "Professor Booker T. Washington. Dined by President Roosevelt - No Colour Line in the White House - An Object-lesson for the South." In its issues for several weeks the affair was treated in the same vein. In one it was declared that "that Roosevelt-Booker Washington episode still remains a big thorn in the side of Southern chivalry, and the endorsement of the President's course by the American Missionary Society, Union Veterans' Union and other organisations, and the Northern press, only adds to the distress. . . The late elections do not show a great reaction in the political world on account of the celebrated dinner and prove that a fair recognition of the merit of coloured men does not detract from the power and popularity of the Republican party."*

The general line of discussion in the coloured press was the same throughout the country. There was the same magnifying of the affair to the proportions of

* Washington Bee, Nov. 9, r $90 \mathrm{x}$. 


\section{Mr. Roosevelt and the Negro}

a set White House function; the same popular and enthusiastic admiration of the President for thus "recognising the race"; the same "no colour line in the White House," with the same resulting "objectlesson for the South"; the same "smashing" of the Southern social equality "idol." The sameness might be wearisome, but it possessed an unmistakable significance for such as could read as they ran. Even from Haiti there has come a tribute to the President for his "stand for the race." An author in that distracted republic, a M. Firmin, has written a volume on Mr. Roosevelt.* A coloured reviewer in this country says: "We shall of course not be surprised to find this Negro statesman warmly praising the President for the Booker Washington dinner episode, for the "square deal" doctrine, and for his staunch declaration against closing the door of hope and of opportunity to the aspirations of his coloured fellow citizens. Such doctrines and declarations make a very natural and congenial appeal to the admiration of Negroes the world over." $\dagger$

Not all the appointments made by McKinley or promised by Grosvenor could have won for the former any such universal and fulsome praise as was bestowed upon Mr. Roosevelt. We have ventured the opinion that the dinner episode had more to do with this storm of applause than most of us imagine. Suppose we glance at the connection and see if there is any logical

\footnotetext{
* "M. Roosevelt, President des Etats-Unis et la Republique d' Haiti."

† "Roosevelt and Hayti," F. R. Steward, Voice of the Negro, June 1906, p. 435.
} 
background for the feeling which Mr. Roosevelt stirred in a greater degree than had been done by any man who had gone before him.

He who undertakes to fathom human conduct, and ventures to assign motives and reasons for the actions of his fellow men, engages in a difficult and dangerous enterprise, provided he has either a name to make or a reputation to lose. Nothing is simpler, and nothing exacts less of honest mental effort, than to indulge in sweeping generalisations upon the causes behind the conduct of others. The human element enters so largely into our own motives that our judgments upon those of others are too often of no real interpretative value. If such conduct is displeasing to us, or in any way is inimical to our interests, it is human to condemn it, and to ascribe it to unworthy motives. On the other hand, if it appeals to us, or pleases us, or redounds to our good, we are quite apt to attribute to it the mainspring of a very proper and noble impulse. This is particularly apt to be true when we have the presence of a complicating racial factor. When a member of either the white or Negro race in this country attempts a study of the impulses and motives of the other, he is quite likely to hasten to conclusions from superficial observation, or make deductions as to the race as a whole from the more or less accurately noted conduct of a few of its members.*

\footnotetext{
* The two things this writer most wishes in this connection are, first to avoid this pitfall of shallow controversialism, and, second, to keep the record clear as to his own animus. I have studied the problems of race relations long enough and broadly enough for the subject to have become saturated with a thoroughly impersonal interest for me. I follow with as close attention the
} 


\section{Mr. Roosevelt and the Negro}

In the Southern white man's disapproval of the particular incident before us, and in his attitude on the general subject, the Northern white man and the Negro usually read race hatred, race prejudice in its lowest sense, barbarous social standards, a desire to humiliate the Negro, and so forth. In the incident itself, and in the attitude of the Northern press and the educated Negro toward it, the Southern white man is likely to read an effort, or desire, to establish "social equality" between the races. In fact there is a deeper meaning than either of these in the attitude of both the Southern white man and the educated Negro. The case of the Northern white man is, in the main, a very natural inability to reach the true inwardness of the situation, to sift the few sound grains from the mass of chaff. It will not be questioned that there are individual white men whose attitude toward the Negro is dictated by "race hatred" pure and simple. It is equally true that there are some educated Negroes who personally, for themselves, desire "social equality," as that term is commonly understood. But these individuals are an insignificant and negligible quantity in the masses of

problems which confront the English colonists in Natal, or those incident to the attempted adjustment of the native question in the grant of responsible government to the Boer colonies, or the problems which the native in politics presents at the Cape, as I do others nearer home. The problem of racial contact between the white man and the black is a world problem to my mind, and I believe that some day it will be generally recognised as such. The problem of interpreting the fundamental causes behind, and the far reaching significance of, the Ethiopian movement, as inaugurated and directed by Mokane, Duane, Mazimba and others, is equally as interesting as that of interpreting the causes and significance of minor racial incidents and movements in our own country. But here we are attempting the one with which we are more immediately concerned. 


\section{4 \\ The American Race Problem}

either race. We are not concerned here with the attitude of the white race at all. And we may dismiss from consideration the great mass of Negroes, both North and South. Social equality for them has no earthly meaning. It is a concept which their minds do not grasp, even in its simplest form. They do not even think about it. It is not possible to establish any logical connection between "social equality" and criminal assault - and the latter crime is not committed by educated Negroes. When I use the term "educated" I do not mean the education which is limited to the ability to read and write. I am referring here to those race groups which contain leaders of positive force and ability, men of activity and determination. These are editors of newspapers and magazines, lecturers, lawyers, teachers, ministers, authors of books and pamphlets, contributors to the current periodical and permanent literature of this country and England. From such men and women it would be possible to quote numerous isolated clean cut, unequivocal declarations which might be construed as mere advocacy of "social equality," per se. But this would miss the mark. If we accepted such declarations at their face value we would be grasping at the shadow and letting the substance go. They mean more than appears upon the surface, more, probably, than even most of their authors fully comprehend.

In the leading Negro school journal in this country, the organ of the oldest coloured industrial school, we may find as clear a statement of the truer meaning and 


\section{Mr. Roosevelt and the Negro}

significance of real "social equality" to the Negro race as it would be possible to frame. It is from the pen of Professor Kelly Miller. His suggestion as to the inevitableness of "frictional problems" between widely different races is also worthy the thought alike of the dilettante who declares there is no problem, and of the optimistic enthusiast who constantly reads its "solution" in the execution of some favourite curative programme. The author's position and name should commend his opinion to the thoughtful consideration of all students of the question.

He says: "Where two races of widely different corporal peculiarities and cultivated qualities are brought into contact, serious frictional problems inevitably arise. The difficulty of adjustment will be greatly aggravated if the prevailing social scheme be of individualistic rather than communistic type. Mohammedanism is superior to Christianity, the Catholic to the Protestant sect, in effective control over the prejudice and rancour of race. There is less race conflict in the Mohammedan than in the Christian world; albeit the disciples of the great prophet still foster the institution of slavery. The Koran demands conformity to the faith but it is indifferent to the ethnological aspect of the adherent. This is also true, though perhaps in a less degree, of the Catholic Church. But not so with the Protestant Teuton. With him blood is not only thicker than water, but its spissitude passes that of knowledge, culture, and the Christian graces. The American Negro may speak the same language, 


\section{The American Race Problem}

conform to the same institutions, and adopt the same mode of religious worship as the rest of his fellow-men, but it avails him nothing in the scale of social eligibility, which is the one determinative test of all true equality. The political, civil, and industrial disabilities under which the Negro labours are but the inevitable outcome of the social fiction which divides the races. Without social equality, which the Teuton is sworn to withhold from the darker races, no other form of equality is possible. The difference between the Negro in Constantinople and Chicago, in Rio Janeiro and Baltimore, in Havana and Philadelphia, is a concrete illustration of the truth of the principle above set forth."*

There is a somewhat similar vein of thought running through some of the writings of another eminent man identified with the race, Dr. W. E. B. DuBois. As a suggestive and fairly typical specific expression, we may select the following, from a significant and well tempered address: "It is hardly necessary for me to add to this very much in regard to the social contact between the races. Nothing has come to replace that finer sympathy and love between some masters and house servants, which the radical and more uncompromising drawing of the colour line in recent years has caused almost completely to disappear. In a world where it means so much to take a man by the hand and sit beside him; to look frankly into his eyes

\footnotetext{
* "The Modern Land of Goshen," Kelly Miller, Southern Workman, Nov., 1900, pp. 601, 602.
} 


\section{Mr. Roosevelt and the Negro}

and feel his heart beating with red blood - in a world where a social cigar or a cup of tea together means more than legislative halls and magazine articles and speeches, one can imagine the consequences of the almost utter absence of such social amenities between estranged races, whose separation extends even to parks and street cars. Here there can be none of that social going down to the people; the opening of heart and hand of the best to the worst, in generous acknowledgment of a common humanity and a common destiny. On the other hand, in matters of simple almsgiving, where there be no question of social contact, and in the succour of the aged and sick, the South, as if stirred by a feeling of its unfortunate limitations, is generous to a fault. The black beggar is never turned away without a good deal more than a crust, and a call for help for the unfortunate meets quick response. I remember, one cold winter, in Atlanta, when I refrained from contributing to a public relief fund lest Negroes should be discriminated against; I afterward inquired of a friend: 'Were any black people receiving aid?' 'Why,' said he, 'they were all black.' And yet this does not touch the kernel of the problem. Human advancement is not a mere question of almsgiving, but rather of sympathy and coöperation among classes who would scorn charity. And here is a land where, in the higher walks of life, in all the higher striving for the good and noble and true, the colour line comes to separate natural friends and co-workers, while at the bottom of the social group, in the saloon, 


\section{The American Race Problem}

the gambling hell, and the bawdy-house that same line wavers and disappears."*

We may add as a third illustrative expression the words of a somewhat younger man than either Dr. DuBois or Professor Miller. His medium is the organ of the more radical school of Negro thought. In a presentation of the respective positions of this school and of the conservatives, identified in this instance with the "Tuskegee idea," Mr. William Pickens has this to say of "social equality": "There is another question, a question purely of personal liberty and individual equality, but which is usually mystified by the following phrase of vicious association, 'social equality.' Here one side advises, 'quietly accept the imposition of inferiority. It is a lie, but just treat it as the truth for the sake of peace. Diligently apply to the white man the title of gentleman, and care not if he persists in addressing you as he calls his horse and his dog. Be patient. This general disrespect and discrimination will develop into the proper respect and impartiality at some time in the long lapse of geological ages, just as the eohippus has developed into the race-horse, and the ancestor of the baboon into a respectable Anglo-Saxon.' The other side says, 'I ask for nothing more or less than the liberty to associate with any free man who wishes to associate with me. Your colour discriminations, legal or not, are all damnable, inasmuch as they draw an artificial

*"The Relation of the Negroes to the Whites in the South," W. E. B. DuBois, "Annals of American Academy of Political and Social Science," Vol. 18, No. 1 , July, x901, pp $x_{38}, 139$. 


\section{Mr. Roosevelt and the Negro}

and heartless line, give encouraging suggestions to the vicious, and allow the stronger in brute power to force bastardy upon the weakcr without remedy. Colour has absolutely no virtue for me, and however much I am outnumbered I will not retreat one inch from that principle. However little my position might affect savage opposition, by the God of your fathers and mine, I will never by voluntary act or word acknowledge as the truth what I know to be the grossest of lies. And you might ask all the truly valiant hearts of the world and the ages how they beat toward these contrary tenets." $*$

Here are the frankly avowed expressions of three representative men. They are men of education, in the highest sense, of trained minds, of broad culture and of irreproachable private character. Personally, they have their associates among others of similar acquirements and tastes. The group to which they belong is to-day easily superior intellectually to any other identified with the Negro race here or elsewhere. It is a group of which the country is likely to hear more some day, if education and brains count for anything in moulding Negro opinion. It is the school with which the advocates of the programme of "industrialism" may also have to reckon. $\dagger$ It would be shal-

* "Choose," William Pickens, Voice of the Negro, June, r906. p. 405.

+ In the article from which we have just quoted Mr. Pickens says, in speaking of political conditions: "Acquaintance with such conditions without at the same time being acquainted with the Negro, particularly with the 'rising generation', would render one pessimistic. But, thank God, there is one great advantage in it all: The Negro is not being fooled. The aspiring, ambitious, intelligent members of the race know what is the matter. And especially is the coming generation alive to the situation. If you have any doubt of the young 


\section{The American Race Problem}

low and absurd to dismiss these declarations as mere expressions of personal desire for "social equality," as that term is commonly used. Probably the only individual outward change which would be wrought for such men by a full compliance with all they would ever demand, would be to afford them greater comfort in travelling and better accommodations at the end of a journey. They do not "crave white society." They have no desire to associate with any man save on mutually agreeable terms. What they would demand is the American privilege of using such purely public accommodations as they might desire to use and for which they might be able to pay, and as individuals to associate with any other individuals who might wish to associate with them. The first is purely a "civil" right; the second, as the world reckons it, is a matter of personal concern; yet, wholly or in part, each is denied the average man of the race in America, regardless of sectional lines. And to the enjoyment of both privileges the white man has applied the comprehensive and forbidding term "social equality," without regard to its derivation or its accuracy of definition. What, then, is the real meaning of their words?

\section{A Phenomenon of Race Consciousness}

Somewhere, probably in his "Africander Land," Archibald R. Colquhoun interprets the "Ethiopian

Negro's choice of the foregoing opinions just acquaint yourself with an intelligent body of them in any part of this country. Spite of seductive influence of gold and silver the Negro of the future promises to be the humanitarian bit of leaven in the American mass of commercialism."-Ibid., p. 407. 


\section{Mr. Roosevelt and the Negro}

Church" movement as a manifestation of the dawning of race consciousness to the South African Negro mind. He thinks that the movement is one of inevitable race cleavage, and that it is racial rather than religious. This seems to me a correct diagnosis. The church is used to effect an organisation. It becomes a nucleus around which social ideas and policies may be developed toward a definite objective. The latter may never be realised, probably will not be, but its articulate expression is "Africa for the Africans" - a slogan which need not be misunderstood. The development of the American Negro has also centred largely about the church organisation. And it is not singular that the movement started in far off Africa should have received its strongest support from the distantly related tribes of the west coast, transplanted to American soil. Nor need we wonder that the cry thus raised in a part of their native land finds an echo to-day in thousands of American Negro hearts. It is probable that every race has its own peculiar "human nature," but there is also a "human nature" common to all the races of mankind. This is the response of people to the calling voice of their own kind, whether the call be a cry of exultation or a wail of despair. It is the response of race instinct, which, and which alone, makes blood thicker than water. It is the common trait which deep in the heart of the mass makes the white man sympathise with the white man and the Negro with the Negro, wherever the lines are drawn between the two. It is this which makes nations and races potentially great. 


\section{2 \\ The American Race Problem}

Its development marks the progress of men from scattered and helpless tribal organisations to a unified, cohesive racial life, and finally makes possible the growth of nation from race.

The white man deceives himself if he cherishes the idea that this universal human impulse is not latent in Negro life. The Negro has not yet developed a race consciousness, and he is still very far removed from anything approaching a national life. But in both Africa and America the dawn of the first is beginning to be seen. And in South Africa he is groping, more or less blindly and awkwardly perhaps, but still groping, toward the light of possible nationality. Their ancient continent is the only place on the globe where a national life is possible - if indeed it prove to be possible there. It is the only place where the experiment may be even tried. We need not stop to so much as consider the artificial travesties erected upon the blood-stained ruins of white civilisation in Haiti and Santo Domingo. They will sometime disappear in a night, when the American white man wants another island for some real or fancied use, even as the "Republic of Panama" was born in a day after a similar conception. In America, and this is all, we may see the Negro instinctively striving after identity with the national existence of which he forms an artificial and unassimilated part. Back of this lies the same impulse of awakening racial life. What the movement here may be, no man may say, nor how it will manifest itself from time to time. Having here no possible separate national life of his 


\section{Mr. Roosevelt and the Negro}

own, his developing instinct manifests itself in an effort toward equality of opportunity and place in that of the white man who surrounds him and hems him in. Every step toward such fancied equality is hailed as a mark of racial progress.

The Negro has had theoretical political equality for many years. It is no longer a novelty in principle, and everywhere in the country to-day the privilege of voting is also practically exercised by varying numbers of the race. The same thing holds as to theoretical "civil rights," save as to such as may chance to fall within the white man's uncertain and somewhat confusing definition of "social equality." And here we come to the ultimate test of real equality in any form. This is the final test which those members of any race which finds itself in contact with another, who feel themselves the moral and intellectual equals of that other, will soon or late make the measure of the degree and character of association which exists between the two. To sum up the case in Mr. Miller's words: "Social eligibility is the one determinative test of all true equality."

If we apply the test to our own individual lives we may better realise its force. What are all the political and civil rights in the world to the man who is a social pariah? And just as the granting of this form of equality is taken to be the final and only admission of equality in every form, so is its denial held to be a denial of true equality in any form. And the rights which we call social play their part in intercourse among 


\section{The American Race Problem}

nations as well as in intercourse among men. No admission of equality which America could make to Japan would atone for the stigma of a national approval of the separation of Japanese children from white in the schools of San Francisco. Social equality has a different significance, a broader, more comprehensive meaning, at the point of racial contact than is apprehended by those against whom it is not threatened and to whom it is not denied. It means more to the Southern white man in his environment than to the Northern white man in his, and racially more to the Negro than to either. If we will but reason it out we need not be troubled to understand the Southern white man's attitude.

The existence of the white American's social barrier is all that stands between the American Negro and American "equality." Every incident which possesses a significance translatable into evidence of its possible removal means for the cruder Negro mind one other faltering step toward the goal which is to mark the end of ostracism. It is hailed by such as these as we have seen the Washington dinner hailed. And the white man whose actions in high position place the stamp of powerful disapproval upon a detested social law is acclaimed an emancipator from a thralldom more galling to the higher Negro groups to-day than was ever the physical bondage of those who fifty years ago cheerfully stood upon a lower plane. But we should keep in mind the groups into which the American Negro has gradually divided. I have said that the lower 


\section{Mr. Roosevelt and the Negro}

group, the masses of the South and of the country, care nothing for social equality in any form. The presence of a white man in any social relation would be to them an intolerably disquieting association. Race consciousness for them is still in its first and lowest stage - that of the instinctive drawing together of a weaker people for defence against a stronger - which, for example, guarantees the fleeing criminal a haven with his race, if only his pursuers are white.

Some inkling of the happenings in higher Negro life filters down to this lower stratum, with more or less of possible, though very indefinable, effect. But nothing is heard from this lowest group on such incidents as we are discussing, just as very little is heard from the highest, such as the men from whom I have quoted. The latter are not deceived by the isolated cases which create such strife in the world about them and below them. They know that one swallow does not make a summer, and, as Kelly Miller quite clearly shows, they know the race which stands before them. For the most part they merely voice the abstract intellectual conviction of the necessity of the removal of social barriers as a condition precedent to the final recognition of a full measure of equality for any race. The clamour comes from the group below these higher types - the editors and essayists who talk about the "smashing of social equality idols" and the "object lessons" furnished one section of the country by the actions of individuals elsewhere. They 


\section{$33^{6}$ The American Race Problem}

are a numerous and a growing class, and their influence upon the masses is probably greater than that of those above them, for they are not as far removed. It is greater, perhaps, than we know.

We shall conclude this branch of the subject with this observation: In a very important sense no "race problem" is susceptible of "solution." A race problem arises from contact along frictional lines between races possessing such inherited physical and mental differences as produce a natural and easily defined line of cleavage between the two. As long as either the characteristic physical or mental differences persist a problem will remain. 'The more marked the differences the greater the resulting problem. The essence of the difficulty is the inability to reconcile these natural differences upon a basis of artificial equality. The problem becomes more acute as the assertion of equality becomes more pronounced. It disappears only with such a degree of assimilation as eliminates the differentiating factors, by merging the two constituent elements of the problem into one. But this is not a "solution." There may be a possible basis of compromise between two races, a sort of treaty of peace, so to speak, under which the two may occupy a common territory with a minimum degree of friction. But on analysis every such adjustment will be found to contain, as a fundamental condition, a recognition, open or implied, of the superiority or dominance of one race, and the reciprocal inferiority or dependence of the other. Such a modus vivendi may easily amount to a practical solu- 


\section{Mr. Roosevelt and the Negro}

tion of certain phases of the problem for the masses of the dependent race. It is a mockery and a sham in so far as the superior members of that race are concerned. For them there is but one "solution," and its very essence, its beginning and its end, all are summed up in the one word "equality." Just in so far as the relation and association between the superior and inferior classes of the weaker race are intimate or remote, will this adjustment between the two races themselves be difficult or easy to establish and maintain. When the superior individual identifies himself, or is identified by the world, with the inferior mass, he may be counted upon to protest against such a compromise. Where he is not so identified, but is treated solely upon his merits as an individual, he will be less apt to prove an opposing factor to such an arrangement.*

Racial conditions in Jamaica fulfill this last requirement, and illustrate our position, better than in any other territory which contains a large Negro population. The absence of a race problem in Jamaica, such as we have here, is often commented on by travellers and publicists, both English and American. It is not uncommon for the island to be held up as an example

* Dr. Woodworth, President of Tougaloo University, Miss., relates a conversation with "a prominent Negro lawyer about the separate car law," which illustrates the point I would suggest. Dr. Woodworth says: "He had nothing to say against the inherent unrighteousness of a colour discrimination, as might have been expected. He summed up his objections in the emphatic statement, -What I dislike about the law is that it puts me in with a lot of niggers with whom I do not wish to associate.' He favoured the European system of class cars."- "Discrimination," Frank G. Woodworth, Southern Workman, Nov., ז900, p. 6 r6. 


\section{$33^{8}$ The American Race Problem}

of what the South could do, if only it were as just and wise. The answer to this involves a consideration of certain fundamental differences between Jamaica and the Southern states which these commentators seem unable to comprehend and which we cannot take up here. Jamaica is a Crown Colony, from which politics were practically eliminated, and largely on the Negro's account, forty-two years ago. At most they can only play at the game. Jamaica is also a detached, oceanbound island, with the peculiar insular freedom from continental complications. Its people are at liberty to work out their own destiny along their own normal lines, without the interference of outside ignorance or interest. The agitator or malcontent finds no field for his vocation. The island is too small for him and he usually drifts to the "States." In Jamaica emancipation occurred practically a generation earlier than in America, which means three decades longer in which to have effected an adjustment than we have had here. And in Jamaica the abolition of slavery was not followed by Reconstruction. But next to differences of political and governmental conditions, the most important consideration is that first suggested.*

The mulatto and Negro types constitute separate and distinct elements of the population. The former is enumerated as "coloured" by the census, while the

* Since the above was written Mr. W. P. Livingstone - the best student of the Negro ever sent to the West Indies by England - has very clearly pointed out the fundamental basis of difference between the American and Jamaican situations which I have indicated here.- "The American and West Indian Negro," North American Review, July 19, 1907. 


\section{Mr. Roosevelt and the Negro}

latter is classed as "black." The mixed class furnishes the business and professional men of "the Negro race," and such representation in the official life of the island as is accorded it. The "blacks" form a peasant class, practically contented, which constitutes no problem graver than that of police surveillance and administration. Theoretically, and sometimes actually, if one of the "blacks" shows evidence of superior capacity he obtains recognition, but he also loses his identity with the real Negro element, as we understand the association here. Whatever basis of racial adjustment might be agreed upon between whites and mulattoes, or evolved in the process of time, was final. It did not need the ratification of the blacks. Before I 86 I the property-holding, free mulatto class of Louisiana had gained for itself such measure of recognition as for many practical purposes removed it largely from the "Negro" class. With emancipation this type became largely identified with the "equalised" Negro, and has been gradually submerged by the heavier mass of the latter. It is not necessary to question the sincerity of the attachment of the superior mulatto, or occasional Negro, individual to the interests of the black masses. When we say that if such individuals were accorded by white people the measure of recognition to which as individuals and as a class they felt themselves entitled by education, culture, and attainments, we would probably hear much less than we do about "the denial of rights to the Negro," we merely recognise a very elementary trait of human 


\section{The American Race Problem}

nature. In doing this we simply take cognizance of the operation of a practically applied theory in the island of Jamaica.

\section{The Southern Referee}

An analysis of the onetime differences between $\mathrm{Mr}$. Roosevelt and the South would be incomplete without a few words for the former's system of Southern "referees." To a "reformer," Southern Republican politics offered an irresistibly attractive field. Mr. Roosevelt was also naturally inclined to break up the old Hanna-McKinley machine. He did it most effectively, North and South. But in the South he was peculiarly unfortunate in his methods. For an appreciation of the full significance of such methods, and of the part they played in erecting a barrier between Mr. Roosevelt and the Southern people, we must again turn to pyschology, sentiment, and Reconstruction.

We may say what we please, and draw as many logical conclusions as we like, about duty and treason. We may be wholly right and accurate in our technical definitions. But what if we are? In the great universal heart of man the only traitor is he who is false to his people, the only treason is that of turning one's back upon one's neighbours and friends. This differentiates foreign from civil wars. In the former the people are one and men are neighbours without regard to distances between them. The cause of the country is the cause of all its people, and treason to 


\section{Mr. Roosevelt and the Negro 34I}

one's country is heinous only because it necessarily involves treason to one's people also. Who were the "patriots" and who were the "traitors" in the War of the Revolution? The answer depends upon whether we are Englishmen or Americans? The "loyalist" of one was the traitor of the other, the traitor of one was the patriot of the other. In a civil war, a war among sectional divisions of the people of the same country, who are traitors and who are loyalists, and what are they treacherous or loyal to? It is idle to talk about theories of government as determining such questions. The final estimate of the world will no more make a "traitor" of a man who, through good repute and ill, stands or falls with his own people, than it can make a "patriot" of one who has to leave his home and desert his people in order to be "loyal" Robert E. Lee is not a "traitor" in the estimation of mankind. There is something almost grotesque in such a suggestion. But this is not because of some fancied virtue derived from the fact that Lee had been taught that a state had the right to withdraw from the Union. It is because of the fact that with a self-abnegation not surpassed in any time and not equalled in our own, putting behind him every consideration of self-interest and every opinion of his own as to the wisdom of the action of his state, he cast his lot with his people and without a murmur shared their fortunes and their fate. We have but to ask ourselves what would have been his place in the estimate of the world, had he remained in the army and fought on the 


\section{The American Race Problem}

Federal side? He would have been a great general, and probably had an equestrian statue in Washington, and Arlington would not now be a national cemetery. $\mathrm{He}$ might have been elected President. But he would not have been the Lee which the world knows to-day.

The converse of this is the estimate in which a man is held who deserts his people in their hour of need. The measure of sentiment against him will be the causes which prompted his course, whether he is credited with motives of principle or charged with impulses of greed. Always the depth and duration of feeling against him will depend upon the circumstances and condition of the people whose cause he renounced. It meant little to a man in the North to espouse the side of the South after war was over, and to plead for fair play toward a defeated and helpless people. $\mathrm{He}$ might clearly claim, and possibly be accorded, the tribute due a generous nature. The situation was different in the South. There was but one course to pursue, particularly after the congressional policy began to assume definite form. Desertion then became a crime more odious and detestable than would have been cowardice or desertion in war. And the course of such as these immortalised an old word and gave a new one to our political vocabulary. As "Burking" once came to stand for the very capstone of Scottish crime, so "Scalawag" stood and still stands in the minds of Southern people as the almost breathing embodiment of an infamy peculiarly its own. Occa- 


\section{Mr. Roosevelt and the Negro 343}

sionally it is sought to turn the point of Southern criticism of Reconstruction with the statement that many of its most vicious features were due to the participation of men born on Southern soil. No Southern man will be found to defend the Southern renegade on such an issue. The outside world probably does not comprehend the depth of Southern feeling toward the creature who forsook his people in their darkest hour and sold himself for a mess of pottage.

Southern people would be less than human if Mr. Roosevelt's referee system did not recall to their minds with painful vividness the most despised of Reconstruction tools. The system, as we are considering it here, consists in appointing a Southern white Democrat to some Federal office, and referring to him all matters of Federal patronage in his state. It is an anomaly in American politics. The referee at once takes the place of the state's Representatives and Senators and of the state party organisation as well. $\mathrm{He}$ becomes the official, or unofficial, medium of communication between the President and the people of the state in all matters of Federal concern. He makes and unmakes politicians, fills local offices, and dispenses administration favours. He is a creature without a place, neither fish, flesh, nor fowl. The system is thoroughly vicious, but that is not our concern. People do not like to see their immediate fellows bought in the political market, even though there are of course some who are always for sale. The system simply served to perpetuate and emphasise the difference between the 


\section{The American Race Problem}

South and the rest of the country. The Southern states, those in which the system was inaugurated, were once more reminded of their satrapical Reconstruction character. There was absolutely no question of politics involved, in so far as the people of the States were concerned. They of course expected no patronage from a hostile administration. The question has its practical bearings, however, for at least in one state the results were as detestable as some features of Reconstruction itself. But above all, the matter was one of sentiment. The referee was too closely related to the "scalawag" not to be a thorn in the flesh. Like his prototype, however, he served his day, and has all but disappeared, save from memory and in name.

\section{Conclusion}

In applying the conclusions of this exposition we would first suggest that if the only parties to be considered were those immediately in interest, an interpretation of the significance of their acts and motives would not be worth attempting. Mr. Roosevelt will not be the last President of this republic, nor Mr. Washington the last leader of his people. The Negroes now in office will disappear and be forgotten. This generation of white people will presently pass away. These individuals are all mere figures on the stage. But the essential elements with which we have tried to deal are permanent and will endure. These are the 


\section{Mr. Roosevelt and the Negro}

factors of race and of human nature. With these only need we be concerned.

With these fixed elements before us we need be given only the historic setting of any racial situation to predicate its sequence. In our narrow view we imagine these problems to be peculiarly our own. In fact there is no novelty in the things which so disturb us here. The social and official attitude of more than one English administrator in British American islands has in time past provoked as bitter criticism as was aroused by Mr. Roosevelt's actions here. We need not think that we are the only people who ever grew excited over a dinner between an eminent Negro and an eminent white man. Twelve years ago a luncheon given Khama, the South African Chief, by the Duke of Westminster in London, provoked the "annoyance and disgust" to use Ambassador Bryce's phrase, of the white people in his native country. And their resentment was as difficult to understand in London as was that of the South by the people in New York or Boston. Good people deplore the lack of "sympathetic coöperation" between the best elements of the races in the Southern states, and apparently fancy themselves to be the discoverers of a unique manifestation of the "colour line." The same absence of coöperation between the same elements is similarly deplored in South Africa. The Southern white man has many things to keep alive the feeling of outside interference and control of which Booker T. Washington appreciates the force. But only yestenday the action 


\section{The American Race Problem}

of the Colonial Secretary in London, in interfering in a matter of local moment between the whites and Negroes of Natal, provoked the deep resentment of the English colonists. So much so, indeed, that some of the ablest and soberest amongst them did not hesitate to suggest a parallel between their possible course under further irritation and that of the American colonists under the policy of Lord North. And always there is in evidence the same dominating motives behind the white man's attitude - apprehension of the effect upon the Negro, coupled with a personal social aversion born of contact with the masses of the race.

We shall have taken our first long step toward the saner discussion and consideration of the problem only when we have learned the simplest primal fact of racial contact, that it is a question of race and not a question of place. The situation is hopeless as long as sectionalism determines our attitude toward it. The Northern white man must learn that there is more in the attitude of his Southern brother than the "senseless race prejudice" of which we hear so much. We must finally realise the latent force of the instinctive sense of racial self-preservation which operates as an unconsciously dominating impulse in higher racial types when in the presence of large masses of a lower, but which otherwise does not make itself felt. The Southern white man must learn that this is all there is in his own attitude, emphasised by the influences which we have attempted to analyse. Also that a different attitude on the part of people elsewhere possesses no 


\section{Mr. Roosevelt and the Negro}

significance, other than as indicating merely an absence of the conditions which dictate his own individual course. The South should know that the North is not, by any individual or group action, trying to derange her social laws or customs. On each side of the line we must grant a larger measure of uncriticised individual conduct on the other. Each of us would as well learn now as half a century hence, that in fact if in the other's place we would do as the other does, entirely regardless of what we now imagine we would do. This is human nature.

The naked fact that certain acts of an individual, who was for the moment President of the United States, provoked the resentment of one section of his countrymen and elicited the admiration and applause of another, may be in itself the merest matter of casual interest. It becomes clothed with deeper meaning when we grasp the significance of the impulses beneath the contrary emotions which the acts arouse. In their final analysis these conflicting emotions possess a significance which is racial in its human breadth and meaning. If we are sufficiently familiar with the broader aspects of racial problems to know that given situations between two races produce practically uniform results, without regard to the subsidiary question of geographical situs, we can at once eliminate the sectional factor from our present equation. If we are ignorant of this fundamental consideration ourselves, and decline to accept the findings of others, then we shall probably becloud the issue and wholly mis- 


\section{The American Race Problem}

interpret the situation before us. In this larger aspect of the case, Mr. McKinley and Mr. Roosevelt and Mr. Washington disappear from view. They are unimportant in themselves. And sectional lines have no more significance, per se, than have these individuals. Had the geographical positions of the people in the sections been reversed, the world would have been none the wiser. Their respective attitudes were, and are, determined merely by the circumstances of their respective environments. Racially they are fundamentally alike, and the same conditions will make the same appeal to each - with certainty of the same response. I have stated this elementary proposition many times. Some day it will cease to be disputed. Of all the inexcusable features of the American race problem the most senseless is the sectionalism with which it has become saturated through the petty differences of environment produced by differences of geographical conditions.

There should be some practical value in interpreting the course of these events. Their history should at least suggest that persons in authority would do well to appreciate the difference between formulating policies for fairly homogeneous peoples, and shaping a course of practical conduct toward populations containing large masses of widely different racial types. They should realise that there are two races in this country, and that they are yet too far apart in history and development to be treated in all things as one. It would be wise to bear in mind, as Mr. Roosevelt has 


\section{Mr. Roosevelt and the Negro}

recently reminded us in another connection, "that in the long run even the most uncomfortable truth is a safer companion than the pleasantest falsehood." There is one clear truth which stands out above the beclouding mists and fogs of forty years of senseless strife, and with the finger of experience points the way to safer paths. If this analysis shows anything at all, it should enable us to see this truth, which is that in many of its acuter phases the problem largely rests with persons in high official place. It is entirely with them to adopt the policy which shall either insure enmity or make for good-will between the masses of the races in the South. There is no abstract question of right involved. It is solely one of wisdom or expediency, as we prefer to call it. But whatever the policy, it should be intelligently pursued. Official conduct should not proceed upon absurdly false assumptions. It is one thing to bring a number of individuals of a distinct American type into official relationship with a political administration. It is something quite different to insist, or imagine, that in doing so we are offering a share in administrative control to another and a different element of the population.

After all, ours is merely a segment in the world-wide circle of problems of racial contact. It existed before the present actors appeared upon the scene. It will remain after they have left the stage. They cannot remove it before they go, nor can they take it with them when they leave. But they may do much to 


\section{The American Race Problem}

make it easier or more difficult for those who stand nearest to it, for those of both races of whose daily life it is a vital part.*

* The substance of this paper was embodied in an article submitted to several magazines while the Crum and Indianola incidents were being generally discussed throughout the country. The article was not found available. This paper was written because of the writer's conviction that the history and course of the events which it attempts to analyse possess a deeper and more permanent significance than is commonly recognised. The now almost forgatten incidents do not in themselves merit consideration. 


\section{VIII}

\section{The Negro in Politics}

THE experiment of Negro suffrage could not have 1 been tried under conditions better calculated to produce disastrous results than under such as existed in the South in 1867. No better means could have been adopted for insuring such results than the measures which accompanied the grant of the franchise to the former slave. It was a curious intermixture of ignorance, philanthropy, malice, quixotic political theory and what not, a sort of nondescript "devil's broth," out of which Negro suffrage was evolved after I865. It stands as the greatest self-confessed failure in American political history. It is a debatable question upon which party was inflicted the greater harm - the Southern white man or the Southern Negro. It is occasionally said in defence that the fact of such failure has not been established; that Negro suffrage was never given a fair trial; that under different conditions different results might follow.

We have but to turn to the debates over the XV. Amendment resolution, and catch the spirit which actuated so many of its supporters, to find the answer to this suggestion. The moving impulse was an almost simple, childish, a scarcely comprehensible, faith in the 


\section{2 \\ The American Race Problem}

ability of the Negro to "take care of himself" if Congress would but throw about him "the protection of the ballot." The very essence of the meaning which lies beneath the surface of the failure of Negro suffrage is found in its failure to accomplish the one, the solitary, purpose which its modern defenders dare urge in its behalf. It has been demonstrated beyond the shadow of doubt that the ballot could not "protect" the Negro. It is queer, this belief in the subtle efficacy of paper laws, enacted in disregard of the sentiment and wishes of those upon whom they are to operate. There is something almost plaintive in Mr. Blaine's querulous complaint against the South for not accepting Negro suffrage with the quiet humility which should have characterised the conduct of people who theoretically occupied the position of suppliants for clemency from a victorious opponent. He says that no one could foresee such unreasonable and violent opposition to so simple an act of righteous justice.

But have we even now progressed very far beyond this state of inability to recognise the force of human nature? During the forty years since the initial grant of Negro suffrage, in the military Reconstruction Act of March 2, 1867, have we in truth learned so very much about even the most elementary considerations which underlie this aspect of our problem? The prediction prompted by the hard common sense of W. $\mathrm{H}$. Councill in $\mathrm{I} 88 \mathrm{I}$ has been fulfilled to its last letter. The Southern white people have "come into power," and have "taken from the Negro the ballot which he 


\section{The Negro in Politics}

continued to cast against them, right or wrong."* And finally the Republican party in the South has sought to "unload the Negro element." Only yesterday a message was delivered by Mr. Taft to his party associates in North Carolina, and through them to the South at large. Its burden was a plea for Republican policies in the Southern states, coupled with thinly veiled ridicule of the "Southern fear" of the Negro in politics. The echoes of his speech had hardly died before the convention to which he had spoken adopted a resolution which practically recognised and approved the Democratic constitutional provisions for restricting the Negro vote. After more than a generation Southern opposition to Negro suffrage had ceased to be a matter of party affiliation.

And such opposition is no longer confined to Southern people. We have but to follow the situations presented at recurring elections in those Northern cities and states in which the Negro is an important political factor, and catch the utterances of men of all shades of opinion, sometimes unguardedly, sometimes deliberately made, to realise the discontent which the Negro voter breeds. He who will do this for a few years and also secure the candid expressions of men in public and private life, must be an optimist indeed if he believes that outside of the South the American people have become satisfied with the Negro element in political life. How many states in the North would vote for Negro suffrage to-day, if it

* See page 279 


\section{The American Race Problem}

were still a Southern experiment and did not exist elșewhere?

It is said that any discussion of Negro suffrage at this late day, is purely academic - that the principle is permanently fixed in our political system. We are not at all concerned with the accuracy or inaccuracy of this proposition. We are not interested in Negro suffrage per se, but rather in its elements - in certain facts which accompany it and characterise it and differentiate it from the concrete act and expression of self-governing capacity among other men. We have so long talked about the Negro that we have fixed him in our minds as the individual object upon which centres an opposition which in fact is really directed to the attributes and traits for which he stands. It would be humanly impossible to perpetuate and disseminate opposition to Negro suffrage, for example, if Negro suffrage did not stand for something more definitely objectionable to the Caucasian mind than a more or less shadowed complexion.

In affirming the validity of the Mississippi constitution of r890, the Supreme Court of the United States adopted the language of the state court, and in effect declared that while the constitution did not discriminate against the Negro in specific terms, it swept the field of expedients in legislating against his racial characteristics. There is a great deal of nonsense indulged in, North and South, about these Southern constitutions. There is not one of them under which the Negro is not disfranchised automatically. The 


\section{The Negro in Politics}

most effective bar to Negro suffrage ever devised is the cumulative poll tax provision of Georgia. Yet Georgia's is not numbered among the offending constitutions. The tax payment requirements of these constitutions are directed against two race characteristics - lack of thrift and absence of foresight - and they operate with telling effect. Couple with these the requirement of registration, and we have practically all there is of the really active features of those instruments. The so-called "understanding clause," for example, in the constitution of Mississippi is a dead letter to all intents and purposes. It is doubtful if it has been resorted to, all told, one hundred times in sixteen years.

The political activity of the Negro masses, and we are speaking of the masses, was almost solely a matter of leadership. Without intensely active leaders, and then only by resort to the spur of most vicious appeals, the potential voting strength of the masses could never have been polled. The first effect of the adoption of any sort of suffrage qualification was upon the leaders themselves, both white and mulatto. They immediately recognised as an inevitable consequence of even the fairest application of any test, such a falling off in the ranks of their cohorts as to leave them practically nothing to lead. They were shorn of their power. Othello's occupation was gone. The scattered remnant of such as could qualify was not worth organising for purposes of active contests in which the end henceforth was known in advance. They deserted the now fruitless field of state politics, and resigned themselves to 


\section{The American Race Problem}

attending national conventions and subsisting upon crumbs from the Federal table. For this purpose only the semblance of party organisation was necessary, and this was maintained. It was this organisation which Mr. Roosevelt upset with his novel "referee" system. With these leaders there was no question of principle involved. To their practical minds there was no longer either reason or sense in attempting to keep up sufficient interest among the masses to induce such as could register to do so. The impetus of their urging thus removed, their remaining followers became as listless as the average "good citizen" or "business man" in the face of an approaching election over a contest for municipal reform.

All form of visible reward having disappeared, and the leader's whip no longer used, the Negro voter practically ceased to exist. He at least became numerically a negligible quantity in the political life of which for almost a generation he had played a serio-comic part. There was no chicanery and no fraud. There was never the least doubt of the effect of any sort of suffrage test upon the Negro masses. And it is only the masses who have been eliminated. I do not mean to say that there are no individual instances of discrimination. I do say that there are no more of these than may be found throughout the country. The South is neither better nor worse than any other section. I know of individuals who have steadily refused to register, for no other reason than that they wanted to nurse and display a sentimental personal grievance. These men 


\section{The Negro in Politics}

should follow the example of more candid members of the race. They should address their complaints to the inherent lethargy of their people, rather than to the acumen of the white man who has merely been wise enough to profit by a racial characteristic of the Negro masses.

No longer opposed at the polls the white man turned his attention to the primary, and became as apathetic at general elections as the few remaining qualified Negroes.* The smallness of the consequent vote needed an explanation away from home. It was speedily forthcoming, in the form of absurd theories of the substitution of modern fraud for Reconstruction force, of the operation of "understanding clauses" in lieu of the persuasion of more violent means. With the falling off of Southern votes there was revived the demand for the reduction of Southern representation. Through it all there runs the same fanciful notion that tens of thousands of qualified Negroes are illegally kept from the polls. How queer are the operations of our minds when we want to believe or disbelieve a given thing. All of us know that one of the greatest difficulties encountered by the American politician, whether ward boss or head of a national campaign, is to "get

* At the Democratic primary election in Mississippi in 1903, to nominate a candidate for governor, with two men in the field $99,28 \mathrm{I}$ votes were cast: at the regular election which followed, with no opposition candidate, but $32, \mathrm{xg} \mathrm{r}$ Democrats went to the polls. The total registered vote in Mississippi is about 133,000. Of these about 17,000 are negroes. At the last national election but 53.376 votes were cast for the Democratic electors, and but 3,189 for the Repub. lican. The Populists, an absolutely negligible quantity in Mississippi, by creating here and there a little interest in their ticket, polled nearly half as many votes as the Republicans. 


\section{$35^{8}$ The American Race Problem}

out the vote." We like to hug the delusion that the "sacred birthright" of the American citizen is a cherished possession which he likes to exercise on all proper occasions. But this too is a conceit of fancy. The real trouble is found in inducing the non-professional voter to go to the polls in anything approaching his proper strength. And with the imposition of even the requirement of registration there is an invariable falling off of votes. We know this, and accept it or deplore it, or strive to overcome it, as our dispositions and interests may determine. Only in the case of the Negro do we attempt to keep up the fiction of an immense number of men devoid of political apathy, eagerly anxious to vote, and only prevented by devious means.

The simple truth is that Negro suffrage was the most artificial creation ever known to our history. The only natural thing about it was its death. It could not be kept alive by normal means. Just as the Reconstruction governments fell to pieces like card houses as soon as the artificial prop of Federal power was removed by Hayes, so Negro suffrage could not survive the first legal test imposed upon it by its opponents. We may force the ballot upon whom we please in this free country, but further than this we cannot go. We cannot insure its intelligent use by persons not intelligent; we cannot insure its honest use by persons without a sense of political morality; we cannot insure its retention by those to whom we have given it, if they were not ready to receive it, or if the grant 


\section{The Negro in Politics}

was unwisely bestowed. Any state in the Union might give the ballot to children fifteen years of age, but no state could guarantee its proper use in childish hands.

And the Negro in the mass is still a child, and for some generations to come may so remain. One of the shrewdest men identified with the race, and one of the most outspoken, goes even further. He says, that the Negro is a "political baby." Those who habitually think of Negro suffrage as a peculiarly Southern affair, and declare that it is not a failure because not fairly tried, might learn something from this Afro-American editor and publicist, Mr. T. Thomas Fortune. He. asks, what standing has the "AfroAmerican vote" in the North and West? and thus answers his own question: "It has no standing: it is never consulted; it gets nothing but crumbs from party success. A few offices of the lowest grade are here and there given to it, for the most part such offices as white partisans do not want. I say this with knowledge that conditions are a shade better in Massachusetts, Ohio, and Illinois, where frequently an elective position in a black ward or district is conceded; but on the whole the same outrageous condition of affairs prevails in all of the states of the North and West. And the Afro-American who points out this condition and protests against it and condemns it as being idiotically stupid if not criminal, is distrusted by his own people and by the leaders of the Republican party, often being branded as 'a traitor and ingrate.' The Afro-American people are like a giant in bulk and a child in strength; 


\section{The American Race Problem}

or they have the strength of a giant and use it as a child. It amounts to the same thing. In the cities of Boston, New York, Philadelphia, Cleveland, Indianapolis, and Chicago the handful of Italians or other foreign contingent have more weight in the councils of the Republican party and get more substantial consideration in the matter of party favours than the Afro-Americans, without whose vote in most of those cities the party would very generally be in a minority. The Afro-Americans of the Northern and Western states should put some common sense into their voting. Surely their low, degraded political condition to-day should convince them that they are a political giant with the strength of a child, and that a race in that condition will get nothing out of politics but sneers and contempt. When a man is a man he should think and act as a man in politics and everything else; as a matter of fact the Afro-American people are the only race element of the American citizenship which habitually thinks and acts the baby in politics."*

From Professor Kelly Miller's relation of his observations on a trip among his Southern brethren we may secure valuable testimony as to conditions in another quarter. He says: "Only a few with whom politics is a business seem to take interest in the subject. This number is rapidly diminishing. There is little or no political interest among the rank and file of the race. Agitation of this question is almost like

* "The Afro-American Political Giant with the Strength of a Child," T Thomas Fortune, Coloured American Magazine, Dec. 1905, pp. 678,679. See also by the same author, "The Negro in Politics," New York, 1886. 


\section{The Negro in Politics}

driving spurs into a dead horse. In Texas, Arkansas, and Tennessee every voter is ostensibly as free to exercise his franchise as he is in New England. And yet very few meet the paltry requirement of a poll tax. In Alabama there are less than three thousand Negro qualified voters. Even under the severities of the revised constitutions and the unfairness of registration offices there ought to be at least ten times as many as are now on the list. Indifference more than any other cause accounts for this condition. 'What is the use?' is the universal response to the inquiry concerning this political inactivity. It seems to me that the coloured race in Texas, Florida, Georgia, and Kansas (Arkansas), where the state constitutions have not been revised, is losing by default the right of which they have been violently bereft in the more stringent Southern states. I suppose that I must have asked a hundred men in different sections if they were in the habit of voting, and was compelled to take no for an answer. Revised constitutions, white primaries and the lily whites form the conventional excuse. A Washington friend of mine who is a loud and persistent advocate of the ballot as the Negro's only salvation retains his legal residence in a Southern state whose constitution has not been revised; and yet he has not voted for fifteen years."*

If we may believe the evidence of these two eminent and competent members of the race, Negro suffrage is not only dead where it was a failure; it is a failure

* "A Circuit of the South," Kelly Miller, Voice of the Negro, Sept. I 906, p. 665. 


\section{The American Race Problem}

where it still survives. We might add the testimony of a prominent Northern newspaper man as to the attitude of the plantation Negro toward the question of suffrage. From the observation of a number of years we can confirm the following from Mr. Raymond Patterson of the Chicago Tribune: "I could not discover that the plantation Negroes with whom I talked had the slightest desire to vote, and even the most casual observation would convince one that if they had the right of suffrage they would sell it to the highest bidder without the slightest compunction, and the white people in the vicinity understand this so well that they are prepared, if the Federal Government or other public opinion once more forces suffrage upon the Negro, to buy it back again at the current market rates and charge it up to the ordinary labour account of the plantation."*

But it is a mistake to assume that the Negro in politics is really dead. In many places he is very much alive, and proves himself capable of creating all sorts of troublesome situations for his Caucasian allies. At a recent election in Chicago the Negroes demanded representation on the city ticket. They were permitted to name one of the judges, and to the discomfiture of the white party their candidate was elected. At least it seemed so on the face of the returns, though he ran some 30,000 votes behind the next lowest man on the ticket. Just as he was receiving the congratu-

\footnotetext{
* "Paradise for the Negro," Raymond Patterson, On Conditions in ILouisiana, Washington Post. July 19, 1903.
} 


\section{The Negro in Politics}

lations of "the race" throughout the country, the Chicago Republicans found a way out of their predicament, and a white man was seated in his stead. Probably it is such instances as these, in recent years too common to excite comment, that cause Mr. Fortune to feel as he does about the situation north of the line.

It is likewise a mistake to conclude that the Negro is no longer a potential power for evil in Southern politics. Just so long as human nature is what it is will white men be found whose one controlling motive in political affairs is the lowest form of selfish ambition. The lust of power and the spoils of office are still determining forces in shaping the conduct of many men in public life. To such as these the Negro vote offers an attractive field for exploitation, and is taken advantage of by politicians without regard to party. The average Negro is a cheaper voter than the white man. His vote may generally be counted on to go en masse. He is more easily "handled" and intimidated, and less apt to "cause trouble." He is usually without any sort of higher public opinion behind him, to act as an impelling force to proper civic conduct. $\mathrm{He}$ is generally a thorn in the flesh of those who seek to break up corrupt municipal machines. Just as he is thus used by white and mulatto politicians in Northern cities, so has he been used time and again in Southern states. His pliability makes him specially valuable in controlling a balance of power, and his greatest potential harm to the Southern white man and himself by no means depends upon a Negro majority. 


\section{The American Race Problem}

To respectable people in the South the most offensive use of the ballot ever made by the Negro, as likewise the most vicious use ever made of the Negro by unscrupulous white men, has been in deciding issues between white men themselves.* And to do this a majority is not necessary - only capable and unscrupulous leadership and a willing and irresponsible tool.

The South has often been congratulated upon the usually decent methods which obtain in her local politics. But this section has also produced its share of the most abject political depravity. The Southern white man, who is necessarily acquainted with the consequences of his conduct, but who in defiance of such results seeks to fatten upon the inherent political viciousness of the Negro masses, is much more vicious and dangerous than the Negroes whom he leads. He is usually cowardly as well. He generally manages to escape the legitimate penalty of his acts, while the Negro plays the part of the vicarious sufferer, as he has since 1867 wherever he has entered the political field.

It is difficult to read with patience some of the utterances of Southern men, who have not the excuse of ignorance, on the subject of the political supremacy of the white man. In entire disregard of the elementary facts and history of the operation of Negro suffrage in the South, they tell how this or that state is now

* There recently came from Kentucky the report that r, roo Negroes had been registered as Democrats in a close precinct, and their certificates bought at $\$ 2$ each. It 1 said that these voters were used in the following Senatorial race. Whether true or not in this instance, similar things have frequently been done. 


\section{The Negro in Politics}

rid of all danger from the Negro in political life. It is doubtful if there is a state in the South which would not be largely controlled by Negro voters if the white people in it were to divide among themselves. It has not been eight years since the country was horrified at the racial political outbreak in North Carolina. The preceding census ( 1890 ) showed but 56 I , or 8 Negroes in the state, as against $\mathrm{I}, 055,382$ whites. The Negroes were thus but 34.7 per cent. of the total population. Out of ninety-seven counties in the state there were only sixteen in which the Negro formed as much as 50 per cent. of the total population. Yet as a result of a division among the white people, and a combination of Populists, Republicans, and Negroes, the latter gained partial control of the state, and a period of corruption and riot ensued which became as intolerable as anything during Reconstruction days. The culmination was a bloody conflict along racial lines, with the usual inevitable result. The decent people of the state gained control, and another amended constitution was added to the honour roll of Southern efforts to insure white supremacy without resort to violence or fraud.*

I have sometimes alluded to the force of the motive of apprehension as a controlling factor in determining

* For an excellent account of the political conditions which brought on this conflict see Mr. Henry Litchfield West's "The Race War in North Carolina," Forum, Jan. 1899. pp. 578, et seq., quoted from below. For a presentation of the case by a prominent figure in the overthrow of Negro rule in Wilmington see Colonel Alfred M. Waddell's account in the publications of the Montgomery Conference on Race Problems in the South, r 900 . See also A. J. McKelway and Kelly Miller, Outlook, Dec. 3r, r898. These papers should be read by anyone seriously interested in the political aspect of the problem of race relations. 


\section{The American Race Problem}

the white man's attitude toward the Negro. He knows the possibility for evil of the Negro in politics; and if he is not an enthusiastic optimist he can see clearly enough that while the Negro masses have been politically eliminated in a temporary sense, their potential power for evil has by no means disappeared. The alluvial district of which the writer's county forms a part in I900 contained 218,392 Negroes and 40,502 white people. The number of Negro males twenty-one years of age was 57,3 I5, or I6,8 13 more than the total white population. Of these 28,643 were literates, and on payment of a poll tax could register and vote under the Mississippi constitution. Thus the number of potential Negro voters was equal to nearly 7 I per cent. of the combined white population, men, women, and children, in an area of about 6,000 square miles. There is no probability that the Negro will ever be a controlling factor in the politics of this section. But let a division arise among the white people, and there is no more doubt that these Negroes would be registered and voted, and would control by sheer force of numbers, than there is that they will never care one iota about voting if only let alone. There is also not the slightest doubt that within a very short time the Negro would again cease to be a political factor, and conditions would resume their normal course, with the added injection of a racial bitterness which just now does not exist. The people who comprise the intelligence and honesty of a community, who pay its taxes and support its government and guarantee 


\section{The Negro in Politics}

it against internal disorders, will control its politics and administer its affairs. And the question of mere numerical majority will not even be considered in arriving at the result.

It may be replied that this proposition holds good everywhere. In fact it is often said that inasmuch as the intelligence of any country or section will control its affairs, there is neither foundation nor reason for the Southern apprehension of the Negro in politics. The two propositions have a different meaning. We may safely say that the honesty and intelligence of New York may be depended upon to control its politics in the long run. This is true only because the "average" white voter is not venal, and because the best men, in point of character and ability, will not permit the rule of corruption beyond a certain point. In the tace of intolerable conditions party lines invariably disappear, and no corrupt combination of political thieves has ever been able to more than temporarily defeat a combination of political honesty.

But it is idle to attempt to apply the same rule to Southern conditions, and expect to obtain the same end by the same means in the face of the situation which exists by virtue of the political solidarity of the Negro. When the respectable white men of a Southern community, county, or state find themselves confronted by a numerical preponderance of Negroes, upon whom are they to call for assistance? They represent the intelligence of their state; they pay its taxes and support its institutions and government. They are opposed 


\section{The American Race Problem}

by a mass of Negroes who, with few exceptions, are inherently ignorant, though they may read and write, who own little property and pay little taxes, who are utterly unfit for political control, and who are led by unscrupulous white men equally as irresponsible and much more vicious than themselves.

Here are the two elements in the body politic of the South to-day, and yet men wonder why the South does not divide on political issues. The "Solid South" simply represents the permanent banding together of its best elements for good government, just as such combinations of the better elements in New York are made temporarily necessary from time to time. There has not been an instance of local or state division in the ranks of the respectable white people in the South which has not been followed by disastrous results. Booker Washington knows that the Negro will not take the advice of his white neighbour in matters of local political concern. Other Negro leaders know it, and Northern white men like the late William $\mathrm{H}$. Baldwin know it. The Southern white man knows it. $\mathrm{He}$ knows more, for bitter experience has taught him that, save with insignificant exceptions, the Negro will not only vote solidly against him on matters of purely local business concern, but that he will sell himself body and soul to any political charlatan who will stoop low enough to fill his ears with false promises and to inspire him with racial hate. It is almost a Southern axiom that a white man cannot remain respectable, cannot retain his own self-respect, and at the same 


\section{The Negro in Politics}

time control the Negro vote. This does not mean, and it must not be so understood, that no Southern Negroes will vote for decent men or go with the respectable element of white people on local political affairs. It emphatically does mean that the number who will do this are a negligible handful, who, furthermore, incur the enmity and displeasure of the masses by such exhibitions of "disloyalty." The greatest Bourbon in America to-day is the Negro in politics, North or South.

From 1867 to the overthrow of the carpetbag governments in $1875-76$, the Southern white man saw the Negro go en masse against him, right or wrong, as Councill puts it. In searching for means to save his interests and his state from utter destruction, the white man then tried the experiment of taking the Negro into political partnership with himself. This was the essence of the "fusion" system, under which the Negro was given a place on local tickets. It meant nothing more or less than the purchase of Negro support, or Negro acquiescence, by giving to individual mulattoes a local office here and there. The only effect was to keep the Negro masses in a continuous political turmoil, without the least resulting benefit to themselves. There was perpetual strife among their mulatto leaders as to which ones were to receive the offices which the white man conceded as the price of being permitted to control his domestic affairs. The last remnant of "fusionism" disappeared with the elimination of the Negro masses from politics by modern 


\section{The American Race Problem}

constitutional provisions. The qualified Negro voters were reduced to an innocuous minority, and the necessity for purchasing the leaders no longer existing, the latter ceased to figure in local affairs.

This has been the Southern white man's experience with the Negro in politics. He has never been able, save on rare occasions, to make any responsive appeal to the Negro voter which was not addressed directly to the cupidity of his leaders. Immediately after the war a few of the old school Southern leaders believed it possible for them to control and influence the Negro voter toward safe participation in administering decent government. But these were the very men who above all others were proscribed by those in control of Federal affairs. They, more than any other class in the South, were felt to be unsafe custodians of the Negro's interests. Despite all this these men made many earnest attempts to influence the Negro for good. But their efforts were defeated, or only in small measure were temporarily and occasionally successful. When men in another political environment speak of appealing to the instinctive sense of right and better judgment inherent in the body politic of the state, they are discussing an entirely different proposition from that which confronts the Southern white man. It is idle to talk of appealing to something which does not exist in the Negro masses. The capacity for self-government is a slow growth at best. Under the artificial and abnormal conditions which have obtained since the Negro's emancipation it promises in his case to be almost hopelessly so. 


\section{The Negro in Politics}

Only a few months ago Mr. Taft delivered an address at Tuskegee Institute, in which he touched on the Negro in politics. He gave the restrictive constitutions of Southern states a quasi endorsement, but added a note of encouragement to the effect that it was impossible to frame a suffrage test which would be allowed to stand by the supreme court which the Negro could not ultimately meet. It is the usual comment of those inclined to look with leniency upon the South's efforts to legally eliminate the Negro masses from politics, that all the North asks is that suffrage restrictions be impartially applied. In Mr. Baldwin's words: "He should be (disfranchised) if he is not properly qualified to cast a vote; but his qualifications should be determined in exactly the same manner as the qualifications of the white man; and to this the Negro has no objection."**

Here we have again the confusing of the concrete Negro with his abstract attributes. Human law does not, cannot, create the capacity for self-government, the possession of which we seek to evidence by certain tangible tests which we loosely call "qualifications." The law cannot qualify a man to vote. It may require an exhibit of certain crude evidences of qualification, or it may dispense with these altogether. This problem of framing a test for self-governing capacity is one of the most serious which confronts a government such as ours - one in which so much depends upon the selfgoverning individual. Its gravity increases or dimi-

\footnotetext{
* Second Capi n Springs Conference. r 1899, p. 98.
} 


\section{The American Race Problem}

nishes with the degree of homogeneity in the mass of the population. In the effort to secure a test which shall be uniform we usually fall back on some form of property or educational qualification. In view of the necessarily limited and narrow application of the educational qualification it is probable that the test of property is really the more valuable of the two. From the acquisition and possession of property, particularly land or a home, we are usually safe in assuming certain homely virtues, such as make for conservatism and good citizenship.

But we attach too much significance to our so-called educational qualifications. There is no American constitution which in fact requires a test of education. At most they only require the ability to read and write. This is a mere kindergarten examination, but it is almost impracticable to provide, define, or apply anything more exacting. Yet there is no magic, no subtle alchemy, arising from the ability to scrawl one's name, or drone the pages of a book, capable of transmuting barbarism into civilisation. Pen and ink and book, powerful as they are, cannot transform the savage of yesterday into the citizen of to-day.

The capacity for self-government is not a grant of law, but a growth of the mind. It comes with the slow processes of time, through the long groping after light and strength which in spite of a thousand difficulties and failures has given the higher branches of the white race dominion over themselves, which is the essence of a government of law and the foundation of the arti- 


\section{The Negro in Politics}

ficial self-governing superstructure. The so-called republican form of government in this country, and the limited constitutional monarchy of Great Britain represent the highest practical expression of the selfgoverning idea. They would be impossible of maintenance by an electorate whose sole qualifying capacity was determinable by certain established formal tests. A self-governing state is founded upon the slowly developed capacity of its people for the form which they themselves create, not upon any artificially determined capacity which it imparts to its creators. Because we do not think it wise to share this tediously developed responsibility undiscriminatingly, we gradually evolve certain tests which we apply to those who seek it. But we mistake the true import of such measures of capacity if we attribute to them a significance which they do not really possess. A child of ten may read more fluently than a man of fifty, or the latter may not read at all. But the child's capacity does not mean the possession of greater wisdom than may have been acquired by the longer and larger experience of the man.

In order to be of any real value such tests must presuppose the same general potential capacity and attributes among all to whom they are applied and whose degree of development they are assumed to indicate. Between the masses of the English-speaking white race and those of the American Negro, no artificial test can indicate the possession of the same measure of capacity for self-government, It is idle to talk about "deter- 


\section{The American Race Problem}

mining in exactly the same manner the qualifications" of two masses possessing such different racial histories and backgrounds, as well as such widely different developments, as those which characterise the white man and the Negro.

It is a common charge against modern Southern constitutions that they are so framed as to admit the illiterate white man while excluding the illiterate Negro. The Negro masses in fact do not have to be excluded. They will disfranchise themselves, if left to their own devices. But what if the charge were true? There was no developed system of public schools in the South before the war, and these states contained, and do contain, a large number of illiterate white men. It would be foolish to contend that all these are capable of intelligent voting. It would be more absurd to class them as "ignorant" because illiterate. It would be stupid to attempt to institute a parallel between their average of intelligence and capacity and that of the Negro masses in the same technical classification. The very fact that these men are white, aside from their common race inheritance, tells strongly in favour of potential intelligence. It guarantees association and contact with others of the same race who have enjoyed greater advantages, and from whom the less fortunate absorb much that is even denied the socalled educated Negro in the mass. We simply attempt the unattainable when we try to devise a test which will apply equally to the two races, as a mechanical index to equal political instinct and capacity. 


\section{The Negro in Politics}

We talk loosely of the failure of Negro suffrage under popular government, but how many stop to reason from the fact to its cause? We are too content, in all this race problem business of ours, to discuss and dispute over its elementary facts. We do not seem so much inclined to work out the significance of the facts themselves. We might learn much from a study of African tribal polity. It is a mistake to assume that the native Negro had no laws, and knew no governmental form. Both are part of his racial heritage. But despite surface exceptions, African native polity was at the farthest possible remove from the basis of a self-governing concept. The only real force and stability which such governments possessed was derived from the opportunity afforded for the occasional accession to power of a man of exceptional individual capacity. The whole race history is opposed to the development of the self-governing idea. The race instinctively accommodates itself to a "strong" government, and seems peculiarly fitted for accepting and adapting itself to one in which an individual personal representative stands for the governing authority.

Even the limited effort at equal suffrage under a representative form of government which Jamaica once tried, proved a disastrous failure. The Jamaica Negro was never better off, and he was never better satisfied, than under the benevolent despotism of Sir John Peter Grant, which followed the first experiment. I once asked an educated, observant American Negro in Bermuda what he regarded as the most important 


\section{The American Race Problem}

influence for good upon the life of the English Negro, and upon race relations in the English islands. Without a moment's hesitation he replied, "The Crown." The visible, tangible representative of power makes a distinct and responsive appeal to the Negro mind, while the conception of his government as one lodged in an individual personality is easily grasped, and is invaluable as a controlling force.

Speaking of West Indian Negroes Mr. Colquhoun says: "In the long reign of the late Queen Victoria she became to them a sort of supernatural ruler, as much part of their traditions as the hereditary heroes and chiefs of other nations."* There was much that gave rise to a similar mental attitude in the form of government and administration of the Southern antebellum plantation system, and in it much that appealed to the Negro's racial instincts and traits. The owner was the immediate embodiment of authority in the plantation world. He stood in loco parentis to all his people, and became to their minds as much a tribal chief and ruler as they and their ancestors had ever known at home. There was no violent alteration of the abstract governing idea or system involved in the transition from the tribal to the plantation organisation. The native mind accepted the change unconsciously and hence without protest, and the Negro was adopted without friction into his new environment. On some plantations in both the South and the West Indies the germs of self-governing capacity had an opportunity

* "The Africander Land," A. R. Colquhoun. I906, p. I04. 


\section{The Negro in Politics}

to develop in the Negro, through the occasional institution of plantation courts for adjusting grievances among themselves. But these were only successful when the planter or his representative acted as a party in power. The order and general wellbeing among plantation Negroes to-day is in fairly exact ratio to the degree of personal authority and disciplinary control exercised by the plantation management. And relations are best where the system is most paternal in its features. For a number of years before the Civil War Negroes in Connecticut elected their "governor," who, though of course utterly without official recognition, at the same time furnished a visible object of authority to his people. The best governed body of Negroes in this hemisphere are the African, or black, "Caribs" of some parts of the Caribbean coast, and their titular, visible, and active head is a "king."

A racial characteristic which is so familiarly displayed in the South as to have become commonplace, is the Negro's inordinate love of parade and show, his consuming passion for "finery and feathers." A competent authority declares that "at heart the Haitians are royalists to-day; that is, they prefer the pomp and ceremonials of courts to the plain simplicity of a republic. They like show and glitter, frills and furbelows, gold lace and epaulets, cocked hats and cock's feathers, and it was a sad day for the masses when the grand marshal, grand almoner, master of ceremonials, Knights of Saint Henry, 'princes of the blood,' dukes, counts, barons, chevaliers, etc., were abolished. But for their 


\section{$37^{8}$ The American Race Problem}

inclination to reduce everybody and everything to the dead level of barbarism, they would take to a reëstablishment of royalty as easily as a duck to water."*

There is much more than an Englishman's preconceptions in the following words from Mr. Colquhoun: "It must never be forgotten that the subject races, whether in Africa or Asia, have the most deeply rooted prejudice in favour of paternal rule, and have never evolved a representative, much less a democratic, theory of government. Just so far as democracy attains its highest ideal in our eyes it becomes to them formless and ineffective." $\dagger$

The most uncompromising advocate of "Negro rights," and the harshest critic of the South, who has held a West Indian post in recent years is Mr. Sydney Olivier, whom we quote below. But even he admits the difficulties of the racial political problem as presented and developed under our form of government by written constitution. He says that such difficulties cannot be met under such a government as they have been under a Crown Colony, as in Jamaica.

When English writers wish a text upon which to frame a sermon on race relations under the beneficent rule of their Government, they generally take Jamaica. In other words, they select the colony in which the incapacity of the Negro for self-government has been frankly recognised and practically acted upon. But they say little about the period of turbulence and un-

* "Our West Indian Neighbours." F. A. Ober. 1904, p. I7r.

$\dagger$ "'The Africander Land," r906 p. 4 I9. 


\section{The Negro in Politics}

rest through which Jamaica passed before the present boasted state of idealism was attained. A local authority says of the present system of government that it "is undoubtedly hybrid in character." "But," he adds, "if all the circumstances of the case are taken into account, it possibly suits the condition of the colony as well as any other that could be devised."*

This government, however, is not one whit more "hybrid" in character than is that of the District of Columbia. And "the circumstances of the case," out of which the condition of hybridity was evolved, were in each instance the same - the presence of a large number of Negro voters, actual or potential. In each case the entire population was deprived of the right of self-government, rather than continue to face the certainty of trouble arising from its attempted exercise by a part of the population not fitted to enjoy it. The truth of the matter is that the administering of a government for a mixed white and Negro population is a much simpler matter for Great Britain than for Continental United States. It is only in our insular dependencies that we are on a footing with the rest of the world in governing for dependent races. There, thanks to an opinion which Mr. Dooley declared "followed the election returns," we are as free to experiment as England is in the West Indies, or as we ourselves are in our own national capital. And there is no reason why we should not be equally as successful. It is

\footnotetext{
* Frank Cundall, Secretary, Jamaica Institute, in British Empire Series Vol. 3, "British America," pp. 420, $42 \mathrm{x}$.
} 


\section{The American Race Problem}

only at home, where the necessity is greatest, that we are encased within the steel framework of rigid constitutional limitations. It is only here that we are forbidden to act upon the evidence of history or to profit by experience and common sense. Only here do we have to observe the form of maintaining the fiction that there are no differences between the needs and capacities and limitations of different races of men. The situation would be farcical if it did not occasionally border upon the tragic in its results.

It is frequently declared that nothing better than the present arrangement in this country has been suggested by its critics - that the system adopted in $1867-70$ was the best that could have been devised. This is superficial. This much only need be suggested in reply: Even a purely negative policy would have been better than the one adopted. Under the former, with the political status of the Negro left with the States, each would have been free to evolve an adjustment which would have been satisfactory to both races. Beyond question this would not have been the same in all the states. The perniciousness of the present system is that it is ironclad. It leaves no room for local and individual adjustment. Under the political status quo ante bellum each state would have been at liberty to experiment along its own lines, and, above all, every state would have had the advantage of the practical operation of the efforts of every other. And these several efforts of necessity would have been in the direction of devising means of admitting to the privi- 


\section{The Negro in Politics}

leges of the body politic such members of the other race as might be qualified by education, property and character.

Since the suffrage would not have been possessed by any at the outset, this is the only course which any change at all could have taken. On the other hand, all were admitted to the suffrage at once, with the result that the ingenuity of each state has been taxed in the opposite direction - that of eliminating the incompetent mass. Instead of each state having the benefit of the wisdom and experience of every other toward reaching a satisfactory adjustment of their common difficulties, each has looked to the other for suggestion as to the mere getting rid of a common incubus. And a dozen plans might have been evolved for guaranteeing both supremacy to the white man and justice and fair play to the Negro. The Jamaican and District of Columbia systems do not exhaust the wisdom of the world in devising schemes for the equitable government of mixed populations. New Zealand has a better system than either - and one which operates without friction and without complaint. There the native Maori is allowed a fixed number of representatives in Parliament. There are simply two constituencies, a white and a native, neither allowed a voice in selecting the representatives of the other. White control is guaranteed by making the number of native representatives fixed and permanent, while white representation is based on population. At the same time the Maori is guaranteed a permanent voice in Parliament, with always an opportunity to 


\section{$3^{82}$ The American Race Problem}

make known his grievances, or otherwise make himself heard. In some instances white constituencies have returned Maori, or half caste, members. Numberless modifications of the scheme are possible.

Of course it will at once be answered by the doctrinaire that this would not be in accordance with the "genius of our institutions," and so forth. The practical man might ask in reply, how many partly Negro constituencies North or South, are just now represented by Negroes in Congress or state legislatures? And the New Zealand solution, engrafted on our political system, would not be one particle more hybrid or anomalous than is the plan of government which we have evolved for either Porto Rico, the District of Columbia or the Philippines. While we are wrestling with our race troubles in this country, and wondering why men will stubbornly refuse to be guided by the golden rule in everyday affairs, England will have adopted the New Zealand system in South Africa long enough to have forgotten that there ever was a political Negro problem there. But let us return to the matter before us.

There is a marvellous degree of similarity running through the history of Negro suffrage wherever it has been tried in connection with a joint self-governing system. The attitude of the white party to the system has been the same the world over. The only exceptions are those communities in which the Negro has been so hopelessly outnumbered as to be politically a negligible quantity. Elsewhere the white man either regards the Negro as a political commodity too valuable to be 


\section{The Negro in Politics}

dispensed with, or considers him an element of evil too dangerous to be tolerated. Everywhere there are men who hold the former attitude. The South was cursed with their nefarious activity during its Reconstruction period. Only because it is no longer possible to keep the Negro masses in politics have these men ceased to use them. Party lines have nothing to do with it. The Negro vote is bought and sold in the open markets of Delaware, Chicago, Indianapolis, New York, Louisville, and St. Louis, by both political parties. Even men who honestly deplore such conditions, and who on account of them would gladly eliminate the Negro from politics, justify themselves for "fighting the devil with fire." They say that as long as the Negro vote is for sale they are compelled in selfdefense to purchase their share in its control. It is easy to say that the fault lies more with the white man who purchases than with the Negro who sells. This does not touch the root of the evil. In the game of party politics each side uses whatever advantage it can command. The highest hope of a self-governing state is in admitting to a share in its control only those who individually hold their privilege as something too high to be trafficked in. The individual who is for sale is not a fit or safe depositary of political power. At best we must always reckon on a number of these in the white body politic - but when we have a racial mass of such individuals we are afflicted with at least the germ of a potentially dangerous disease. 


\section{$3^{8} 4$ The American Race Problem}

It is probably natural that the course and motives of the Southern men who initiated the movement for the destruction of this germ in the political life of the South, through the legal disfranchisement of the Negro masses, should have been misunderstood. Misunderstandings were for many years the normal relation between the Northern and Southern states. It is unfortunate, however, that the fiction should have been perpetuated. The South did not disfranchise this ignorant and helpless horde in order to get control of political affairs. There was not a state in the South which was not as absolutely and unconditionally in the power of its white people in I880 as it has been since 1890 . The states of Georgia, Arkansas, Florida, Tennessee, and Texas have no such constitutions as are foolishly and ignorantly denounced in Mississippi, Louisiana, and South Carolina. Yet they are no less firmly within white control. The repeal of every amended constitution in the South would not change the complexion of a single Southern delegation in Congress, just as their adoption did not shift political control in a single state.

The motives which actuated those who inaugurated and executed the movement for an amended constitution in Mississippi, which took the first step in 1890 , were higher than any mere question of party gain. They were men who realised from bitter experience the vital necessity for white control, but who deplored with equal intensity the methods necessary to secure and perpetuate it. Not since the foundation of this 


\section{The Negro in Politics}

Government was laid has there been any movement in America which had its roots more deeply planted in the highest conceptions of political morality. They were sick at heart over the course of events which had followed as the inevitable sequence of as cruel a situation as ever confronted men with whom a high sense of political honesty was a traditional habit of life and a controlling principle of conduct.

When a Northern reporter went down to study the conditions out of which grew the upheaval in North Carolina in 1898 , here is what he found at a political meeting in Wilmington: "I had an opportunity to observe that they were earnest, dignified, sober men, heads of families, and owners of property, engaged in the best mercantile and professional pursuits. All shades of political belief were represented. Some of the citizens had voted for Mr. McKinley, and others for Mr. Bryan; some were Gold and some Silver Democrats; some favoured protection, and others advocated free trade; but in the presence of what they believed to be an overwhelming crisis, they brushed aside the great principles that divide parties and individuals, and stood together as one man. Their language indicated the intensity of the situation, as they viewed it."*

$\mathrm{He}$ again observes: "Ordinarily, social revolutions in the United States are accomplished through a medium of a change in political parties. In Wilmington pol-

* "The Race War in North Carolina," Henry Litchfield West, Forum, Jan. 1899, p. 579 . 


\section{The American Race Problem}

itics played a most subordinate part. The first definite movement toward the overthrow of Negro rule was taken by the Chamber of Commerce, a non-partisan organisation, which adopted resolutions declaring that the situation was a menace to peace and order, and calling upon 'every good citizen to exert his utmost influence and personal effort to effect results which will restore order, protect property, and give security to our lives and homes.' The President of the Chamber of Commerce-a New Englander and a Republican promptly signed this declaration; and every firm connected with the organisation attached its signature with equal alacrity. With this substantial inauguration the movement for white supremacy progressed rapidly. Party divisions disappeared; and the colour line was the plain, recognised, and openly acknowledged issue. Even the Republican postmaster of Wilmington, a Northern man who had never voted the Democratic ticket in his life, recognised this fact. 'I had thought at first,' he wrote to United States Senator Pritchard, 'that it was the usual political cry and a fight for office; but I am now convinced that the feeling is much deeper than this, as it pervades the whole community, and there seems to be a settled determination on the part of the property owners, business men, and taxpayers to administer the city and county government.' . . . There was still, however, no disguising of the white men's intentions. They believed that if they paid, as they did, 97 per cent. of the taxes, and if they alone had demonstrated their capacity for developing and 


\section{The Negro in Politics}

governing the city, they alone should rule; and this point they were prepared to establish at any cost."*

If one will read Mr. West's account of this "Race War in North Carolina" he will understand, perhaps, why the respectable white people of the state determined to remove by constitutional means, as far as was in their power, the possibility of its recurrence. He should also be able to grasp the more elementary facts and impulses which underlie the actions of Southern white men who have been confronted by the Negro in politics. He might even realise how childish to thoughtful Southern people seem the charges which would indict them for having been actuated by base and selfish political motives in seeking to eradicate the disease which was eating at the very vitals of their domestic life.

It is a far cry from the Southern states to the South of Africa and the Englishman is not an American, nor the Kaffir the son of a Congo slave. But the white man remains a white man, and the Negro is a Negro still, and politics is politics. A well-known English observer thus discusses the situation in Cape Colony: "Already the coloured man is a formidable force in the game of party politics in one, and the oldest, South African colony. The most deplorable feature of the Cape elections which have just ended was the power exercised by the native vote. . . The gravity of the situation is unfortunately not appreciated in

\footnotetext{
* "The Race War in North Carolina," Henry Litchfield West, Forum, Jan. x 899, pp. 582,583 ,
} 


\section{The American Race Problem}

England, or, at all events, appreciated by only a very few. Perhaps this is not surprising when one remembers that many South Africans, blinded by the political expediency of the moment, fail completely to discern the peril which is close upon them. Future calamity, however stupendous, is to them as nothing compared with present political gain, however mean. . . What if the native does form an extravagant estimate of his own importance, and cultivate an unbounded contempt for the white man? A seat has been won for the party."*

There, just as here, we have the spectacle of the political manipulation of the Negro voter, followed by his casting off till another election comes round. And anyone who has seen the Negro take part in a close local contest between white candidates can appreciate the force of the above suggestion of effect upon the South African native mind. And in Cape Colony the "Ethiopian Church" is as deep in politics as the Negro churches were when the Negro was a factor in Southern affairs. And also at the Cape there are Negro political associations and newspapers, supported by, and, as Mr. Jones remarks, "the henchmen of one or other white political party." The parallel is almost complete.

The report of the non-partisan Inter-Colonial Commission, made in 1905 , while permeated with a spirit of liberal justice to the natives, recognises the gravity

\footnotetext{
* "The Black Peril in South Africa," Roderick Jones, Nineteenth Century and After, May, r904, p. 7 r 3.
} 


\section{The Negro in Politics}

of the situation created by their growing political importance. To quote Mr. Jones's comment on the report, a year after his former discussion: "They dismiss the proposition that 'full and equal political rights should be granted to all classes of men fulfilling the necessary franchise qualifications,' and observe that 'in the present state of parties the native vote has acquired an excessive importance.' The commission also says "that in the near future native voters in at least some of the constituencies will outnumber the Europeans. Under such circumstances the voting of the future may proceed upon race lines, and no one acquainted with the conditions of life in South Africa will hesitate to say that a conflict would then arise fatal to the good relations which have upon the whole hitherto existed between white and black in this country."*

Here is a frank suggestion of the effect of a political conflict upon race relations which American history confirms in all its possibilities. There is also a bare hint at a recognition of an almost inviolable law which governs the white attitude toward the Negro in politics. Where the Negro is in a hopeless minority his vote is sought by white factions - and is either purchased or secured by petty places, such, as Mr. Fortune suggests, as the white politician does not want. As long as he is numerically too weak, or the white vote is not equally enough divided, to enable him to con-

\footnotetext{
* Quoted in "The Black Problem in South Africa," Roderick Jones, Nineseenth Century and After, May, 1905, pp. 762, 763.
} 


\section{0 The American Race Problem}

stitute a real balance of power, he is tolerated or encouraged, or both, by white politicians. As such plaything of the white partisan he is almost as dangerous an element, certainly as vicious and demoralising an influence, as when he possesses greater numerical strength. But your white politician of the average type cares nothing for this. $\mathrm{He}$ is blind to everything save personal advantage in America as in South Africa. When, however, the Negro's numerical increase is sufficient to create a direct or indirect menace to the unquestioned political supremacy of the white man, party lines disappear, and the colour line becomes the controlling consideration with the rank and file.

The difference between the two situations suggested here is illustrated by the difference between present conditions in Cape Colony, with a limited number of Negro voters, and the conditions which the commission foresees when the native vote shall be sufficiently strong to create a political colour line. It is likewise illustrated in the difference between conditions in Ohio, New York, Indiana, Illinois, or Pennsylvania, and conditions in any one of the Southern states. If the movement of Negroes toward the North assumes sufficiently large proportions, the next two or three decades or so will likely create some interesting political history in this country, with the Negro a central figure. Meanwhile we may look toward Africa. The Boer leaders may have known nothing about the Negro in American politics, but conditions nearer home were sufficient to make them hold out for a stipulation in 


\section{The Negro in Politics}

the Vereeniging Peace Covenant which bound England to refrain from broaching the question of native suffrage until full autonomy should have been granted their colonies. The dream of more than one South African statesman has been and is of a confederacy somewhat after the Australasian type. But Natal thus far stands as immovable as the Mediterranean rock, in opposition to a union which would be born with the insidious affliction of Negro suffrage - the heart-disease of selfgoverning colonies and states.

The difference between the shadow and the substance of self-governing capacity and right have not anywhere been more clearly pointed out than in this passage from the pen of an eminent New England Senator, the late Orville H. Platt, of Connecticut: "To insure the success of free government certain conditions seem indispensable. There must be a homogeneous people possessed of a high degree of virtue and intelligence. A sentimental longing for liberty will not itself insure the maintenance of a republic. Liberty is a word of quite elastic meaning. Licence is not true liberty. It is orderly liberty only which constitutes the sure basis of free government. That government only is really free and independent where liberty is restrained and buttressed by law, and where the supposed rights of the individual are limited by the rights of all. To establish such liberty there must be an intelligent understanding of the social system and a comprehension of the just principles upon which true government must always rest. The consent of 


\section{2 \\ The American Race Problem}

the governed must be an intelligent consent. Where the capacity to consent does not exist, no government can be permanently maintained upon such consent. Where a majority of voters neither understand nor respect the true principles of government, there may be a republic in name, but in fact it will only be a dictatorship, in which the purpose and power of its president control, rather than the consent of the governed."*

We may set over against this utterance that of another eminent American. At the twenty-fifth anniversary celebration at Tuskegee in 1906 , Booker T. Washington expressed himself on an aspect of the problem of his people of which he seldom speaks. A few months later he repeated his remarks at the celebration of the fiftieth anniversary of Wilberforce University. $\mathrm{He}$ said on the latter occasion: "Let me repeat in substance what I recently said in the heart of the South, that in connection with our religious, educational, and material growth we should not loose sight of the fact that if this country is to continue to be a republic its task will never be completed as long as seven or eight millions of its people are in a large degree regarded as aliens, and are without voice or interest in the welfare of the Government. Such a course will not merely inflict great injustice upon these millions of people, but the nation will pay the price of finding the genius and form of its government changed, not perhaps in

\footnotetext{
* "America's Race Problems," Annals of the American Academy of Political and Social Science, Vol. 18, No. r, July, .901, p. 148.
} 


\section{The Negro in Politics}

name, but certainly in reality, and because of this the world will say that free government is a failure."*

Below the surface of the words of these two men there lies the fundamental difference of the point of view of respective racial self-interest. To the mind of Dr. Washington this government will be "a republic only in name" if a certain large mass of its population does not share equally in its control. To the mind of Senator Platt successful free government must be based upon a homogeneous population, possessed of a "high degree of virtue and intelligence," while without an understanding of "the true principles of government" we have "a republic only in name." Mr. Washington sees some millions of Negro citizens "governed without their consent," if we may so interpret his words. Mr. Platt is looking only at those qualities the possession of which must be a condition precedent to even "the capacity to consent," if the government is to endure. And to Senator Platt's utterances is added an additional significance. He was addressing himself immediately to the question of the possibility of maintaining a self-governing republic, in fact as well as in form, in a country wherein about one-third of the people were of the race for which Mr. Washington is the usually accredited American spokesman. The author of the "Platt Amendment" was discussing the future of Cuba.

We have been taught in this republic, taught from national infancy, to encougage similar forms of government always and everywhere. And it is apparently

* Coloured American Magazine, Aug. 1906, pp. 76, 77. 
 \\ The American Race Problem}

hard for us to accept the seemingly bitter truth that for some people other systems are better, and that some people are not adapted to ours. Forty years ago we began the experiment of forcing another race into our political mould, apparently confident that a constitutional straight-jacket could create a selfgoverning man. We have been loath to admit our failure, and we are reluctant to recognise the results of even practical experience which elsewhere adds weight to the evidence which we are so unwilling to believe. Cuba is but another addition to the list of failures recorded against the self-governing efforts of the Negro - in the United States, in Haiti, in Jamaica, in Liberia, in South Africa. Yet, as long as there is any possible or impossible alternative hypothesis upon which to account for the poor fiasco which has so recently made necessary our second occupation of the island, we accept it and nurse it and in it try to find a prop to our failing faith.

In 1898 , and in the city of Boston, while the country was ready to go into hysteria over "Cuba Libre," the latest born of American republics, a cold-blooded, nonsentimental student ventured a forecast which is worth recalling. After a severe characterisation of the Negroes of the island he said: "Such are the liberators of Cuba. The Cuba Libre of the blacks would be a veritable hell upon earth, a blot upon Christian civilisation. . . Knowing the island as I do, I fear that an independent Cuba will be an impossibility. As an American colony she will blossom and bring forth her increase. Then, 


\section{The Negro in Politics}

and then only, will the black plague of central and eastern Cuba cease to be a nightmare. It is a question of time. Cuba will be the brightest spot in the colonial possessions of the United States."*

"We are in danger of becoming another Haiti if left to ourselves," said a prominent Cuban tobacco grower to William Inglis, after the recent revolution. He added: "You have noticed among the soldiers in the rebel army many Negroes with their front teeth filed down to sharp points like saw teeth. This is a form of personal decoration in vogue among the black dandies of the Congo. There are in this island many thousands of Negroes not one step higher in civilisation than those you find in the African jungles. These fellows take the field with any leader to whom they are attached. They do not ask why they are taking up arms, so long as they are following their chiefs, living on the fat of the land and hoping for a life of ease in office when the so-called "war' is ended." $\dagger$ And upon his own observation $\mathrm{Mr}$. Inglis concurred.

The man most familiar with the West Indies and the West Indian Negro, himself a native of Massachusetts, records this conviction: "There are those who declare that English rule in the West Indies is retardative, even retrogressive, as exemplified in the Bahamas; but when we reflect what a bulwark England has provided against the ever-threatening flood of

* "Cuba: Past, Present and Future," Dr. Wolfred Nelson, F. R. G. S. "Proceedings of the American Association for the Advancement of Science," Boston, 1898, pp. 552, 553.

† "The Future of Cuba," North American Review, Nov, 16, 1906, p. 1039. 


\section{The American Race Problem}

black barbarians, we cannot but admit that she is entitled to the gratitude of civilised humanity in general. But for British officialism in the West Indies, with its prestige of might behind it and visible cordons of soldiers around it, there are many islands which would soon resemble Haiti in other and blacker features than complexion merely."*

And what of Haiti, as we pass along? The same authority says: "What an outspoken editor of a local paper, the Gazette du Peuple, wrote more than twenty years ago applies to the condition of affairs in Haiti to-day: 'For sixty-eight years, or from the date of our national existence, what have we done? Nothing, or almost nothing. All our constitutions are defective, all our laws are incomplete, our customs badly administered, our navy is detestable, our police ill-organised, our army in a pitiable state, our finances rotten to the base, the legislative power is not understood and never will be, the primary elections are neglected, and our people do not feel their importance. Nearly all our public edifices are in ruins; the public instruction is almost entirely abandoned." " $\dagger$

Recalling Mr. Roosevelt's appeal for a ratification of the treaty with Santo Domingo, in order to "save" that country from anarchy, we may ask ourselves, what is to be our future part in the affairs of these Dominican, Cuban, and Haitian cousins of our own "brothers in black"? Will we recognise the truth, as

* "Our West Indian Neighbours," Frederick A. Ober. 1904, p. 7.

† "Idem" p. 163. 


\section{The Negro in Politics}

England long since recognised it? Or will we sacrifice good government, good order, and good sense to the fetich of racial equality? But that is another story.

A few years ago this writer suggested that it would be wise for us frankly to take account of the ignored mulatto factor in the American race problem. The conviction has deepened that unless we do, there is no shore to the sea upon which we shall drift in our aimless and fruitless discussion of a, question as broad as the English-speaking world. If we have reached the conviction that there are in fact no fundamental differences of race; if we believe that there are no diffèrentiating racial traits and tendencies in the life history and heritage of the Caucasian, the Mongolian, and the Negro - then of course we need not concern ourselves about the byproducts resulting from a blending of either of these with another. But if we believe that each of these races, no matter how much like the others along certain broad lines, possesses its own distinguishing characteristics, then in any consideration of the problems which arise from the contact of race with race we are unwise to ignore the connecting link between the two.

It is very convenient for the Southern white man to include everybody with a trace of Negro blood under the general race designation. Nothing is more human than that the Northern white man who happens to be interested in the Negro should insist upon the privilege of claiming for his protége credit for any and everything accomplished in the work of the world by men whom 


\section{The American Race Problem}

the South calls Negroes, no matter how straight the hair or how fair the skin. Possibly it is natural that the man of mixed blood who finds himself identified with the Negro by the dominant element of both sections of the country, should accept the classification bitterly, sullenly or cheerfully, according to temperament - should accept it and make the best of it, for either himself or the race to which he is assigned. Certainly it is natural that the Negro masses, ever ready to identify themselves, or be identified, with people mentally or physically of a higher type, should with few exceptions welcome the mulatto as an equal, follow his leadership, and even resent the drawing of a line between themselves and him. All this may be natural, but the combined influence of Northern and Southern white men, and of Negro and mulatto, can no more perpetuate it than they could make perpetual any other absurd and unscientific fiction.

The mulatto is not a Negro, and neither written nor social law can make him one. By consent of all parties, including himself, he may be called a Negro. But we can no more make a Negro by such a process than we can alter the life traits and nationality of a Russian peasant by bestowing upon him an English name. The essential fallacy which underlies this classification will sooner or later make the latter impossible to maintain. The South has certain more or less definite convictions on the question of Negro inferiority. If all mulattoes are Negroes there is scarcely one such conviction which may not be rendered 


\section{The Negro in Politics}

wholly absurd by the achievements in science and art and letters of persons of mixed blood. The North has idealised the gentleness, docility, good nature, nonresentment, affection, amiability, and so forth, of the Negro character. The danger to this theory which lies in the failure to differentiate the two types may be read in the words of the best student we have of the Jamaica "black," Mr. William Pringle Livingstone. Strongly sympathising with the subject of his study, he says: "The loose nomenclature which prevails has frequently injured the reputation of the Negro; he has been made responsible for faults of which he is not guilty, and for movements and deeds in which he has taken no part."* He deprecates this "habit of the outside world," and approves the "right distinction, made and adhered to by all concerned" in Jamaica.

There is no purpose here to do more than suggest a line of thought on a subject which demands, and some time must receive, the attention of students of the race problem. Mr. Livingstone's observation brings us to the point we had in view in touching the subject at all in this connection. We have been discussing the Negro as a political factor in self-governing communities. This writer frankly admits his conclusion to be that without regard to the question of potential self-governing capacity, the Negro as the world knows him to-day, is politically a failure. If we wish to couch it in other terms, we might say that as a race, excluding

* "Black Jamaica, A Study in Evolution," London, r899, pp. 6, 7. The allusion is evidently to the so-called "Gordon riots" of 1865 , led by a mulatto of that name. 


\section{The American Race Problem}

individual exceptions, he has not yet developed, in his process of evolution, the instinct, or idea, or capacity necessary to successful participation on equal terms with the higher branches of the white race in a selfgoverning system. It is idle to deal in superlatives, and characterise racial traits and limitations as "perpetual," "unchangeable," and so forth. "Perpetual" means a longer stretch of time than this writer cares to deal with. I do not even pretend to say what the Negro may or may not finally develop in the field of self-governing capacity. I am concerned here only with the practical facts of the immediate past and present. This much, however, I am willing to venture: If ever the Negro masses shall develop the necessary ability, the capacity of intelligent consent, they will enjoy their share in the government of the country of which they may form a part; but as long as they are content to remain, or do remain, "the driven cattle of the political arena," to borrow a phrase from Mr. Roosevelt's Harvard address, they will not be permitted to share "equally" in the government of Englishspeaking white men - where their numbers are suffcient to menace white control. And I am not concerned to limit the proposition to any section or any country.*

This view of Negro political capacity seems to be shared by the pronounced "pro-Negro" English pub-

\footnotetext{
* It must be constantly borne in mind that this entire discussion deals with the Negro masses, the childish millions of the race. There are many individuals, of apparently unmixed blood, who constitute a safe, intelligent, honest, respectable property-holding minority.
} 


\section{The Negro in Politics}

licist and administrator, Mr. Sydney Olivier. The article from which we quote was commended in the highest terms by various "race papers" in this country, but no mention was made of the real heart of his discussion. Mr. Olivier says, frankly enough: "The recently emancipated slave is not qualified for political self-government under electoral institutions. I go further and say that the Jamaican Negro of to-day, after two generations of emancipation, is not qualified for self-government." To this he adds: "It is quite possible to justify a political generalisation - not as a truth, but as a working formula - that it is advisable to restrict the franchise where the majority of the population are Negro peasants. But it is not possible, either as a working political formula, or as an anthropological theorem, to justify a generalisation that there is any political or human function for which coloured persons are disqualified because of their African blood."*

Here we have a recognition of another political factor, one neither white nor black. It comes to view in drawing the line between "black" and "coloured," as known to Jamaica - between "Negro" and "mulatto" as known to the United States.

There can no longer be a question as to the superior intelligence of the mulatto over the Negro - of his higher average potential capacity. It is not clear, however, that if clothed with authority, without the steadying influence of general white control, he would

\footnotetext{
* "The White Man's Burden at Home," International Quarterly, April, rọo5, pp. 2x, 22.
} 


\section{2 \\ The American Race Problem}

use his power with wisdom. The capacity of a mulatto to administer an executive office, in a department under white supervision at its head, is one thing. The ability of any group of mulattoes to govern a country with a mulatto and Negro population is quite another. The mulatto shares the inheritance of a double racial ancestry, and just as he derives his superior mental endowment from his white forebears, so does he inherit their traits with their blood. The American or Jamaican mulatto is not the mulatto of the Spanish or French West Indies, or of Central America or Brazil. Nor should the "coloured" type in British South Africa, the descendants of English, Dutch, and Scotch parentage, be confused with the Portuguese half-caste of Angola.

The infusion of Negro blood has played its part in Central American "revolutions," and Spanish mulattoes have furnished their share of the political and military "leaders" of these affairs. The general condition of Haiti may truthfully be described as more brutishly degraded than that of Santo Domingo, but the political stability of the yellow "republic" is no greater than that of the black. Liberia is practically under the absolute political control of its mulatto element, with "Anglo Saxon" rather than Latin blood. It is a decadent state, it is true, but it has never been cursed with the revolutionary turmoil which has characterised Latin American peoples with an infusion of Negro blood, or Dominican mulattoes with their infusion of French and Spanish. 


\section{The Negro in Politics}

It would be merely speculative to say that the higher types of American mulattoes would have developed into a safe and conservative political element had they not been so violently thrust into the position of joint leaders with unscrupulous white men of an ignorant, half-barbarian horde of superstitious and emotional Negro children. This, however, was their fate. They went up like the rocket, and came down like the stick. A part, and an unfortuately prominent part, of the saturnalia which has passed into history as "Reconstruction," they have shared with the carpetbagger and scalawag the odium which always attaches to leadership under a corrupt and vicious régime. The rehabilitation of their political reputation, or the building of a new one, is a matter which rests almost entirely in their own hands. They are largely the architects of their own political fortunes. If they insist upon continued political identification with the Negro masses, merely for the sake of retaining a constituency which they can control, that is their concern, not ours.

To return to Mr. Olivier. As individuals we may or may not fully accept either branch of his proposition. But we would be wise to recognise the line which he draws. He says that Negroes are accorded equal opportunities and privileges with the coloured man, but adds: "In practice it is the rule that the pure Negro does not show the capacity and ambition of the man of mixed race, and there are consequently few persons of pure African extraction in positions of high 


\section{The American Race Problem}

consideration, authority or responsibility."* In other words, the exceptional Negro is recognised as such, while, with a common sense which we would do well to practise ourselves, the rule is also recognised that it is the man of colour, the mulatto, who really shares in the administration of the government or fills private positions demanding ability and character. We appoint a host of mulattoes to office, with here and there a Negro, and with a solemnity which would be amusing were its results less serious, proclaim our purpose to be the "rewarding" and "stimulating" of "worthy blacks." North and South we have identified the mulatto and the black man politically. We have forced the two into political life on equal terms, and both on terms of equality with the white man. Then when the combined forces of the two, the Negro masses almost invariably led by the mulatto, have threatened the white man's political supremacy, we have had riots and bloodshed and anarchy. And who has been the chief sufferer? The Negro, almost without exception, just as it is the Negro who to-day suffers the results of strained relations and racial ill feeling when a mulatto is appointed to office over local protest.

But even Mr. Olivier fails to recognise the most important result which accrues to Jamaica through this drawing of an inter-racial colour line, with the consequent fuller recognition of the mulatto by the white man. Nor does any American writer with whom

\footnotetext{
* "The White Man's Burden at Home," International Quarterly, April, x905. p. 9.
} 


\section{The Negro in Politics}

I am familiar manage to reach the reason for the absence of friction between the races in Jamaica, and the absence of agitation by "the Negro." For one thing, we have there only an insignificant handful of white people, and they of the governing class. There is practically an absence of a white proletariat. And where this condition obtains, whether here and there in the South, or in Jamaica, or elsewhere, there is almost entire freedom from racial friction, save along the one line of political contact. And the white people of Jamaica and the authorities in England combined to remove that ground of friction forty-two years ago. Jamaica was reduced from a substantially self-governing to a Crown Colony by the process, but the Negro was eliminated from politics.

In the second place, whether we want to or not, we are forced by the fact to recognise that the racial agitation for "rights" of one kind or another, is not the work of the Negro. Save in rare instances it is the mulatto who is the heart and soul of these complaints. And in the Jamaican system the mulatto is given no cause to complain, by being granted privileges which are as fully accorded in no place where he is identified with the Negro. By also admitting the few Negroes who prove their capacity, a line is drawn between these two groups and the black mass - while in this country we insist upon a single inclusive classification.

If Mr. Olivier had been as familiar with conditions in Cape Colony as one should be who claims to study 


\section{The American Race Problem}

the question broadly, he would have known that the situation for which he blames the Southern people is not peculiar to the South. I have a letter before me from one of the leaders of "coloured," not "native," thought in South Africa. The writer was educated in England and has travelled in the Southern and Northern states of America. He declares that "there is not a state in the South of the Union in which conditions for the coloured man are half as hard, taken on a whole, as here in my native country." Mr. Colquhoun, out of his abundant experience, writes: "The bitter note in the South African native press comes, as a matter of fact, chiefly from a special class, those who are neither white nor black."* Mr. Colquhoun thinks these "half-castes" have no real grievance at the Cape, as they are under no restrictions "save those imposed by social custom." Apparently we cannot escape the "social aspect" of the problem, either in America or Africa. He tells the South African "coloured" man that "if he wants to see a country where he may ride in any part of the train or tram, provided he is well conducted, walk where he pleases, fill any post save the highest administrative ones, follow any trade or profession and be treated with respect if he deserves it, he must go, not to the Southern states where he has the franchise, but to Jamaica where he has not, and where he has actually been deprived of some of the rights he once possessed." $\dagger$

* "The Africander Land," A. R. Colquhoun, 1906, p. I 20.

†Idem, p. 124 . 


\section{The Negro in Politics}

This question of differentiating between the "native," or Negro, and the "coloured," or mulatto class, is now engaging the serious attention of commissioners and individuals in South Africa, and it is altogether possible that they may evolve some scheme after the Jamaican plan. Our political system, and our sectional and partisan manner of treating the subject, would probably render impossible any such formal action in America. If it came at all it would have to be as a gradual process of evolution. And whether it ever comes or not will depend largely upon the coloured class themselves. Looking at the matter squarely and candidly, in the light of the history of race relations here and elsewhere, there is no escaping certain fairly definite conclusions as to the course of such relations. First, the white race bases its opinion of all members of the Negro race upon its observation of the types with which it is most familiar, which accounts for the difference between Northern and Southern opinion of "the Negro." The attributes of the mass thus become identified with colour, and are attached naturally to all individuals of that colour. The white attitude toward individual members of the race will in the main be determined by white attitude toward the mass.

Second, the natural tendency is to associate the disability of colour, under which the Negro universally labours as a race, with all persons having any visible admixture of Negro blood. This tendency operates more or less strongly as the persons of mixed blood 


\section{The American Race Problem}

identify themselves in a greater or less degree with Negroes of unmixed blood. Third, the pronounced voluntary identification of themselves with Negroes is largely sentimental on the part of most mulattoes who do so. In many cases they are much more white than Negro, and often belong in law to the former race. Fourth, the white race will not discriminate between the Negro and mulatto until they first discriminate between themselves. Whether such inter-racial discrimination would be followed by similar white action here as fully as in Jamaica, under our system at this time, is problematical. That such an internal line is developing there is abundant evidence; that it will some time make itself felt, over the protests and efforts of mulatto leaders, is not unlikely.*

The absence of divisional lines is characteristic of all embryonic social organisations. As the organisation develops, lines develop, and social groups, "sets" or "circles" come into existence, each with its own fairly distinct membership. As long as the number of higher types of either Negroes or mulattoes might be insuffi-

* I have never discussed the matter, personally or by correspondence, with any mulatto "leader" who was willing to admit that any such line was possible, likely, or desirable. I have discussed it with few of the rank and file who did not favour it, and frankly own the opposite view. The reasons in each case are obvious. It should be remarked here that no absolutely exclusive line is openly established in Jamaica. The coloured class is recognised as such, but this does not mean that no black man is admitted to this class, on the one hand, or that every mulatto is admitted, on the other. Those persons of mixed blood whose habits, tastes, and acquirements identify them with Negroes, find their level with the masses of that race. The occasional individual, without apparent admixture of white blood, whose education, habits and capacity tend to separate him from the blacks, finds his way into the mulatto class. As to the more intimate social relations between "coloured" and "black" I am not prepared to speak. 


\section{The Negro in Politics}

cient to form separate social organisations the line of cleavage between the two would hardly become apparent. With increasing development the possibility of distinct cultural groups increases, and the movement toward separate organisation along colour lines normally follows. It came about in Haiti.* It is indisputably existent in Liberia. Here and there it makes itself felt in America. $\dagger$

Whether such physical separation ever takes place or not, we are foolish to ignore the existence of the differences upon which it might be based. And nowhere is this truer than in our treatment of the Negro in politics. If we wish to appoint mulattoes to office (and, barring an occasional apparent exception, they are here, just as in Jamaica, the only ones who receive positions of any importance), let us not do so under an almost inexcusably ignorant misapprehension. We have reached the point where we should know and

* Christophe was probably primarily responsible for the line between the blacks and mulattoes. Even a strain of white blood has never been popular in Haiti. Mr. Ober says that Toussaint l'Ouverture was not held in as high esteem as either Christophe or Dessalines, because "he was a coloured man in whose veins ran the blood of the hated blanc."-" "Our West Indian Neighbours," p. I69.

† The colour line has been drawn occasionally in the selection of officers for the most prominent coloured woman's organisation in this country. Not long since the same thing came out in a "mass meeting" in Washington, to protest against certain features of the public school management. According to a local paper the origin of the trouble was a report that "a committee of mulattoes" had called on the superintendent of schools "to ascertain if it were not possible to draw a colour line in the coloured schools; that is to have the black Negroes attend one class and the lighter coloured Negroes another." It was charged that the black children "are coerced into attending the manual training school, while the lighter coloured pupils are encouraged to attend the M Street High School and fit themselves for teachers' places." - Washington Herald, Jan. 31,1907 . I have attended services in a coloured church in Washington in which not a Negro was present. The minister, choir and congregation were, on the occasion in question, without exception mulattoes. 


\section{4ro The American Race Problem}

realise that such appointments are devoid of the significance to the Negro which our cherished delusions may honestly have attached to them. We like to imagine that our democratic institutions possess the subtle virtue of destroying not only class but racial distinctions as well. In fact they have done, and can do, neither. Human nature is older than the Constitution of the United States. It is also probably more permanently established.

Men fall by nature, or at least naturally, into both class and racial groups. The most our institutions have been able thus far to do, is to make possible the rise of individuals from their class or racial environment. It is not likely that more than this can be done. Certainly it is humanly impossible to abolish either class or racial lines. In the case of the Negro masses a class and a racial line run in concentric circles. There are a few old English words at the use of which we needlessly shy in this country. One of these is "peasant." The Negro masses of America at present form a peasant class, and we could much more truly help them by frankly recognising the fact. Every race has its peasant stage, and in his evolutionary processes the Negro is no exception to the rule. It seems to me to be the part of wisdom to recognise the existence of this great class, numbering millions of people, to recognise it frankly as such, and to wisely study its necessities and honestly administer to its needs. It does not need politics, and it does not need agitation. In the words of Mr. Roosevelt, at Tuskegee, and of Booker 


\section{The Negro in Politics}

T. Washington everywhere, it does need the friendship and coopperation of the Southern white men among and with whom its life must be lived. It needs trained and educated teachers; it needs education along moral lines; it needs an honest, moral and educated ministry; it needs protection, encouragement and advice from the white man nearest at hand; and it needs to be let alone.* Above all it needs to be dissociated in the minds of politicians, doctrinaires, and practical men from the higher mulatto class, which they constantly but unconsciously have in mind in all their considerations and discussions of "the American Negro."

After all is said that can be said of abstract right and duty, of justice and oppression, of constitutions and laws, of Negroes and mulattoes and white men in politics, to this complexion does it come at last: "The suffrage never has been and is not to-day regulated on any other principle than expediency." This is the sane conclusion of a review of the history of American suffrage by one of the foremost living American historians, Professor McMaster, of the University of Pennsylvania. He was discussing the question of

* One of the most pernicious influences to-day operating upon the general situation is the Northern mulatto agitator. He is generally utterly ignorant of Southern conditions, and frequently equally so of the Southern Negro whom he would keep in constant turmoil. In enumerating what he calls "the elements of danger in the present situation," Booker T. Washington mentions first of all the advice of extremists among Northern Negroes, with "little knowledge of actual conditions in the South," "to resort to armed resistance or the use of the torch in order to secure justice." He has spoken nothing truer than when he said that such "incendiary utterances from black men in the North will tend to add to the burdens of our people in the South rather than relieve them." - "Future of the American Negro," pp. 205, 206. But evidently he was using "Black" in its poetic sense. 


\section{The American Race Problem}

suffrage in relation to our colonial dependencies, and his summary is applicable to the political problems presented by all backward races, to the Negro equally with the Filipino: "Congress is indeed morally bound to give the very best government that circumstances will permit; but it is also morally bound not to be carried away by theories of human rights which even the States themselves ignore. We have no such thing as unrestricted universal suffrage. In the states east of the Mississippi no woman may cast a ballot for governor, for a congressman, or for Presidential electors. Yet in each of them are numbers of women who own property and pay taxes amounting sometimes to thousands of dollars a year. What government derives its just powers from their consent? Are they not taxed without representation? Do they not obey laws in the making of which they have no voice? All this is utterly inconsistent with the broad doctrines on which our republican form of government is founded. The truth is, the suffrage never has been and is not to-day regulated on any other principle than expediency. Nor is this to be regretted. No government is worth a rush unless it is practical; and to be practical it must not be in advance of the intelligence and capacity for self-government possessed by the people for whose welfare it has been created. This has been the characteristic of every government yet set up in state or territory, and it is greatly to our credit; and this is the course we must pursue in the treatment of any people, whatever their stage of civilisation, 


\section{The Negro in Politics}

who may come to us with new acquisitions of territory." * And he might have added, or who have themselves been already "acquired."

And if it be asked, what is expedient or wise, and who is to judge of its wisdom or expediency, we need not go far for an answer. The judges will be those who are able to enforce their decree, and to compel the approving verdict of the world upon their course. Forty-one years ago in Boston a farseeing man thus foretold whose this voice would be if the then impending conflict were forced upon the Negro and the white man in the South: "It may be asked, why not demand suffrage for coloured men, in season for their vote in the business of reorganisation? My answer is - I assume that the coloured men are in favour of those measures which the Union needs to have adopted. But it would be idle to reorganise those states by the coloured vote. If the popular vote of the white race is not to be had in favour of the guarantees justly required, then I am in favour of holding on just where we now are. I am not in favour of a surrender of the present rights of the Union to a struggle between a white minority aided by the freedmen on the one hand, against a majority of the white race on the other. I would not consent, having rescued those states by arms from secession and rebellion, to turn them over to anarchy and chaos. I have, however, no doubt, none whatever, of our right to stipulate for coloured suffrage. The question is

* Annexation and Universal Suffrage, “J. B. McMaster, Forum, December, 1898, p. 402 . 


\section{I4 The American Race Problem}

one of statesmanship, not a question of constitutional limitation." And he had just uttered this prophetic declaration: "When the day arrives, which must surely come, when an amnesty, substantially universal, shall be proclaimed, the leading minds of the South, who by temporary policy and artificial rules had been, for the while, disfranchised, will resume their influence and their sway. The capacity of leadership is a gift, not a device. They whose courage, talents and will entitle them to lead, will lead. And these men, not then estopped by their own consent or participation in the business of reorganisation, may not be slow to question the validity of great public transactions enacted during their own disfranchisement. If it is asked, in reply, 'What can they do?' and 'What can come of their discontent?' I answer, that while I do not know just what they can do, nor what may come of it, neither do I know what they may not attempt, nor what they may not accomplish. I only know that we ought to demand, and to secure, the coöperation of the strongest and ablest minds and the natural leaders of opinion in the South. If we cannot gain their support of the just measures needful for the work of safe reorganisation, reorganisation will be delusive and full of danger."*

A generation later another Northern man moralised in this wise upon one concrete instance of the "anarchy and chaos" against which Governor Andrew had forewarned triumphant partisanship's unlistening ear:

\footnotetext{
* Valedictory Address. Gov. John A. Andrew, to Massachusetts Legislature, Jan. 4, 1866, Mass. Senate Doc. No. 2, pp. 18, 1 5, 16.
} 


\section{The Negro in Politics}

"No one who has witnessed the condition of affairs in the South can believe that the Negro is, at the present time, capable of governing. All his efforts in this direction have been lamentable, direful failures. On the other hand, no one acquainted with the spirit and temper of the Southern people believes that the Negro, whatever his future capacity may be, will be allowed to govern the white race. These two assertions, that the Negro cannot govern, and that the white men will not let him govern, are axioms."*

Perhaps we may learn something from the conclusions of yet another Northern man, a citizen of the great state of which Andrew was governor. $\mathrm{He}$ is a historian of the modern school, and in closing the labour of nineteen years he expresses this conviction: "No large policy in our country has ever been so conspicuous a failure as that of forcing universal Negro suffrage upon the South. . . . From the Republican policy came no real good to the Negroes. Most of them developed no political capacity, and the few who raised themselves above the mass did not reach a high order of intelligence. At different periods two served in the United States Senate, thirteen in the House; they left no mark on the legislation of their time; none of them, in comparison with their white associates, attained the least distinction. When the Southern states recovered home rule, Negroes were of course no longer sent to Congress from the South but they

\footnotetext{
* "The Race War in North Caralina," Henry Litchfield West, Forum, Jan, 1899, p. 590.
} 


\section{${ }_{416}$ The American Race Problem}

have had a fair chance at the North where they obtained the suffrage in every state within a few years after the Civil War. Politically very active and numerous enough in some of the Northern states to form a political force, that has to be reckoned with, no one of them (I believe) has ever boen sent to Congress; few get into legislature or city council. Very few if any are elected to administrative offices of responsibility. The Negro's political activity is rarely of a nature to identify him with any movement on a high plane. He takes no part in civil service or tariff reform; he was not a factor in the contest for honest money; he is seldom, if ever, heard in advocacy of pure municipal government and for him good government associations have no attraction. He is greedy for office and emolument; it is for this reason that he arrogantly asserts his right to recognition; and he has had remarkable success in securing offices under Federal Government. In a word, he has been politically a failure and he could not have been otherwise. In spite of all the warnings of science and political experience, he was started at the top and, as is the fate of most such unfortunates, he fell to the bottom. . . . His old masters, who understood him best and who, chastened by defeat and by adversity, were really his best friends, were alienated. $\mathrm{He}$ fell into the hands of rascals who through his vote fattened on the spoils of office. He had a brief period of mastery and indulgence during which his mental and moral education was deplorable and his worst passions were catered to. Finally by force, by craft 


\section{The Negro in Politics}

and by law his old masters have deprived him of the ballot, and, after a number of years of political power, he has been set back to the point where he should have started directly after emancipation. $\mathrm{He}$ is trying to learn the lesson of life with the work made doubly hard by the Saturnalia he has passed through." *

And from it all what lesson do we learn? Nowhere in all our public life does partisan intent and thought approach so dangerously near to criminal act as when it seeks for selfish ends to keep alive the torch it lighted from the flames of war. Responsibility goes with power, and those in control of the Government to-day are the same, as party goes, who placed the ballot in the Negro's childish hand. When the South in desperation took it from him by art or force, she was denounced as for a common crime. When her older, wiser men devised a means by which the Negro's racial history and traits could be invoked to his own and the white man's good, still fault was found. The cry of fraud was raised, and threats were made. Those who have control of the machinery of government owe this much to the country: They should either take action or let the matter rest. Quadrennial threats are entirely sufficient to keep the Negro vote in line, it is true. The pitiful thing about that vote, as many of the ablest of the race admit, is the ease with which it can be kept in line by threats against the South or promises to itself.

\footnotetext{
* "History of the United States," James Ford Rhodes, Vol. 7, pp. 168, 169, I70, $\times 7 x$.
} 


\section{${ }_{41} 8$ The American Race Problem}

But these platform threats only serve to provoke and perpetuate a sectionalism which fattens politicians throughout the country but injures the country itself.

And the country has a right to demand from politicians some definite action in the case. The threat should be executed, or this should be said to the Negro: You are an American citizen. As such you derive your political privileges only from the state wherein you reside. You have been the object of Congressional solicitude for forty years, and it has profited you nothing. Take the matter up yourselves with the white people of your respective states, and see if you two cannot come to terms at home. To the South should be said: After more than a generation of worse than fruitless strife, we propose to leave the matter of Negro suffrage to you and the Negro. We shall look to you two for at least better results than we have been able thus far to secure without your aid.

It is of course too much to hope that local politicians will cease to use the Negro vote, either as a tool in one section or a scarehead in the other. But the great body of American people have a right to expect something more from men in control of national affairs. A glance at the record shows that not one platform has ever been framed by the party which has been almost unbrokenly in power since the Negro was emancipated which has not contained its "Negro plank." Almost invariably the other great party has answered in kind. And in each case it is mere brutum fulmen an opera bouffe affair, with the Negro occupying the 


\section{The Negro in Politics}

centre of the serio comic stage. There is nothing substantial in these periodic threats.

One of the most astute politicians this country has produced, James A. Garfield, after as earnest deliberation and as thorough study as the question is ever likely to receive, more than twenty-five years ago openly abandoned the effort to reduce Southern representation, as an impracticable proposition. He found that the framers of the XIV. Amendment had authorised a line of action for the execution of which they had palpably failed to provide the necessary machinery. Yet we go ahead with our strife-breeding policy, and every four years hoodwink the Negro and stir up the South by a threat which cannot be enforced, and probably is not intended to be. It is idle to talk about the Negro having been "removed from politics" in the South, as long as Northern state and national platforms and politicians use him to furnish an exhaustless supply of ammunition for consumption South of the line. It is equally idle to talk of a division among Southern white people as long as Republican presidents deliberately and tenaciously adhere to a policy which guarantees a "solid South."

We need be neither radicals on the one hand nor doctrinaires on the other in this matter. We need only have the courage and wisdom to face the truth. And it is as true to-day as when John A. Andrew talked to his people, that any plan of action, any policy, any line of conduct, which concerns the Southern Negro and ignores, or cannot secure, the support and coopera- 
tion of the Southern white man, is "delusive and full of danger." The question is to-day as truly one of statesmanship, rather than constitutional limitation or right, as it was when Governor Andrew so declared it to be in I 866. The Southern white man, in the face of handicaps and obstacles which might well have palsied a less determined people, has demonstrated his ability absolutely to control his domestic affairs, regardless of the Negro within or the white man without. It cannot be questioned that he will do so in the future, as he has in the past. Whatever share in that control the Negro masses may be permitted to have, can come only as a grant from those who hold it within the hollow of an iron hand.*

Every policy of this Government which has touched the Negro's political life has been based upon the assumed opposition of the Southern people. And failure

\footnotetext{
* Like the preceding paper this discussion is immediately related to concrete incidents. In another form it was submitted for magazine publication during the national campaign of 1904. The Republican platform of r 900 denounced as "revolutionary" the efforts of state governments "to avoid the purpose" of the XV. Amendment. The Democratic platform was silent on the subject. The Republican platform of 1904 declared in favour of Congressional action to determine whether the franchise had been "unconstitutionally limited" by any state, with a demand for a reduction of representation in Congress and the electoral college if such limitation were found to exist. The Democratic platform replied by "deprecating" such efforts "to kindle anew the embers of racial and sectional strife." My interest in the action of each convention was largely that of a student of the race problem, and I observed as closely as possible the effect of the Republican declarations upon Southern white people and on Negroes generally. The net result, absolutely the only result, was the continued support of the Negro in doubtful States (which was certain in any event), and the furnishing of texts to Southern speakers. Seven years have elapsed since 1900 and three since 1904 , yet there has been no "investigation" and no "reduction." But the Negro is pitifully gullible, and can be influenced as easily by similar declarations in 1908 as he has been in the past. I believe there are to-day many thousands of people in the Southern States who would actually welcome any Congressional action in the matter, even to a reduction
} 


\section{The Negro in Politics}

is written large across the record. Why not raise the matter out of the quagmire of present politics and ancient sectionalism, and frankly leave it where it belongs, and where the very logic of its inherent elements inevitably must some day place it, with the people of the South, both white and black? Why not try the plan? Its execution would be extremely simple. What the Negro needs just now is a political "rest cure." His daily litany should include a prayer to be let alone.

of representation, if only it would be final, and would put an end to the periodic agitation of the subject. My own belief is that such action is wholly impracticable, for the fundamental reason that it is impossible to devise any means for determining the basis of reduction. There is simply no machinery for ascertaining the number of voters who merely fail to go to the polls, and the number who are "unconstitutionally prevented" from voting. This writer is not a politician, and his interest in politics is wholly abstract. The conviction is non-partisan and disinterested that the cessation of national political agitation of the subject would inevitably be followed by similar cessation in the States, from both of which the Negro masses would be the chief beneficiaries. 
. 


\section{PART FOUR}

\section{AN UNCONSIDERED ELEMENT}

IX. The Mulatto Factor in the Race Problem 


\section{,}




\section{IX}

The Mulatto Factor in the Race Problem :

T IS a matter of regret that in organising the twelfth 1 census it was determined to attempt no separate enumeration of the mulatto element of our population, using the term in its popular sense, as denoting all persons having any admixture of white and Negro blood. It will not do to say that the failure to do this will in any wise affect the solution of our race problem, for to do so would be to regard it as admitting of a sort of blackboard treatment, the only essentials to success being an array of statistics and their proper handling. But anyone who endeavours to go beyond the superficialities of the problem - to do something more than academically consider, from his particular standpoint, its external symptoms-must feel that such data would at least be of value, whatever ideas he may entertain as to its ultimate solution.

Any consideration which fails to reckon this mulatto element as an independent factor ignores what is possibly the most important feature of the problem, and is faulty in its premises, whatever the theoretical conclusion arrived at. Yet we see this constantly done, and of the hundreds of such discussions annually en-

* From the Atlantic Monthly, May, x903. 


\section{The American Race Problem}

gaged in, it is safe to say that scarcely one is entirely free from this blunder. There appears in them but a single "problem," and every panacea proposed - education, voting, industrial training, or what not - is made to fit the same Procrustean bed. It is a primal postulate of these discussions that the Negro is an undeveloped not an inferior race. They fail to realise that backwardness and inferiority, as long as the backward state exists, are for all practical purposes synonymous terms. To this basic error may be attributed much of the confusion which surrounds the entire subject.

We have too long been guilty of the folly of trying to legislate the Negro into a white man, and a pyramid of failures has apparently not yet convinced us of the futility of the undertaking. We have ignored the scientific truth of the ethnic differences among the human family, and have blindly disregarded the fact that the Negro, in common with all other races, possesses certain persistent, distinguishing characteristics. Foolishly attempting to evade the stubborn fact that the Negro in Africa is to-day just what we know him to have been since he first appeared on that continent, we have sought in slavery an excuse for the natural and inevitable resemblance between the native and transplanted branches of the family, and have proceeded toward the American Negro as though heredity could be overridden by constitutions and laws. Probably nothing has contributed more toward the persistence of this effort at creating an artificial being than 


\section{The Mulatto Factor}

the absolute elimination of the mulatto equation from all our considerations of the subject.

It is this that has enabled those who have so long ignored the laws and operations of heredity to point, in proof of the correctness of their theory of raceproblem treatment, to the achievements of men loosely accredited to the Negro race. Unless through discussion the American people be able to reach a common ground, a century of polemical strife will accomplish no tangible good; and I know of no surer means of reaching a working agreement than by the frank acknowledgment of the mulatto factor in the race problem. I would not be guilty of complicating a situation already sufficiently complex, through the introduction of a new factor; I rather hold to the hopeful belief that the consideration of one which already exists, though commonly ignored, may at least serve to simplify discussion, even though it fail at once to point a way out of existing difficulties. When we recognise the very simple and very patent fact that the intermixture of white and black races has given us a racial type that is neither the one nor the other; when we get far enough along to separate this type from the Negro masses in our efforts at determining what may be best for the latter; when the South is willing to lay at the white man's door many of the failings of this mulatto type and much of the meanness which he too frequently exhibits, and Northern opinion is sufficiently candid and honest to persist no longer in ascribing all his virtues and accomplishments to the 


\section{The American Race Problem}

Negro, I think we shall have made a distinct gain in race-problem discussion.

One of the greatest needs in the equipment of those who discuss the Negro from a distance is a better knowledge of the real Negro, and nothing would so promote this knowledge as a recognition of the fact that in crediting his race with the achievements of its mulatto element they but becloud the question. How may we reasonably hope to know what is best to be done for the Negro until we first truly grasp the facts of his moral and intellectual possibilities and limitations, as well as needs? And how may we hope to do this under our present method of treating the subject?

In reviewing the work of the most distinguished writer accredited to the Negro race - though he has scarcely a visible trace of Negro blood in his veins the foremost living American author has used this language: "They [referring to the mulattoes] need not be ashamed of the race from which they have sprung, and whose exile they share; for in many of the arts it has already shown, during a single generation of freedom gifts which slavery apparently only obscured." This criticism develops the very foundation of the theory upon which all such discussions are based, and which we have referred to above - that the Negro is an undeveloped, not an inferior race - that in all essential particulars the white man and the black are by nature equally endowed. Thus is placidly ignored the truth that the Negro is one of the oldest races of which we have any knowledge, and that its very failure 


\section{The Mulatto Factor}

to develop itself in its own habitat, while the Caucasian, Mongolian, and others have gone forward, is in itself sufficient proof of inferiority. Conveniently disregarding the fact of the persistence of a racial status fixed several thousand years ago, they tell us that forty years of freedom are not enough to develop "gifts which slavery apparently only obscured."

The years, both of slavery and of freedom, passed by the Negro on this continent constitute but an insignificant span in the life of that people; yet if we blot out the achievements of the American Negro who has passed through slavery, what has the race left to boast of? And if we but go one step farther, and from the achievements of the "American Negro" obliterate all that the American mulatto has accomplished, what ground indeed would be left to those whose sentiment and sympathy have apparently rendered them so forgetful of scientific truth?

In 1902 a movement was inaugurated in Congress looking to the investigation of the suffrage laws of the various states. No attempt was made to conceal the real purpose of the movement and even though we go so far as to credit the proponent of the measure with honesty of opinion as to its necessity, what must be thought of his wisdom, and of the point of view from which he would have the so-called "investigation" made, when he himself, in the face of the facts of history and the experiences of recent years, calmly affirms that "there is no doubt that the Negro is capable of unlimited development," and declares his belief in the 


\section{The American Race Problem}

virtue of "participation in politics" as a means of "uplifting the race"? Yet such is our looseness of expression in discussing this question, that to challenge either the wisdom or correctness of such views is to hear, as their sole support, a recital of the achievements of "famous men of the Negro race," while, as a matter of fact, the names brought forward are merely those of well-known mulattoes - from Murillo's favourite pupil, down to Crispus Attucks, Benjamin Banneker, Douglass, Bruce, Lynch, DuBois, Washington, Chesnutt, and others.

I am well acquainted with the exceptions that may be urged here, but this is a plea for greater scientific precision in laying the foundations of race-problem study and treatment, and the student of Negro ethnology knows that these exceptions are more apparent than real. The traffic which furnished slaves to the Americas and the West Indies was no respecter of ethnic distinctions, and, while the great majority of those brought over were pure Negroes, through it a few of the higher types of Fulah and other stocks found their way into foreign servitude, and with their blood have occasionally transmitted some measure of their ability. Othman dan Fodio, the poet chief of the Fulahs, was no more a Negro than was Othello, nor was Abdul Rahaman, the Moorish chief, who was a Mississippi slave in the early part of the last century. Thus it will not answer to cite such sporadic examples as the revolutionary leadership of Toussaint L'Ouverture,*

\footnotetext{
* It is now stated by the best West Indian student we have, Mr. Ober, that even Toussaint was a man of mixed blood.
} 


\section{The Mulatto Factor}

the political cunning of Elliott, or the ballads of Dunbar.

Just as the crossing of the Spaniard upon the Indian has given us the mestizo of Central America and Mexico, so the blending of white and Negro blood has given us a type which combines some of the racial characteristics - good and bad - of both its progenitors. But in a sane treatment of the race question this hybrid can no more be regarded as typical of the potentiality of the Negro than can Porfirio Diaz be considered an index to the "undeveloped ability" of the native Mexican Indian whose blood he has in part inherited. It would certainly seem to be the part of wisdom frankly to recognise the Negro's own racial characteristics and honestly study them. But this cannot be done so long as in our consideration of the problem of what is best to be done for him we continue to confuse the great mass of American Negroes with the exceptional mulatto types, and point to the accomplishments of the latter as evidence in support of crass and preconceived notions as to the capacity of the former.

When free from white or mulatto influence, the Negro masses are of a contented, happy disposition. They are docile, tractable, and unambitious - with but few wants, and those easily satisfied. They incline to idleness, and though having a tendency to the commission of petty crimes, are not malicious, and rarely cherish hatred. They care nothing for "the sacred right of suffrage," and, when left to their own inclinations, will disfranchise themselves by the thousand 


\section{The American Race Problem}

rather than pay an annual poll-tax. They infinitely prefer the freedom and privileges of a car of their own to the restraint of one in which they would be compelled to mingle with white people. Surrounded by larger possibilities for material betterment than have ever been possessed by any land-tilling people in the world, in the peaceful enjoyment of church and lodge, they fret not themselves because of evil-doers, nor trouble about "participation in politics," nor suffer dreams of social equality to mar the peaceful tenor of a care-free mind.

No truer utterance was ever made, nor one which contains more of wise and helpful suggestiveness, if but taken to heart, than the declaration of MajorGeneral N. P. Banks, to a Boston audience in 1864 , that "the people of the North are much more disturbed and distressed at the condition of the Negro than he is himself." This is the real Negro, the Negro of the masses, not the artificial product of vicious advice or ill-considered philanthropy. As such, he presents few, if any, serious problems, and none which he may not himself work out, if let alone and given time. But it will be an individual rather than a race solution: the industrious will, as children, acquire a common school education, and as adults will own property; those capable of higher things will find for themselves a field for the exercise of their talents, just as they are doing to-day; the vicious and shiftless will be as are the vicious and shiftless of other races.

If we will but study the true sources of the agitation 


\section{The Mulatto Factor}

over "Negro disfranchisement," "Negro cars," the deprivation of "the Negro's rights," etc., it will be found that in it all the Negro takes but an insignificant if any part. The cry that goes up over "the lack of opportunities under which the Negro labours," and the "injustice of race distinctions," does not proceed from the Negro. It is the voice of the mulatto, or that of the white politician, that is heard. If the statutes of those states which have been charged with discriminating against the Negro were not in any wise enforceable against the mulatto, I strongly suspect that America's race problem would speedily resolve itself into infinitely simpler proportions.

Through the medium of race papers and magazines, the pulpit, industrial and political gatherings and associations, the mulatto wields a tremendous influence over the Negro. It is here that his importance as a factor in whatever problems may rise from the Negro's presence in this country becomes manifest, and the working out of such problems may be advanced or retarded, just as he wisely or unwisely plays the part which fate - or Providence - has assigned him. The Negro, like the white man, responds more readily to bad influences than to good, and the example and precepts of a hundred men like Washington may be easily counteracted by the advice and influence of men of whom the mulatto type unfortunately furnishes too many examples. Booker Washington may in all sincerity preach the gospel of labour; he may teach his people, as a fundamental lesson, the cultivation 


\section{The American Race Problem}

of the friendship and esteem of the white man; he may point out the truth that for the Negro the privilege of earning a dollar is of much greater importance than that of spending it at the white man's theatre or hotel; yet all these lessons must fail of their fullest and best results so long as the Negro's mind is being constantly poisoned with the radical teachings and destructive doctrines of the mulatto of the other school.

The most prominent mulatto editor of the country is credited by the Washington Post with having declared that he was "tired hearing about good niggers, that what he wanted was to see bad niggers, with guns in their hands." One of the leading race papers in the country, published at the national capital, in enumerating certain things which it would like to see occur, as being beneficial to the Negro, included "the death of a few more men like Charles Dudley Warner," and this merely because that good man and true friend of the Negro had, shortly before his death, reached and expressed conclusions concerning Negro higher education at variance with opinions he had formerly entertained. With Booker Washington crying peace from the housetops, and the most widely read and influential of race magazines silently furnishing to the private precincts of the home and chimney corner stories revolving around themes of race prejudice, and appealing to passion and hate, together with articles which would inculcate lessons dangerous to even a stronger people, which voice is in the end likely to prove more potent in its influence upon this childish race? 


\section{The Mulatto Factor}

In 1902 the country was shocked by the horrible affair growing out of the murder of two New Orleans policemen by Robert Charles - while the bloody affrays in Alabama and Georgia in which the Negroes Henderson and Brewer, and several white men, lost their lives may be easily recalled. At the time there appeared in the most prominent coloured magazine in the country a leading article demanding continued race agitation, and in these words glorifying these murderous criminals as martyred heroes, worthy of emulation: "We have produced a Bob Brewer in Georgia, a Robert Charles in Louisana, and a Will Henderson in Alabama, and we have hopes of having similar exhibitions of courage in all of the Southern states." This same magazine printed a biographical sketch of the editor whose inflammatory utterances have been quoted above, which, in speaking of his father, used this language: "Everybody in Jackson County not only knew that he was a dead shot, but that he would shoot. That is not a bad reputation for an Afro-American to have in the South even at this time." Such utterances might be indefinitely multiplied, but I have mentioned enough to illustrate the point I wish to emphasise - the existence of a distinct mulatto factor in our race problem, and the fact that, while in some quarters its influence is being directed as wisely as may be possible, there is in it a large and powerful element that is wholly bad. The varied tragedy of human life furnishes few more pathetic spectacles than that of the educated mulatto 


\section{The American Race Problem}

who is honestly seeking the welfare of a race with which a baleful commingling of blood has inexorably identified him - who is striving to uplift to his own level a people between whose ideals and ambitions and capabilities and his own a great gulf has been fixed by nature's laws. Frequently inheriting from the superior race talents and aspirations the full play of which is denied him by his kinship with the inferior - through no fault of his own he is doomed to be an anachorism in American political and social life. A generous mind should not too sweepingly condemn his occasional outbursts of bitterness, but rather wonder that they are not more frequent than they are. Just in proportion as their numbers diminish or increase, and their great influence be potential for good or for evil, will the problem of the future become the problem of the colour line. But that of the present, whatever it may be adjudged to be, is still the problem of the Negro. While it so remains, let us treat it as such, by considering it in its simplest terms; and in seeking the real good of the real Negro let us invoke the aid of the best and wisest of that class with which he has so long and to so little purpose been confused.

\section{THE MULATTO}

In your issue of June $27^{*}$ you print a communication

\footnotetext{
* An open letter to the 'Outlook, August 8, x903. The appearance of the preceding paper created considerable discussion, most of which wholly misconstrued the purpose and meaning of the writer. This open letter was written in the hope of making clear the real intent and spirit behind the article. It is reproduced here as a conclusion to a very elementary discussion of what this writer believes to be a very important subject, that of the mulatto's part in the race problem.
} 


\section{The Mulatto Factor}

from the Rev. Thomas Nelson Baker correcting a construction which an editorial of yours had placed upon his reference to my article on the mulatto. I have no quarrel with Mr. Baker's comments upon my utterances, and have no desire to consume your space and tax the patience of your readers by indulging in an idle controversy. But the conclusion indicated in this communication demands, it seems to me, some reply.

All that I attempted to do in the article in question "The Mulatto Factor in the Race Problem"- was to set forth briefly certain features of the "problem" which it appears to me to be unwise to ignore in our consideration of it. At most, I could make so short a discussion merely suggestive, and no more than this was contemplated by me.

I have no fault to find with those who take issue with me, but I do object to having entirely incorrect motives ascribed to me, and false conclusions drawn from my words. The fact that this has been done by so many of my critics - to say nothing of one or two unintentionally misleading "interviews" on the subject - warrants me in making this correction.

My position is simply that, in its mental and moral equipment, if I may so express it, the Negro race is the inferior of the white; that most of the men who have come to the front as "race leaders," and who are pointed to as the highest intellectual types of the race, are, in fact, not really Negroes - under any exact definition of the word, as descriptive of a race; that these mulattoes, from their position of leadership, wield a 


\section{The American Race Problem}

large influence over the more than nine millions of our population classed as Negroes - and that it behooves them to see to it that that influence should be for good rather than for evil.

I do not mean to say that there are no pure Negroes who have risen to eminence in this country, and I would be the last to ignore such as have. I speak, however, of the masses of the race when I ascribe to it certain characteristics, just as I refer to the large body of "race leaders" when I speak of them as mulattoes. This does not mean to say that there are not many Negroes who have risen superior to the character of the mass, any more than it means to say that every man is fitted for high station in the race just because he happens to be a mulatto.

Mr. Baker speaks of the "poor thinking" the white man is capable of "when dominated by prejudices and preconceived opinions." It is this, and the term "negrophobist," used by some of my critics, to which I take exception. The people of this country, North and South, white and black, have misunderstood and abused each other long enough over this "race question" to have learned that nothing is to be gained by using harsh terms and indulging in recrimination. Neither section, neither race, can lay claim to the exclusive possession of all the wisdom on the subject, nor justly charge the other with all the prejudice and ignorance. The situation demands a large measure of sympathy and charity from all sides, and the according of honest motives to honest thought, even though it lead to 


\section{The Mulatto Factor}

conclusions at variance with one's own. He who cannot criticise without the questioning of motive - who cannot differ without indulging in reproach or abuse cannot justly claim much of that kindly feeling which should characterise any discussion of the race question to give it one of its highest elements of value. 


\section{PART FIVE}

PAPERS BY WALTER F. WILLCOX

\section{I.-Negro Criminality}

II.-Census Statistics of the Negro

III - The Probable Increase of the Negro Race in the United States 



\section{Negro Criminality*}

\section{$7 \mathrm{HE}$ number of prisoners in the United States \\ 1 was reported at the last census, showing those of African descent and those of pure white blood. In} the Southern states there were six white prisoners to every ten thousand whites and twenty-nine Negro prisoners to every ten thousand Negroes. $f$ This seems to indicate that the liability of an American Negro to commit crime is several times as great as the liability

* An address delivered before the American Social Science Association at Saratoga, September 6,1899 , preceded in its printed form by the following note: The right of one born and reared almost within sight of Bunker Hill to speak on the Negro question may perhaps be challenged. Yet one who knows the passions aroused by the Civil War only through hearsay, and the Negroes mainly through type and as a college teacher, gains a remoteness and perspective that should help him to be fair-minded, clear-sighted and outspoken. In some quarters, too, a Northern student may get credit for these qualities more easily than a Southerner or a man of affairs, and contribute his mite to the formation of public opinion.

In preparing my manuscript for the printer, I have made full citation of authorities, being willing to risk the appearance of pedantry, if thereby I might aid anyone to find the main sources of $m y$ information. I have been greatly aided by correspondents, especially in the South, all of whom have answered the inquiries of a stranger with the utmost courtesy; and I gladly take this opportunity to express my grateful thanks to Mr. Leroy Daniel, Dr. W. E. B. DuBois, Mrs. T. M. Greene, Dr. George H. Hepworth, Ex-Governor W. J. Northen, Mayor G. L. Simpson, and Booker T. Washington.

This address was delivered before the results of the Census of 1900 and of the enumeration of Prisoners and Juvenile Delinquents taken in 1904 were available and no changes in its text have been made for the present volume. Some indication of the manner in which the argument might be modified by a consideration of later figures will be found in an article in the forthcoming issue of the Encyclopædia Britannica on "Negroes in the United States."

† Eleventh Census, "Crime, Pauperism, and Benevolence," I., p. 125 and II., p.3. 


\section{The American Race Problem}

of a white. But those who are unwilling to admit this inference sometimes urge that the judicial system of the South is almost entirely in the hands of the whites, and that it is not administered with impartiality to the two races. They claim that a Negro is convicted, on the average, upon less evidence than is required to convict a member of the dominant race; that, if found guilty, he is less likely to escape prison by paying a fine; and that, if both are imprisoned, the Negro is likely to receive a longer sentence for a like offense. To meet these objections to the entire satisfaction of the person raising them would probably be difficult or impossible, and so, for the sake of my argument, let me for the moment admit their validity. If one thinks they furnish an adequate explanation of the large number of Negro prisoners in the South, he may be asked whether they lie also in the North. Does it take less evidence to convict a Negro here, or is a Negro's sentence for the same offense likely to be longer? Such a claim has never to my knowledge been raised. Yet in the Northern states, in 1890 , there were twelve white prisoners to every ten thousand whites, and sixty-nine Negro prisoners to every ten thousand Negroes. In our own state of New York the Negroes, in proportion to their numbers, contributed over five times as many as the whites to the prison population. These facts furnish some statistical basis and warrant for the popular opinion, never seriously contested, that under present conditions in this country a member of the African race, other things equal, is much more likely to fall into 


\section{Negro Criminality}

crime than a member of the white race. This is the unanimous opinion of the Southern whites, and is conceded by representative Negroes. Thus, among the resolutions adopted by the Negro Conference at Hampton, Va., in July, 1898, was the admission that "the criminal record of the coloured race in all parts of the country is alarming in its proportions."*

The Negro prisoners in the Southern states to ten thousand Negroes increased between 1880 and 1890 29 per cent., while the white prisoners to ten thousand whites increased only 8 per cent. $\dagger$ Here, again, to the obvious inference that crime is increasing among the Negroes much faster than among the whites, the same objection is sometimes raised, namely, that prejudice against that race is so influential in the South as to invalidate the argument. The same appeal as before to the figures for the North and West constitutes a convincing reply to any such contention. In the states where slavery was never established, the white prisoners increased 7 per cent. faster than the white population, while the Negro prisoners increased no less than 39 per cent. faster than the Negro population. Thus the increase of Negro criminality, so far as it is reflected in the number of prisoners, exceeded the increase of white criminality more in the North than it did in the South. To bring the facts home, I may add that for New York State in 1880 there were sixteen white prisoners to every ten thousand white population; and in

* Hampton Negro Conference, No.2, p. Ir.

† Compare preceding citation from the Eleventh Census with the Tenth Census, XXI., p. 479. 


\section{${ }_{44} 6$ The American Race Problem}

I 890 the proportion has risen to eighteen. But the Negro prisoners of the state in I 880 were seventy-seven, and in 1890 one hundred to every ten thousand Negroes. These figures serve to show both the higher rate and the more rapid increase of Negro criminality, and in both respects New York is a fair type of the conditions elsewhere in the country. In these figures one finds again some statistical basis for the well-nigh universal opinion that crime among the American Negroes is increasing with alarming rapidity.* In further support of this conclusion, I may quote the concession of the Negro who is perhaps doing as much as any member of his race to throw light upon its present condition. Professor DuBois, of Atlanta University, in a recent address before the Negro Academy, said: "The Negro Academy ought to sound a note of warning that would echo in every black cabin in the land. Unless we conquer our present vices, they will conquer us. We are diseased, we are developing criminal tendencies, and an alarmingly large percentage of our men and women are sexually impure." $\dagger$

Let us grant, then, that there is a large amount and

* The serious difficulties in the way of comparing the criminal tendencies of different classes by inferences drawn from the statistics of prisoners are ably stated by R. P. Falkner, "Crime and the Census" (in "Annals American Academy," January, 1897). I do not believe that his objections vitiate my inferences in the guarded way in which they have been stated. While the statistics of prisoners in one way which he has pointed out exaggerate the criminal tendencies of Negroes, yet a comparison between the prisoners and persons of all ages tends to understate the true criminality of a race, a disproportionate number of which are children, and so under the criminal age. These two obstacles to accuracy in quantitative statements of the amount or increase of crime thus tend to neutralise each other.

† W. E. B. DuBois, "The Conservation of Races," p. 44 (in American Negro Academy, Occasional Papers, No. 2). 
a rapid increase of Negro crime in the United States. This gives rise to a serious practical problem - How may this amount be reduced or at least the increase checked? The answer to that largely depends upon the answer to a more theoretical question, which will define my theme this morning - What are the causes of Negro crime? If those causes can be detected and removed or counteracting causes set at work, the practical problem will have been advanced toward solution.

The criminal is one who refuses to obey the laws of the community in which he lives. Such obedience to the law in the face of temptation is not an instinct or birthright, but a product of training, and in the great majority of instances that training is obtained in the family. The primary cause of crime, therefore, is defective family life and training. Hence crime is most common during the years just after a child has passed out of the control of the family, and while he is finding himself ill-adapted by his past training to the new sphere of life. In proportion to population of the same age, the prisoners between twenty and thirty are much more numerous than those of any earlier or later age period;* and, if the date of committing the first crime could be ascertained - and that is the important time - the juvenile character of our criminal population would appear yet more clearly. This youthfulness in comparison with the population outside is characteristic of all classes of prisoners, but preëmi-

\footnotetext{
* Eleventh Census, "Crime, Pauperism, and Benevolence," I., p. 163
} 


\section{${ }_{448}$ The American Race Problem}

nently of the Negroes* - a fact which tends in a measure to confirm the frequent statement that Negro criminals spring especially from the rising generation. If that be so, a further increase of Negro criminality in the future is probable, and this probability renders the situation still more serious.

Under the slavery régime the Negro had a feeble family life, much of the responsibility for the proper rearing of the family falling upon the master. The emancipated slaves have not been able in a single generation of freedom to develop or to imitate that family life which it has cost the whites many centuries to acquire. The difficulty is the more serious because to-day the conditions of civilised life do not foster the family virtues as they have done in the past. The white race is living on its inherited capital of family organisation and responsibilities; the Negroes have no such capital, but must acquire it, and that speedily, if the race is to survive.

What is the most effective safeguard against crime that the family furnishes the son or daughter? Not education, not even direct moral or religious training. The Negro and the injudicious among his friends too often look on education and religion as fetiches, that is, something external, the possession of which guarantees the possessor a charmed and happy life here or hereafter. In distinction from these, the most effective safeguard against crime which parents can offer to their children is the desire and ability to support one's self

*Idem, I., p. 167. 


\section{Negro Criminality}

by legitimate industry. A formal education is subsidiary to this; it is important mainly because it increases the avenues through which self-support is possible. If ever it serves to decrease the desire for self-support, it is to that extent baneful. If ever it decreases the recognised avenues for self-support by arousing the belief that certain lines of legitimate industry are degrading and therefore inadmissible, it is to that extent baneful. This may give a standpoint from which to judge the difficult question of Negro education. If the Negro family on the average is far less effective than the white, the education provided for Negro children should aim frankly to supplement the shortcomings of their family life and reduce their temptations to crime by increasing their desire and ability to live by legitimate industry. Probably the best means by which to reach and reënforce the family life of the Negroes is a school system which frankly sets this up as its aim.

A closely related series of causes for Negro crime may be grouped as industrial. Under the compulsory coopperation of slavery, little competition between the two races was possible. Manual labour in many pursuits, notably those of agriculture, was deemed by the whites servile and degrading. Since the war this motive for the white man to avoid field-work or other forms of manual labour has diminished in importance, and he has gradually entered upon tasks which before the war were closed to him by the pressure of social sentiment. In ceasing to be master he has become 


\section{The American Race Problem}

competitor, and to the pressure of this competition not a little Negro crime must be attributed.

Hence it is no digression to invite your attention to some evidence of the increasing competition between the two races. The staple crops upon which the Negroes were occupied before the war were probably cotton, tobacco, sugar, and rice. In I860 the great mass of the work in the cotton fields was done by Negro labour. White labour was used, to be sure, in Texas, but at that time the whole cotton crop of Texas was less than one-twelfth of the country's product.* It would probably be a conservative statement to say that at least four-fifths of the cotton was then grown by the Negroes. The only official estimate for any date since that time is that of the statistician to the Department of Agriculture in $1876 . \dagger \mathrm{He}$ concluded that about three-fifths of our cotton was raised in that year by Negroes. At the present time probably not one-half is thus grown. In I859 Texas produced onetwelfth, in $1897-98$ one fourth, $\ddagger$ of the cotton of the United States; and, as in that state white labour is usually employed in the cotton fields, the advance of Texas means the advance of white agricultural labour.

Similar changes have been going on in the tobacco crop. In 1859,28 per cent. of it was grown in Virginia and mainly, it seems, by Negro labour. In I 899 less than ro per cent. of our crop was grown in that state, and the Virginia crop of that year was less than two-fifths of

* Eleventh Census, Abstract, pp. I 22-1 25.

+ Department of Agriculture, Report, r876, p. 136 .

$\ddagger$ Department of Agriculture, Year Book, 1898, p. 683 . 


\section{Negro Criminality}

what it had been thirty years before. In I889 Kentucky produced over 45 per cent. of the tobacco of the country, while ten years earlier it produced only 36 per cent. American tobacco growing evidently is tending to centre in Kentucky, and yet it is the only Southern state in which the number of Negroes decreased during the last decade. In over half its counties and in the state as a whole, the Negro population decreased while the white increased between $r 880$ and $1890 *$ It seems that tobacco growing, like cotton growing, is passing more and more into the hands of the whites. Some light upon this change may be derived from a passage in the last Annual Report of the Secretary of Agriculture: "The tobacco business has become very highly specialized. Each market has its own requirements, each class of users has its own particular style, and each season brings some change of style which must be met by the tobacco grower. There is a great deal of competition in our own country, and very serious competition from abroad. . . . To meet this competition, it is absolutely necessary that our farmers should have at their disposal a thorough knowledge of their own conditions, and of the conditions of the soil, climate, methods, and labour conditions of competing districts." $\dagger$

Of the cane sugar crop of the United States in 1889 , over 97 per cent. came from Louisiana; and the increase of yield in the preceding decade was almost confined to that state, where the acreage under cane increased 7

* Eleventh Census, Abstract, p. 40, and Population, I., 41 2, ff.

$\dagger$ Department of Agriculture, Year Book, 1898, p. 42, ff. 


\section{The American Race Problem}

per cent. and the yield 42 per cent.* Apparently, the increase of yield in the last ten years, notwithstanding the losses resulting from recent Federal legislation, has been quite as rapid. In a paper read in 1898 before the Louisiana Agricultural Society the statement was made that this rapid increase in the production of cane sugar was "due especially to the establishment of large central factories." $\dagger$ The machinery in these factories is managed, I am informed, almost entirely by white men.

With regard to the rice crop of the country, in 1879 , less than one-fourth of the acreage was in Louisiana; in r889 over one-half was there. $f$ During the last decade the acreage outside Louisiana decreased 42 per cent., while that within the State more than doubled. In this, as in other staple agricultural industries, there has been a marked tendency toward concentration; and the centre of production has passed away from South Carolina, which in 1849 produced three-fourths of our crop, but in 1889 less than one-fourth. This transfer of the rice growing industry is largely due to the superior efficiency of white labour. A pamphlet distributed at the Louisiana Building during the World's Fair in 1893 and thus given apparently official indorsement, says: "Not long since the Carolinas raised the rice of the United States, and the delta of the Mississippi the rice of Louisiana, all done by coloured labour. The immigration agent of the Southern Pacific Railroad

* Eleventh Census, Abstract, pp. 1 26-128.

† State Agricultural Society. Proceedings, Twelfth Session, p. II7 (in Louisiana Commissioner of Agriculture, Biennial Report, 1898).

$\ddagger$ Eleventh Census, Abstract, pp. r30-133. 


\section{Negro Criminality}

Company induced the men of the Northwest to come into southwestern Louisiana, bringing their improved farm machinery. They supplanted the hook and sickle then in use by twine-binding harvesters, of which many hundred are now employed in the Louisiana rice fields; and this machinery is handled by white men."* Corroborative evidence is found in a recent paper read before the Louisiana Agricultural Society, which states that there are now in the rice fields of Louisiana nearly five thousand selfbinding harvesters with steam threshers by the hundred, and that artificial irrigation employing steam pumps has been introduced on a large scale. $\dagger$

From all the evidence obtainable it seems clear that Southern agriculture is becoming increasingly diversified, and is demanding and receiving a constantly increasing amount of industry, energy and intelligence characteristics which the whites more generally possess or more readily develop.

Some evidence upon the lack of industry of Negro farmers in the black belt of Alabama may be derived from a recent Bulletin of the United States Department of Agriculture dealing with their food. Eighteen families near Tuskegee, Alabama, were selected as typical and studied by officials of the department in coopperation with representatives of the Tuskegee Normal Institute. The agent of the Department reported: "The Negro farmer generally works about seven and a half months during the year. . . The rest of the

\footnotetext{
* Southwest Louisiana on the Line of the Southern Pacific Company, pp. 45, ff.

† State Agricultural Society. Proceedings, Twelfth Session, p. 39 (in Louisiana Commissioner of Agriculture, Biennial Report, 1898).
} 


\section{The American Race Problem}

time is devoted to visiting, social life, revivals, or other religious exercises, and to absolute idleness. Few farmers work on Saturday even during the busy season of cotton-picking." *

The same study gives evidence of the poor food supply of the Negro farmers. In the diet of the average Negro family the amount of protein - that is, of the material needed to form blood, muscle and bone, and to make up for the wear and tear of the bodily machine-was from one-third to three-fourths that which has been found in the diet of well-fed American whites, and "no larger than has been found in the diet of the very poor factory operatives and labourers in Germany and the labourers and beggars in Italy." $\dagger$

In agricultural pursuits the competition between whites and blacks can be traced more clearly than elsewhere, because in that field we have fuller information. Still there is some evidence, derived mainly from statements of educated Negroes, that in other occupations, also, this competition is seriously felt.

Thus Professor Hugh M. Browne, of Washington, said, in a speech,delivered in 1894 , to a Negro audience: "White men are bringing science and art into menial occupations and lifting them beyond our reach. In my boyhood the household servants were coloured, but now in the establishments of the four hundred one finds trained white servants. Then the walls and ceilings were whitewashed each spring by coloured men; now

\footnotetext{
* Department of Agriculture, Office of Experiment Stations, Bulletin 38 . "Dietary Studies with Reference to the Food of the Negro in Alabama." p. I8. † Idem, p. 68.
} 


\section{Negro Criminality}

they are decorated by skilled white artisans. Then the carpets were beaten by coloured men; now this is done by a white man, managing a steam carpet-cleaning works. Then laundry work was done by Negroes; now they are with difficulty able to manage the new laboursaving machinery."*

Similar testimony comes from another Negro, Mr. Fortune, editor of an influential Negro paper. He said in 1897: "When I left Florida for Washington twenty years ago, every brakeman, every engineer and almost every man working on the railroad was a black man. To-day a black man can hardly get a job at any avocation. This is because the fathers did not educate their children along the lines in which they were working, and, as a consequence, the race is losing its grip on the industries that are the bone and sinew of life." $\dagger$ At the same conference Mr. Fitch, the field missionary of Hampton Normal Institute, reported that he found the old men everywhere working at the trades they learned in slavery, but nowhere did he find young men learning these trades. $\ddagger$ Similarly, Principal Frissell, in the opening address, said: "There is great danger that the coloured people will be pushed out of the occupations that were once theirs, because white tradesmen are coming to fill their places." 9 This competition between the races is accentuated by the trade-union policy of exclusion, which often denies Negroes the

* Reported in A. M. E. Zion Church Quarterly for April, r894.

† Southern Workman and Hampton School Record, September, r897, p. r79.

$\ddagger I d e m$, p. $x 68$.

I Idem, p. 167 


\section{The American Race Problem}

right of membership in labour organisations, and then opposes the employment of non-unionists, the net result of which is to antagonise the entry or continuance of Negroes in the field of skilled labour.*

Every improvement in agriculture or industry anywhere tending to lower the price of a staple product is a spur to former producers. They must meet the situation by economies of production or economies of consumption, by improving their own methods or by living on a smaller return. Those who are sanguine of the future of the Negro in the United States usually rest their hopes upon the evidence of Negro progress since emancipation, measured against some assumed absolute standard. They point to a decreasing illiteracy, to accumulations of property, to a decreasing death rate, etc. But the test which the race has to face is the test of relative efficiency. If they are to hold their own in this country, they must improve as fast as the whites, and the progress of the Southern whites since emerging from the dark shadows of slavery, the war and Reconstruction is one of the marvels of present history.

\footnotetext{
* The preliminary report of the Third Hampton Conference offers confirmatory evidence on this point. The Committee on Business and Labour reported on the condition of Negro skilled labour in certain large cities. Of Richmond, Va., they say: "Perhaps two thousand are employed in the iron works. This branch of business was at one time controlled almost entirely by coloured men, but now they are employed chiefly as common labourers, with only here and there a master mechanic." The general trend of the report is summed up as follows: "The trade-unions along the border line of slavery have generally pursued a policy of exclusiveness on account of colour, and refused to include the coloured craftsmen in their scheme of organisation. . . . In the North coloured men, when competent, are generally received into local unions and treated fairly. In the South they work side by side, when not organised. When organisation takes place, the coloured workman as a rule is excluded."-Southern Workman, September I899, pp. 333, ff. Meagre evidence from other sources does not confirm the above statement so far as it applies to the attitude of Northern trade-unions.
} 


\section{Negro Criminality}

Partly under the stress of this competition to which the Negroes are being subjected, partly as a natural result of their emancipation, they are gradually drawing apart into social classes. The successful families refuse to associate with those who morally and industrially are stationary or retrogressive. Dr. DuBois has recently made a valuable report on the members of his race living at a small county seat in the Virginia tobacco district. About 260 Negro families were studied, of which 40 belonged to the higher class, I 70 to the middle, and perhaps 50 to the lower. He describes the members of the lower class as "below the line of ordinary respectability, living in loose sexual relationship, responsible for most of the illegitimate children, and furnishing a half-dozen street walkers and numerous gamblers and rowdies. They are not particularly vicious and quarrelsome, but rather shiftless and debauched. Laziness and promiscuous sexual intercourse are their besetting sins."* In other words, this class lacks the family virtues and the industrial virtues which have made the white man what he is. It may be styled potentially criminal. A class of such people is found, to be sure, in every civilised country, but in our Southern states the proportion of this potentially criminal class is abnormally and dangerously large. About one-fifth of the Negro families or over one-tenth of the total population in Farmville are assigned by Professor DuBois to this group. This growing social stratification of the Negroes

\footnotetext{
*"The Negroes of Farmville, Va.," p. 37 (in Department of Labour Bulletin, January, I 898).
} 


\section{The American Race Problem}

makes all efforts to judge them as a race rather than by classes, localities, or even individuals, increasingly unjust and irritating to them.

The strenuous and increasing industrial competition between the two races often results in local displacement of coloured labor. The Negro cotton grower, unable to live on the decreasing return from his land, gives place to another tenant, white or black, and the former family drifts away. The current of Negroes to the cities is somewhat greater than that of whites and seems to consist of two classes, those who have earned a promotion to city life by their success in the country or small town, and those who have failed in country life and flow cityward to live on their neighbours or by their wits. Neighbours and pickings are more numerous in an urban community. This Negro driftwood is likely to feel sore toward the whites. The latter are held responsible for the organisation of society, and their fault it is if the Negro can find in it no place for himself. They cared for him in slavery, and either their old masters or their new emancipators are bound to furnish him a chance for a livelihood. He is a voiceless Socialist. Hence this driftwood belongs to the potentially criminal class.

A third group of causes leading to a large amount and rapid increase of Negro crime may be embraced under the loose term race friction. All witnesses agree that since emancipation the two races have separated more and more in life and thought. Ex-Governor Northen, in an address at Boston in 1899 , seems to attribute this to the national policy toward the South during the Recon- 


\section{Negro Criminality}

struction period.* We may agree with him in part and still believe, as I do, that the industrial competition just sketched was probably inevitable, and is another important factor in drawing the races apart. But, whatever be the explanation, the fact is undeniable. Under the slavery system the main motives in governing the Negroes were personal loyalty and force, and the emphasis upon one or the other varied with the character of the work and of the owner or overseer. As the races have drawn apart, this feeling of personal loyalty has become feeble, and many of the whites have felt that the only alternative mode of governing the increasing number of criminals was force, and that the more speedily and surely force could be applied the greater its deterrent influence.

But, as the Negroes have separated from the whites, they have drawn or been crowded together, and have come to feel a race unity and race pride, and are developing a race public opinion which may prove of great importance in controlling the Negro criminal class. The existence of this Negro public opinion, as distinct from that of the whites, is hardly recognised with sufficient clearness by the dominant race, and to illustrate it the argument must be amplified. This can best be done by the aid of a typical instance, and I have selected for the purpose the series of events at Palmetto, Ga., in the first four months of 1899 , culminating in the death of Sam Hose. $\dagger$

\footnotetext{
*"The Negro at the South," W. J. Northen, p. 7.
}

$\dagger$ My information has been gleaned from a file of the Atlanta Daily Constitution, the only Atlanta daily paper of which the current issues are accessible in the Library of Congress, and from correspondents both white and coloured, in the North and in the South. 


\section{The American Race Problem}

Palmetto is a town of perhaps six hundred people in a county which contains no place of much greater size. About two-thirds of the county's population are Negro. In the early morning of Tuesday, January 24, I899, a fire broke out in the centre of the town, destroying the hotel, two stores and a storehouse, and seriously threatening half the town. Some citizens moved out their goods, through fear that the fire would spread, and in this way they, too, suffered losses. There was little insurance on the property destroyed, and the contemporary newspaper account $*$ throws no light upon the place of origin or the cause of the fire. On the following Saturday morning, not long after midnight, a second fire occurred, by which twelve property-holders suffered serious losses. These fires together destroyed nearly all of the two business blocks in the town. The second was clearly incendiary, for in another block a fire was found the same night kindled against the outside of a store. The Atlanta Constitution of March I 7 th says $\dagger$ that two other fires occurred in the same town during February, but I have found no contemporary mention of them in the columns of that journal, and am uncertain whether the statement is correct. A reward was offered for the detection of the incendiaries, but for some weeks all efforts to ferret them out were fruitless.

About the middle of March evidence was obtained implicating nine Negroes. An editor of an Atlanta daily paper, who made a special investigation of the facts

* Atlanta Constitution, Jan. 25, r 899, p. 3, col. 5. .

† Idem, Jan. 29, 1899, p. 4, col. 4. 


\section{Negro Criminality}

after the terrible climax, has written me that the evidence against the Negroes consisted in a conversation overheard by a reputable white citizen while in hiding under the house of a Negro, and in a confession of the ringleader. The Negroes were arrested, placed under a guard of six white men, and confined for the night of March ${ }^{5} 5_{\text {th }}$ in a warehouse at Palmetto to await trial the next morning. A Negro at Atlanta, who also had made a special effort to get at the facts, reported to me that the nine had been examined, released for lack of evidence, and subsequently rearrested. I find no confirmatory evidence of this, and it seems almost certainly incorrect. At the same time I am confident that my informant, who is an impartial aud judicious man, believed it. In that case the two stories illustrate the conflicting accounts accepted even by conservative members of the two races.

Soon after midnight a masked mob of perhaps fifteen men* pushed open the door of the warehouse, ordered the guards to throw up their hands, and fired two volleys into the nine Negroes, killing four, seriously wounding two, slightly wounding two, and leaving one unharmed. Although the Governor of Georgia offered the largest reward allowed by law, $\$ 500$, for the arrest of the first member of the mob and $\$ 100$ for that of each additional member, no one of the criminals was detected. They were said to have come from a distance, but the evidence warrants the conclusion that they probably came from Palmetto or its immediate vicinity. For the

* Idem, March 17, 1899, p. 1, col. I 


\section{The American Race Problem}

indignation over the fires was most intense in that community, and, furthermore, the confession of the Negro leader, apparently the immediate cause of the lynching, was made so shortly before, that the news of it could hardly have spread very far through the scattered population of that region.* As the motives to disclaim responsibility for the action of the mob were obvious and strong, the local statements denying complicity can hardly be given great weight. If this view of the probabilities be accepted, it throws light upon the action or inaction of the guards. The Negro interpretation of their conduct is that they were dummies, aware that the lynching party was coming, and sympathising with its action. The whites do not admit this, and yet even they, if the Atlanta Constitution may be deemed their spokesman, felt the guards' conduct to be suspicious. Note the questions asked editorially by that paper: "What was the guard there for? Were the guardsmen asleep while on duty? What became of their guns while the assailants were shooting down their prisoners? These are questions which should be answered, though it is hard to conceive what answer can be given." $†$

Whether any members of the mob of lynchers were recognised by the Negroes who survived, it seems impossible to tell. According to newspaper accounts the mask was torn from the face of one, and the leader spoke in giving orders to his followers. Undoubtedly,

* "It is practically certain now that the news of the confession, which spread quickly throughout the town, brought on the mob yesterday morning." Idem, p. 2, col. 2.

†Idem, March x8, I899, p. 4, col. 2. 


\section{Negro Criminality}

however, many Negroes believed, rightly or wrongly, that members of the squad had been recognised.

Four weeks later, in the immediate vicinity of Palmetto, Alfred Cranford was killed by a Negro, Sam Hose, and ten days after Hose was put to death by a white mob. So far, and only so far, all accounts agree, but two widely different stories of the accompanying events have been printed, one coming from the whites, the other from the Negroes. I may review and criticise the two narratives in detail. For the Negro version the sources are the report of a detective sent by Northern Negroes to investigate the facts. This was printed both in the New York Age of June and and in briefer form as a letter by Mr. Fortune, the editor of the Age, in the New York Sun of June 2 oth. In regard to the events prior to the killing of Cranford, these accounts say that "one or two barns or houses had been burned" at Palmetto, and that the nine coloured men arrested "were not men of bad character, but quite the reverse." The incorrectness of the former statement has already been shown; that the latter is equally inaccurate appears from the county records of Campbell County, which show that four of the nine had been indicted, the leader five times, another for burglary, and two for misdemeanours.* The Negro story also states that Cranford was killed in the yard, and not in the house. To get light upon this radical difference in the two accounts, I wrote to the Atlanta editor, already mentioned, asking these questions: "Was the body of Alfred Cranford found in the

*Idem, March I8, I 899, p. 2. col. 3. 


\section{The American Race Problem}

supper room or in the yard?" He answered, "In the supper room." "Do you know this fact of your own knowledge or by testimony of others?" To this his reply was, "Blood showed position; eye-witnesses testified as to place." In addition to these errors of statement the Negro version reads like a plea, and not an impartial balancing of evidence, and puts aside as untrustworthy the sworn testimony of Mrs. Cranford.

For these reasons, and others I need not stay to mention, I am compelled to reject what at the first I was disposed to accept-this account of the events. Still, in some respects I cannot but believe that it suggests the probable facts. The version of the whites usually implies that lust was the main motive for the crimes of Sam Hose, and omits as irrelevant all reference to prior events at Palmetto, a view which seems to me untenable. The lynching of the Negroes charged with arson and the crimes of Sam Hose were, perhaps, the most serious results of race friction that have appeared in Georgia of recent years. Assume that the first in no wise caused the second. In that case the chances against both occurring in the same small town and within four weeks of each other would be indefinitely small. I am compelled, therefore, to believe that the close proximity in space and time is evidence that the second was caused in part by the first. That is, the furious wrath kindled among the Negroes of Palmetto by the 1ynchers was probably a potent influence upon the criminal nature of Sam Hose in bringing about his deed. The criminal nature and the special incentive reënforced each other 


\section{Negro Criminality}

and the result was a crime at which Georgia and the country stood aghast. The Negro version, as set forth by a correspondent, says that Cranford was conspicuous in that region as "a nigger-hater," and was probably the leader of the party of lynchers four weeks before. Whether that be true or not, it seems likely that the dominant motive for the murder and rape was revenge. On this theory the stoical silence with which Hose borc his tortures, and the evident pride of the Negroes in that silence, receive new meaning. It was the weapon whereby, even in death, they felt that he triumphed over their enemies and his.

In the fate of Sam Hose as an individual, I have little interest. I believe the tortures he inflicted upon Mrs. Cranford by the murder of her husband, and in the hours that followed, were more terrible than those he suffered at the stake. But the point I would urge is that the illegal execution of Negroes by lynching, even when torture is added, has an inciting rather than a deterring influence upon the large number of potential criminals. I believe that the lynching of Negroes at Palmetto tended to create the animosity out of which the crimes of Hose sprang, that the tortures and death of Hose tended to create the feeling out of which the crimes at Bainbridge, Darien, and elsewhere sprang. Along such a road one can see no end but a precipice.

During the Middle Agés such terrible events as have occurred sporadically at the South of recent years were frequent expressions of religious hatred. With the beginning of the sixteenth century, religious animosities 


\section{The American Race Problem}

receded into the background, and race animosities, resulting from the interpenetration of higher and lower races, came into prominence. The hatred between Catholic and Protestant in Europe appeared in the colonies as hatred between whites, reds, and blacks. Powerful as these modern race passions are in the southern United States, they are, perhaps, stronger in the Southern Philippines, where religious hatred and race hatred, the medieval and the modern hate par excellence, concur and reënforce each other. One may perhaps forecast the future increase of race hatred between the lower classes of the two races in the South, if the trend be not changed, by reflection upon the attitude of certain Mohammedan Malays toward Christian Caucasians in the Philippine Islands as described by Professor Worcester.

"Finally, there was a rumour that a band of juramentados was about to attack the place. Now a juramentado is a most unpleasant sort of individual to encounter. The Moros believe that one who takes the life of a Christian thereby increases his chance of a good time in the world to come. The more Christians killed, the brighter the prospect for the future, and, if one is only fortunate enough to be himself killed while slaughtering the enemies of the faithful, he is at once transported to the seventh heaven.

"From time to time it happens that one of them wearies of this life, and, desiring to take the shortest road to glory, he bathes in a sacred spring, shaves off his eyebrows, dresses in white, and presents himself to a 


\section{Negro Criminality}

pandita to take a solemn oath (juramentar) to die killing Christians. He then hides a kris or barong about his person or in something that he carries, and seeks the nearest town. If he can gain admission, he' snatches his weapon from its concealment and runs amuck, slaying every living being in his path, until he is finally himself dispatched. So long as the breath of life remains in him, he fights on.

"Eye-witnesses have repeatedly informed me that they have seen juramentados seize the barrel of a rifle, on being bayoneted, and drive the steel into themselves further, in order to bring the soldier at the other end of the piece within striking distance and cut him down.

"The number of lives taken by one of these mad fanatics is sometimes almost incredible, but he is eventually killed himself, and his relatives have a celebration when the news of his death reaches them. They always insist that, just as night is coming on they see him riding by on a white horse, bound for the abode of the blessed."*

The white Caucasians of the Philippines regard a juramentado as a peculiarly fiendish criminal; many of the brown Malays regard him as a saint and emulate his deeds. The white Caucasians of Georgia regard Sam Hose as a peculiarly fiendish criminal; many of the black Africans, I fear, regard him as an innocent man and a martyr. As this point is of much importance for my argument, and will not meet ready acceptance among those who, like myself, are convinced of his guilt, I offer all the evidence on both sides that I have secured.

* Worcester, "The Philippine Islands," pp. 175, ff. 


\section{The American Race Problem}

I have talked with two Negroes of national reputation and of the highest standing among the best members of both races. Each doubted that Sam Hose was guilty of rape, and yet neither was willing to express that doubt over his own name. A well-known representative of a Northern paper went South to report upon the facts, and during his investigation had a meeting with a dozen or more representative Negroes of Atlanta, to get their point of view. Both by him and by another of those present I am assured that none of the Negroes at the conference was convinced of the guilt of Sam Hose. To this evidence should be added that of the detective employed by the Negroes, and probably reflecting their beliefs. On the other side the only important testimony that has reached me is contained in a letter from ex-Governor Atkinson, written shortly before his death: "I have delayed answering your inquiry, in order that I might talk with some of the white and coloured people from that section of the country in a confidential way. . . The investigation made by me satisfies me that there is no reason for the doubt expressed by you in your letter. The Negroes with whom I have talked would have had no hesitancy in giving me the information asked for, as in each case I assured them that their names would not be used and that I did not wish their personal opinion, but wished to know what the other Negroes thought. One of my informants was a Negro client of mine, who is a well-to-do man living in that neighbourhood, knows the opinion of the coloured people, and I know would not hesitate to have told me that the Negroes doubted 


\section{Negro Criminality}

Hose's guilt if such doubt had existed." Even this evidence, strong as it is, does not outweigh in my mind that on the other side These Negroes may have been unwilling to speak the truth even to Governor Atkinson upon a matter on which feeling was so tense or they may have been representative of the class of Negroes in close touch with the whites and more ready than others to derive their beliefs from that source, or it may be that in the Negro community where the Cranfords and Sam Hose were known belief in his guilt is more prevalent than elsewhere. On the whole, therefore, I conclude that a large proportion of the Negroes of Georgia do not share the belief of their white neighbours about the guilt of Sam Hose.

In a recent appeal to the people of Georgia the Governor said: "Lynch law does not stop arson or murder or robbery or rape;" and the Atlanta Constitution said editorially: "The punishment of the criminals who are overtaken, no matter how swift or how bloody, seems to have no effect whatever on the criminal class among the Negroes. They seem to go as cheerfully about their crimes as if they were candidates for a martyr's crown; they murder, ravish, and rob with all the zeal and fervour of religious fanatics." These opinions testify to a growing disbelief among whites in the efficacy of lynch law as a deterrent. As force is failing, some other means must be enlisted in defence of civilisation. In slavery days such crimes were almost unknown, and mainly because of the loyalty of the slaves to their owners. Any effort on the part of members of either race to break down 


\section{The American Race Problem}

those barriers between them, which have been reared under Reconstruction and race competition, and to restore the former relations must be of service. But, if this divergent trend of the two races continues, the only effective means of governing the criminal Negro is through the coopperation of the better elements of his own race. Negro criminals have little regard for the condemnation of whites, whom they have learned to hate. Their feeling toward the better class of coloured men cannot be of the same sort. The Atlanta Constitution recently appealed to the Negroes as follows: "The honest, industrious, and self-respecting Negroes - . should take some measure calculated to deter the criminals of their colour from their horrible work. . . . The Negroes would have little trouble in reaching the ears of the criminals. . . The Negroes alone can put an end to a condition of affairs that is growing worse every day." I believe this to the full, but I also believe that the whites cannot win this coöperation from the Negroes unless they are prepared to give a quid pro quo.

After the killing of Sam Hose, the Governor of Georgia is reported to have said: "The Negroes of the community lost the best opportunity they will ever have to elevate themselves in the estimation of their white neighbours. Had they helped to bring Hose to justice, it would have helped the cause in the eyes of the people. . . The good and law-abiding Negroes must aid in bringing criminals to justice, whether they be white or black." If Governor Candler was correctly reported and weighed his words, he clearly implied a belief that 


\section{Negro Criminality}

Hose was brought to justice when he was illegally put to death. Killing by a mob for any offence, however hateful, is regarded even by conservative and orderloving Negroes as an injustice, and, where there is a tacit understanding in the community, as there was during the pursuit of Hose, that the criminal if caught will be lynched, nothing more than quiescence can be secured from the Negroes. If my conclusion is correct, the Southern whites must choose in such cases between gratifying a strong and natural desire for immediate retaliation, and coolly selecting the course which is best adapted to prevent such crimes in the future. I believe that ex-Governor Atkinson, in dissuading the mob from burning Hose at the stake and urging them to let the law take its course, was choosing the wise way of preventing such crimes in the future, was the real defender of Southern homes and Southern women.

Now it seems clear that the guilt of Sam Hose was established by more convincing evidence than is secured in nine cases out of ten, perhaps in ninety-nine out of one hundred, in which a lynching occurs. If this evidence has failed to convince a large proportion of Southern Negroes, including probably nearly all those of criminal tendencies, then in other cases, where the evidence is less conclusive, they must be less convinced. What the facts are is of less importance than what they are believed to be, for belief, not fact, is the motive by which men are swayed.

To make my conclusions upon this subject clearer, I may briefly state certain views with which I cannot agree: 


\section{The American Race Problem}

I. I cannot accept a large proportion of the accounts printed in Northern papers, describing the relations of the two races in the South. One of the virtues of civilisation imperfectly developed in the Negro race is veracity, and accounts coming from them must be tested carefully before acceptance. Where nothing is known regarding the trustworthiness of the witnesses or the inherent probability of the statements, the presumption is in favour of the white man's testimony. Hence those newspapers which apparently make the contrary presumption are often misled. One instance which came under my own observation may serve for a hundred. A lynching occurred in 1899 at Alexandria, Va., within five miles of the national capital. A Washington correspondent of the Boston Transcript described the facts, and said that the Negro boy was guilty of nothing more than insulting a child. The Springfield Republican reprinted the letter, and in editorial comment said that the boy's only crime was his colour. I went at once to the mayor of Alexandria, and learned from him that at a hearing over which he presided the eight-year-old girl testified that the Negro had been guilty of indecent familiarities upon her by force. Probably any Southern jury, on hearing the child's testimony, would have found the Negro guilty of an attempt to commit rape. Yet representative Northern newspapers in reliance upon their sources of information have seriously misrepresented the facts.

2. On the other hand, I cannot admit that all or most of the alienation between the races is due to the grave 


\section{Negro Criminality}

mistakes of the Reconstruction period or to the present policy of Northern papers. Race antagonism appears in other parts of the country, and in other countries, where this cause does not exist. To ascribe race friction at the South, as certain Southern writers and speakers do, solely or mainly to the past or present policy of the Government toward the Southern states or to the tone of Northern papers, and then to say almost in the same breath that race friction and lynching are found in the North, is clearly inconsistent. The friction between the races was probably an inevitable result of emancipation, although hastened and intensified by the blunders of Reconstruction.

3. It seems improbable that the policy of enlisting Negroes as Federal soldiers has had a decided effect in increasing Negro crime. Certainly, the evidence offered in favour of this claim is by no means sufficient to establish the conclusion.

4. A restricted suffrage in the Southern states will probably not avail materially to improve the conditions. Negro crime is apparently about as frequent and heinous in the District of Columbia, where for a generation the race has had no political privileges, as it is in the states of the far South.

5. Education, in the ordinary sense of that term, will not materially improve the situation. An education which will aid the Negro in securing self-support is of primary importance.

6. No Federal legislation, such as that demanded by certain Negroes against lynching or that demanded by 


\section{4 \\ The American Race Problem}

certain of both races making large appropriations for deportation of the Negroes, seems likely to be enacted or offers a real and adequate solution of the problem.

Positively, I may sum up my conclusions as follows:

A large and increasing amount of Negro crime is manifested all over the country.

This raises a problem pressing with especial weight upon the states where Negroes are numerous.

The causes may be grouped as defective family life, defective industrial equipment and ability in comparison with their competitors, increasing race solidarity among the Negroes, and increasing alienation from the whites.

Southern whites often exaggerate the agency of Northern whites or Northern Negroes in causing the present condition, and thus minimise their own responsibility.

Northern whites often ignore the burden which Southern whites and the better class of Negroes are carrying and the degree to which the Federal policy since the war has contributed to increase race friction and Negro crime. Hence they are often ignorant and unjust in their criticisms.

These misunderstandings are the strongest basis for the continuance and possible increase of sectional antagonism between North and South.

Lynching is harmful mainly because it prevents the rise of a public opinion based on a careful sifting of the facts. Where practised under any provocation, however great, by members of one race upon those of another, it fosters the development of separate public opinions, 


\section{Negro Criminality}

one for each race, and hence tends to make coöperation of the two in one government impossible.

There has probably never been a more complete democracy than in the New England towns. Modern governments tend toward a more democratic form, and at the North the belief is very deep seated that the progress of humanity is dependent upon the maintenance and progress of democratic government. Now democratic government is essentially a government by organised legal public opinion. Any attempt to introduce government by disorganised public opinion secures at best the will of only a fraction of the public. Hence a believer in democracy is bound to be an opponent of lynch law, and the strength of the opposition in the North to lynch law is due, not as is sometimes said to hatred of the South, but rather to a love for democracy.

The greatest problem which modern democracy has to face is perhaps this: Can the democratic forms developed among a homogeneous people with unifying traditions, like the people of England, Old and New, be extended to people widely different in race, religion, and ethical and social code? Can English forms of government ultimately apply to India and Egypt and South Africa? Can American forms be extended to the two races at the South or in the Philippines? Either the public opinion of one race must dominate, as that of the whites has done in India and the South, or the two races must coöperate so far as to develop a common public opinion. The latter is the only true democracy. 


\section{Census Statistics of the Negro*}

7 HERE is no leading country in which the relations of widely different races are so important as in the United States. As a natural result of this, there is no country in which statistical investigation of race questions is so highly developed, or in which the records cover so long a time. In Europe it is not customary to recognise or emphasise the race classification of the population in statistical returns. In India the race classification while recognised is subsidiary to that of religion and of language. In American countries to the south of the United States, where race relations are as complex and as diverse as theyarewith us, the statistical method is imperfectly developed or of recent introduction. The main sources of statistical information, therefore, regarding race relations are the figures for the United States and those for several of the West Indian Islands.

Since the Civil War the statistical study of certain aspects of race questions in the United States has been entered upon by different governmental agencies. The Department of Agriculture has made investigations of the diet and food supply of Negroes and of whites with especial reference to the bodily heat and the energy it

* Yale Review, November, 1904. 


\section{Census Statistics of the Negro}

can produce. The Department of Labour has made a number of suggestive reports upon the condition of Negro communities in certain typical localities. Various municipal health reports throw light upon the vital statistics of the two races. The Bureau of Education has gathered much information regarding the educational development of Negroes and whites. But no one of these and perhaps not all of them combined have furnished or are furnishing at the present time as much information regarding the statistics of race in the United States as the Census Bureau.* It is of the highest importance that the information thus gathered should be carefully and intelligently interpreted and its lessons correctly read. The object of this paper is to state certain conclusions to which I have been brought by my statistical studies of the subject and especially of the recent census figures.

The population of the United States is divided by the census returns into four classes, the native white of native parents, the native white of foreign born parents, that is, the children of immigrants, the immigrant or foreign born white class, and the other races than the white, sometimes called collectively the coloured, perhaps more accurately described as the "non-Caucasians." The most accurate description of them is to enumerate the great races to which they belong, namely, the Negro, Indian, and Mongolian. Of this fourth group, the non-Caucasians, more than nineteen-twentieths

\footnotetext{
* See especially Census Bulletin 8, entitled "Negroes in the United States," Washington, 1904.
} 


\section{The American Race Problem}

are Negroes and therefore when statements are made, as I shall be compelled sometimes to make them, not for the Negroes but for the non-Caucasians, it will be understood that nineteen-twentieths of these are Negroes and what is true, therefore, of the non-Caucasians is probably true of the Negroes. These four classes correspond roughly to four grades of economic well-being - the native white of native parents at the top, the Negroes, Indians, and Mongolians at the bottom. Now it is a general fact that the lower the scale of economic wellbeing the less accurate on the average will be the answers to questions put them. A measure of this can be derived from the answers to the age question. It can be easily proved that the errors in reporting ages among the immigrant white are about twice as numerous as among the native white and among the non-Caucasians about twice as numerous as among the immigrant white. Where age is stated erroneously it is usually stated at a round number as a multiple of 5 . The excess in the reported number at these multiples of five over the estimated true number is thus a measure of the accuracy of the figures. This excess in r 900 among persons between twenty-eight and sixty-two years of age inclusive for the native whites was 12.4 per cent. of the total estimated number at multiples of 5 , for the foreign born white 29.8 , and for the Negro $8 \mathrm{r} .2$ per cent. What is true of the inaccuracies in the field of age statistics is probably true of other sorts of inaccuracies. A larger proportion of the Negro population than of the white is homeless and therefore likely to be omitted by enumerators instructed 


\section{Census Statistics of the Negro}

to visit every home in the country. In Maryland a careful recount of nearly 63,000 people was had a few months after the census day in the effort to detect suspected fraud. The recount showed that in the original count the omissions among Negroes had been 3.7 per cent. and among whites $\mathrm{r} .3$ per cent. These omissions were probably greater than in the general population, but it is not unlikely that the per cent. of omissions among Negroes is twice as great as the per cent. among whites.

There is no race question upon which we have so great a lack of scientific information at the present time as that of the degree of direct intermixture of the two races. Public opinion at the South seems to be almost unanimous in its belief that, since the Civil War and emancipation, intermixture of the two races has decreased and that the mulatto population at the present time is largely the offspring of mulattoes alone or of mulattoes and Negroes, and that there has been relatively little new infusion of white blood. But no statistical basis for this opinion exists, and general observation on a question so difficult and delicate must be regarded as a very slippery foundation for the belief. Questions on this point were introduced into the censuses of $185^{\circ}$, $\mathrm{r} 860,1870, \mathrm{r} 880$, and $\mathrm{r} 890$, and the results were tabulated and published for each of these censuses except 1880 . Prior to 1890 the question was asked in substantially the same terms, that is, simply the number of mulattoes. In I890, unfortunately, it was sought to amplify the question and Congress required the Census Office to 


\section{The American Race Problem}

report the number of mulattoes, quadroons, and octoroons. Such precision in this field is unobtainable and, in natural reaction against the misleading results obtained in 1890 , the office in I 900 omitted the question entirely. I cannot feel that this was wise. The results obtained in $185^{\circ}$, I 860 and 1870 for the whole United States showed substantial agreement, the per cent. of mulattoes among the total Negroes having been reported as in I850, I1.2; in 1860, I3.2; in I870, 12.0. These figures cannot be accepted as showing an increase in the proportion of mulattoes down to the Civil War and a slight decrease after that time, much less can the slightly larger proportion of mulattoes reported in 1890 (r 5.2 per cent.) with a different form of question be regarded as any evidence of an increase of race mixture since emancipation, but the general conclusion that between one-eighth and one-ninth of the Negro population at about the time of the Civil War was mulatto may be regarded as probable.

I believe that, if the question should be repeated in I 910 in substantially the same terms as those employed in $1850,1860,1870$, and 1880 , the results would be likely to indicate far more accurately than general observation can do whether the proportion of mulattoes among the Negroes has increased or decreased since emancipation. To establish this, one need not believe that the reported percentages at former censuses were correct. All that would be necessary for such a result would be that the question put in substantially the same terms at intervals during half a century would secure answers which 


\section{Census Statistics of the Negro}

if not entirely accurate would at least err in the same direction and by about the same relative amount.

At the present time there are about nine and onefifth million Negroes under the United States flag, including those in Porto Rico, Alaska, and Hawaii, as well as the Negroes of continental United States. This does not include the Negritoes, much less the Malays, of the Philippine Islands. In continental United States, excluding Alaska and our insular accessions, there are about eight and five-sixths million Negroes. Nearly nine-tenths of them (89.7 per cent.) live in the Southern states, that is, the states south of Mason and Dixon's line, the Ohio River and the parallel of the southern boundary of Missouri. The per cent. living in the Southern states, however, is very slowly decreasing. In I860, 92.2 per cent. were living there; in $1880,90.5$ per cent.; in $1900,89.7$ per cent., or in other words, in 1860 , 78 Negroes among each 1,000 in the country were living outside of the South, in I900, I03 in each $\mathrm{I}, 000$. Apparently there was a considerable change in the distribution of the Negroes as a result of the upheaval in the Civil War. Then followed a period of relative quiescence, but in the last decade of the century there was an increase in the northward current of Negro migration, especially to northern cities. That the Negro population in our large cities is increasing with greater rapidity than the white population appears clearly when the totals of the two races are obtained for the thirty-eight cities, each of which had at least 100,000 inhabitants in 1900 . The increase of Negroes in these cities, I890 to I 900 , was 


\section{The American Race Problem}

38.0 per cent., and that of whites 32.7 per cent., and in the five Southern cities of this class, Baltimore, Washington, Louisville, Memphis, and New Orleans, the increase of whites was 20.8, and of Negroes 25.8 per cent. Washington was the only Southern city of this class in which the Negro population did not increase, 1890 to I 900, with greater rapidity than the white. This rapid increase of the Negro population in the larger cities of the country is the more significant, because thirty-three of these thirty-eight cities lie in the north and west and therefore increase of their Negro population usually results from long-distance migration, and because also the Negro population of smaller cities and of country districts has been increasing as a rule less rapidly than the white population.

There is no traceable tendency to a separation between Negroes and whites in the South whereby the Negro population is becoming more predominant in the rural districts and the white population in the cities. Perhaps the best evidence on this point is that derived from the 242 cities in the South Atlantic and South Central states, which had at least 2,500 inhabitants both in 1890 and in 1900 , and for which, therefore, the race composition of the population was separately returned. The Negro population of these 242 places increased between I 890 and 1900 by 21.7 per cent., the white population by 26.5 per cent. The Negro population of the rest of the Southern states outside these 242 places increased I6.4 per cent., while the white population outside these 242 places increased 25.0 per cent. The figures show the 


\section{Census Statistics of the Negro}

remarkable fact, which so far as I know is unparalleled, that the growth of white population in the South has been almost as rapid in the country districts as in the cities. Whether this means that the white population is betaking itself more to agriculture, it would be difficult to decide from the figures. The Negro population is increasing in Southern cities about one-third faster than in country districts. Or, the facts may be stated perhaps more intelligibly in this way. In the 242 Southern cities for which the race figures are distinguished both for 1890 and for 1900 , there were in 1890,464 Negroes to $\mathrm{x}, 000$ whites; in 1900 there were 447 , a decrease of $\mathrm{I} 7$. Meantime, in the country districts there were in 1890 , 522 Negroes to I,000 whites, and in I 900 there were 486 , a decrease of 36 . These figures show that the decrease in the proportion of Negroes relative to whites in the Southern states in the last decade has been twice as rapid in the country districts as in the cities.

In studying the increase of the Negro population it must be borne in mind that the figures of 1870 are admitted to be seriously inaccurate. There are some reasons also for doubting the accuracy of the census of the Negroes in 1890 . In order to avoid using these erroneous or questionable figures and also in order to base the computation on long periods of time, the increase has been computed for each of the five twentyyear periods of the nineteenth century. As the Negro problem is preeminently one of interest to the South it seems fairer to compare the growth of the two races in that region. Such a comparison shows that the Negro 


\section{The American Race Problem}

population of the South increased most rapidly during the first twenty years of the nineteenth century and that its rate of increase steadily declined to the end of the century. The rate of increase of Southern whites was highest not from I 800 to I 820 , but I 840 to 1860 . Perhaps the results may be stated in a way to make them most easily intelligible by treating the rate of increase of whites in the Southern states in the given twenty-year period as 100 and comparing with it the rate of increase of Southern Negroes during the same period of time. Following this method, the increase of the Southern Negroes, I 800 to 1820 , was to that of Southern whites as I 25 to Ioo, that from I 820 to I 840 was I Io, that from I 840 to I 860 was 87 , that from I 860 to I 880 was 90 , and that from 1880 to 1900 was 57 . These figures show that since 1840 the increase of Southern Negroes has been less rapid than that of Southern whites, and that the increase from I 860 to 1880 was relatively more rapid than in the preceding or the following twenty-year period, suggesting that the period of war and of Reconstruction affected the increase of the white race more than that of the Negroes. At the beginning of the nineteenth century the Southern Negroes were increasing much faster than the Southern whites. At the end of it they were increasing only about three-fifths as fast.

But to complete the presentation of the results reached by the Census Bureau on this point, it should be added that if the results for the last twenty-year period be analysed by decade's a different conclusion is indicated. Comparison of the rates of growth of Southern 


\section{Census Statistics of the Negro}

Negroes and Southern whites for those two decades shows that the rate of increase for Southern Negroes, 1880 to I 890 , was to that of Southern whites as 55 is to 100 , while in the decade from I 890 to I 900 it was as 68 to Ioo. I confess myself skeptical of the accuracy of these figures. It is difficult for me to accept results which show on their face that the rate of increase of Southern whites east of the Mississippi River was less, 1890 to I 900 , than it was I 880 to I 890 , the rate falling from I 9.1 to 18.7 , while that for Southern Negroes in the same area was much greater in the second decade, the rate rising from 10.6 to 15.7 . At the same time I see nothing better at present than to mark these figures as questionable and to suspend judgment until the results for I 9 Io are published. It may be that the increase among the Negroes has been affected by the marked prosperity of the South in recent years and has been affected more conspicuously than the figures for the whites.

With reference to sex, it may be noted that there is an excess of females among the Negro population of the United States, while this is not true either of the Indians or of the native whites. Strangely enough, this excess of females is found even at the very earliest ages. It is a general rule that the number of male children born exceeds the number of female. Among roo children born, on the average about $5 \mathrm{I}$ are male and 49 female. The scanty records of births in cities where the Negroes constitute a considerable element of the population show that in this respect the Negroes conform to the rule. Yet Negro children even at the very earliest ages, as 


\section{The American Race Problem}

enumerated by the census, show an excess of females over males. This is true of Negro children under one month, and of each of the four other subdivisions of age under one year. Indeed, it is true for every year of age up to nine. It may be noted that this anomaly appears for the first time in the figures for I goo. Whether it is due to the fact that that census first made the distinction between Negro population and the total coloured, including the Indians and Mongolians, I am unable to say.

In the city population of the United States as a rule, females outnumber the males. This generalisation holds true of the great majority of cities east of the Mississippi River. It is more true of the Negroes than it is of the whites. In the Southern cities and towns having at least 2,500 inhabitants in 1900 , there were 9 more Negro females than males in each roo of Negro population. Among children the two sexes were approximately equal in numbers, so that if the figures allowed us to exclude the children the preponderance of females would be still greater. The cause is doubtless to be found in large measure in the greater demand and greater opportunity for female labour in cities.

At the present time rather more than half of the Negroes over ten years of age are able to write. The per cent. of illiteracy has decreased rapidly in the last ten years. In r890 it was 57.1, while in I 900 it was 45.5 . This rapid decrease in Negro illiteracy has gone on parallel with the rapid decrease of illiteracy among whites. At the present time the Negroes as a race show about seven times the proportion of illiterates that the whites 


\section{Census Statistics of the Negro}

do and about four times the proportion of illiterates found among Southern whites, and these ratios between the two races have not materially changed since 1890 . Illiteracy is much more prevalent in the country districts than it is in the cities. About half of the Negroes living outside cities having at least 25,000 inhabitants are illiterate, while in these cities less than one-third are illiterate. The rapid development of the educational system among Negroes in the South has left clear traces upon the proportion of illiterates in the several age classes. The highest proportion of illiterates is found among Negroes at least sixty-five years of age, the lowest among Negroes ten to fourteen years of age. The difference between these two age limits is rather greater than the difference between city and country Negroes, the illiteracy of all Negroes over sixty-five being rather greater than that of Negroes in country districts, and the illiteracy of Negroes between ten and fourteen years of age being rather less than that of all Negroes living in cities having at least 25,000 inhabitants. If the per cent. of illiteracy among Negroes should continue to dwindle in the future as rapidly as it did, I 890 to 1900 , an improbable contingency, Negro illiteracy would disappear by 1940 .

No noteworthy results appear from the statistics of marital condition among the Negroes. They correspond closely with the statistics for Southern whites, the main differences being that the race has a very much larger proportion of widowed and divorced persons and that in the last ten years there has been a decline in the propor- 


\section{The American Race Problem}

tion of adult Negroes who were married, while among Southern whites there has been an increase in the proportion who were married. Both races show a decided increase in early marriages, this being true for the country as a whole and probably the result of the high prosperity which prevailed immediately before I 900 .

Perhaps the most important suggestions derived from the analysis of the figures for the Twelfth Census are found in the statistics of occupations. The detailed results of these must be regarded as open to some question since the classification of occupations is perhaps as difficult a problem as any with which the Census Bureau has to grapple, and it is possible that the figures for 1890 and I 900 may not be strictly comparable in all cases. Still certain salient results appear to be established.

Among all the Negroes at least ten years of age about five-eighths, 62.2 per cent., are engaged in money-getting or gainful occupations. The corresponding proportion among Southern whites is less than one-half (46.9 per cent.). The difference between the two races is almost entirely explained by the greater prevalence of moneygetting occupations among female Negroes, 4r.3 per cent. of the Negro females and only ir. 8 per cent. of the Southern white females reporting a gainful occupation. This fact accounts for about three-fourths of the entire difference between the Negroes and the Southern whites. An explanation of the remaining fourth is found in the fact that Negro boys go to work earlier and Negro men retire later than white men. In general it may be said that the lower the earning capacity of a productive class 


\section{Census Statistics of the Negro}

the greater the quantity of labour required for its support; the greater the prevalence, therefore, of female labour, of child labour, and of the labour of old men. Part of this greater prevalence of child labour and old man labour is due to the fact that the Negroes are predominantly engaged in agriculture and that this industry affords greater opportunities than most others for the work of children and old men. Yet this fact only partly accounts for the difference.

The most important specific occupations for the Negroes are those of agricultural labourers, farmers, planters and overseers, and labourers not specified. These three classes are probably more numerous than the total number of persons engaged in agriculture, for the number of labourers not specified who were engaged in other occupations than agriculture is probably greater than the number of persons engaged in agriculture and not enrolled in any one of these three occupations. The total number of Southern Negroes, with the few Indians and Mongolians engaged in this line of industry increased between 1890 and 1900 by 30.4 per cent., the Southern whites in the same occupations increasing in the same period by 43.5 per cent. As a result the non-Caucasians constituted in 189044.4 per cent. of the population in these classes, while in 1900 they constituted 42.0 per cent. These three classes together include two-thirds of all the Negro breadwinners. In a number of specific occupations involving some degree of skill, the non-Caucasians in the South constituted a somewhat smaller proportion of the total 


\section{The American Race Problem}

number of labourers in the South in I 900 than they did in 1890 . This statement holds true for launderers and laundresses, carpenters, barbers, tobacco and cigar factory operatives, and engineers and firemen (not locomotive). In some other leading occupations the Negroes were more numerously represented in I 900 than in 1890 . These include in the professional classes, teachers and clergymen, and in the skilled labour classes, miners and quarrymen and iron and steel workers.

While the future of the Negro race in the United States seems to be essentially an industrial and economic question, turning upon their efficiency in comparison with classes of the population who compete with them in their staple occupations, the net results of these various and complex industrial changes can perhaps best be measured by the vital statistics of the race. The Census Bureau has no direct information regarding births or marriages. Its information regarding deaths is confined to the Negro population living in the registration area and amounting to between one-seventh and oneeighth (I 3.4 per cent.) of the entire Negro population of the country, over 93 per cent. of it living in cities. The death-rate of Negroes in the registration area in 1900 was reported as 30.2 per thousand, that of the whites in the same area being I7.3. But of the Negroes in this area the majority were female and the female is the healthier sex. They were also predominantly adult and the adult years are the healthier ages. To allow for these differences a computation has been made to ascer- 


\section{Census Statistics of the Negro}

tain what the death-rate for the Negroes for the whole country would be, if the death-rate observed in the registration area for each sex and each age had been true of the Negroes of that sex and age in the country as a whole. On this basis the estimated Negro deathrate of the United States as a whole is 34.2 instead of 30.2 per thousand, or just about double that of the whites.

In 1890 the death-rate of the Negroes in the registration area as distinguished from the Indians and Mongolians was not computed. That of the three races combined, nineteen-twentieths being Negroes, was in 189029.9 , and in $1900,29.6$ per thousand, a decrease of three deaths per ten thousand. In the same area the death-rate of whites in 1890 was 19.1 and in $1900,17.3$, a decrease of 18 per ten thousand. It is uncertain how far these figures may be accepted as indicative of the actual changes. They are submitted not as entirely trustworthy, but as the best information available.

Indirect evidence of the birth-rate among the Negroes may be obtained by computing the number of children under five years of age to each 1,000 women fifteen to forty-four. These computations show a very marked decline between $\mathrm{I} 880$ and $\mathrm{I} 900$ in the proportion of Negro children, but show that the proportion of children at the present time is greater for Negroes than for whites.

But when the country is considered in sections, separating the population of the South from that of the 


\section{The American Race Problem}

North, different results appear. Negroes, as a whole, have a larger proportion of living children than whites, but paradoxical as it may seem, it is also true that Southern Negroes have at present a smaller proportion of living children than Southern whites, and Northern Negroes have a smaller proportion of living children than Northern whites. In other words, the difference in the proportion of children stated in the preceding paragraph, is fundamentally a geographical or sectional difference and not a racial one. Negroes have a high proportion of children not because they are Negroes, but because nine-tenths of them live in the South and show the effect of influences which establish a high birth-rate there. The South at the present time is increasing in population faster than the North, with all its immigration, largely because $\mathrm{r}, 000$ white women at the North, fifteen to forty-four years of age, could show at the census only 470 children under five years of age, while at the South I,, 00 Negro women of those ages could show $62 \mathrm{I}$ children, and $\mathrm{r}, 000$ white women 633 children. In the Southern states prior to the Civil War the proportion of children under five years of age to 1,000 women of childbearing age was about the same for the two races. The immediate result of the Civil War, emancipation and Reconstruction, was to decrease slightly the number of white children and increase the number of Negro children, so that in $\mathrm{I} 880$ for $\mathrm{I}, 000$ women of the specified race and of child-bearing age, there were in the South 82 more Negro than white children. In 1890 the difference in favour of the Negro race had sunk to 17 , and in 


\section{Census Statistics of the Negro}

I 900 it had disappeared and been replaced by an excess of $\mathrm{I} 2$ white children.

The American Negro, after the turmoil of Civil War and Reconstruction, found himself thrown on his own resources as he had never been before. This occurred at the beginning of a period of rapid, almost revolutionary, industrial change in the South, a change which did not at first affect seriously the staple crops upon which most of the Negro's labour as a slave had been spent, but which apparently is beginning to affect even those. In seeking other avenues of self-support than agriculture and domestic service, he is seriously handicapped by unfamiliarity with such work, a lack of native aptitude for it, so it is alleged, absence of the capital often requisite, and a preference on the part of most of the whites, even when other things are equal, as they seldom are, to employ members of their own race. In the industrial competition thus begun the Negro seems during the last decade to have slightly lost ground in most of those higher occupations in which the services are rendered largely to whites. He has gained in the two so-called learned professions of teachers and clergymen. He has gained in the two skilled occupations of miner or quarryman and iron or steel worker. He has gained in the occupations, somewhat ill-defined so far as the degree of skill required is indicated, of sawing-mill or planing-mill employee, and nurse or midwife. He has gained in the class of servants and waiters. On the other side of the balance sheet he has lost ground in the 


\section{The American Race Problem}

South as a whole in the following skilled occupations: carpenter, barber, tobacco and cigar factory operative, fisherman, engineer or fireman (not locomotive) and probably blacksmith. He has lost ground also in the following industries in which the degree of skill implied seems somewhat uncertain: laundry work, hackman or teamster, steam railroad employee, housekeeper or steward. The balance seems not favorable. It suggests that in the competition with white labour to which the Negro is being subjected he has not quite held his own.

These figures of occupations seem to me to furnish the best statistical clue yet obtained for an understanding of the industrial and social changes affecting this question in the South. My interpretation of their meaning might be criticised on the ground that when the Negroes are increasing more slowly than the whites, as they are at present in the South, it should not be expected that they would increase as fast as whites in the skilled occupations. This objection seems to me to invert the true order of causation, to put the cart before the horse. Should we not rather say that Southern Negroes are increasing at the present time only twothirds as fast as Southern whites, while from I 800 to $\mathrm{I} 840$ they increased faster and from 1840 to I 880 nearly as fast, because they are not succeeding in entering new occupations or prospering as well in their old as the competing race is doing?

If this view of the process is correct, then one may add in closing that, as these occupation figures throw much 


\section{Census Statistics of the Negro 495}

light upon the causes, so the figures of an almost stationary death-rate for Negroes compared with a rapidly decreasing death-rate for whites, and an apparently declining birth-rate for Negroes compared with an actually increasing birth-rate for Southern whites, are the best statistical keys to its effects. 


\section{III}

The Probable Increase of the Negro Race in the United States*

T N THE century-long problem of the adjustment of 1 relations between whites and Negroes in the United States the probabilities regarding the increase of each race constitute an important element. Those relations are influenced in manifold ways by the numerical proportion of the races in the country as a whole, and in its various divisions. Consequently the question of the relative growth of the two races in the near future is one of much importance. The factors controlling it are not well enough known to make any accurate forecast possible, yet perhaps we are now in a position to anticipate the course of events in this field during the century just beginning, with closer truth than has yet been done.

A starting-point may be found in certain opinions that have been expressed and controverted since the Civil War. In articles published in 1883 and 1884 , and based mainly upon the census figures for 1870 and $1880, \dagger$ Professor E. W. Gilliam estimated the probable Negro population of the Southern states alone in 1980 at I $92,000,000$ (or about $200,000,000$ in the entire country).

\footnotetext{
* This paper gives the substance of a lecture delivered at Harvard University in April, 1905.-From the Quarterly Journal of Economics, August, 1905.

†Popular Science Monthly, Vol. XXII, pp. 433-444, and North American Reviow, Vol. CXXXIX, pp. 4I7-430.
} 


\section{The Probable Increase}

He estimated the probable number of whites in the country in 1985 at $336,000,000$. In other words, he predicted that before the end of the twentieth century the Negro race would amount to three-eighths of the total population of the United States. The errors in the bases on which this conclusion was rested, and the fallacies in the arguments by which it was supported, have been effectively exposed $*$ and do not need to be restated.

In a book published in $1899 \mathrm{Mr}$. Booker T. Washington wrote: "I think I am pretty safe in predicting that the census to be taken in 1900 will show that there are not far from ten millions of people of African descent in the United States." $\dagger$ The number reported by the Twelfth Census fell short of this predicted number by more than $\mathrm{r}, \mathrm{r} 50,000$, and, even if those enumerated by the War Department in Porto Rico and Cuba are included, a total of only about 9,700,000 is reached. $\mathrm{Mr}$. Washington added: "It is my opinion that the rate of increase in the future will be still greater than it has been from the close of the War of the Rebellion up to the present time." $\ddagger$ The evidence against this opinion will be presented later. Neither in that book nor, so far as I know, elsewhere, does he attempt an estimate for the remoter future.

In a book published in $1904 \mathrm{Mr}$. Thomas Nelson Page wrote: "Unless conditions change, it is possible that

\footnotetext{
* Notably by Henry Gannett, in Popular Science Monthly, Vol. XXVII, pp. 145-150.

† "The Future of the American Negro," p. 5.

$\ddagger 1$ dem, pp. 6,7 .
} 


\section{The American Race Problem}

before the end of the century there may be between sixty and eighty millions of Negroes in this country." * And a little further on he adds: "It is true that prognostications of increase in a population often fail, but judging the future by the past and taking into account known racial characteristics, it would appear that the number thus prophesied will, in all human probability, exist in the United States by the end of the century." $\dagger$

The foregoing are all the estimates regarding the probable future increase of the Negro race in the United States which I have met with in my reading. Unsatisfactory as the evidence is, it points to a conclusion widely different from any of these. Disregarding the figures for Porto Rico, Hawaii, and Alaska, the table on the next page shows the Negro population of the United States at each of the twelve censuses, and the amount, rate and of increase by ten and twenty year periods.

This table shows that during the nineteenth century the Negroes of the United States increased, as a rule, by greater and greater amounts, but at a less and less rate. If attention is confined to the five twenty-year periods of the century, this rule is without a single exception. But, among the decennial increases, that from 1830 to I 840 was less than that from I 820 to 1830 , which was probably due to the emigration of many slaveholders with their slaves from the United States to Texas between 1830 and 1840 . That from 1860 to 1870 was not much above half that from 1850 to $\mathrm{x} 860$, for which

* "The Negro: The Southerner's Problem," p. 288.

† Idem, p. 289. 


\section{The Probable Increase}

TABLE I. Negro population and amount and rate of increase for Continental United States by ten and twenty year periods: 1790 to $1900 .{ }^{*} \quad$ (Unit $=$ I0,000.)

\begin{tabular}{|c|c|c|c|c|c|}
\hline \multirow{2}{*}{ Date of Census. } & \multirow{2}{*}{$\begin{array}{c}\text { Negro pop- } \\
\text { ulation. }\end{array}$} & \multicolumn{2}{|c|}{$\begin{array}{l}\text { Increase during } \\
\text { preceding }\end{array}$} & \multicolumn{2}{|c|}{$\begin{array}{l}\text { Per cent. of increase } \\
\text { during preceding }\end{array}$} \\
\hline & & ro years. & 20 years. & ro years. & 20 years. \\
\hline $\begin{array}{l}x 790 \ldots \ldots \ldots \ldots \ldots \\
1800 \ldots \ldots \ldots \ldots \ldots\end{array}$ & $\begin{array}{r}76 \\
100\end{array}$ & 24 & - & 32.3 & \\
\hline $1810 \ldots \ldots \ldots \ldots$ & 138 & 38 & 一 & $37 \cdot 5$ & \\
\hline $1820 \ldots \ldots \ldots \ldots$ & 177 & 39 & 77 & 28.6 & 76.8 \\
\hline $1830 \ldots \ldots \ldots \ldots$ & 233 & 56 & - & $3 \times .4$ & \\
\hline $1840 \ldots \ldots \ldots \ldots$ & 287 & 54 & $x \times 0$ & 23.4 & 62.2 \\
\hline $1850 \ldots \ldots \ldots \ldots$ & 364 & 77 & - & 26.6 & \\
\hline $1860 \ldots \ldots \ldots \ldots$ & 444 & 80 & $\times 57$ & $22 . x$ & 54.6 \\
\hline $1870 \ldots \ldots \ldots \ldots$ & 488 & 44 & - & 9.9 & \\
\hline $1880 \ldots$ & 658 & $x 70$ & 214 & $34 \cdot 9$ & 48.2 \\
\hline $1890 . \ldots$. & 748 & 90 & - & $\times 3.5$ & \\
\hline $1900 \ldots$ & 883 & $\times 35$ & 225 & 18.0 & 34.2 \\
\hline
\end{tabular}

the Civil War and the serious omissions at the census of 1870 must be held jointly responsible; and that from 1880 to 1890 was only about half the apparent increase from 1870 to 1880 . I am inclined to the opinion that the census of 1890 , like that of 1870 but to a much less degree, suffered from omissions in the South and especially among the Negroes. To give the reasons at length would require a separate article. The most important ones are suggested by the series in the foregoing table, and are strengthened when the increase of Negroes is compared with that of Southern whites and the rates of

* The exact census figures on which the per cents. are based and some minor explanations, unimportant for present purposes, will be found in Twelfth Census "Supplementary Analy sis and Derivative Tables," p. 202,

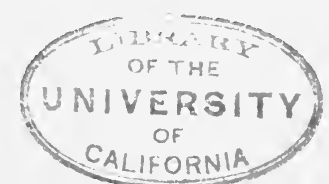




\section{The American Race Problem}

increase for the two races in city and country are separately computed.

For present purposes I have sought to correct Table I. by inserting estimates in place of the census figures of I870 and I890. For I870 I have taken the geometric mean of the figures for 1860 and 1880 . Normally, but for the Civil War, the rate of increase in the later decade would probably have been less than in the earlier. I assume, therefore, that the effect of the war was to concentrate all the slight reduction in the rate of increase which occurred between 1860 and I880, as compared with the rate between $I 850$ and 1860 , in the decade 1860 to 1870 , and make the rates in the decades 1860 to 1870 and $\mathrm{I} 870$ to $\mathrm{I} 880$ the same. This assumption raises the true number of Negroes in the United States in 1870 from 4,880,000 to 5,405,000, and makes the omissions of Negroes in that census 525,000. I believe the true number of Negroes in 1870 was in the neighbourhood of $5,400,000$, and probably less rather than greater. If the same method of estimation be employed to determine the probable Negro population of the United States in I 890 , the result is $7,622,000$ instead of $7,480,000$, indicating the omission of 142,000 Negroes by the Eleventh Census. But I see no reason, except the census figures, for believing that the rate of increase of the Negroes, which fell almost steadily between I 800 and I 890 , was as high between 1890 and 1900 as in the preceding decade. If any assumption at all is admissible, I believe it should be the assumption of a decreasing rate and a constant amount of increase; or, in other words, that the true 


\section{The Probable Increase}

figures of 1880, I 890 , and I 900 constitute an arithmetical rather than a geometrical progression. On this assumption the number of Negroes in the United States in 1890 was 7,705,000 instead of 7,480,000, and the omissions of Negroes at the eleventh census were 225,000. At any rate, these assumptions are plausible, and furnish a more uniform series than the unadjusted figures of the census upon which to attempt a forecast of the future.

The revised table is as follows:

TABLE II. Negro population and amount and rate of increase for Continental United States by ten and twenty year periods: I 790 to I 900 (Adjusted figures indicated by asterisks; unit $=\mathrm{10,000.)}$

\begin{tabular}{|c|c|c|c|c|c|}
\hline \multirow{2}{*}{ Date of Census. } & \multirow{2}{*}{$\begin{array}{c}\text { Negro } \\
\text { Pop- } \\
\text { ulation. }\end{array}$} & \multicolumn{2}{|c|}{$\begin{array}{l}\text { Increase during } \\
\text { preceding }\end{array}$} & \multicolumn{2}{|c|}{$\begin{array}{l}\text { Per cent. of increase } \\
\text { during preceding }\end{array}$} \\
\hline & & ro years. & 20 years. & ro years. & 20 years. \\
\hline $1790 \ldots \ldots \ldots \ldots$ & 76 & & & & \\
\hline$x 800 \ldots \ldots \ldots \ldots$ & roo & 24 & 一 & $32 \cdot 3$ & \\
\hline$x 810, \ldots \ldots \ldots \ldots$ & $\times 38$ & 38 & - & 37.5 & \\
\hline $1820 \ldots \ldots \ldots \ldots$, & 177 & 39 & 77 & 28.6 & 76.8 \\
\hline $1830 \ldots \ldots \ldots \ldots$ & 233 & 56 & - & $3 \mathrm{x} .4$ & \\
\hline $1840 \ldots \ldots \ldots \ldots$ & 287 & 54 & rIo & 23.4 & 62.2 \\
\hline $1850 \ldots \ldots \ldots \ldots$ & 364 & 77 & 一 & 26.6 & \\
\hline $1860 \ldots \ldots$ & 444 & 80 & 157 & 22.1 & 54.6 \\
\hline $1870 \ldots \ldots$ & $54 \mathrm{I}^{*}$ & $97^{*}$ & - & $21 \cdot 7^{*}$ & \\
\hline $1880 \ldots \ldots$. & 658 & II $7^{*}$ & 214 & $21.7^{*}$ & 48.2 \\
\hline $1890 \ldots \ldots \ldots \ldots$ & $770^{*}$ & I I $2 *$ & - & I $7.0^{*}$ & \\
\hline r900.... & 883 & I $13^{*}$ & 225 & $14.7^{*}$ & 34.2 \\
\hline
\end{tabular}

The last columns of Tables I. and II. show that the rate of increase of Negroes declined throughout the nineteenth century, that between 1880 and 1900 it was less than half of what it was between r 800 and 1820 


\section{The American Race Problem}

and less than two-thirds of what it was between 1840 and 1860 . It shows, therefore, that, if the future may be judged by the past, there is no warrant for the opinion of Mr. Washington, "that the rate of increase in the future will be still greater than it has been."

The estimate of Mr. Page, that the year 2000 A.D. "will in all human probability" see from $60,000,000$ to $80,000,000$ Negroes living in the United States, appears to be reached by projecting into the future the rate of increase which prevailed between 1860 and 1880 . If that rate were to persist throughout the twentieth century, there would be $63,000,000$ Negroes in the United States in $2000 \mathrm{~A}$. D. If the rate shown by Table I. for the decade I 890 to I 900 should persist, there would be 46,000,000 Negroes in the United States in 2000 A.D. If the rate shown by both tables for the twenty years, I 880 to I 900 , should persist, there would be $38,000,000$ Negroes in the United States in 2000 A.D. If the rate shown by Table II. for I 890 to I 900 should persist, there would be about $35,000,000$ Negroes in the United States in 2000 A.D. And, finally, if the rate shown in Table I. for 1880 to 1890 should persist, there would then be about 3I,500,000 Negroes.

If it were admissible to assume that any rate of increase would persist through the twentieth century, it would be best to accept that for the twenty years between I 880 and I 900 , because it is based on the longer period and involves no correction of census figures. But the history of the nineteenth century and what is known about the increase of population concur in testifying 


\section{The Probable Increase}

that the rate of increase is likely to dwindle, and that $38,000,000$ Negroes in Continental United States in 2000 A.D. is much too large an estimate. Emancipation wrought so radical a change in the economic condition of the Negro race that its increase before 1860 affords almost no clue to its probable increase in the future. The period since $\mathrm{r} 860$ is too short, and the returns are affected by too large errors, admitted or suspected, to furnish much basis for a forecast. Yet, if we take as our base the rate of increase I 880 to I900-namely, 34.2 per cent.-and assume that in each score of years during the twentieth century the increase of the Negroes will be less by 4 per cent. than in the preceding score of years-and this slackening is only about one-third of that which has taken place since r860 among the Negroes, and one-half of that among the whites - the per cents. of increase during the century just beginning will be as follows:-

\begin{tabular}{|c|c|c|c|c|c|c|c|c|c|}
\hline I 900-I 920 & - & - & - & . & • & - & - & - & - 30.2 \\
\hline I $920-1940$ & • & • & - & • & • & - & - & - & - 26.2 \\
\hline I $940-1960$ & . & - & - & . & • & - & • & • & . 22.2 \\
\hline I $960-$ I 980 & • & - & - & - & - & - & - & • & . 18.2 \\
\hline I 980-2000 & . & . & . & . & . & . & . & . & . 14.2 \\
\hline
\end{tabular}

The Negro population at the end of the present century will then be less than $24,000,000$. On the whole, I am disposed to believe that this assumption is as favourable to the Negro race as the facts warrant, that $25,000,000$ is the maximum limit of the probable Negro population of this country a century hence, and that it may fall several millions short of that figure.

Whether this opinion-for it is hardly more than 


\section{The American Race Problem}

that-does or does not find acceptance, there is no questioning the testimony of the figures that the rate of increase of Negroes declined steadily throughout the nineteenth century, and, if we reject or disregard the census figures of 1870 and 1890 , at no time so rapidly as between 1860 and I900. This is made most obvious, perhaps, by comparing the rate of increase at each twenty-year period subsequent to 1820 with that of the preceding period treated as roo per cent. The rate of increase 1820 to 1840 was 81.0 per cent. of that I 800 to I 820 ; the rate of increase 1840 to 1860 was 87.8 per cent. of that $I 820$ to $I 840$; the rate of increase $I 860$ to $I 880$ was 88.3 per cent. of that 1840 to 1860 ; but the rate of increase 1880 to 1900 was only 7 I.० per cent. of that I 860 to 1880 .

The rapid decline of white increase has been mentioned, and it might be thought that in this checking of Negro increase we have to do, not with a racial problem but with a general problem of American population. This is a superficial view. It is true that the whites in the country as a whole, in spite of the swarms of immigrants who come to swell their numbers, are increasing at a slackening rate. But nearly nine-tenths of the Negroes live in the Southern states, a region to which a small and dwindling proportion of our foreign-born population goes, and yet in the South the white population is growing with augmented rapidity. The evidence for this surprising fact has been presented in the "Supplementary Analysis" of the Twelfth Census*

* See p. 203. 


\section{The Probable Increase}

published in 1906 , and need not be repeated. Suffice it to say that, if each of the two races in the South should continue throughout the present century to increase at the rate that characterised it between $\mathrm{r} 880$ and $\mathrm{I} 900$, there would be in the South in 2000 A.D. about $33,000,000$ Negroes and I 55,000,000 whites, and the Negroes would constitute 17.6 per cent. of the population of the Southern states, in which they now constitute 32.4 per cent. Doubtless each of the above figures is much too large; but, if the checking of growth which will appear in each race shall affect them in such a way as to keep the ratio of their increase what it has been for twenty years and I think this also is an assumption as favourable to the Negro as the facts will warrant - then the ratio of the above figures will be correct, and we may expect that the Negroes, who in 1800 were 35.0 per cent. of the population of the Southern states, who in 1840 , when they were relatively most numerous, were 38.0 per cent., and who in 1900 had receded to 32.4 per cent., will continue to recede, and in 2000 A.D. are likely to be not more than 17.6 per cent. of the Southern population.

Whether these forecasts have any value depends mainly upon whether the causes of the different rates of growth of the two races at the South can be ascertained, and a judgment formed upon the question whether those causes are likely to persist and whether counteracting influences are likely to arise. This raises the question, what are the causes of the slackening rate of growth among Southern Negroes? That race, unlike the whites, receives practically no reinforcement from 


\section{The American Race Problem}

immigration. Only about 20,000 foreign-born Negroes were enumerated in 1900 , or about $I$ in 500 of the Negro population of the United States. For this reason the increase of Negroes must be controlled by the balance of births and deaths.

Regarding the birth-rate of the Southern Negroes we have no direct information. In default of that the best available substitute is to compute the number of children under five years of age to each r,000 women of child-bearing age, namely, fifteen to forty-nine or fifteen to forty-four years of age. I reject the figures of the censuses of 1870 and 1890 , both because of the acknowledged errors in the former and the suspected ones in the latter, and because in 1890 the form of the age question was different from that employed at other censuses. For the sake of comparison the figures for Southern whites also are introduced:

TABLE III. Children under 5 years of age to 1,000 women, ${ }_{5}$ to 49 years of age, in the South Atlantic and South Central States.

Date of census

Non-Caucasians* Whites

$\begin{array}{llllllllll}1850 \cdot & \cdot & \cdot & \cdot & \cdot & \cdot & \cdot & \cdot & 705 & 695 \\ 1860 \cdot & \cdot & \cdot & \cdot & \cdot & \cdot & \cdot & \cdot & 688 & 682 \\ 1880 \cdot & \cdot & \cdot & \cdot & \cdot & \cdot & \cdot & \cdot & 737 & 656 \\ 1900 \cdot & \cdot & \cdot & \cdot & \cdot & \cdot & \cdot & \cdot & 577 & 581\end{array}$

These figures show that before the war the proportion

* "Non-Caucasians" is preferred to the ambiguous "coloured," which means sometimes Negroes, sometimes Negroes, Indians, and Mongolians, and sometimes mulattoes. In every case in which non-Caucasian is used Negro might be substituted for it without material inaccuracy, and for this reason I have occasionally, for the sake of variety or simplicity, used Negro when non-Caucasian would be more exact. 


\section{The Probable Increase}

of children to potential mothers was almost the same among Southern Negroes and Southern whites. They show that the proportion among Negroes was higher in 1880 than in $185^{\circ}$ or 1860 , suggesting that the Negro birth-rate immediately after emancipation and the reëstablishment of orderly government was higher than toward the end of the slavery régime. They indicate, also, a notable and surprising fall in the birthrate between 1880 and 1900 . During the same period the proportion of children among Southern whites fell steadily but more slowly, the total decline for the fifty-year period being 128 children for 1,000 nonCaucasian women and II 4 children for I,000 white women. As a result the proportion of white children in the South in 1900 , for the first time, was greater than the proportion of Negro children. Still more remarkable is the fact that during the last twenty years of the nineteenth century the decline in the proportion of Southern Negro children was 160 and that in the proportion of Southern white children only 75 . The following table shows the states in which the proportion of children is highest or lowest, and those in which the decline has been greatest. For the sake of comparison the figures for whites are added.* It will be noticed that the child-bearing age in this table has been defined a little more exactly than was possible from the census data of 1850 and 1860 , as 15 to 44 years of age.

\footnotetext{
* Fuller figures on the subject will be found in the "Supplementary Analysis" of the Twelfth Census, pp. 241, 424,427-429.
} 


\section{The American Race Problem}

TABLE IV. Children under five years of age to 1,000 women, I5 to 44 years of age, by race for the South Atlantic and South Central States: I880 and I900.

\begin{tabular}{|c|c|c|c|c|c|c|}
\hline \multirow[t]{2}{*}{ Division. } & \multicolumn{2}{|c|}{$\begin{array}{c}\text { Non- } \\
\text { Caucasians. }\end{array}$} & \multicolumn{2}{|c|}{ Whites. } & \multicolumn{2}{|c|}{$\begin{array}{c}\text { Decrease in } \\
\text { twenty years for }\end{array}$} \\
\hline & 1880. & I 900. & I $88 \circ$. & I 900. & $\begin{array}{l}\text { Non- } \\
\text { Cauca- } \\
\text { sians. }\end{array}$ & Whites \\
\hline South Atlantic...... & 787 & 630 & 666 & 595 & $\times 57$ & $7 \mathrm{I}$ \\
\hline Northern South Atlantic & 695 & 525 & 623 & 542 & 170 & $8 \mathrm{I}$ \\
\hline Delaware...$\ldots \ldots \ldots$ & 632 & 499 & 516 & 446 & 133 & 70 \\
\hline Maryland........... & 614 & 483 & 539 & $46 \mathrm{I}$ & 131 & 78 \\
\hline District of Columbia... & 428 & 254 & 420 & 302 & 174 & 118 \\
\hline Virginia............. & 762 & 594 & 657 & 591 & 168 & 66 \\
\hline West Virginia......... & 699 & 514 & 757 & 649 & 185 & 108 \\
\hline Southern South Atlantic & 833 & 674 & $7 \times 3$ & 653 & 159 & 60 \\
\hline North Carolina........ & 838 & 674 & 703 & 677 & 164 & 26 \\
\hline South Carolina......... & 867 & 712 & 714 & 630 & 155 & 84 \\
\hline Georgia............. & 818 & 663 & 721 & 642 & 155 & 79 \\
\hline Florida............. & 752 & 599 & 718 & 639 & 153 & 79 \\
\hline South Central............ & 799 & 612 & 749 & 659 & 187 & 90 \\
\hline Eastern South Central... & 785 & 598 & 712 & 630 & 187 & 82 \\
\hline Kentucky........... & 664 & 454 & $68 \mathrm{r}$ & 601 & 210 & 80 \\
\hline Tennessee........... & 770 & 544 & 721 & 615 & 226 & 106 \\
\hline Alabama............. & 792 & 624 & 734 & 680 & r68 & 54 \\
\hline Mississippi......... & 843 & 652 & 747 & 675 & $x 9 x$ & 72 \\
\hline Western South Central.. & 824 & 633 & $8 \times 3$ & 692 & I9I & $12 \mathrm{I}$ \\
\hline Louisiana........... & 773 & 620 & 680 & 652 & I 53 & 28 \\
\hline Arkansas............. & $86_{3}$ & $6 \mathrm{II}$ & 845 & 689 & 252 & 156 \\
\hline Indian Territory...... & $?$ & 782 & $?$ & 731 & & \\
\hline Oklahoma............ & $?$ & $63 x$ & $?$ & $7 \times 6$ & & \\
\hline Texas................. & 869 & 642 & 853 & 698 & 227 & 155 \\
\hline
\end{tabular}

Table IV. shows that in every Southern state the decline in the proportion of Negro children between I 880 and I900 was much greater than the decline in the proportion of white children, and that with both races the proportion was smallest in the border states, and reached a very marked minimum in the District of Columbia. The last fact suggests that the proportion 


\section{The Probable Increase}

of Negro children may be very small in other cities. We have figures on this only for 1890 and 1900 . They show that in the entire country, outside the large cities, the proportion of Negro children to 1,000 women fell from 672 in 1890 to $65 \mathrm{I}$ in 1900 , or $2 \mathrm{I}$. But the proportion in the cities was 305 in 1890 and 260 in 1900 , a decrease of 45 . These figures show that the proportion of Negro children in cities is about two-fifths of the proportion in country districts, and has decreased in cities with more than twice the rapidity with which it has decreased in country districts. The following figures compare the proportion and decrease of Negro children in Southern cities and country districts with the proportion and decrease of white children:

TABLE V. Children under five years of age to $\mathrm{I}, 000$ women, I5 to 44 years of age. For the South Atlantic and South Central States: 1890 and I 900.

\begin{tabular}{|c|c|c|c|c|c|c|c|c|}
\hline \multirow{3}{*}{ Division. } & \multicolumn{4}{|c|}{ In cities of 25,000 . } & \multicolumn{4}{|c|}{ In rest of area. } \\
\hline & \multicolumn{2}{|c|}{$\begin{array}{c}\text { Non- } \\
\text { Caucasian. }\end{array}$} & \multicolumn{2}{|c|}{ White. } & \multicolumn{2}{|c|}{$\begin{array}{c}\text { Non. } \\
\text { Caucasian. }\end{array}$} & \multicolumn{2}{|c|}{ White. } \\
\hline & 1890. & 1900. & I 890. & I 900. & 1890. & I 900. & 1890. & 1900. \\
\hline South Atlantic & 311 & 269 & 385 & 365 & 685 & 687 & 627 & $64 x$ \\
\hline South Central & 331 & 274 & 402 & 384 & 690 & 653 & 693 & 692 \\
\hline
\end{tabular}

Negro children are much less numerous than white children in the cities of both divisions. They are less numerous in the country districts of the South Central division, but more numerous in the country districts of the South Atlantic. In the large cities of the South 


\section{The American Race Problem}

Atlantic division the decrease of Negro children, I89o to I 900 , was 42 per I,000 women, that of white children only 2o. In the large cities of the South Central division the decrease of Negro children was 57 per I, 000 women, that of white children only 18 . Outside of these cities in the South Central division the decrease of Negro children was 37 to $\mathrm{x}, 000$ women, and of white children only I. Outside of those cities in the South Atlantic division the increase of Negro children was 2 to $\mathrm{I}, 000$ women, and of white children the increase was 14 . The growth of cities in the South and the effect of city life upon the birth-rate are thus proved to be potent influences, but not the only influences, producing the rapid decrease of the Negro birth-rate.

Immigration of whites into the South might tend to maintain the birth-rate and the rate of increase of whites, and thus account for the growing disparity between the figures for the two races. This immigration is of two sorts, immigration of foreign-born whites and immigration of whites born in other parts of the United States. The number of foreign-born whites in the Southern states, excluding Oklahoma and Indian Territory, was 516,000 in 1890 and 542,000 in 1900 , an increase of only 5.0 per cent., while the increase in the country as a whole was $\mathbf{2 . 0}$ per cent. Of the total white population of the Southern states in 18903.9 per cent. and in 19003.4 per cent. were of foreign birth. Immigration of foreign-born whites cannot be a very potent influence in maintaining the birth-rate or the rate of increase of Southern whites. 


\section{The Probable Increase}

The immigration of foreign-born whites to the Southern states is not offset by an appreciable amount of emigration of white natives of the South to foreign countries. But on the part of native whites the currents of migration between the Southern states and the rest of the country flow in both directions, and it is necessary to consider the net result or balance. In doing so it is best to exclude Oklahoma and Indian Territory from the Southern states. In 1890 there were $\mathrm{r}, 038,000$ white natives of the Southern states (excluding Oklahoma and Indian Territory) living in other parts of the country: in I 900 the number had risen to $1,116,000$. To offset this current there were, in $1890,582,000$ white natives of the North and West living in the South (still excluding Oklahoma and Indian Territory), and in I 900 there were 725,000 . The native white population of the Southern states has suffered a net loss by interchange with other parts of the country, but that loss is a decreasing one. In 1890 it was 456,000 and in 1900 it was 391,000 .

As the Negroes in the South receive very few recruits from foreign countries, so, also, they receive very few recruits from the North and West. In studying these currents of migration it is necessary to include with the Negroes the native Indians and Mongolians, these classes not having been distinguished from the Negroes for the birthplace tables at the census of 1890 . They were so few relatively as not to distort the figures. In I 890 there were $24 \mathrm{I}, 000$ non-Caucasian natives of the South living in the North and West, in I 900 there were 


\section{The American Race Problem}

349,000 . In 1890 there were 22,400 non-Caucasian natives of the North and West living in the South, in I 900 there were 26,500 . In 1890 the net loss of Southern Negroes by emigration to other parts of the country was 218,000 , in 1900 it was 323,000 . During the decade 1890 to 1900 the net loss of Southern native whites by emigration to other parts of the country decreased 65,000, and the net loss of Southern Negroes increased r 05,000. The net loss of Southern native whites by emigration to each 10,000 native whites residing in the South was 365 in 1890 and 255 in 1900 . Corresponding figures for the non-Caucasians in the South were 324 in 1890 and 410 in 1900 . The relative loss of the Negroes in 1890 was less than that of the whites, but in 1900 it was greater by three-fifths.

The evidence thus far has indicated two of the influences at work in reducing the proportion of children, and probably the birth-rate, of Southern Negroes much more rapidly than of Southern whites. The first is the growth of cities, especially of Southern cities, and the powerful and increasing influence they exercise upon their residents, especially their Negro residents, in depressing the birth-rate. The second is the decreasing net loss of Southern whites and the increasing net loss of Southern Negroes by the currents of migration between the South and the North and West. So far as one can judge, both of these influences are likely to persist, and even to become more potent. Indeed, they bid fair to be reinforced by a third, which has not yet produced a noteworthy effect upon the popula- 
tion of the South - the increased influx into the South of white immigrants from Europe, especially from Southern Europe. The evidence in hand, therefore, meagre as it is, points to a continuance of a proportion of children among Southern Negroes smaller than among Southern whites - a relation which was first manifested in I 900 - and probably to an increasing difference in this respect between the two races.

The increase of Negro population in the United States is the result, as already stated, of the balance between births and deaths. It has been shown that the proportion of Negro children is rapidly decreasing. But, if the proportion of them who die - or, in other words, the death-rate - is decreasing as fast or faster, the rate of increase might continue at its present height or even rise. It is important, therefore, to ascertain how the death-rate of the Negroes is changing. This rate is known only for the registration area, as it is called; that is, for those states and cities in which the local death records are believed to be accurate enough to deserve consideration. Probably some omissions of deaths occur in nearly all parts of the registration area. Probably these omissions are more numerous in the South than in the North, and in any given place perhaps more numerous among the Negroes than among the whites. Still, these figures for deaths in the registration area are the best we have. They are based upon a large non-Caucasian population, 950,000 in 1890 and $1,250,000$ in 1900; and the evidence they present, although not beyond challenge, is very weighty. 


\section{The American Race Problem}

Among 1,000 non-Caucasians in the registration area in 1890 there were 29.9 deaths and in 190029.6 deaths. These figures point to a very high death-rate and to a very slight decrease between $\mathrm{I} 890$ and $\mathrm{I} 900$.

The largest body of statistics with which I am familiar, at all comparable with these figures, but indicating the conditions of the Negroes at various times and places before the war, may be found in the volume on mortality in the Eighth Census of the United States.* The statistics thus collected are for the eleven cities of Boston, New Bedford, Providence, New York, Buffalo, Philadelphia, Baltimore, Washington, Charleston, New Orleans, and Memphis, and for various dates between 1818 and $186_{3}$, with the exception of Boston, the figures for which include also the period from I 725 to I774. Returns from these cities ought to be fairly comparable with those for the registration area of $\mathrm{I} 890$ and $\mathrm{I} 900$, which also was largely Northern and urban. The comparison is indicated in Table VI on the following page.

Probably these figures warrant the inferences that the death-rate of each race has greatly decreased in the United States in fifty years, and that the decrease

\footnotetext{
* See page 280 of that volume. These figures were originally compiled for the American Freedmen's Inquiry Commission, and the results were first published in the report of that commission to the Secretary of War (38th Congress, First Session, Senate Executive Documents No. 53, p. xо5.) The statistical work of that commission was "greatly aided by Dr. Edward Jarvis of Boston," one of the most careful and competent students of vital statistics we have ever had in the United States. He "kindly opened to the commission the treasure of his valuable statistical library" and "personally superintended some of the researches." The figures were republished two years later with some additions in the census volume. It is from this latter source that the first line of Table yI has been prepared.
} 


\section{The Probable Increase}

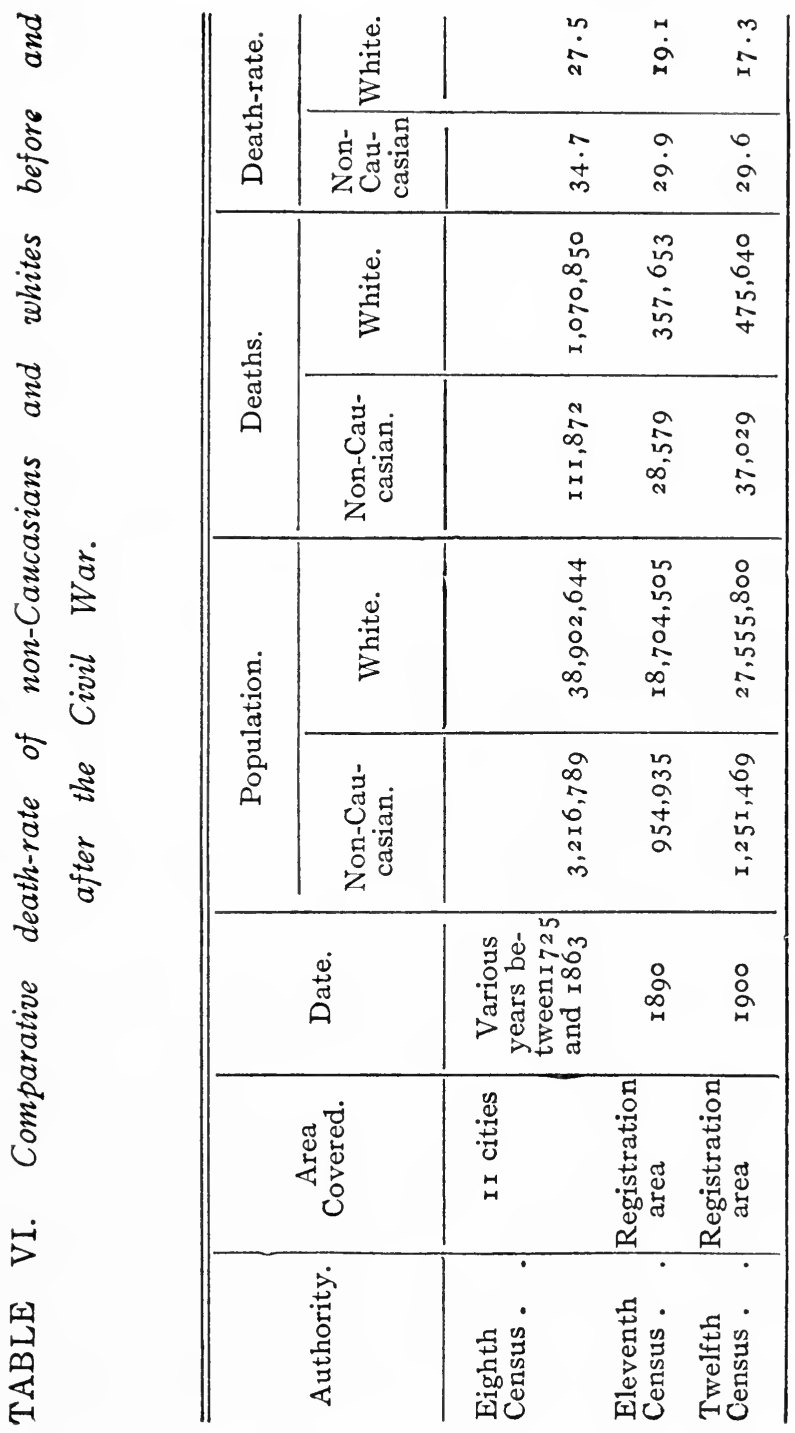




\section{The American Race Problem}

for the Negroes has been much less rapid, both absolutely and relatively to the initial amount, than the decrease for the whites. The death-rate indicated for Negroes in 1900 is more than five-sixths ( 84.6 per cent.) of what it was at the earlier period. That for whites is less than two-thirds (64.I per cent.) of what it was at the same period. At the earliest date the death-rate of Negroes exceeded that of whites by 29.8 per cent of the lower rate, in 1890 it exceeded the death-rate of whites by 56.5 per cent., and in 1900 by 71.5 per cent. Before the war the difference between the death-rates of Negroes and whites was 8.0, in r9oo it was r2.3. Clearly in this field the benefits of progress are accruing more to the white than to the Negro race, and the difference between the two races is growing.

In order to get more specific information, the population of each race must be divided into sex and age classes, as in Table VII on page 5I7.

From the figures in this table the death-rates of the non-Caucasians in the registration area by age and sex may be computed for 1890 and 1900 , and the change for the decade estimated. The results are given in Table VIII on the same page, into which the death-rates of whites have been introduced for comparison.

Table VIII indicates that there was a decline in the mortality of Negro infants between 1890 and r9o0, a decline, however, less than half that in the mortality of white infants. There was likewise a decline in the death-rate of Negro children five to fourteen years of age, which was about half the decline in the 


\section{The Probable Increase}

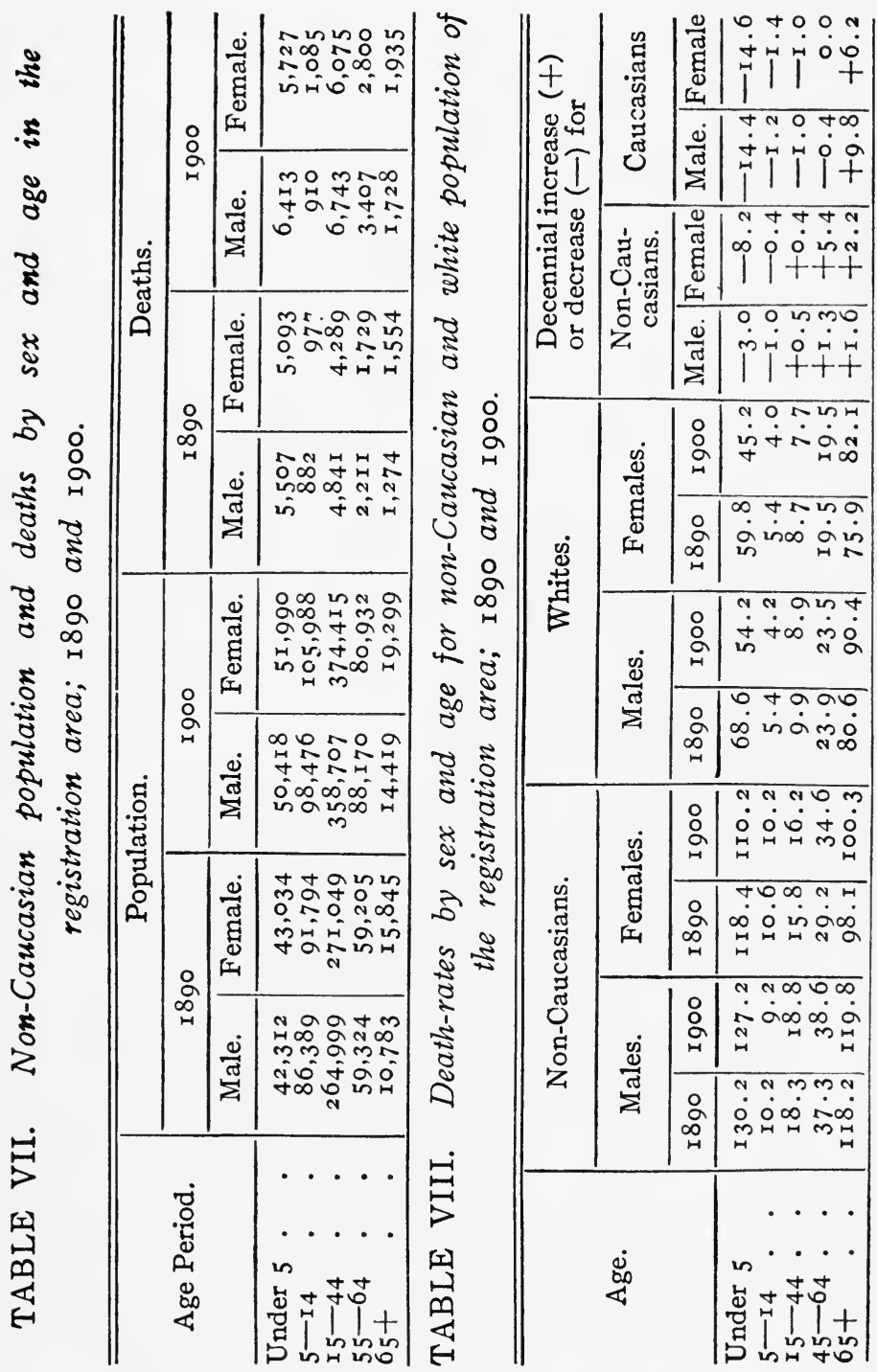




\section{The American Race Problem}

death-rate among white children. But at the ages of early adult life, fifteen to forty-four the Negro deathrate increased and the white decreased; and at the ages of forty-five to sixty-four the Negro death-rate increased, while that for white males fell and for white females was unchanged. At ages above sixty-five the death-rates of each race increased.

The slight improvement in the death-rate of Negroes of all ages, between I 890 and I 900 , is thus seen to be due to a decided fall in the rate for children and youth, largely counterbalanced by an increase in the deathrate of adult and aged Negroes. Apparently the deathrates of the two races, at ages between fifteen and sixtyfour, are changing in opposite directions, those for whites decreasing and those for Negroes increasing. The only way of escaping this inference is to claim either that the records of deaths among Negroes in I 900 were kept so much more accurately than in 1890 as to convert a real decrease among adults into an apparent increase - which seems improbable - or to claim that no inference can be drawn from figures relating to the registration area, 92 per cent. of the Negro population of which lives in cities, to the Negro population of the entire country. The last objection is weighty. The only answer to it is that we have no other evidence; that these figures, while not conclusive, are indicative, and probably do show the present tendency in a large and increasing fraction of the race. The evidence, then, indicates a high but rapidly decreasing birth-rate among Southern Negroes as a whole, 


\section{The Probable Increase}

a very low and rapidly decreasing birth-rate among urban Negroes in all parts of the country, a high and very slowly decreasing death-rate for urban Negroes, and an increase in the death-rates of urban Negroes at ages above fifteen years.

Owing to the courtesy of the Census Office in furnishing me with certain figures not contained in the published volumes of the Twelfth Census, I am able to add to the preceding data indicating the absolute and relative decrease of the Negro death-rate, the following table, comparing the death-rates of white and Negro in 1900 at twenty-four age periods. To facilitate that comparison a column is added showing the ratio of the non-Caucasian death-rate to the white.

Table IX. on page 520 shows that in the registration area in 1900 the death-rate of Negroes was greater than that of whites at each age below eighty. The lower death-rate of Negroes above eighty years of age indicated by the table is probably due to the large number of elderly Negroes who overstate their age to the census enumerators. These errors are undoubtedly more common in the returns of age for the living population than in the returns of age for decedents. Because of them little confidence can be placed in the deathrates at very high ages. At practically all ages under thirty the death-rate of Negroes is between twice and three times as great as that of whites; at ages between thirty and sixty-five the death-rate of Negroes is less than twice, but more than one and one-half times as great as that of whites. The difference between the 


\section{The American Race Problem}

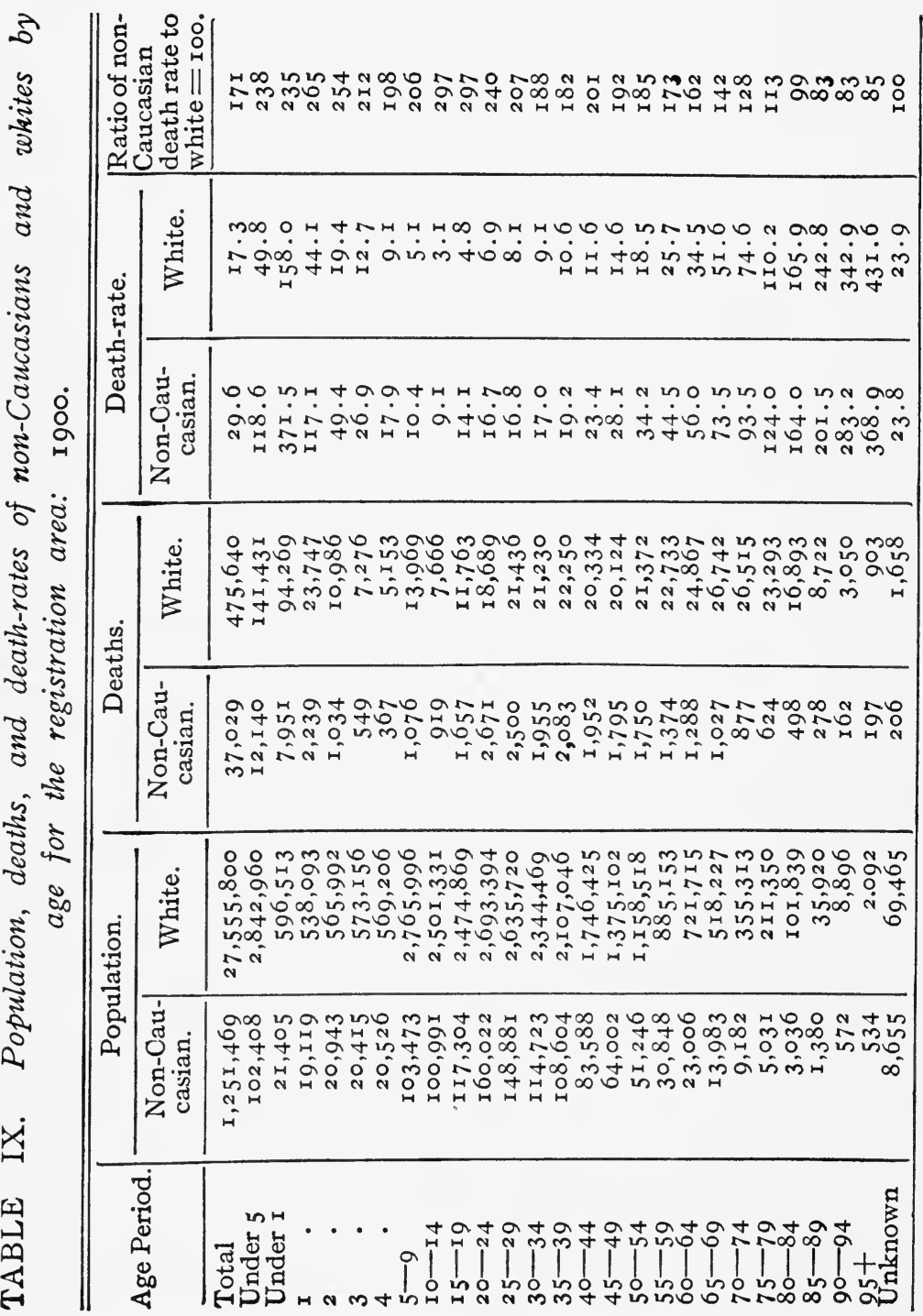




\section{The Probable Increase}

races seems to reach its maximum at the healthiest period of life, ten to twenty years of age, when the Negro death-rate is about three times that of the whites, and to decrease from that age with advancing years.

The fundamental explanation of the falling birth-rate and almost stationary death-rate, seems to me to lie in a growing competition between Negroes and whites, and a decrease in the relative efficiency of Negroes compared with whites - a decrease which is by no means incompatible with an increase in their efficiency when compared with their own standards under slavery or in the early years after emancipation. If such a competition has been in progress, some reflection of it should be found in the statistics of occupations.* In those statistics the non-Caucasians were first distinguished in I890, so that comparisons can be made only for the last decade of the nineteenth century. By confining the figures to the South more satisfactory results are reached, both because that region contains few Indians and Mongolians, and because, if figures for the whole country are used, geographical differences between North and South might be mistaken for racial ones.

There are certain occupations in which the Southern Negroes have increased proportionately to the whites. Among them we may distinguish several classes.

First are those which make heavy demands upon the muscular system. Workmen in such occupations in-

* For detailed figures and a fuller analysis see "Supplementary Analysis" of the Twelfth Census, pp. 225-237 and Census Bulletin 8, "Negroes in the United States," pp. 52-64 and 164-187. 


\section{The American Race Problem}

clude miners and quarrymen, 29.7 per cent. of whom in the South in 1890 , and 31.5 per cent. in 1900 , were Negroes; saw-mill and planing-mill employees, 4r.6 per cent. of whom in 1890 , and 46 . I per cent. in 1900 , were Negroes; and iron and steel workers, 23.2 per cent. of whom in 1890 , and 31.0 per cent. in 1900 , were Negroes.

A second class includes those occupations requiring little skill, and in many cases followed only in an irregular or casual way. Such occupations are those of servants and waiters, 74.3 per cent. of whom in 1890 , and 77.6 per cent. in r9o0, were Negroes.

A third class is one in which the service is rendered almost entirely to members of the Negro race. Examples of these are teachers, 18.3 per cent. Negro in I 890 and 19.2 per cent. in I900; and clergymen, 36.5 per cent. Negro in 1890 and 37.5 per cent. in I900. The supply of Negro clergymen relative to the Negro population of the South is now greater and increasing more rapidly than the supply of white clergymen. There is a noteworthy difference in this respect between the United States and Cuba, Porto Rico and the Philippine Islands. Cuba and Porto Rico have about the same proportion of Negroes as our Southern states, but in the two islands in I 899 only six Negro clergymen were reported, or one in seventy, while in the Southern United States more than one clergyman in three is a Negro. In this regard the Philippine Islands occupy an intermediate position. With more than 99 per cent. of the population Malay, less than three-fifths of the clergymen in the islands belong to that race. 


\section{The Probable Increase}

Those occupations in which the Negroes have lost ground at the South since 1890 may likewise be grouped into classes.

One class includes occupations in which persons work without close and constant supervision. This is true of draymen, hackmen, and teamsters, of whom 50.8 per cent. in 1890 and $47 . \mathrm{I}$ per cent. in 1900 were Negroes.

Another class includes occupations in which the amount of skill is not indicated by the group name. Here would fall: launderers and laundresses, 93.5 per cent. Negroes in 1890 and 91.5 per cent. in 1900 ; steam railroad employees, 39.5 per cent. Negroes in 1890 and 37.6 per cent. in 1900 ; housekeepers and stewards, 32.4 per cent. Negroes in 1890 and 23.2 per cent. in 1900 ; engineers and firemen, 20.9 per cent. Negroes in 1890 and 20.7 per cent. in 1900.

There is also a class of handicrafts which require skill and capital, in which the Southern Negroes lost ground. Such handicraftsmen include: carpenters, 17.8 per cent. Negroes in 1890 and 16.2 per cent. in 1900 ; blacksmiths, 23.4 per cent. Negroes in 1890 and 18.2 per cent. in I900; barbers, 60.4 per cent. Negroes in I 890 and 49.4 per cent. in I 900 ; fishermen and oystermen, 38.I per cent. Negroes in 1890 and 31.9 per cent. in 1900; tobacco and cigar factory operatives, 49.I per cent. Negroes in 1890 and 44.6 per cent. in 1900.

The preceding figures seem to show that the Negro race at the South, in its competition with the whites, lost ground between 1890 and 1900 in the majority of 


\section{The American Race Problem}

skilled occupations which can be distinguished by aid of the census figures.

Confirmatory evidence may be derived from the figures for cotton-mill operatives. There is no line of expansion in the South more important than the growth of cotton mills. We are told in the special report on that industry that its growth in the South is the one great fact in the history of cotton manufacturing between I 890 and I900. The number of spindles in the cotton manufacturing States of the South - North Carolina, South Carolina, Georgia, and Alabama - more than trebled in that decade. But this invasion of the Negroes' home by cotton manufacturing has furnished little occupation to the Negro. In I 900 the number of cotton-mill operatives reported in the country was 246,000 , about one-third of them in the cotton mills of the South; but only a paltry I,400 were Negroes. Cotton manufacturing is by far the most important industry in Georgia. The capital invested in it is double that in any other manufacturing industry of the state. There are more than I, $, 00,000$ Negroes in Georgia, yet only $4 \mathrm{I} 7$ are reported as cotton-mill operatives. Doubtless some overflow of the general prosperity has reached the Georgia Negroes, but it is only the crumbs that fall from the rich man's table.

A similar movement, beneficial to the South as a whole but benefiting in the first instance the whites and only indirectly and remotely the Negroes, may be traced in Southern agriculture. The evidence is not so broad, the statistical induction is less complete; 


\section{The Probable Increase}

but as corroborative testimony certain aspects of it deserves attention.*

The acreage sown to rice in the United States more than doubled between 1890 and 1900 . Most of this increase has been in Louisiana, which produces about three-fifths of the American crop. The crop of Louisiana is produced mainly in three parishes which contain about two-fifths of the country's acreage and produce more than two-fifths of its yield of rice. The acreage of rice in those three parishes multiplied more than five times between 1890 and rgoo. With the development of this great new industry the population of these parishes has made a long stride forward, increasing 57 per cent., or at more than twice the rate of the state as a whole. But the proportion of Negroes in those parishes is only about two-fifths of the average in the state, and, while the Negro population has increased in the ten years by 6,800 , the white population has increased by more than 20,000 . The increase of the whites in those three parishes consequent upon the prosperity of the rice industry goes far toward explaining the decrease in the proportion of Negroes in the entire State of Louisiana from $5 \circ$ per cent. in 1890 to 47.I per cent. in 1900.

Factors in this development have been: the discovery of abundant supplies of oil in the vicinity furnishing needed power; the construction of expensive irrigation works; the introduction of varieties of rice from which water can be drawn away toward the end of the season,

* For other evidence on this point see pages $450-454$ of this volume. 


\section{The American Race Problem}

leaving a firm soil at harvest time; the introduction of modern agricultural machinery, the gang-plough, the horse-drill, the twine-binder, and the steam-thresher. "One harvesting machine," we are told, "operated by one man and five mules, does in one day what formerly required a whole family and hired help to do in a season."* White men have come in to manage this machinery, to carry on agriculture by improved methods. They have come from the North; the increase of the natives of the north central states in Louisiana in the last ten years has been marked. But, doubtless, the most important increase has been among the white natives of that region, who have availed themselves eagerly of the new avenues to prosperity.

It seems inevitable that changes having a similar effect upon the competition of the two races should go on in cotton growing. I may refer briefly to one that is a serious problem now in Texas and a serious menace to the rest of the cotton-growing area of the country, the insect pest known as the cotton boll weevil.

This pest first appeared in Texas in 1892 and in Louisiana in 1903 , so that it required about eleven years to cross the largest state and the greatest cotton-growing state in the Union. On the average it extends its field of activity from fifty to sixty miles in each season. The work of the United States Department of Agriculture has not resulted in devising any means of preventing or materially retarding its progress, and the department expert reported in 1903 that "the steady

* Twelfth Cenșus, Vol. IX., p. 568. 


\section{The Probable Increase}

extension of the territory affected by the weevil. has convinced all observers that it will eventually be distributed all over the cotton belt."* The amount of loss already incurred and likely to result from this scourge is entirely uncertain. The census figures for total yield of cotton in 1899 and of the yield per acre do not indicate that the position of Texas as the banner cotton state is endangered. In 1889 she produced less than one-fifth, and in 1899 more than one-fourth of the cotton of the country. The only evidence I have derived from the figures in support of the claim that widespread injury has been done is that the yield of cotton per acre in Texas very slightly decreased from $\mathbf{x} 889$ to $\mathrm{x} 899$, while in the rest of the cotton states the average yield per acre was noticeably greater in 1899 than in 1889 .

But in any case this pest has rendered cotton a more difficult and uncertain crop. The methods recommended for minimising the loss are early planting, use of early maturing varieties of seed, and chopping and burning the plants as soon as the weevils have prevented the maturing of more cotton. Energy, ingenuity, and perseverance in surmounting new difficulties are far more characteristic of whites than of Negroes. It is well known that a large part of the field work in the cultivation of Texas cotton is done by whites. It seems probable that, when the boll weevil reaches the cotton-growing district of the lower Mississippi, as it is almost certain to do in the next

\footnotetext{
* Department of Agriculture, Year Book, 1903, p. 211.
} 


\section{${ }_{528}$ The American Race Problem}

ten years, and finds a region where practically all the cotton growing is done by Negro labour, it will bear more hardly upon the yield in that district than it has borne upon the yield in Texas, and that the new pest will contribute in some measure either to decrease the importance of that area as a cotton centre or else to decrease the dominance of Negro labour in the cotton fields there. A movement to displace Negro labour by immigrant Italian labour in Mississippi and Louisiana has already passed the incipient stages. I may quote a few sentences from a recent article* by a cotton planter of that section describing clearly the difference between the two sorts of labour as he knows them. After asserting that the number of Italians engaged in cotton growing along the lower Mississippi, while not large, "is constantly increasing," that the Italian can "produce more cotton on a given acreage than the Negro," and "gather a greater percentage of it without outside assistance," and that he "works more constantly than the Negro, and, after one or two years' experience, cultivates more intelligently," the writer continues: "From the garden spot which the Negro allows to grow up in weeds, the Italian will supply his family from early spring until late fall, and also market enough largely to carry him through the winter. I have seen the ceilings of their houses literally covered with strings of dried butter beans, pepper, okra, and other garden products, while the walls would be hung with corn, sun-cured in the roasting eaı stage. In the rear of a well-kept house

\footnotetext{
* "The Italian Cotton Grower" in S. Atl. Quart., vol. IV (1905) pages, 45-46
} 


\section{The Probable Increase}

would be erected a wood-shed, and in it would be seen enough firewood sawed and ready for use to run the family through the winter months. . . I have seen them make more cotton per acre than the Negro on the adjoining cut, gather it from two to four weeks earlier, and then put in the extra time earning money by picking in the Negro's field. . . Handicapped as they are at first by ignorance of the language and ignorance of the cultivation of the plant they raise, still they are becoming property owners, tax-payers, and citizens."

What is true of the Italian immigrant must be still more true of the native American from the North and West, the increase of whom in the South has already been mentioned.

The conclusion to which I am brought is that relatively to the whites in the South, if not absolutely as measured by any conceivable standard, the Negro as a race is losing ground, is being confined more and more to the inferior and less remunerative occupations, and is not sharing proportionately to his numbers in the prosperity of the country as a whole or of the section in which he mainly lives.

How far this is due to racial characteristics, disabling him from effective competition with the rival and dominant race, and how far it is due to economic discrimination against members of the race, the evidence does not indicate. That both of these factors now coöperate in the result seems clear. That the economic discrimination has developed and is maintained, not only for 


\section{The American Race Problem}

economic reasons, but also in part and perhaps mainly for social and political reasons, seems equally incontestable. How much of it shall be assigned to one and how much to the other influence could be measured only if either occurred without the other.

No reason appears for expecting that the tendencies which I have sought in this article to demonstrate and to explain will soon cease to be controlling. They have set in recently, to be sure, but they seem to be increasing in scope and intensity, and to be likely to continue so to increase. Should they do so, the differences in the rates of growth of the two races at the South are likely to become wider, and the increase of Negroes, both absolute and relative, to be slower than any of the foregoing estimates has assumed.

LIST OF OTHER WRITINGS OF WALTER F. WILLCOX ON THE NEGRO

"Migration of Negroes" (Review) in American Statistical Association Publications, Vol. V. (1897), pp. 371,372 .

"Race," in Census of Porto Rico (I 899), pp. 55-62. An address before the First Annual Conference of the Southern Society for the Promotion of the Study of Race Conditions and Problems in the South. Montgomery, Ala., May, I900, pages I52-I56.

Preface to "The Negro in Africa and America," by J. A. Tillinghast in American Economic Association Publications, Vol. III. (I902), No. 2. 


\section{The Probable Increase}

"Negro Population," Bureau of the Census, Bulletin 8 (I 904), pages I r 68.

"Negroes of Columbia, Mo.," by W. W. Elwang (Review), American Statistical Association Quarterly Publications, Vol. IX, (I904), p. I32.

"Negro Education not a Source of Crime," Leslie's Weekly, March $\mathrm{I} 7, \mathrm{r} 904$.

"Economic Position of the American Negro," American Economic Association Publications, Vol. VI. (I 905), p. 216

"The Colour Line," by W. B. Smith (Review), Political Science Quarterly, Vol. XX. (r905), p. $32 \mathrm{x}$.

"Race" and "Negroes" in Bureau of the Census, "Supplementary Analysis ind Derivative Tables" (I g०6), pp. I75-275.

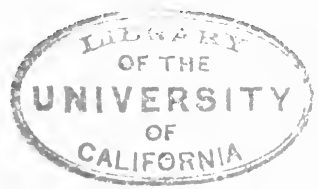



INDEX 



\section{INDEX}

Abdul Rahaman, slave, but not Negro, 430

Abolition of slavery, and reconstruction, Jamaica and United States, 338

Absorption of races, 233; in Central America, 26, 27 ; political and social, 26 . (See also Admixture, Amalgamation, Assimilation, Intermarriage, Miscegenation)

Accommodations, public, Negro and, 330. (See also Separate cars, Separate schools)

Acreage of cotton, working hand, Italian and Negro, Sunny Side, $182,183,196$

Acton, J. E. E. D. (Lord), dictum of, $H$. O. Lea on, 7,9

Adaptability of the Negro, $234,235,236$; to Southern climate, 173

Administration, capacity of mulatto for, 402. (See also Self-government)

Admixture of races, Eliot, of Harvard on, 6I ; French and Spanish, compared with Anglo-Saxon, 402. (See also Absorption, Amalgamation, Assimilation, Intermarriage, Miscegenation)

Africa, inferiority of Negroes of, 428, 429; partition of, 55; race solidarity in, $\mathrm{H}$. A. Wilson on, 239 ; tribal polity of, 375 ; tribal polity compared with plantation government, , 376; "Africa for Africans," $33 \mathrm{I}$
African Society of London, $\mathbf{4 2}$

Afro-American vote, T. T. Fortune on, 359, 360; Kelly Miller on, 361

Age, accuracy of answers to questions regarding, 478

Agitators, mulatto, influence of, 434 ; Negro, in the North, 4 I I

Agriculture, cultivation in, Negro and Italian care in, 192,196 ; Italian and intensive, 185,186 ; Negroes in, 47 , I 77, 489, 524, 525; machinery and the Negro farm hand, 526; Booker T. Washington on Negro opportunity in, I 7 I. (See also Cotton, Gardening, Rice, Tobacco)

"Agriculture in Delaware," $9 \circ$ Alabama, mulatto and Negro population, $4 \mathrm{r}$; percentage of Negro population, 44, 45

Alexandria, Va., lynching at, I 899, 472 .

Allen, Sarah A, on McKinley and the Negro, 288

Amalgamation, racial, 26, 27; Massachusetts, $1843,60,61$; in West, 65. (See also Absorption, Assimilation, Intermarriage, Miscegenation)

Ambition, Negro, I IO

Andrew, John A. (Governor of Massachusetts) on Negro suffrage, 4I $3,4 \mathrm{I} 4$; on nonslaveholding whites, 260 ; on Reconstruction policy, 414 ; on slavery, 260

Anglo-Saxons, attitude toward Negro race, $6,55,56$;

E. A. Ross on, 24 I. 


\section{The American Race Problem}

Antipathy, racial, definition of, $2 \mathrm{I} 2$

Arkansas, Italian experiment in, $180 ;$ mulatto and Negro population, $4 \mathrm{I}$

Arson, Negroes and, 459-62,464 Assimilation, of races, in the United States, 56. (See also Absorption, Admixture, Intermarriage, Miscegenation)

Association of ideas, and relations between white and Negro races, 266 et seq.

Atkinson Edward, on Negro wealth, 150

Atkinson (Ex-governor of Georgia), on guilt of Sam Hose, 468, 469

Atlanta Exposition, Negro recognition at, 308

Attitude, race, 221-6, 234; effect of numbers on, 13 , I $4,26,29,32,35,40,53-5$, 217,390 ; Southern, to Negro, 25; white, to native Hawaiian, 54; necessity of uncompromising, E. A. Ross on, $24 \mathrm{I}$

Attucks, Crispus, a mulatto, 430

Baker, T. Nelson, on mulatto factor, 437

Baldwin, W. H., on Negro suffrage, 277 ; on social equality, 316,317 ; on suffrage restrictions, $37 \mathrm{I}$

Ballot, non-exercise of right to, 361 ; right of, against proper use of, 358. (See also Suffrage)

Baltimore, industrial ostracism in, 170

Bamboula, 16

Banks, N. P., on Northern solicitude for the Negro, 432

Banneker, Benjamin, a mulatto, 430

Bantu stock, imported in slave trade, $43^{\circ}$
Barbadoes, Negro population compared with Mississippi,47

Barbers, Negroes as, decline of, 523 ; efficiency as compared with white, I68; lessening number of, in Chicago, New York, I 55, I 57

Barney, Nathaniel, on separate coaches, 67

Bee, Washington, on Washington-Roosevelt Dinner, 3 r8, 319

"Benders," II 4

Bequests, from white ancestors to Negroes, 153

Berbers and Negroes, race prejudice between, 230

Birth-rate, Negro, 49r; Negro and white, 1850-1900, 506 et seq.

"Black and Tan" Legislatures, work of, 263,264

"Black belt," 82

"Black codes" (ante-bellum) severity of, proportionate to Negro population, 2I 7. (See also Freedmen's statutes)

Blacksmiths, Negro, decline of, 523

Blaine, James G., on South and Negro suffrage, $35^{2}$; on Southern attitude to freedmen, 20; on Southern, freedmen's statutes, I 2

Boers and native suffrage, $39 \circ$ $39 \mathrm{I}$; and rights of Negroes, 27

Bonding of free Negroes and mulattoes, Massachusetts, I $788-1834,58$

Bootblacks, Negro, supplanted by Greeks, in Ohicago, 157 ; in New York, 154 ; in Topeka, Kansas, 159 ;

Boston, Mass., economic decline of Negro in, 159; hotel accommodations for Negroes in, 317 ; race prejudice in schools of, $2 \mathrm{xI}$; race relations in, Augusta P. Eaton on, 236; white women and intermarriage, 62 
Boston Reform League on race prejudice in domestic service, $16 \mathrm{I}$

Brewer, Bob, Negro murderer, 435

Brown, John, 8

Browne, Hugh M., on industrial decline of the Negro, 454,455

Bruce, Senator B. K., a mulatto, 430

Bruce, Philip Alexander, on plantation system, 89

Bruce, R. C., 88

Bryce, James, on colour line in South Africa, 166; on Jamaica, 37 ; on Khama and social equality in South Africa, 345; on segregation in South Africa, 24; on self-governing colonies, 38,39

Butlers, Negro, decline of, in Boston, $\mathrm{I} 6 \mathrm{I}$

Cabins, 98

California, Japanese exclusion, 7

Callis, H. J., on Negro church in Boston, 160

Candler, Allen (Governor), on lynch law, 469, 470

Cape Colony, Ethiopian Church in, 388; half castes of, A. R. Colquhoun on, 406; Negro in politics, 387 , 388 ; political rights, 27 ; suffrage, 34,35 ; Natives, conditions compared with that of Negroes in South, 406; their population compared with that of Mississippi, 46

"Caribs," government of the, 277

Carolina rice-crop, 14

Carpenters, industrial decline of Negroes as, 523

Carpet-bagger, $26 \mathrm{I}$
Oars, discrimination on, $33^{\circ}$; riding in, Negroes and, I I0. (See also Separate cars)

Cash advancement to Negro hands on Dunleith Plantation, 148

Caterers, Negro, 155

Catholicism and race control, $230,23 \mathrm{I}, 325$; and race prejudice 230-3I; and French invasion of the Indians, 267

Census and the Negro, 476, et seq.

Central America, Negro influence in revolutions of, 402 ; political and social absorption of the Negro, 26, 27

Character, Negro, I 45, 147. (See also Negro, characteristics of)

Charles, Robert, Negro murderer, 435

Charleston County, S. O., Negro population, 44

Ohesnutt, Charles W., 206; a mulatto, 430 ; on mulattoes, 428

Chicago, industrial decline of Negro in, 157; election of Negro judge, 362

Ohildren, statistics of, Negro and white under five, $185^{\circ-}$ I 900,506

Chinese, exclusion of, 8 ; race friction, 219, decline of due to decline of population, 218; racial superiority of, $2 \mathrm{I} 4$

"Christmas money," I39, 148

Circus, 1 ro

Cities, Negro population in, $48 \mathrm{r}, 482$

Civil equality, $28,33 \circ$

Civil Rights Act, in District of Columbia, etc., 3 ro

Civil service, Roosevelt and Negroes in, 3II, $3 I_{2}$

Oivil Service Commission, report on coloured race in Federal service, 312 (note) 


\section{$53^{8}$ The American Race Problem}

Civil War, compared with foreign wars, 340; verdict of, and the South, 297

Clemens, Samuel L., 295

Clergymen, Negro, in United States, Cuba, Porto Rico, and Philippines, 522

Climate, Southern Negro adaptability to, I 73

Coachmen, efficiency of white versus Negro, 167

Coleridge-Taylor, 206

Colonies, American, government of, 379,$380 ; \mathrm{J}$. B. McMaster on 4I 2, 4I 3

Oolonisation of the American Negro, Jefferson on, 233

Colorado, Negro suffrage in, 3 I

Colour line, abolition of, Du Bois on, $24 \mathrm{I}$; general drawing of, in South, I65; in South, Councill and DuBois on, 262,263 ; inter-racial, in America, 408, in Jamaica, 404, in South Africa, 407, Reconstruction and, 259

Colour prejudice, 20,22

Coloured American Magazine, on Orum appointment, 302, $3 \circ 3$

Colquhoun, Archibald R., on Ethiopian movement, 33I; on capacity for self-government in races of Africa and Asia, 378 ; on half-castes of Cape Colony, 406; on West Indian Negroes, 376

Columbia, the United States and white domination in, 55

Competition between the races, $45^{\circ}$; effect on Negro death rate, $52 \mathrm{I}$; effect on Negroes, I 49 et seq., on social relations, 88

Congress, investigation of suffrage laws by; 429 ; Negroes in, 4I5; Southern representation in, 4I9, 42 I (note)

Oonnecticut, Negro governor, in Civil War, 377; Negro suffrage, $3^{I}$
Consent of the governed, O. H. Platt on intelligent, 392 ; J. B. McMaster on women and, 4 I 2

Constitutions, Southern, and disfranchisement of the Negro, 384 ; and the illiterate white, 374

Contact, personal, with Negro, effect of slavery on, 225 ; law of 2 I $7-9$, Northern white man and, 223224 ; ultimate effect of, 78

Convict system, 96

Corbin, Austin, and the Italians in Arkansas, 180

Corn mill, i 7

Cost of living, Italian versus Negroes, I 84 et seq.

Cotton, acreage production, 138; boll weevil, and necessity for intelligent white labour, 526, 527; crop in Yazoo-Mississippi Delta, 84; Italians and, I 79, I 80; industry, 47 ; mill-operators, decline of Negro, 524; pickers, scarcity of, ro3, I 4 ; value, Dunleith Plantation, I48; white and Negro labour in, 450; yield, Yazoo - Mississippi Delta, I 14

Councill, W. H., on colour line, 262 ; on evils of Negro solidarity, 279; on relation of master and slave, 256 ; on white supremacy and Negro suffrage, $35^{2}$

Country, Negro population in, $48 \mathrm{r}, 482$

Cranford, Alfred, killed by Sam Hose, a Negro, $46_{3}$

Credit system, I 0 I

Crime, Negro, 443, et seq.; lynching, and decrease in, 473; Massachusetts and, 57,58

Crittenden \& Co., O. B., successors to Sunny Side Company, I8r 
Crop lien system, IоI, I02, I 03,136

Cropper system, 99

Crum appointment, 246 et seq.; 302,303

Cuba, capacity for selfgovernment, Wolfred Nelson on, 394395 , W. Inglis on, 395 ; domination of white race in, 55; Negro clergymen in, 522; Negro population, compared with Mississippi, 47; Platt Amendment, 393

Cultivation, care in, Italian versus Negro, 192, 196. (See also Agriculture)

Cundall, Frank, on Jamaican form of government, 379

Cutler, James Elbert, 47 ; on lynch law, 74

Daniels, John, on economic condition of Negroes in Boston, I 60

Death-rate, Negro, 490, 49 r; before and after civil war, 5 ${ }^{1} 3^{-2} \mathrm{I}$

DeBerry, W. N., at Springfield, Mass, I6r : on industrial race prejudice, 19

Delta. See Yazoo-Mississippi Delta

Democracy and lynching, 475

Deportation as a means of lessening Negro crime, 474

DeTocqueville on results of emancipation, 232

Dining cars, displacement of Negroes as waiters on, I 59

Discrimination against Negro, 59; before the war, 227 ; complaints of, from mulattoes rather than Negroes, 433; economic, I4, I6I, 529,530 ; in Massachusetts, 57,58 ; by New Bedford Traction R. R., 67; North and South, I 3, I 4 ; suffrage, and, $35^{6}$
Disfranchisement of the Negro, $371,384-7$; in the South, $354,355,361$; necessity for, $4 \mathrm{I} 7$

District of Columbia, civil rights in, 3 ro; government of, 379,382 ; Negro in, 38 ; political equality in, 227

Distribution of Negro population, effects of, on race relations, I3, I4, 26, 29, $32,35,40,53-5,217$, $39^{\circ}$

Domestic service, decline of Negro in, Boston, Chicago, the South, $15^{8-61}$

"Door of Hope," 286, 287; Negro closing, against himself, 202; Theodore Roosevelt and, 246,286

Douglass, Frederick, a mulatto, 430 ; on dependence of South on Negro labour, I 72 ; on Kansas exodus, I 72 ; on Negro achievement, 150

Drainage, I 77

Duane, James, and the Ethiopian movement, 323 (note)

DuBois, W. E. B., 206; a mulatto, 430; on colour line, 262,263 ; on general equality of races, $240,24 \mathrm{I}$; on Negro crime, 446 ; on Negro immorality, 205; on Negro wealth, 150; on Negroes of Farmville, Va., 457; on Northern slave trade, I 4 ; on race contact, 326 ; on relation of master and slave, 256 ; on Southern people, 75

Dumas, Alex., a mulatto, 41

Dunbar, Paul L., 206; on kindliness between races, 258; on Reconstructions, Negro, 283

Dunleith Plantation, experiment on, 197, 198; statistics, $1899-1903,148$ 


\section{The American Race Problem}

Dunning, W. A., 47; on Negro suffrage in Reconstruction, $27 \mathrm{I}$; on relation between master and freedmen, in Reconstruction, 309

Eaton, Augusta P., on race relations in Boston, 236

Education, industrial, 89 ; Negro, and decrease of crime, failure of, 473 , effect on desire for self-support, 449 , as suffrage qualification, 372

Efficiency of the Negro, compared with Italians, I 73 et seq., at Sunny Side, I83, I 84 ; relative, 456 ; decline in relative $52 \mathrm{I}$; in Mississippi, J. C. Hardy on, I 77 et seq., in South, I74 et seq.

Elevation of the black race, office holding and, 306,307

Eliot, Charles W. (President Harvard), on admixture of the races, 6I; on separate schools, 68

Emancipation, Jefferson on, 233 ; Lincoln on, 8, 33; Freedmen's statutes of, attitude of North to, II, I 2; race friction and, 472,473 ; race problems and, 253, 254 ; restrictive legislation of, Io

Emigration to North, Negro, 5 I 2 ; B. T. Washington on, 53

Enlistment of Negroes, in North, 29

Environment, influence of, on race attitude, 6 , I $5,43,44$, 81,390 . (See also Numbers)

Equality, economic, 20I; in the South, 228; Lincoln on, 20 ; industrial, see Industrial equality; political, see Political equality; racial, 2 I 4 ; fetish of, 397; social, see Social equality
Ethiopian movement in South Africa, 323 (note), 388; A. $R$. Colquhoun on, 33 I

Exclusion, Negro, in Massachusetts, I 8 I 2,58

Excursions, Negroes and, I Io

Expediency, J. B. McMaster on principle of, in suffrage laws of United States, 4I2, 4I 3

Expense account, Negro versus Italian, I 84 et seq.

Family life among Negroes, 448 ; relation of, to 'obedience to laws, 447. (See also Home life)

Farm, U. S. Census definition of, 90

Farming, Negro, see Agriculture

Farmville, Va., W. E. B. Du Bois on Negroes of, 457

Females, Negro, excess of, 485 ; in city population, 486 ; in occupations, 488

Fertility of soil versus white .management, Mississippi, I 78

Fertilizers in Delta, II3

Fifteenth Amendment, 30, 283 (note)

Financial returns, security of, Italians versus Negroes, I 92

Firmin, A., on Roosevelt, 32 I

Fitch (of Hampton Normal Institute), on industrial decline of the Negro, 455

Florida, percentage of Negro population, 49

Food, Negro, character of, 454

Fort, J. H., I 29 (note), I 82 (note)

Fortune, T. T., on condition of Negro in the South, 203, 204 ; on industrial decline of Negro, 43-5; on standing of the Afro-American vote, 359

France and Indians, E. E. Hale on, 266,267 


\section{Index}

Free Negroes, 29; in $1860, I_{5}$; in Illinois, Indiana, Oregon, Ohio, 57 ; attitude of Massachusetts toward, in $182 \mathrm{I}$, 57,58

Freedman's Bureau, 27 I

Freedmen and former masters, 276

Freedmen's statutes, Io, II; James G. Blaine on, I 2 ; James Ford Rhodes on, I 2; Mississippi 34, 35. (See also Black codes)

Friction, see Race friction

Frissell, H. B. (Principal of Hampton Institute), on industrial decline of the Negro, 455

Fulah stock, in slave trade, 430

"Fusion" system, 369

Future of the Negro, 203, 204; and immigration, $172 ;$ in the South, I 7 I, I 72

Gambling, Negro propensity for, 107

Gardening, Negro and Italian, I 95, I 97

Garfield, James A., on reduction of Southern representation, 4 I 9

Georgia, cumulative poll tax and Negro disfranchisement, 355; mulattoes in, 4I; Negroes in cotton mills of, 524; Negro suffrage in, 35; proportion of Negro population, 44, 45, 49; Legislature, censure of McKinley, 283,293294 , eulogy of McKinley's fraternal sentiments, 297

Gilliam, E. W., estimate of Negro population in 1980 , 496,497

"Gordon riots," I 865, 399 (note)

Government, adaptation to people and races to be governed, $348,375,376,394$; and consent of the governed, O. H. Platt on, 392; Jamaica form, Cundall on, 379 ; mulatto capacity for, $40 \mathrm{r}$; Negro and responsible form of, 37 ; without representation, B. T. Washington on, $39^{2}, 393$

Grant, J. P., despotism of, in Jamaica, 375

Great Britain and the race problem, 382, 396, 397

Greenville, Miss., Negro population $\mathrm{r} 900,50,5 \mathrm{I}$

Grimke, Archibald W., on race prejudice in Boston, I 67

Grimke, Rev. Francis J., I 6

Grosvenor, C. H., on McKinley and the Negro, 282, 293

Haiti, inter-racial colour line in, 409; Negro dominion in, 332 ; its accomplishments, 396; Negro race in, 27, political instability of, 402 , revolution in, 269 , population, Negro, compared with Mississippi, 47, white expulsion by, 267

Hale, Edward E., on FrenchIndian warfare, 266, 267

Half-castes, in Cape Colony, 406; Portugese, 406. (See also Mulattoes)

Hammond, M. B., 47

Hampton Negro Conference, on Negro crime, 445

Handicrafts, decline of Negro in, 523

Hardy, J. O., on economic conditions in Mississippi, I77, I 78

Hart, A. B., on Negro suffrage in Reconstruction, 270

Hawaiian Islands, decline of race friction proportionate to decline of native population, 54; overthrow of native Negro government, 54 


\section{The American Race Problem}

Hayes, R. B., and death of Reconstruction governments, $35^{8}$

Henderson, Will, Negro murderer, 435

Hinds County, Miss., economic efficiency of Negro in, 178

Hindu, and racial superiority, $2 \mathrm{I} 4$

Hoch (Governor of Kansas), on separate schools, 70

Hoffman's "Race Traits and Tendencies of the American Negro," 62

Hogansville, Ga., Negro postmaster at, 283,294

Home life of Negro, 146,207 , 448. (See also Family life)

Hose, Sam, lynching of, 463 ; opinions as to guilt of, 468,469

Hotels, Boston, accommodations for Negroes in, 317

Houses, Negro, in Delta, 98 , 1 × 8

Howells, W. D., 42 ; on Charles W. Chesnutt, 428 ; on New England discrimination, 67

Hyde, W. DeW., on Reconstruction, 265

Illinois, exclusion of free Negroes, 32 ; exclusion of Negroes, 33 ; proportionate Negro, population, 49; suffrage in, 33

Illiteracy, advantage of white race inheritance in, 374; decrease in, among Negroes, 486,487

Immigration, assisted by Italian cotton growers, 192; and economic future of the Negro, I72; into South, 510, 5II; Italian, at Sunny Side, r 94 ; Western states, prohibition of Negro, in, 32

Immorality of the Negro, 205 et seq.; DuBois on, 205

Improvidence of the Negro, 205

Incendiarism, Negroes, and Palmetto, Ga., 460-2
Indiana, prohibition of free Negroes, 32

Indianola post office, 247 et seq., 309

Indians, decline of race friction with, due to decline in proportionate population, 54,56 ; attitude of white races to, 56

Indolence, Negro, 145

Industrial equality, $20 \mathrm{r}$; and social equality, 329,330 ; in the South, 228; Lincoln on, 20; in Yazoo-Mississippi Delta, 88

Inferiority of Negro race, 426 , 428,429

Inglis, W., on capacity of Cuba for self-government, 395

Initiative, white versus Negro in, 179

Instability of Negro, 202

Inter-Colonial Commission, report, $1905,388,389$

Intermarriage, between white and Negroes and mulattoes, inWest, 65 ; in Massachusetts, $60,6 \mathrm{I}$, with white women, r843, 60, 6r. (See also Absorption, Amalgamation, Miscegenation)

Iron works, Negro employees in, $45^{6}$ (note)

Issaquena County, Miss., percentage of Negro population, 85

Italians, care in cultivation, 192, 196; characteristics of, O. Scott on, I94, 195; compared with Negroes in cotton fields, $182,528,529$; as cotton-growers, 179, at Sunny Side, 182 ; economic efficiency compared with that of Negroes, 155,156 , r $57, \quad$ r 74 et seq.; in South, 174 ; experiment in Arkansas, 180; in Mississippi, 174 ; Willcox on Italians and the sugar-cane crops, I73 
Jamaica, and South Africa, Colquhoun on contrasting conditions, 406; charter, surrender of, a generation after emancipation, 37; government of, restrictive form of, 375 ; F. Cundall on, 379 ; inter-racial colour line, 404; race problem, absence of, 35 ; conditions favorable for harmonious race relations, 378,379 ; mulattoes and Negroes in, W. P. Livingstone on, 399; mulattoes in, 401 ; Negro and politics in, 227 , 405; population compared with Negro population of Mississippi, 47; suffrage in, 35

Janitors, Negroes as, decline of, in Chicago, New York, I 55, I 57

Japanese, assertiveness of, and race friction, 2 I 9 ; exclusion of, 7 ; racial superiority of, 2 I4; San Francisco schools, 334 ; in Korea, 8

Japanese-Russian War, effect of yellow victory on Negro races, 239,240

Jefferson, Thomas, on colonisation of American Negroes, 233; on emancipation, 233

Jenifer, G. D., on relation of master and slave, 257,258

Jockeys, coloured, displacement of, 168

Jones, Roderick, on Negro in Cape Colony politics, 388 ; on white supremacy in Cape Colony, 36

Jones County, Miss., economic efficiency of Negro in, 177

"Juramentados," in Philippines, 466,467

Juxtaposition of the races, see Contact

Kansas, exodus, Fred. Douglass on, 172; white competition, 159
Kansas City, Kans., separate schools, 69

Kealing, H. T., on Negro character, 189, 190; on Negro wealth, I 50

Kelsey, Carl, 47; on Negro's garden, 195; on Northern view of Negro, $7 \mathrm{I}$; on white managers, 179

Kentucky, mulattoes and Negroes, proportion of, in, 4I; purchase of Negro votes, 364 (note); separate coaches, 66

Khama, 24; and social equality in South Africa, 345

Kidd, B., on race superiority, 206, 207

Kimberley mines, 145

Kindliness, B. T. Washington on, $25 \mathrm{I}$; P. L. Dunbar on, 258

Kingsley, Mary, on Negro capacity, 42

Koran and indifference to race in religion, 325

Korea, Japanese in, 8

Labouchere, Henry, on segregation, 24

Labour, scarcity of Negro, as cotton pickers, 103, I 25 ; white versus Negro, in various crops, 450-3; unions and contracting in the South, I 69

Lamar, on Reconstruction and Negro suffrage, 272

Land-owners, Negro, I I $3, I_{43}$

Latins and Anglo-Saxons, as related to the mulatto, 402 ; and race prejudice, $23^{\circ}$

Lea, H. C., on Lord Acton's standard of conduct, 7,9

Lecky, W. E. H., on prosperity of nations, 207

Lee, Robert E., as a traitor, $34 \mathrm{I}$

Leupp, F. E., B. T. Washington at White House, 244 (note) 


\section{The American Race Problem}

Liberia, inter-racial colour line in, 409, mulatto governor in, 402; the Negro in, 27

Lincoln, Abraham, on emancipation, 8, II; on emigration of Negro to North, 33 ; on Negro equality, 20 233; on race differences, 233

Lincoln-Johnson Reconstruction plan and Negro suffrage, 278

Lint cotton per acre, Dunleith, I 48; per hand, at Sunny Side, 183 et seq.; per acre, at Sunny Side, 183 et seq.

Livingstone, W. P., on American and West Indian Negro, 338 (note); on Jamaican "black," 399

Local conditions and the race problem, see Environment

Louisiana, farm machinery in, 525,526 ; free mulatto class, 339; Italian immigration into, I 73; Mulattoes and Negroes in, 4I; Negro adaptability to climate of, $F$. Douglass on, 173 ; population, increase of white, 525,526 ; proportion of Negro, 49; rice crops and increase of white population, 525,526

L'Ouverture, Toussaint, probably a mulatto, 409 (note), 430

Lowndes County, Miss., economic efficiency of Negro in, 177

Loyalty of the South, 298

Lyman, Theo., Jr., on proposed exclusion of Negroes from Massachusetts, 57

Lynch, John R., a mulatto, 430

Lynch law, Governor A. Candler of Georgia on, $469470 ;$ J. E. Cutler on, 74
Lynching, 47, 92, 93; Democracy and, 475; at Palmetto, Ga., 46I-5; as preventing development of public opinion common to both races, 474; legislation versus, and decrease of crime, 473

Machinery, farm, and decline of the Negro in agriculture, 526 , and the Negro labourer in Louisiana, 453

McKinley, William, and the Negro, 276 et seq.; tact and diplomacy of, 285 , 286

McMaster, J. B., on expediency as the principle of suffrage, 4II; on government of American colonies, 4 I 2, 4I 3; on necessity for practical suffrage laws, 4 I I-4

Maine, mulatto and Negro population, $4 \mathrm{I}$

Majorities and race control, 367

Managers, white, I 78 et seq.; plantation, 91, 92

Manual labour, social sentiment toward, $449,45^{\circ}$

Maoris, decline of race friction due to decline in population, and white control in New Zealand, 38r, 382

Marion, Mass., and white labour, 7

Marriage, statistics of Negro, 487 ; Negro regard for, I08

Massachusetts, and the slave trade, I4; and proposed exclusion of free Negroes and mulattoes, 1821,57 , bonding of, I $788-1834,58$; mulatto and Negro population, 4I; proportion of Negro population, 49; relative numbers and race relations in, 57; white women and intermarriage in, 62 . 


\section{Index}

Masters and slaves, relations between, 326; and former slaves, reconstruction as engendering animosity between, 276

May, Samuel, on separate coaches, 67

Mazimba and the Ethiopian movement, 323

Menial labour, Negro, in Baltimore, Washington, 170

Mestizo, 43 I

Métayers, Italian, 99; J. S. Mill on, $174, \mathrm{I} 94$

Mexico, political and social absorption of Negro in, 26, 27

Michigan, mulatto and Negro population, 4I; percentage of Negro population, 49

Middle Ages, race hatred in, 465-6

Migration, Negro habit of, I09, I 45

Mill, John Stuart, on Italian métayer, I $23,174,194$

Miller, Kelly, on lack of Negro interest in politics, $360,36 \mathrm{I}$; on social equality of races, 230,325

Minnesota, Negro suffrage in, 3 I

Miscegenation, 6r. (See also Absorption, Amalgamation, Assimilation, Intermarriage)

Mississippi, alluvial district, population of, 1900,366 ; climate of, F. Douglass on Negro adaptability to, I 73; Constitution of 1890 , conditions antecedent to, 384 , 385 , discriminations against Negro in, 354; equality, legal, 73; farms in, 90, 9I; fertility of soil and white managers, I78; Freedmen Statutes, attitude of North to, 34, 35; population, compared with South Africa and West Indies, 46, 47, Negro, 1900, 50, proportion of Negro to white, $44,45,46$, 49,52 , mulatto and Negro, $4 \mathrm{I}$; proportion of population applied to other localities, $5 \mathrm{I}, 85$; suffrage in, 366 , polled and registered vote, 357 (note); Yazoo-Mississippi Delta, 83 et seq.

Mixed population and classification of mulattoes with Negroes, 399; government for, 39

Mohammedanism and race control, 325

Mokane and the Ethiopian movement, 323 (note)

Money, advancement of, Dunleith, 148

Mongolians, attitude of white races to, 55

Monroe doctrine, 8

Moors, not Negroes, 430

Morals, Negro, 107,205 ; standards of, local adaptation of, 7 ; illustrations of, 7-9

Morocco, Sultan of, his Negro blood and Berber prejudice, 230

Motives, assigning of, 322

Mulattoes, 21, 27; as agitators, 434; T. Nelson Baker on, 437 ; capacity of, 404 ; factor in race problem, 397 et seq., 425 et seq.; free in Louisiana, 339; in Jamaica, 399, 40I, intelligence of, $40 \mathrm{I}$; Jamaican and American, 402; Liberia, governing class in, 402; Latins and AngloSaxons and, 402; leaders of Negroes, 29I; Massachusetts and the, in I 821,47 ; Northern, 40; office holders, 305 , 369; proportion to Negroes, 4I et seq., 397; Reconstruction, 255, political opportunity of, in, 403 ; and social equality, 288; statistics of, 479 et seq.; Spanish and American, 402. (See also Half Castes) 


\section{The American Race Problem}

Murders, Negro, glorification of, 435 ; statistics of, Miss., ro7; Texas, 66; Kansas City, 69 Murillo's pupil a mulatto, 430

Nast, Thomas, on Southern people during Reconstruction, 265

Natal, native problem in, 323 (note); opposition to Negro suffrage in a South African Confederation, 39 I ; population compared with that of Mississippi, 46; resentment against Great Britain in local difficulties, 364 ; rights of Negroes in, 27

National Negro Business League, 153

Negro, achievements, of 151 ; and the Berber, 230; antiquity of race, 428 ; as federal soldier and increase of crime, 473 ; as a peasant class, 4I0; as a labourer, work per annum, 453; as soldier, 29 ; as voter, 356,357 . 362,363 ; birth rate, 491,506 , Capacity of, 4I; Mary Kingsley on, 42 ; Oliver on, 403 Characteristics of, Ioo, $102,108,109,145,147,184$, I 88, 192, 205, 355, 359; ambition, Iro; gambling, I07; improvidence, 205, indolence, 145 , initiative, I 79, instability, 202

Classes of, 40, 335;

DuBois on, 457; higher classes and effect on crime, 469,470 ; their relation to the whites, 292 ;

Economic future of, in South, 198,199

Education and, 324

Ethnic history of, 426

Food of, 454

Free, 29

Immorality of, 205

In Africa, 331, 332, 428,
429; identity of American with, 428,429 ; opposition to suffrage, $390,39 \mathrm{I}$; in South African politics, 387,388 ; venality of Negro voter in South Africa, 388

In business, Wanamaker, on, 153

In Cuba, personal decoration, 395

In North Carolina, census I 890,365 ; Negro rule, 365 In office, attitude of North to, 249, Chicago, 362 ; in North, 304; (note); 4 I 6 Roosevelt and, 279 et seq. In politics, $35^{\mathrm{I}}$ et seq.; Dunbar on, 284; elimination of, in Jamaica 405, in Boston, I59 et seq.; in the minority, the politician's tool, 389, 390; Jamaica, District of Columbia and New Zealand, 381, 382; scorn of white man's advice in, 368; South African, 387,388 ; W. Taft on, 353, 371

In the North, B. T. Washington on, $20 \mathrm{I}$

In the South, economic future of, in, 18-20, 198, 199; F. Douglass on Negro as economic author of prosperity, I73; responsible for the Solid South, 278

In West Indies, F. A. Ober on, 395,396 ; characteristics of, 376 ; failure of self-government in, 394

Incapacity for self-government, 399-40I ; in West Indies, 394

Industrial decline of, $453^{-6}, 493,494, ;$ H.M. Brown on, $454,-$ Fitch on 455 ; H. B. Frissell on, 455;

T. T. Fortune on, 455; W. F. Willcox on, in the South, I7I, industrial decline of, in Boston, 159 et 
Negro-Continued

seq. in Chicago, 157; in New York City, 154, 155; in the South, I $7 \mathrm{I}$

Industrial monopoly of, in $1865,15 x$

Industrial opportunity, 2 I

Industrial ostracism, of

Springfield, Mass., I62; threatened in South, I69, I70 Industrial service from, demand for better, in South, I 66

Jamaican, 338; classes of, 339 ; capacity for selfgovernment, 40I; and the mulatto, 399; politically, $38 \mathrm{I}, 382$

Leaders among, 355

Love for royalty, $375^{-8}$ McKinley and, 242 , et seq. and Mulatto, classification of mulattoes as Negroes, 398 ; northern identification of, 398 , 404; mulatto achievement credited to Negro, 427,428 ; mulattoes, as leaders among, 29I; and mulattoes in the South, 397

Point of view of, 15 et seq. Political relations of, types, 26-8

Population, Negro districts, I6; distribution of, in United States, 48r; in Yazoo-Mississippi Delta, 84; outside the South, 238; probable increase in, I8; urban, $238,45^{8}$

Proportionate population and suffrage, $30,3 \mathrm{I}$

Race solidarity of 45965; attitude toward the white race, 300,301 ; W. H. Councill on evils of, 279 ;

Reconstruction and, $26 \mathrm{I}$, 262 ; type, 283,284 ; LincolnJohnson plan, 278

Representation at Atlanta Exposition, 308
Republican Party and, the "Negro plank," 418

Roosevelt and, 242 et seq., 276 et seq.

Social equality, attitude of, toward, $221,226,234,237$

Statistics of, 47

Suffrage, failure of, J. F. Rhodes on, 41 5, 416, a non-party opposition to, 353 ; and Lincoln-Johnson Reconstruction plan, 278; opposition to, in South Africa, 390, 39r ; and reduction in Southern vote, 357

Teuton and Latin races and, 326

Italian and, 74 et seq.

Voter, character of, 362 , 363 ; in relation to suffrage tests, 356,357 ; venality of, 383 , in South Africa, 388

Wealth, Edward Atkinson and W. E. B. Du Bois on, 150 . (See also under names of states and cities)

Nell, W. O., 2 I I

Nelson, Wolford, on capacity of Cuba for self-government, 394,395

Nevada, conditions of admission to Union, 8

New Bedford Traction R. R., Negro exclusion from cars of, 67

New England, political equality in, 227; population, proportionate 48 ; estimate on basis of Mississippi Negro, proportion, $5^{\mathrm{I}}$

New Jersey, percentage of Negro population, 44

New Orleans, tragedy of 1902 , 435

New York, "San Juan Hill," 48; Negro quarters, I 56

New York Age, on industrial decline of Negro in New York City, I 54, I 55

New York State, estimate of Negro population on besis 


\section{$54^{8}$ The American Race Problem}

of Mississippi proportion, 5I; percentage of population, Negro, 44, 48, 49

New York Union League Club, and coloured servants, 159

New York World on Negro wealth, 150

New Zealand, race relations in, 4II; method for South Africa, 382

North, attitude of, toward Negro crime, 472 ; Negro in, economic condition of, $20 \mathrm{I}$, economic future of, I 72 , economic opportunity in, I 7 et seq.; Negro agitators in, 4 I ; Negro immigrationfrom South into, 512 ; Negro type in, 40; and Negro policy, 46; Negro viewed by, as "Dark skinned white man," Kelsey on, $7 \mathrm{I}$; unfounded solicitude of, for Negro's condition, N. P. Banks on, 432 ; and Washington dinner at White house, 246

North Carolina, Constitution of 1898 , conditions antecedent to, 385 ; race war in, 365

Northen, W. J., on causes of race friction, 458,459

Northern industrial ostracism, Springfie ld, Mass., I $62, \mathrm{I}_{3}$

Noxubee County, Miss., economic efficiency of Negro in, 178

Numbers (or numerical proportions) of races, effect on race relations, $13,14,26$, $29,32,35,40,53-5,217$, 366, 390; DuBois, on, 14; B. T. Washington, 53 ; their relation to control in politics ${ }_{367}$; in New Zealand, 38r, 382

Ober, F. A., on Haitian Negroes, 377 ; on West Indian Negro, 395,396

Occupations, colour line in, r 66; Negroes in statistics of, 488,489 ; skilled, 522,523 , (See also specific occupations e. g., Barbers)

Office holding, I I 2 ; questionable benefit to black race, 305,306

Ohio, percentage of Negro population in, 49 ; prohibition of free Negroes, 32

Oklahoma, mulatto and Negro population, 4I

Olivier, Sydney, on capacity of pure Negro, $40_{3}$; on capacity for self-government, $40 \mathrm{I}$; on mulattoes, 40I; on "Negro rights," 378

Opportunity, class and racial, and the law, 4ro; industrial, $2 \mathrm{I}$

Oregon, prohibition of free Negroes, 32

Ostracism, industrial, Springfield, Mass., I62; threatened in South, 169, 170; social, as a Southern weapon, 275

Otman dan Fodio, not a Negro, 430

Outlook, on Negro in office, 280

"Overcrop," I 6

Overseers, see Managers

Oyster shuckers, 180

Page, Thomas Nelson, on probable increase in Negro population, 498

Palaver, Negro love for, 287

Palmetto, Georgia, race friction at, $459-65$

Panama, Republic of, 8

Party versus corruption, 367

Patterson, Raymond, on Negro suffrage, 362

"Peasant" class, Negro as, 4 ro

Pennsylvania, Negro population, percentage of, 44, 49, estimate on basis of Mississippi proportion, 5I; Negro suffrage, 64 ; suffrage article in constitution, 30

Peonage, 72 


\section{Index}

Perry County, Miss., economic efficiency of Negro in, 178

Philadelphia, exclusion of Negroes from cars in, 67; Wanamaker on Negro business men in, 153

Philippine Islands, government of, 382 ; Negro clergymen in, 522 ; race problem in, 2 I $4,250,466,467$

Pickens, William, 328

Plantation, duties of, owners, 91, 92; government of, similarity of African tribal polity, 376; system, Bruce on, 89 ; statistics of, 128 et seq.

Platt Amendment, 8, 393

Platt, Orville $H$., on conditions necessary for self-government, 39r

Point of view, Negro, I 5 ; North and South, 347

Political equality, 261, 333; ante-bellum discrimination, 227 ; impracticable test of, B. T. Washington on, 307; in the South, proper source of, 309, 310; in South Africa, Inter-Colonial Commission report on, 389 ; and race intermixture, 376

Politics, in the race question, in North Carolina, nonpartisanship of, 385,386

Negro in, 35 I et seq; Dunbar on, 284 ; as the politician's tool, 389,390 ; character of his participation in, 416; in South Africa, 387, 388 ; status in North, 31,32 ; in Reconstruction, 261,262 ; elimination of, in Jamaica, 405 ; his scorn of white man's advice in, 368 ; Jamaica, District of Columbia, and New Zealand, 38r, 382

Polity, African tribal, 376

"Poor white" in YazooMississippi Delta, 87

Population, census omissions,
479; increase in, due to agriculture, 525, 526; relation to race friction, 32,57 , 218,390 ; mixed, and classification of mulattoes with Negroes, 399

Negro, 3I, 48I, in 1900, 50, increase in, 1790-1900, 499-501, I 860-I 900, I 52, probable increase, 496 et seq. ; distribution of, 40 et seq., 44, proportionate and Negro suffrage, $30,3 \mathrm{I}$, proportionate to white, $57,177,48 \mathrm{I}-4$, estimates of, $5 \mathrm{I}$, and rape, 94, agricultural, 177 , centre of, 43 , North Carolina, 365 ; distribution of, on Mississippi proportion, 5 I, Massachusetts, increase, r 8 ro-r $820,59,60$, rural and urban, 53

White, increase of, due to extension of agriculture, 525,526

Porto Rico, government of, 382; Negro clergymen in, 522 ; Negro population compared with that of Mississippi, 47

Prejudice, industrial, I 82, $20 \mathrm{I}$; absence of in South, 168 . (See also Race prejudice)

Presidents of the United States and the Southern people, 295,296

Primaries in South and reduction in Southern vote, 357

Prisoners, Mississippi, I06; Negro, in North, 444, in United States, 443, 445

Professions, Negro in, increase of, 493,522

Property, ownership of, relation to Government, 386, 387; Negro ownership of, I 12,152

Prosperity of nations, W. E. H. Lecky on, 207

Protestantism and race relations, 230. 231,325 


\section{$55^{\circ}$ The American Race Problem}

Psychology and race relations, 266 et seq

Puck on Roosevelt and the Negro, 289

Qualifications, suffrage, Negro and white, 374

Race, antipathy, 212

Attitude, $221-6,234$, Anglo-Saxon, 6, 55, 56, 331,336 , effect of numbers on, $x_{3}, x_{4}$, $26,29,32,35,40,53,55,2$ I 7 , 366,390 , E. A. Ross on necessity of uncompromising, 24I, Southern, to Negro, 25 , white to native Hawaian 54

Assimilation, 56 ; classification, 215, 216; contact, law of, $6,33,97$; consciousness, 240, 33I, 332; control, 55 et seq., abstractions versus conditions in, 74 et seq., Catholicism and, in Mississippi, 366 ; differences, Lincoln on, 233

Friction, 70, 2 I I et seq., $226,325,355,45^{8}, 459,47^{2}$, 473 , and the Chinese, 8,218 , 2 I 9 , in Middle Ages, 465, 466, Reconstruction and, 472 , 473; Government and race, $349,375,376$, in South Africa, 389, 401

Intermixture, see Absorption, Amalgamation, Assimilation, Intermarriage, Miscegenation

Prejudice, 26, AngloSaxons and Latins and, 402, Arabs and, 230 , and Japanese exclusion, 7 , in Boston, $16 \mathrm{I}$, $2 \mathrm{I}$, in industry, 19 , and intermarriage, 63 , and race preservation, 69, and slavery, N. S. Shaler on, $22 \mathrm{I}$, in Springfield. Mass., 161, in the South, B. T. Washington on, 165 , and suffrage, 29.

Preservation, 69,346 , in
South, I65, I66; proportion, effect on race prejudice, 48

Relations, Jamaica, 378 , New Zealand, 38r, 382, problems of, 493, Protestantism and, $230,23 \mathrm{I}, 325$, B. T. Washington on kindliness in, $25 \mathrm{I}$, variety of, 252 , respect, 95 ; solidarity, Negro, 239, 459; superiority, necessity of, $96, B$. Kidd on causes of, 206, 207; race war, North Carolina, 356; problem of, obliteration not solution, 336; sectional influences and, 3, 4, countries where it obtains, 9 , 10

Railroads and Negro labour in Delta, 87

Rand, gold mines, 145

Rape, 92, 93, 94, 95; Mississippi, 86, 97, 98; Alexandria, Va., 472 ; absence of, in Yazoo-Mississippi Delta, $86,96,97$

Reconstruction, 47; character of, 265 ; effects of, 264,265 , 276 ; experiences in, 268; Hayes and, $35^{8}$; Northern, on friction due to, 458,459 ; Rights of South in, J. A. Andrews on, 4I4; Negro suffrage and, W. A. Dunning and Lamar on, 272; Negro, in politics of, $261,262,369$; Jamaica, absence of, 338 ; and the Negro, 249 et seq., $261,262,276,278,369$; Revels, H. R., on, 278; and the Referee System, 343

Reed, T. B., on Roosevelt, 287 "Referee system," 242 note, $309,314,340$ ct seq., 356

Registration, 355 , $35^{8}$

Regulation of slaves, see Slavery

Religion, Negro enthusiasm for, 16

Removals, farm, 133

Renting system, 99, 100, II 5, I $29,136,137$ 
Representation in Congress, Southern, proposed reduction, 419, 42 I (note)

Republican Party, and the Negro, 353, 365, 4 I 8 ; in Colorado, Connecticut, Minnesota and Wisconsin, $3 \mathrm{I}$; in North Carolina, $365 ;$ and Negro suffrage, $3 \mathrm{I}$

Revels, H. R., on effect of Reconstruction on the Negro, 278

Revolution, loyalists and traitors of, $34 \mathrm{I}$

Rewards, political, and Negro leaders, $355,35^{6}$

Rhode Island, percentage of Negro population, 45

Rhodes, J. F., on Blaine's account of Freedmen's Statutes, 12 ; on failure of Negro suffrage, 4I 5, 4I 6

Rice, Louisiana, decrease in Negro population in rice districts, 525, 526 ; white and Negro labour in, 452

"Rights," Negro, 3 10

Roosevelt, Theodore, and the Negro, 242 et seq., 276 et seq., 286, 3IO, 3II , $4 \mathrm{II}$; his diplomacy in the South, 286; T. B. Reed on, 287 ; and San Domingo, 396; and social equality, 245; R. H. Terrell on, 3 II

Ross, Edward A., on AngloSaxons and the Negro, 24I

Royalty, Negro love for, $375-8$, 395,396

Russo-Japanese war, effect of yellow victory on Negro races, 239,240

"San Juan Hill" district, New York, 48

Santo Domingo, Negro domination in, 27, 332; Negro population compared with that of Mississippi, 47; Roosevelt and treaty with, 396
Saturday holiday, 454

Scalawags, $34^{2}$

Schurz, Carl, on wealth of Negroes, 156

Scott, C., on Italian cotton growers, 194

Scottron, S. R., on economic statistics of the Negro, 154

Secession, right of, $34 \mathrm{r}$

Sectionalism and race relations 3,4 , 10, $347,348,418$; in South and Natal, 346

Segregation of the Races, 5 , $63,64,66,67,233,237$; in South Africa, 24

Self-government, conditions necessary for, $4 \mathrm{I} 2 ; \mathrm{O}$. H. Platt on, 39I ; Negro capacity for, $36,37,370,372,373$, 399,400 , H. L. West on, $4 \mathrm{I} 5$, S. Olivier on, 40 $\mathrm{r}$, in Africa and Asia, 375, A. H. Colquhoun on, 378 , in Jamaica, 375; Plantation self-government, 377 ; in Cuba, W. Nelson, W. Inglis on, 394,395 ; J. B. McMaster on, 4II, 4I 4 . (See also Administration)

Separate cars, 64, 217, 337 (note); in Kentucky and Texas, 65, 66; Samuel May and N. Barney on, 67

Separate schools, 68 et seq., 217 ; in Boston, 211 ; President Eliot on, 68; in Kansas City, 8; in San Francisco, 334 Separation of the races, hardships of, on higher class of Negroes, 67,337

Servants, household, decline of Negroes as, 158

Sex, excess of Negro females, 485

Sexual relations, Negro, Io8

Shaler, N. S., on amicable race relations, $22 \mathrm{I}$

Share system, I 26, 136, 137

Shootings, Negro, in Texas, 66

Slaughter, Linda Warfel, on Southern education, 275 


\section{The American Race Problem}

Slave trade, Anglo-Saxon race and, 55 ; DuBois on the North and, I 4

Slavery and race friction, 220, 230; Shaler on, 221 ; economic conditions and, 14; and relations of master and slave, 253, 254, 255, J. A. Andrews on, 260, W. H. Councill on, 256, DuBois on, G. D. Jenifer on, 257,258 , J. H. Smyth on, 256, "Traveller" in New York Evening Post on, 259; statutes of, IO

Smyth, J. H., on relations of master and slave, 257

Social equality, 22, 229, 3I 3 et seq., 333; and the lower Negro classes, 335 ; and the mulatto, 238 ; among strata of Negroes, 457; claims to, and race friction, 219,220 , in Central America, 27; in Mexico, 27, in South Africa, 24, 25, 345, 406, in South America, 27; Japanese and, 334; Khama and, 345 ; DuBois on, 326 , 327; Lincoln on, 233 ; W. Pickens on, 328; Kelly Miller on, 230, 325; Roosevelt and, 245 ; regulations of, 25 ; social separation of Mississippi, 86;

South, birth rate and immigration, $510,5 \mathrm{Ir}$; statistics of, 508, 509; economic opportunity in, 164, 199; lawless conditions of, B. T., Washington on, 73 ; loyalty of, 298 ; Negro in, Birth rate of, 508, 509, 510, 5 II ; charities for, 327 , DuBois on, 75; condition of, compared with Cape Colony, 406, F. Douglas on, $172, T$. T. Fortune on, $17 \mathrm{r}$; Future of, I7 I; Danger of control by, 365; Disfranchisement of, 354,355 ; immigration and,
200 ; in local politics, 364 ; mulattoes and, 397 ; rights of, 301, 420; Roosevelt and, 242 et seq.; solidarity of, 367 ; and suffrage, 363

Referee system and, 340 et seq.; scalawag in, 343; Roosevelt in, 299; plantation system and African tribal polity, 376; Solid South, 265, 266, 278, 308, $368,369,419$, reasons for, $278,308,368$, Negro responsibility for, 278 ; Washington dinner and, 320; Teachers of Negro schools in, 272, 274 South Africa, and "Africa for Africans," 240, 33I; Bryce on colour line in, I66; Negro in, in politics, 387 , 388 , population of, compared with that of Mississippi, 46, suffrage of, and proposed South African Confederation, 390, 39I; New Zealand method for, 382 ; Jamaica and, contrasting conditions of Negroes in, Colquhoun on, 406; " a white man's country," 229 ; racial discrimination in, 24

South America, political and social absorption in, 26, 27

South Oarolina, mulatto and Negro population, 4I; percentage of Negroes, 49

Southern constitutions, and disfranchisement, $36 \mathrm{I}, 384$; and restriction of Southern representation in Congress, 357,42 I (note), J. A. Garfield on, 4I 9

Spanish-American war, McKinley's Southern appointments in, 296

Springfield, Mass., race prejudice in, I9, I6I

Squads, Negro and Italian at Sunny Side, comparison of, 185,186 


\section{Index}

"Square deal," 286

Stock, Sunny Side, ownership of, by Negroes and Italians, I9I

Stone, A. L., on Northern education of the South, 273,274

Stone and Fort, I $17, \mathrm{I}_{24}, \mathrm{I}_{2} 8$

Suffrage, Congressional investigation of laws of, 429 ; exercise of right, neglect of, $35^{8}$;

Negro, $35 \mathrm{I}$, indifference of, to, 237 ; proportionate population, and $30,3 \mathrm{I}$; Reconstruction and, 253,270 ; relation of, to crime, 473 ; restriction of, $353,380,38 \mathrm{r}$; W. H. Baldwin on, 277 ; A. B. Hart on, 270; J. B. McMaster on, 4II-4 B. T. Washington on, 277 ; J. A. Andrews on, 4I 3, 4I 4 ; Republican party and, $3 \mathrm{I}$; in British West Indies, 27; in Cape Colony; 27, 34,35 ; in Colorado, $3 \mathrm{I}$; in Connecticut $3 \mathrm{I}$; in Illinois, 33 ; in Jamaica, 35 ; in Minnesota, 3I ; in Wisconsin, $3 \mathrm{r}$;

Qualifications for 372 ; restrictions on, $28,29,30,4 \mathrm{r} 2$; tests for, $37 \mathrm{r}$; a state's right, 418; in Pennsylvania, 30, 34 ; woman's, 4I2.

Sugar cane, white and Negro labour in crop, $45 \mathrm{I}, 45^{2}$; Italians in Louisiana, 173 Sunny Side Company, i 80, I 8 I

Supervision of mulatto administration, necessity of, 402

Supplies, advancing, to Negro sharehands, II 8

Swedes, as janitors, 157

Taft, William, on Negro in politics, $353,37 \mathrm{I}$; at Tuskegee, $37 \mathrm{I}$

Taylor, R. S., on Delta, 83
Teachers of Negro schools, Southern attitude toward, 272-4

Teeth, filing of, Cuban soldiers and, 395

Tenantry, Italian and permanency, 192, 193; Negro and permanency, $\mathrm{I}_{27}, \mathrm{I} 30$

Tennessee, mulattoes and Negroes in, $4 \mathrm{r}$

Terrell, R. H., on Roosevelt, 3 I I

Texas, mulattoes and Negroes in, $4 \mathrm{r}$; Negroes in 1900,65

Thriftlessness, Negro, 100, 102

Tobacco, decline of Negro operatives in, 523; white and Negro labour in, 450, $45 \mathrm{I}$

Tontitown, Italian settlement at, $18 \mathrm{r}$

Trade unions and the Negro, I $66, \mathrm{x} 68,455,456$

Transvaal, Negro population of, compared with that of Mississippi, 46

Travel, Negro love for, Iro

Tribe, polity of African, compared with plantation government, 376

Trinidad, Negro population of, compared with that of Mississippi, 47

Tuskegee, 328 ; Taft at, $37 \mathrm{r}$

Twain, Mark, see Clemens, S. L.

2,000 A. D., Forecast of Negro population in, $5 \circ 5$

Types of Negroes, 40

"Understanding clause," 355 , 357

Union County, Miss., economic efficiency of Negro in, 178

United States, percentage of Negro population, 49

Unreliability, Negro, ro9, I92, r 99, 200

Urban population, Negro, B. T. Washington on, 146 , r 47; in North, 52, 53 


\section{The American Race Problem}

Value of products per acre, Italian and Negro labour, Sunny Side, 183

Venality of Negro vote, 362 , 368

"Veneeriging Peace Covenant" and native suffrage, South Africa, 39 I

Waddell, A. M., on Negro vote in North Carolina, ${ }_{3}^{6} 5$ (note)

Wages, Mississippi Delta, I I 2 Waiters, Negro, decline of, I 59

Wanamaker, John, on Negro business men, 153

Warner, O. D., Negro comment on death of, 434

Washington, Booker T., a mulatto, 430; estimate of Negro population in 1900 , 497; on future of American Negro, 204, 4II; on government without representation, 392,393 ; on industrial education, 89; on industrial prejudice, I68, in the South, I65; on lawless conditions in the South, 73 et seq.; on mulatto agitators, 434 ; on needs of the Negro race, 4 I I ; on Negro Federal appointments, 307 ; on Negro immorality, $25 \mathrm{I}$; on Negro industrial opportunity in the North, I7, 19, I63, I64; on Negro migration 46 , to North, 53 ; on Negro rights, 25I; on Negro suffrage, 277 ; on race relations, 299 , 300

Washington-Roosevelt dinner, 243 et seq., 295, 3 I 4, 3 I 5, 318 , et seq.

Washington, D. C., industrial ostracism in, I70; interracial colour line, 409 (note)

Washington County, Miss., Negro population of, 44, 48,50
Washtenaw County, Mich., estimate of Negro population on Mississippi proportion, 52

Wealth, Negro, 150 ; distribution of, 135

Weeksville, changing population of, 155

West, H. L., on Negro capacity for self-government, 415; on race war in North Carolina, 365 (note), 385,386

West Indies, mulattoes of, 402 ; Negroes in, Colquhoun on, 376, F. A. Ober on, 395, 396; Negro political rights in, 27 ; Negro population compared with that of Mississippi, 47

West Virginia, erection of state, 8

Western states, discrimination in, 32; proportion of Negro population, 48

White House, see Washington-Roosevelt dinner

White labourers, absence of in Yazoo-Mississippi Delta, 8 , 88

White manipulation of Negro in politics, 368 ; in South Africa, 387,388

White race, superiority of, 207, 208

White supremacy, North Carolina, $385-7$; and Negro suffrage, $352 ;$ in Cape Colony, 36

Willcox, Walter F., 47; on industrial decline of Negro in South, $17 \mathrm{I}$; on Negrowealth, I 50; writings of, 530,53 I

Williams, D. H., 206

Williams, Fannie Barrier, on industrial decline of Negro in Chicago, 157

Wilmington, N. O., necessity for white control, 385

Wilson, H. A., on race solidarity in Africa, 239

Winston, G. T., on Southern race conditions, 93 


\section{Index}

Wisconsin, Negro suffrage in, 3r; percentage of Negro population, 45

Women, in fields, Italian versus the Negro, 186, I 87 ; Negro, decline of, as household servants, I 58, I 59; suffrage in United States, $4 \mathrm{I}$; white, and intermarriage (Mass.), 62

Woodworth, Frank G., on separate car law, 337

Worcester, Dean, on race hatred in the Philippines, 466,467
Work, and race respect, 88 , 97 ; Negro disinclination to, I 99

Wu Ting Fang, 25

Yale university, Negro at, 23

Yazoo-Mississippi Delta, $\mathbf{8 2}_{2}$ et seq.; absence of rape in, 86 ; importance of, in future of Negro, 84 ; its fertility, Richard S. Taylor on, 83; percentage of Negro population, 85; railroads and increase of Negro population in, 87

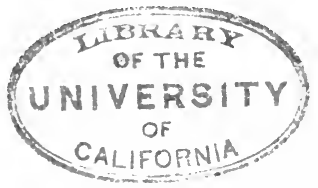





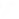




\section{RETURN CIRCULATION DEPARTMENT}

TO Oก? Main Librarv

\section{RETURN CIRCULATION DEPARTMENT}

TO $\longrightarrow 202$ Main Library

\begin{tabular}{l|l|l}
\hline $\begin{array}{l}\text { LOAN PERIOD } 1 \\
\text { HOME USE }\end{array}$ & 2 & 3 \\
\hline 4 & 5 & 6 \\
\hline
\end{tabular}

ALL BOOKS MAY BE RECALLED AFTER 7 DAYS

Renewals and Recharges may be made 4 days prior to the due date.

Books may be Renewed by calling $\mathbf{6 4 2 - 3 4 0 5}$

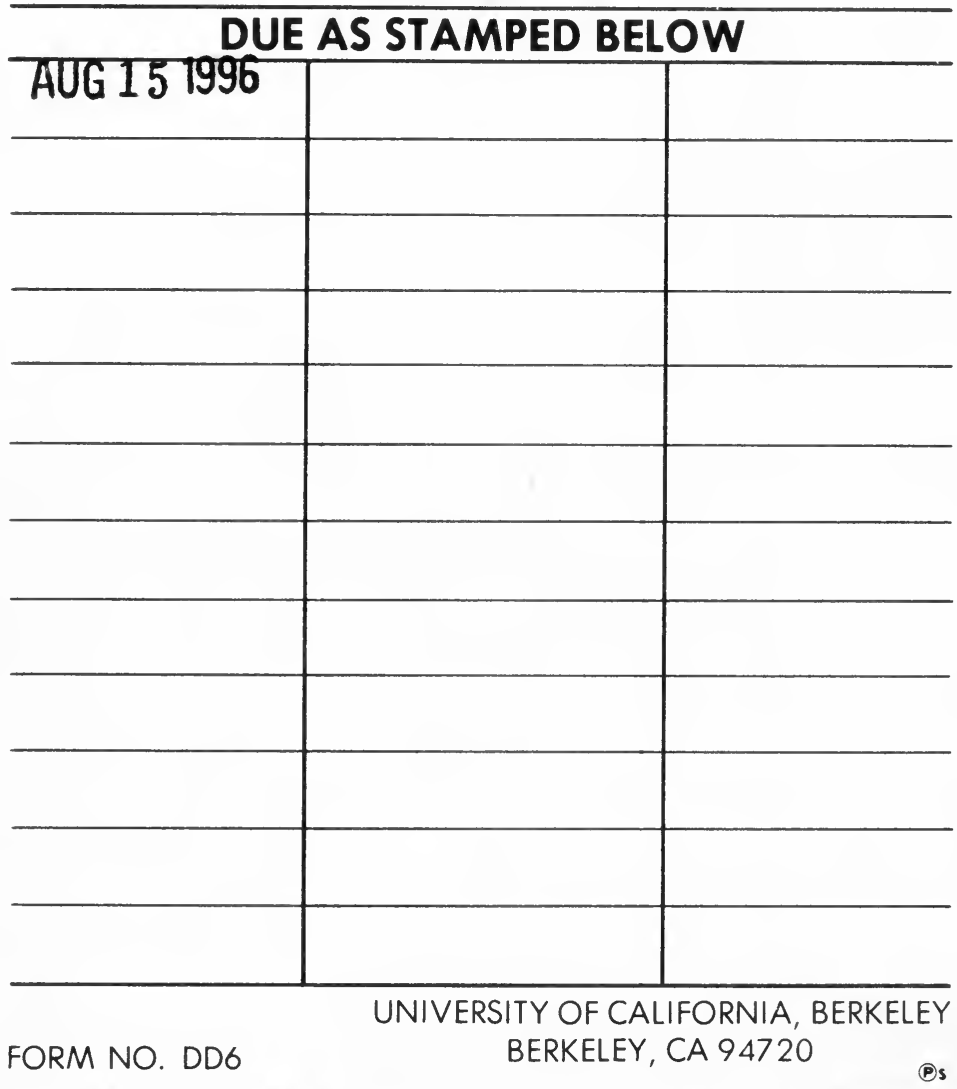


GENERAL LIBRARY - U.C. BERKELEY

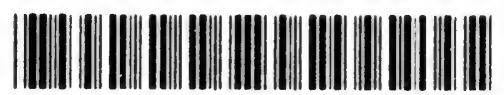

8000780142

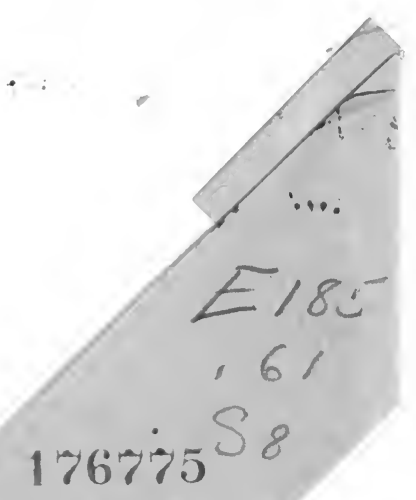



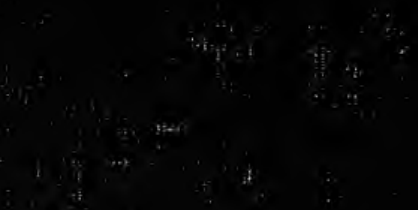

,

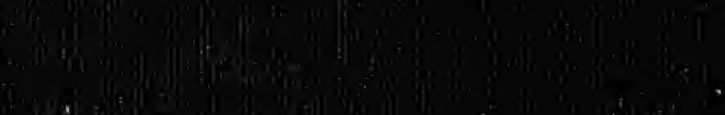
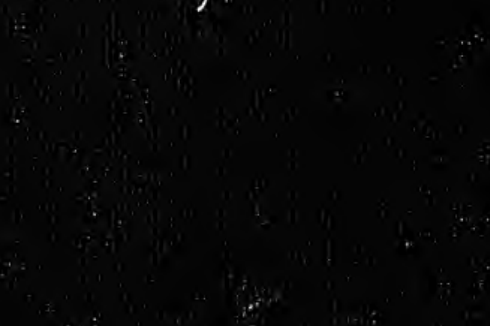

2) 